\title{
Characterization of Ni-Mo based Electrocatalysts for Hydrogen Evolution from Water
}

\author{
Karakterisering van op Nickel Molybdeen \\ gebaseerde Elektrokatalysatoren voor \\ Waterstof Evolutie uit Water \\ (Met een samenvatting in het Nederlands)
}

\section{Proefschrift}

ter verkrijging van de graad van doctor aan de Universiteit Utrecht op gezag van de rector magnificus, prof. Dr. H.R.B.M. Kummeling, ingevolge het besluit van het college voor promoties in het openbaar te verdedigen op 6 april 2020 des middags te 12:45 uur

door

\section{Jochem Hendrikus Johannes Wijten}

Geboren op 10 oktober 1991 te Hilvarenbeek, Nederland 
Promotor: Prof.dr.ir. Bert Marc Weckhuysen

This PhD thesis was accomplished with financial support from NWO's (Nederlandse Organisatie voor Wetenschappelijk Onderzoek) NIOK Solar Fuels graduate program grant. 
The future is never far away, and each child is the future of their parents. The future is born from the past and could not exist without it. The future learns from the past and strives to grow from it. The future is eternally grateful for the past. 
Author: Jochem H. J. Wijten

Title: Characterization of Ni-Mo based Electrocatalysts for Hydrogen Evolution from Water

ISBN: 978-90-393-7273-9

Printed by: Ridderprint | www.ridderprint.nl.

Cover designed by the author, based on a picture of Mt. Fuji, Japan, by the author 


\section{Table of Contents}

Chapter 1 General Introduction

Chapter 2 Electrolyte Effects on the Stability of

33 Nickel-Molybdenum

Chapter 3 Ni-Fe-S as OER Catalyst in a Solar-Driven

67 Cell Operating at Low Overpotential

Chapter 4 In Situ Study of Ni-Mo Stability: Effect of 93 Substrate and Potential

Chapter 5 Cathodic Electro-deposition of Ni-Mo on

121 $\mathrm{NiFe}_{2} \mathrm{O}_{4}$ for Photo-electrochemical HER

Chapter 6 Alkali Promotion on Ni Catalysts in $\mathrm{CO}_{2}$ 147 Hydrogenation using Renewable $\mathrm{H}_{2}$

Chapter 7 Summary, Concluding remarks and Outlook 167

Nederlandse Samenvatting (Dutch Summary)

178

List of Abbreviations

185

Publications and Presentations

188

Acknowledgements

190

About the Author

193 

"You were born too soon, Pencroft. Those words I grew up with." I look over at my dad, wondering what the old geezer is going on about this time.

Dad keeps on reminiscing: "They already predicted the future more than an age ago, son." I sigh, "And what future is that then?" "Water, as a fuel. Finally, after such a long time, it's becoming the truth." "Sure, if that's so why didn't they go for it right away then? We've got water aplenty."

"They had the idea already, but not the technology."

"What technology then?"

Dad smiles, looking at the large TV and the phone in my hand. "All kinds of technology, efficient ways to make electricity and catalysts to split this water, to name a few" "And then what's stopping them now, we've got those now I guess?" My dad sighs and looks downcast. "Money, son, that would be money."

The quote 'You were born too soon, Pencroft' is from Jules Verne - The Mysterious Island (1874) 

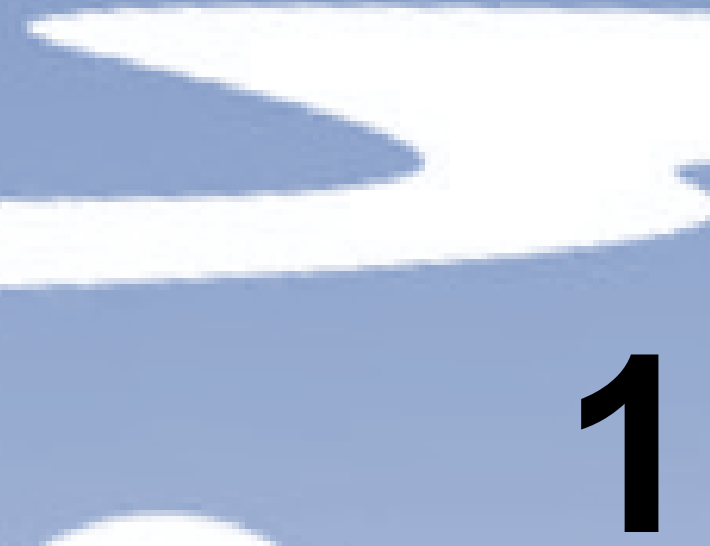

\section{General Introduction}

The worldwide energy consumption keeps on growing, while at the same time the need, and request for cleaner resources increases. Application of renewable energy harvesting via, for example, solar panels, tidal waves, and windmills is steadily growing, but there is often a mismatch in energy consumption and generation. This is easily illustrated by the day-night and summer-winter cycles. To bridge these daily and seasonal gaps in renewable energy production, proper energy storage infrastructure has to be developed. In this PhD Thesis, the use of water splitting to form hydrogen as a renewable energy carrier is explored. This introductory Chapter aims to introduce the reader in the energy challenge as well as in the scientific and technical hurdles of hydrogen production via water splitting. At the end of this Chapter, the scope and outline of this PhD Thesis will be described. 


\subsection{Introduction}

The need, and request, for a cleaner and better future, is what has driven research, like the one described in this PhD Thesis. ${ }^{[1-9]}$ More and more, our society realizes the need for utilizing renewable energy sources, but the transition towards this completely green energy infrastructure is inherently slow due to the significant costs that come with it. ${ }^{[1,2,10,11]}$ Due to this simple to understand, but incredibly complex challenge, both fundamental and applied research towards better sustainable technologies are funded and performed. ${ }^{[1,2,5-8,10]}$ This Chapter aims to give the reader an understanding of the basic concepts and related materials, and the scientific and technical challenges thereof, which are central in this PhD Thesis: the splitting of water, the resulting hydrogen and its uses; and the nickel-molybdenum (Ni-Mo) material, which is a potential catalyst for water splitting.

Solar fuels is often the name given to hydrogen produced from water splitting via solar energy. ${ }^{[3,4,9,12]}$ Similarly, when looking into this subject also the products, formed via the catalytic $\mathrm{CO}_{2}$ reduction making use of renewable energy, are called solar fuels. ${ }^{[6-8,12-18]}$ Furthermore, it is often overlooked that wind is also a form of solar energy and that this is not just sunlight and the heating by that radiation. ${ }^{[10]}$ By definition, this renewable electricity can come from any source but, ideally, it is the result of renewable energy harvesting, regardless of this being via solar panels or wind turbines. ${ }^{[1,8,10]}$ The resulting solar fuel, renewable hydrogen, sometimes also named green hydrogen, is the desired product, or intermediate for further steps, including the catalytic (thermal) reduction of $\mathrm{CO}_{2} \cdot{ }^{[15,19,20]}$

\subsection{Towards a more Sustainable Society}

Nevertheless, why do we even wish to perform water splitting? It is well known that the world's population is growing, meaning more people that want for energy. ${ }^{[2,5,8,10]}$ Furthermore, the energy demand per person is growing as well; in 2018 we consumed about $20 \mathrm{TW}$-year (which is $1.75 \times 10^{14} \mathrm{kWh}$ ) compared to 15 TW-year in 2005. ${ }^{[1,6-8]}$ It should also be noted that June 2018 news came out we reached 1 TW of potential energy generation using solar panels and wind turbines combined. [21] While the large steps made ensure this number will grow fast, there is another, inherent, issue to address when it comes to solar energy utilization: a mismatch in supply and demand (Figure 1.1). ${ }^{6,7,10]}$ Solar energy is intermittent, meaning that we only produce significant amounts of energy with solar panels during the day, whereas the peak in energy consumption is during the night. This challenge is even larger when considering the winter-summer cycle, meaning we need flexibility in handling energy, likely via a combination of adjustable energy production, expansion of the energy grid, responding systems to energy demand and finally energy storage. ${ }^{[5,10]}$

Batteries are the first technology to come to mind when thinking of electrical energy storage. However, back-on-the-envelope calculations with AA-batteries suggest that even storing the energy for a day would require approximately a 

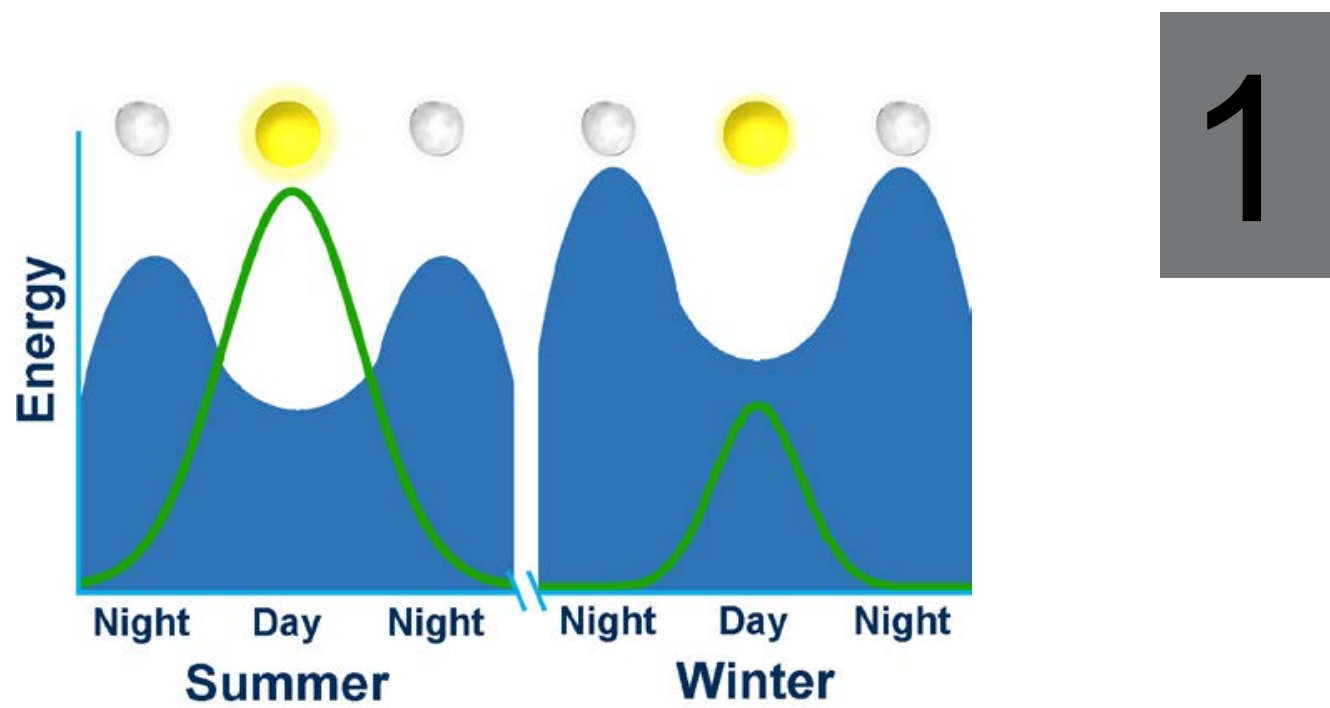

Figure 1.1: Schematic representation of the intermittency of sunlight for solar light (green line) and the mismatch with energy consumption (blue area).

hundred times more Li than is projected to be available on Earth. ${ }^{[22]}$ Luckily, AA-batteries are not the apex of battery technology and more advanced technologies, such as those used in electric cars, are more efficient. ${ }^{[3,5,23]}$ Another set of estimations shows however that these cars, which often use for example Co, use so much of such materials that there is not enough in the world to replace all the cars currently registered globally.[22] There are exceptions: cars which use smaller batteries and batteries based on other materials. Also, note that all these estimations are made with the assumption all resources would be available for this purpose only. Overall, battery technologies are being developed and will play a significant role, but on a world energy scale are likely still far off from being the only answer to achieve flexibility. Due to this, chemicals such as hydrogen are also considered as a medium into which to store the abundance of energy during peak hours. ${ }^{[15,20]}$

Hydrogen is the chemical of choice in this work for various reasons. First, there is a lot of preceding experience with this compound and the production thereof. It is one of the most energy-rich compounds known $(120 \mathrm{MJ} / \mathrm{kg})$, which is nearly three times the amount found in gasoline $(44 \mathrm{MJ} / \mathrm{kg})$. A note has to be made here, however, that hydrogen has a much lower volumetric energy density. ${ }^{\left[{ }^{[}\right]}$It has no environmental footprint by itself since, when consumed, it leaves only water in its wake and it can be also obtained from (brackish) water, which is a highly abundant resource in many parts of the world. ${ }^{[5,8]}$

\subsection{Different Colors of Hydrogen: Production and Use}

Handling hydrogen is challenging. Transport, storage and safety considerations make it that paths are considered in which hydrogen is again converted to more manageable chemicals or products. ${ }^{[5,24,25]}$ With relatively expensive 
technologies, the hydrogen can be cooled and subsequently compressed for further use. Hydrogen has a high solubility in many metals, which poses a challenge. Many equipment designs are prone to embrittlement by this hydrogen dissolution making it hard to use in the current pipeline network. ${ }^{[5,26]}$ Furthermore, it tends to result in relatively high leakage rates of product compared to other chemicals, such as methane and methanol. ${ }^{[5,26]}$ Hence, it is likely the best option to use hydrogen at the location of production to reduce maintenance and leakage. ${ }^{[14,15]}$

Currently, as illustrated in Figure 1.2., the bulk of hydrogen produced is used in fossil fuel processing and the Haber-Bosch process. ${ }^{[27]}$ In oil refineries, hydrogen is used in several processes, such as hydrocracking, hydrodealkylation, hydrodesulfurization (HDS), hydrodenitration (HDN), hydrodemetalation (HDM) and the Fischer-Tropsch synthesis (FTS) process. ${ }^{[24,28-32]}$ All these catalytic processes consume hydrogen to upgrade the quality of the products.

Hydrocracking is a process in which heavy oil fractions are converted into lighter, more useful ones. This reaction consumes hydrogen to replace the

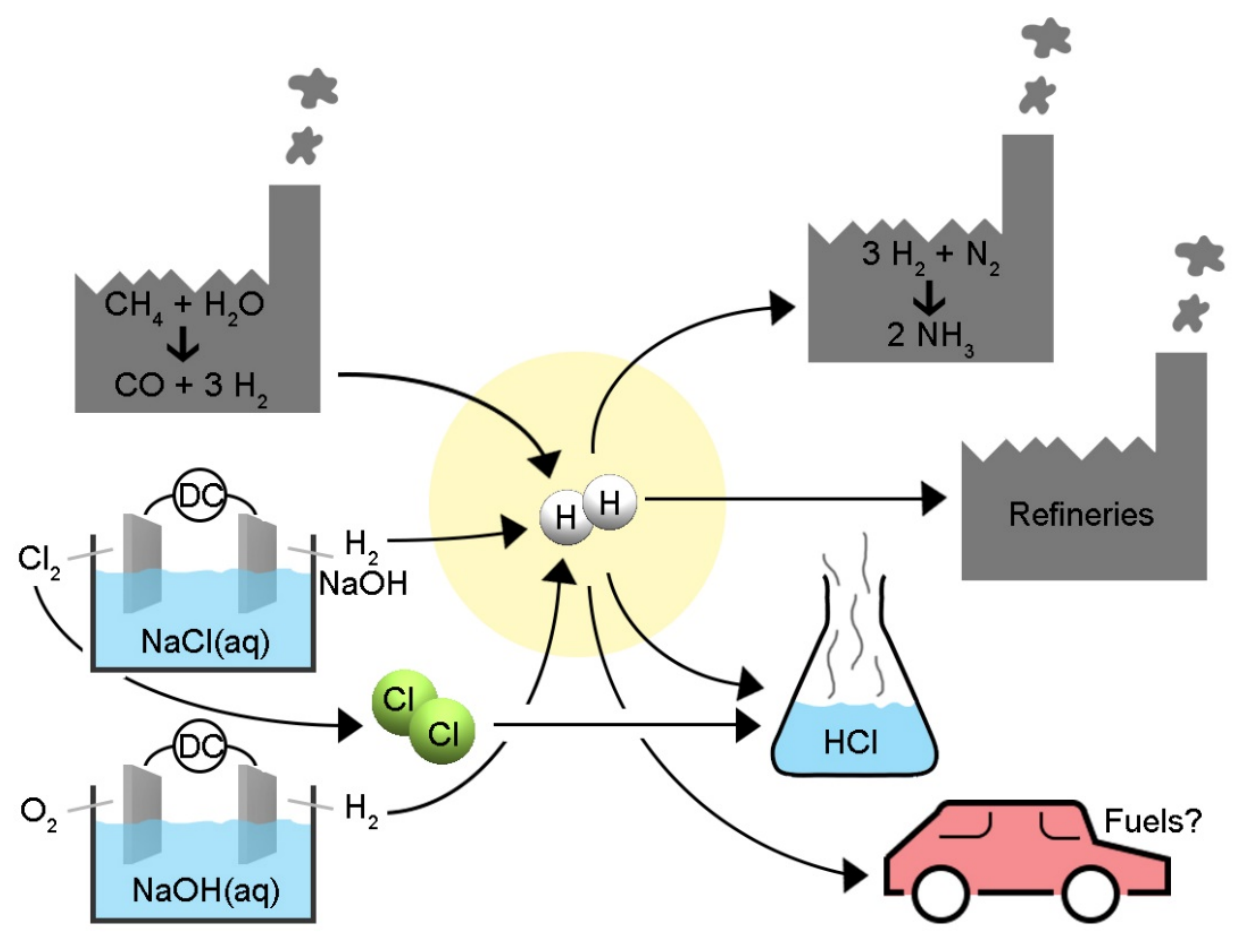

Figure 1.2: Schematic overview of the main production methods of hydrogen on the left, showing the water gas shift reaction, the chlor-alkali process and the upcoming water electrolysis method. On the right the main consumers of hydrogen showing the HaberBosch process, refineries (Fischer-Tropsch synthesis (FTS), hydrodesulfurization (HDS), hydrocracking and hydrodealkylation), hydrochloric acid synthesis and possibly fuels as an upcoming use. 
carbon-carbon bonds that break during this reaction. ${ }^{[28]}$ Hydrodealkylation is similar in the sense that carbon-carbon bonds are broken, but in this case, functional groups are removed from aromatic compounds to form simpler aromatics, such as the formation of xylenes from trimethyl benzenes. ${ }^{[28]}$ The FTS process consumes hydrogen by reacting it with carbon monoxide to form hydrocarbon chains. ${ }^{[24,31,32]}$ Finally, HDS, HDN, and HDM are the processes that remove sulfurous, nitrous and metallic compounds from fossil fuel feedstocks to prevent acid rain and environmental contamination, again consuming hydrogen upon use. ${ }^{[29,30]}$

Other uses include reacting hydrogen with chlorine to produce hydrochloric acid. This is generally done on-site using the hydrogen by-product of the chloralkali process. ${ }^{[33,34]}$ Hydrogen also sees use in cooling applications due to its high thermal conductivity. ${ }^{[26]}$

The bulk of hydrogen produced at the time of writing is still via steam reforming from natural gas or other fossil carbon sources, such as crude oil and coal with decreasing efficiency (Figure 1.2), forming grey hydrogen. ${ }^{[1,25]}$ The efficiency of natural gas steam reforming is around $60-70 \%$. In this process, water and methane are reacted at high temperatures $\left(700-1100{ }^{\circ} \mathrm{C}\right)$ to yield $\mathrm{CO}$ and three equivalents of $\mathrm{H}_{2}$. $\mathrm{CO}$ can further react at lower temperatures $\left(360{ }^{\circ} \mathrm{C}\right)$ in the water gas shift (WGS) reaction consuming one more molecule of water to result in $\mathrm{CO}_{2}$ and $\mathrm{H}_{2}$. This process produces several tons of $\mathrm{CO}_{2}$ per ton of $\mathrm{H}_{2}{ }^{[1,25]}$ If the produced $\mathrm{CO}_{2}$ is captured and stored (CCS) then the hydrogen is regarded as blue hydrogen. Similarly, methane can be pyrolyzed, yielding not $\mathrm{CO}$ or $\mathrm{CO}_{2}$ but graphite and hydrogen. Hydrogen produced this way, since it does not result in any gaseous by-products is referred to as turquoise hydrogen. The graphite can either be buried or used as a material feedstock.

Hydrogen is also possible to partially oxidize hydrocarbons or gasify coal to CO and $\mathrm{H}_{2}$ to form syngas, which is used in the FTS reaction. ${ }^{[24,31,32]}$ Syngas synthesis can also be done electrochemically via $\mathrm{CO}_{2}$ reduction, which has $\mathrm{H}_{2}$ as a by-product, and thus can be used to form syngas and thus be used in the Fischer-Tropsch synthesis. ${ }^{[24,35]}$

Hydrogen is also a by-product of the chlor-alkali process in which chlorine and sodium hydroxide are generated via electrochemistry: $2 \mathrm{NaCl}+2 \mathrm{H}_{2} \mathrm{O} \rightarrow 2$ $\mathrm{NaOH}+\mathrm{H}_{2}+\mathrm{Cl}_{2} \cdot{ }^{[3,34]}$ Finally, several hydrogen production plants operate on water electrolysis. However, this only accounts for a few percentages of the yearly hydrogen production. ${ }^{24]}$ Water electrolysis usually operates at low temperatures of $50-80^{\circ} \mathrm{C}$. In industry, most cells operate in alkaline solutions either with or without proton exchange membranes (PEM) using Raney nickel electrodes. ${ }^{[24]}$ Cells operating with PEM are usually more expensive but can result in being more cost-effective since no further separation of the produced gasses, hydrogen and oxygen, is necessary. State of the art electrolyzers with PEM operate at about $80-82 \%$ efficiency. ${ }^{[24]}$ Assuming the use of renewable electricity, the hydrogen produced in this way is known as green hydrogen. 


\subsection{Strategies for Water Splitting}

Several strategies are available for splitting water into its elemental components: hydrogen and oxygen. It can be done through radiolysis, using radiation energy to split it ${ }^{[36,37]}$, or through thermolysis where heat is used as the energy source. ${ }^{[1,38]}$ These are outside the scope of this PhD Thesis and will not be discussed.

The most studied method of water splitting is through electrolysis (Figure 1.3). ${ }^{[9,13,24,39-42]}$ Here electricity is applied over two electrodes to split water into hydrogen on the cathode and oxygen on the anode. ${ }^{[9,24,43,44]}$ To perform $a$ reaction, like water splitting, which is kinetically and energetically unfavorable since water is such a stable molecule, we need materials, which facilitate the process. Such materials are catalysts: materials that lower the energy barrier of a reaction by lowering the kinetic energy required and are not consumed by the reaction. ${ }^{[45]}$ In heterogeneous catalysis, which is the group of catalysts that are in a different phase (often a solid) than the reactants (often a liquid or a gas), it is usually the catalyst surface that does the work. Reactants can adsorb on such surfaces, which can weaken chemical bonds to facilitate subsequent chemical reactions and usually serve in bringing reactants together faster so that the reaction is sped up. ${ }^{[45]}$

Water electrolysis using renewable energy and catalysts can effectively be split into three main approaches: photo-catalytic water splitting ${ }^{[12,46-48]}$, photoelectrochemical water splitting[3,12,16,39,44,49-51], and electrochemical water splitting ${ }^{[24,39-42]}$. Photo-catalytic water splitting uses catalyst particles, often in suspension, which absorb light and perform the water splitting. Photoelectrochemical water splitting is a process where light-absorbing materials, similar to solar cell materials are either catalytic or combined with catalysts to

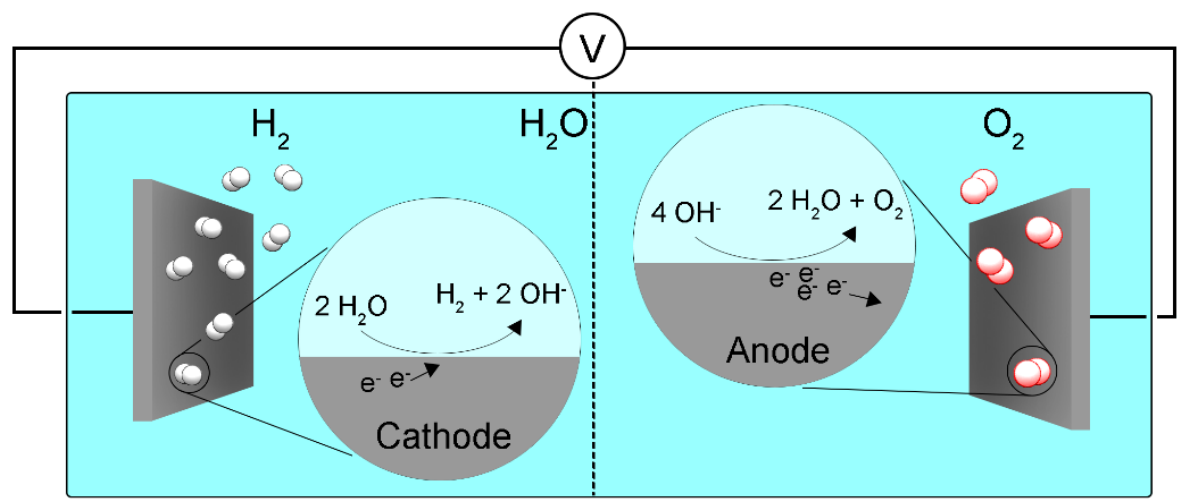

Figure 1.3: Schematic representation of electrochemical (alkaline) water splitting, with hydrogen evolution at the cathode (left) and oxygen evolution at the anode (right). 
split water over two separate electrodes. Finally, electrochemical water splitting decouples the generation of renewable energy and the electrolysis step. Usually, in such electrochemical studies, electricity, preferably from renewable sources, such as windmills and solar panels, is used with two electrocatalytic electrodes to split water.

The splitting of water is an easy reaction to understand:

$$
2 \mathrm{H}_{2} \mathrm{O} \rightarrow 2 \mathrm{H}_{2}+\mathrm{O}_{2} \quad \mathrm{E}=1.23 \mathrm{~V} \text { (Eq. 1.1) }
$$

In electrolysis, the generation of hydrogen and oxygen are decoupled into a reduction, the hydrogen evolution reaction (HER), and oxidation, oxygen evolution reaction (OER), step..$^{[9,24,43,44]}$ This has the advantage that gas generation can be spatially separated and eliminates the need for a separation step of the two gasses, which is technologically challenging. ${ }^{[24]}$

To consider the reduction and oxidation steps, one has to take into account the $\mathrm{pH}$ of the water, which is being electrolyzed ${ }^{[9,24]}$ In acidic media, protons play a role and the half-reactions would be as follows:

$$
\begin{array}{ll}
4 \mathrm{H}^{+}+4 \mathrm{e}^{-} \rightarrow 2 \mathrm{H}_{2(\mathrm{~g})} & \mathrm{E}(\text { vs. NHE) }=0.00 \mathrm{~V} \text { (Eq. 1.2) } \\
2 \mathrm{H}_{2} \mathrm{O} \rightarrow \mathrm{O}_{2(\mathrm{~g})}+4 \mathrm{e}^{-}+4 \mathrm{H}^{+} & \mathrm{E}(\text { vs. NHE) }=1.23 \mathrm{~V} \text { (Eq. 1.3) }
\end{array}
$$

In alkaline media the reactions are similar, with $\mathrm{OH}^{-}$as the charge carrying ion:

$$
\begin{aligned}
& 4 \mathrm{H}_{2} \mathrm{O}+4 \mathrm{e}^{-} \rightarrow 2 \mathrm{H}_{2(\mathrm{~g})}+4 \mathrm{OH}^{-} \mathrm{E}(\text { vs. NHE) }=-0.83 \mathrm{~V} \text { (Eq. 1.4) } \\
& 4 \mathrm{OH}^{-} \rightarrow \mathrm{O}_{2(\mathrm{~g})}+4 \mathrm{e}^{-}+2 \mathrm{H}_{2} \mathrm{O} \quad \mathrm{E}(\text { vs. NHE) }=0.40 \mathrm{~V} \text { (Eq. 1.5) }
\end{aligned}
$$

In either case, it can be easily observed that the two half-reactions combine into the total water splitting reaction mentioned before. Even though the chemical reactions seem similar on paper in practice usually alkaline media are used. ${ }^{[24,40,52,53]}$ To understand this one must realize that the electrons, $e^{-}$, in these reactions are present on the electrodes. The fact that electrons electrostatically move away from the anode through oxidation means that the metallic electrodes are very often prone to corrosion, for example in chemical reactions like $\mathrm{M} \rightarrow \mathrm{M}^{\mathrm{x}}+\mathrm{x} \mathrm{e}^{-}$(Eq. 1.6) where $\mathrm{M}$ is the metal of the cathode. ${ }^{[4,9]}$ This is much less severe in alkaline media. On one hand, the electrodes usually oxidize towards their oxides, meaning they do not corrode..$^{[4,9,54]}$ A simplified example of such a chemical reaction would be: $\mathrm{M}+2^{*} \mathrm{xOH}^{-} \rightarrow \mathrm{MO}_{x}+\mathrm{x} \mathrm{H}_{2} \mathrm{O}+$ $2^{\star} \mathrm{x} \mathrm{e}^{-}$(Eq. 1.7). On the other hand, in alkaline media also the oxygen evolution reaction (Eq. 1.5) is kinetically easier than the same reaction in acidic media (Eq. 1.3). The reason for this is the fact that one of the elementary reaction steps, the dissociation of water into $\mathrm{OH}$ and $\mathrm{H}$, is not necessary for alkaline media. ${ }^{[4,9]}$

In a similar fashion, the hydrogen evolution reaction is kinetically less favorable in alkaline media than in acidic media, because in this case, the water 
dissociation step is necessary. Nevertheless, due to the HER being a twoelectron reaction it usually goes much faster than the four-electron OER. The bulk of literature and existing industrial processes focus on alkaline media due to these reasons. ${ }^{[24]}$ For the same reason, in this PhD Thesis, we will also focus mostly on alkaline media.

\subsubsection{Photo-catalytic Water Splitting}

Although they are not studied in this PhD Thesis, to more easily understand photo-electrochemical systems, understanding photo-catalytic systems helps. In the previous section, we already mentioned that the active material in photocatalytic water splitting systems is a suspension of particles. ${ }^{[12,46-48]}$ These particles are often metal oxide semiconductors that can absorb light to result in an excited electron in the conduction band and a resulting electron vacancy, or hole, in the valence band.

One of the most studied photocatalysts, as well as the first reported water splitting photo-catalyst, is $\mathrm{TiO}_{2}$. Fujishima and Honda introduced this material and showed that under UV irradiation water splits into hydrogen and oxygen when it is present. ${ }^{[4,48,55]}$ A lot of work has followed their initial publication, which discusses photo-catalysts, introducing both new materials and strategies to tackle the numerous challenges that are inherent to these materials. ${ }^{[46,48,55]}$

Amongst these challenges are stability, charge carrier recombination, conductivity, charge carrier trapping, and activity. ${ }^{[12,46-48,54-56]}$ Stability and activity are well-known factors in the field of catalysis. ${ }^{[12,45,47,48]}$ While the catalyst is, by definition, not consumed in the desired reaction, as was stated

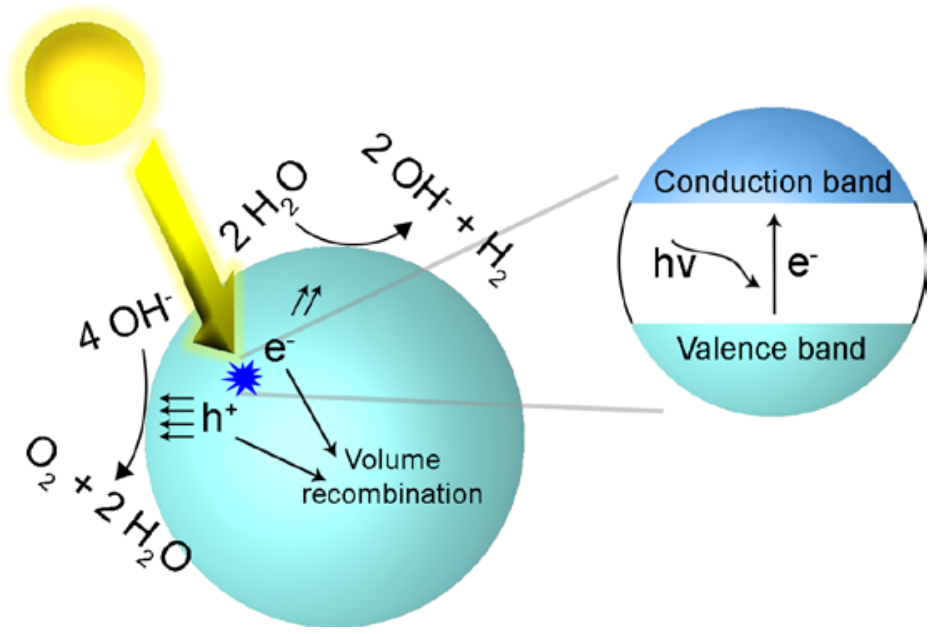

Figure 1.4: Schematic representation of a photo-catalyst at work. Light is absorbed to form a hole-electron pair by exciting an electron from the valence band to the conduction band. Four holes oxidize hydroxide to oxygen and water. At the same time two electrons reduce water to hydroxide and hydrogen. A large contributor to the loss of efficiency is volume recombination of the charge carriers. 

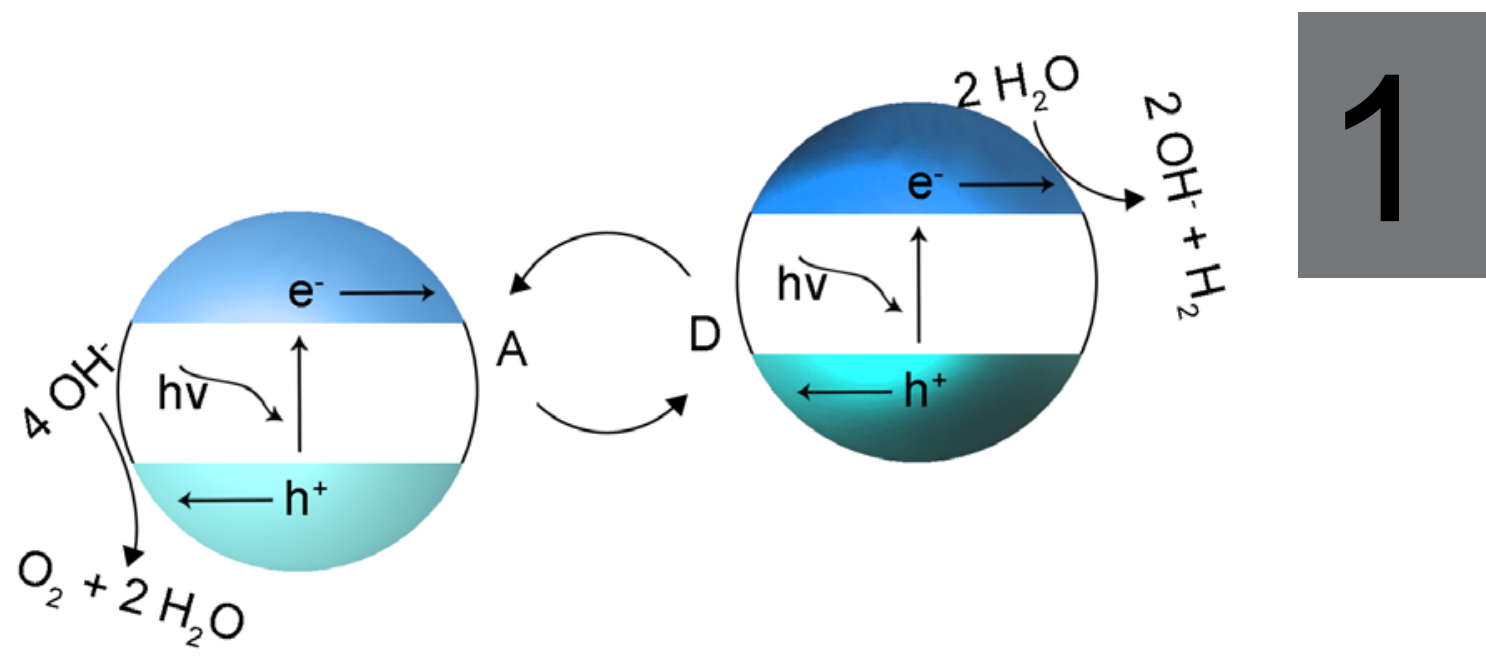

Figure 1.5: Schematic representation of the Z-scheme strategy often seen in photocatalytic systems. Here, two different materials are used to perform either the oxygen evolution (left) or the hydrogen evolution (right). An acceptor (A)/donor (D) couple is used to compensate the charge between the two different materials.

in the previous section, it can still deactivate in side reactions. Destabilization of photo-catalysts often occurs via redox reactions, since these samples are always under reducing and oxidizing stress inherent to the reaction mechanism of water splitting. ${ }^{[12,47,48]}$ Often, the catalyst oxidizes, reducing the number of active sites or dissolving, or it reduces which results in a loss of light-absorbing properties.

The other side of the catalytic coin is the activity of a material. For a catalyst to be active, it first needs to be thermodynamically suited to perform the reaction. In the case of photo-catalysts, this means that the band potentials of the material need to be suited for the desired reaction of water splitting (Figure 1.4). ${ }^{[46-48,55,56]}$ While this sounds simple, in practice such materials are scarce. Often these materials either have large (higher than $3 \mathrm{eV}$ ) bandgaps, such as $\mathrm{TiO}_{2}$ or $\mathrm{ZnO}$, or tend to be unstable (and often toxic), such as CdS. ${ }^{[46-48,55,56]}$

The conduction band has to be at a more negative potential than the $\mathrm{H}_{2} \mathrm{O} / \mathrm{H}_{2}$ reaction potential, at the same time the valence band has to be at a more positive potential than the $\mathrm{OH}^{-} / \mathrm{H}_{2} \mathrm{O}$. The issue with materials having large bandgaps means that light absorption gets limited to low wavelengths only. For example, a $3 \mathrm{eV}$ bandgap means that at most $410 \mathrm{~nm}$ can be absorbed.

On top of this, charge carriers can also recombine. This means that a photon that is absorbed generates charge carriers, which then return to the ground state often by generating heat. Effectively, this is a loss of efficiency. ${ }^{[46-48,54,56]}$

Several approaches are possible to reduce the aforementioned challenges. One is the application of the Z-scheme (Figure 1.5), where a mixture of two different photo-catalysts is utilized. ${ }^{[44,46,47,49]}$ In these systems, one photo- 
catalyst is responsible for the OER while the other performs the HER. In the solution a donor/acceptor mixture, e.g. $\mathrm{Fe}^{2+} / \mathrm{Fe}^{3+}$, is then present to complete the scheme. ${ }^{[44,46,47]}$ In another approach, co-catalysts are added to the photocatalyst, which often function both as charge collectors and as catalytic materials. ${ }^{[12,44,46]}$

Nevertheless, even if the numerous complications can be overcome there is still another practical consideration that has to be taken into account. The hydrogen and oxygen gas form in one pot, from one single dispersion. This means that the separation of the gasses is necessary. ${ }^{[4,46]}$ Apart from the separation being costly, in terms of both money and energy, the mixture of hydrogen and oxygen that is being formed is also a potent explosive.

A solution to this is to spatially separate the generation of the gasses. This is applied in electrochemical systems and will be discussed in the form of photoelectrochemical water splitting cells and electrochemical water splitting cells.

\subsubsection{Photo-electrochemical Water Splitting}

The spatial separation in photo-electrochemical systems is possible because the reactions occur at different electrodes. Much like the Z-scheme that was discussed in the previous section, two materials are used to reduce the number of necessary properties of a material. In photo-electrochemical water splitting systems, at least one electrode is a material that is capable of absorbing light. These materials are often similar to those used in photo-catalysis. Different combinations of electrodes are possible, e.g. a photo-anode with a metallic

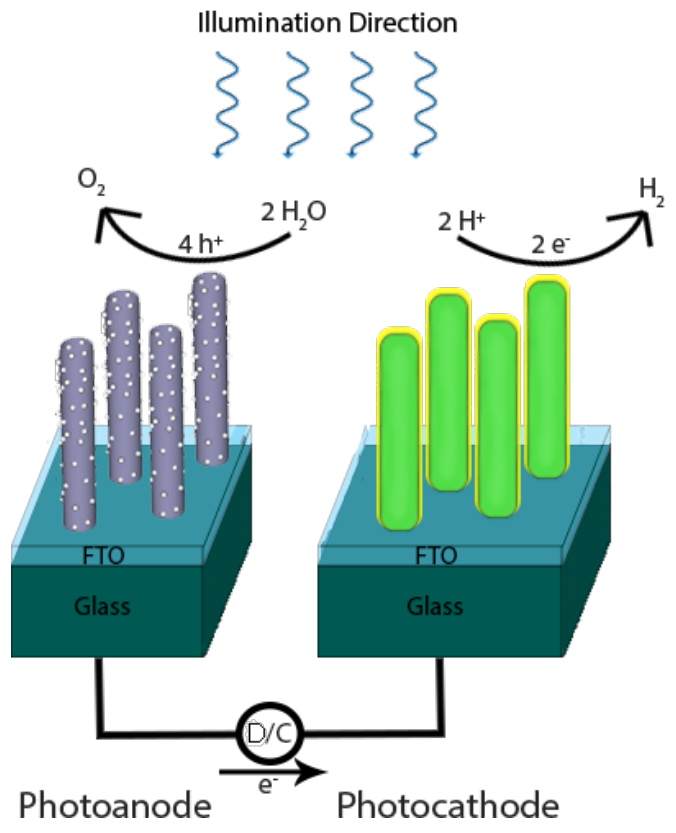

Figure 1.6: Schematic view on a complete PEC cell with nanorod photo-absorbers. On the left the photo-anode is shown which performs the water oxidation with the nanoparticle co-catalyst strategy. On the right the photo-cathode performs the proton reduction with the multilayer strategy. An electrical bias can be applied between the electrodes to increase the reaction rate. 
cathode, or a metallic anode with a photo-cathode. It is also possible that both electrodes are photo-electrodes (Figure 1.6). ${ }^{[16,49-51,54]}$

The principle of each configuration is the same: the photo-electrode(s) absorbs light and generates an electric potential. This potential then drives the two halfreactions, OER and HER, on the anode and cathode, respectively. $[3,12,16,39,44,49-$ 51] Furthermore, additional potential can be applied to the system in case the semiconductor does not produce enough to drive the reaction at appreciable speeds. ${ }^{[39,50,51,57]}$

In photo-electrochemical as well as photocatalytic systems oft-seen strategies are the functionalization of the photo-absorbers. ${ }^{[9,50,51,54]}$ In Figure 1.6, two of those strategies are schematically visualized. On the photo-anode, nanoparticle functionalization is shown, where nanoparticles are added to collect the current generated by light absorption and perform the catalytic oxidation reaction. On the cathode side, the use of a protecting coating is shown. Here, a layer, often catalytically active is coated on the photo-absorber. This approach is especially useful when the photo-absorber is unstable in the often harsh chemical conditions of solar-driven water splitting setups. ${ }^{[9,50,51,54]}$

A process that happens at semiconductors in solution, so also for photocatalysts, is band bending. ${ }^{[9,39,50,51,54,57]}$ Band bending occurs because of the

a

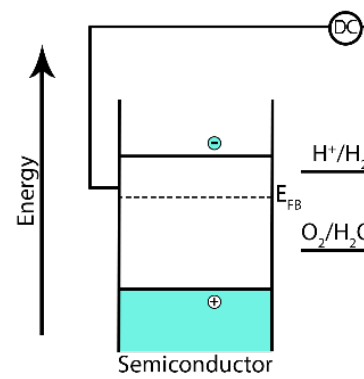

b

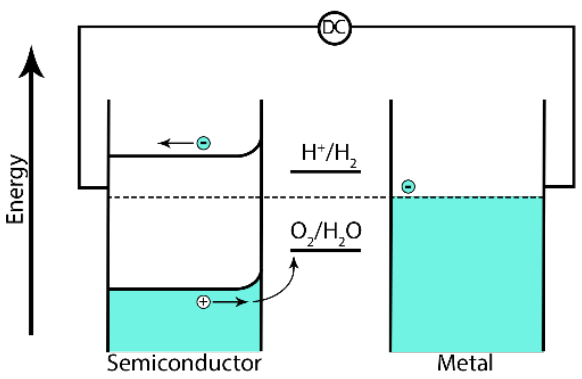

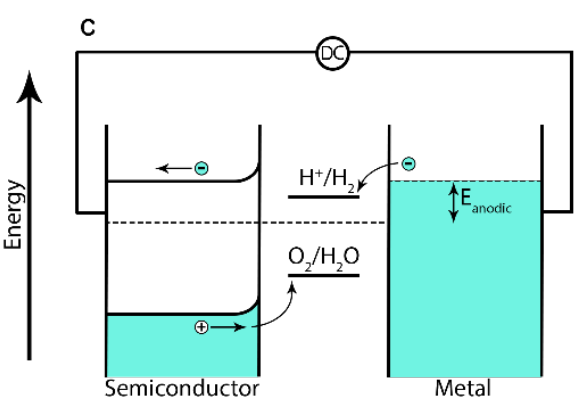

Figure 1.7: Schematic representation of band bending and the effect of applying an electrical bias. a) gives the representation without band bending taken into account, $b$ ) a representation with band bending taking into account and c) a representation where an anodic external bias is applied as well. 
interaction of the electrolyte with the semiconductor. If mainly positive ions adsorb on the surface then the bands bend down, directing electrons towards the surface. If these are negative ions, the bending likewise goes in the opposite direction, upwards, to direct holes towards the surface (Figure 1.7). $[9,39,50,51,54,57]$

Often an extra bias is applied in these cells, this effectively changes the band position of the metal electrode to overcome the energy barrier of water splitting. It also aids in driving charge carriers through the photo-electrode. This is one of the strengths of using photo-electrochemical cells over photo-catalytic systems; the dependency on the band positions and energetics of the materials themselves is less. ${ }^{[39,50,51,57]}$

\subsubsection{Electrochemical Water Splitting}

A challenge that is still seen often with photo-catalysis and photoelectrochemistry is that the systems have too many requirements. The need for them to absorb light, be stable in harsh chemical conditions, have proper energetics, and have catalytic activity towards water splitting might be a lot to ask. To bridge the long time needed to develop such systems in an economical way electrochemical systems are often considered. ${ }^{[24,39-42]}$

We have seen a schematic of electrochemical water splitting earlier in Figure 1.3. The advantage of an electrochemical system is that the materials no longer need to absorb light efficiently and the focus can be fully on activity and stability. In section 1.3 the potentials related to water splitting were already given. Electrochemical water splitting is well studied and mechanisms of hydrogen evolution are known (Figure 1.8). ${ }^{[24,40-42]}$ These are similar to the Eley-Rideal (Heyrovsky step) and Langmuir-Hinshelwood (Tafel step) mechanisms often described in heterogeneous catalysis. ${ }^{[45]}$

The main difference between these mechanisms is, as seen in Figure 1.8, that electrons from the electrode are reactants. Thus, not all reactants are outside of the catalyst as is the case with most heterogeneous catalysis systems. Furthermore, it is known that the parameter known as the Tafel slope tells which mechanistic step is rate determining. ${ }^{40-42]}$ The Tafel slope is the number of volts needed to increase the current by an order of magnitude, so to increase it by a factor ten. Note that this only holds when there are no mass transport limitations.

As shown in Figure 1.8, the mechanism is not static. It always starts with the initial hydrogen adsorption in the Volmer step. Whether the Heyrovsky step or the Tafel step is then predominant depends on the used potential, E, which corresponds to the hydrogen coverage, $\theta_{\mathrm{H}} \cdot{ }^{[40-42]}$

The fact that each of the steps has a Tafel slope makes it easy to understand that, if a higher current is desired, a higher potential needs to be applied. As shown in section 1.3 the thermodynamic potential for water splitting is $1.23 \mathrm{~V}$. This does not consider kinetics; to drive the reaction at appreciable currents 

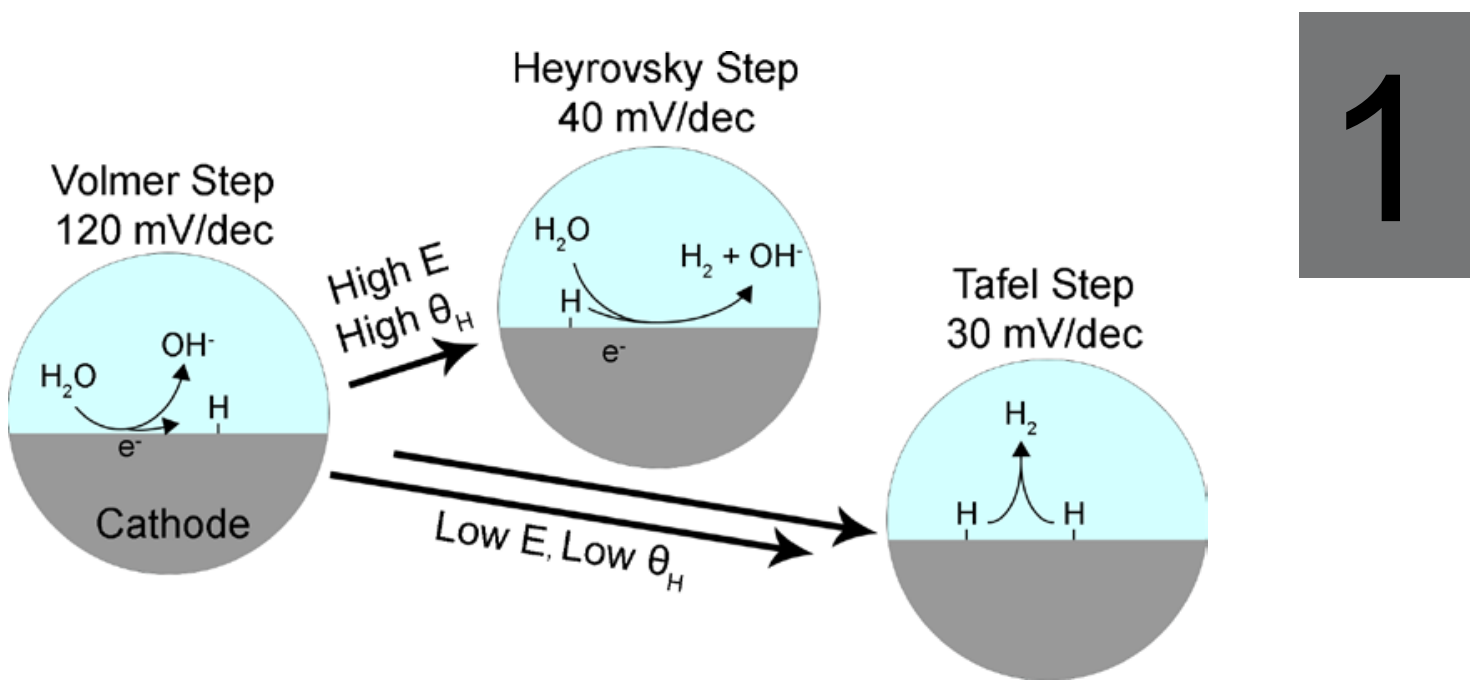

Figure 1.8: Schematic representation of the mechanism of the hydrogen evolution reaction in electrocatalysis showing the initial adsorption (Volmer step), the EleyRideal-like desorption step (Heyrovsky Step) and the Langmuir-Hinshelwood-like desorption step (Tafel Step). Each of these steps has a typical Tafel slope when it is the rate determining step as given in the image.

one needs to invest additional potential to drive the electrons into, in this case, hydrogen formation. This additionally applied potential is termed the overpotential $(\eta) \cdot{ }^{[4,41,42]}$ Note that current can easily be understood as electrons per second. Assuming $100 \%$ Faradaic efficiency (\% of electrons invested in the desired reaction) the current is a measure of hydrogen production.

The overpotential is essentially a loss of energy. In an ideal system the energy that can be gained from hydrogen follows the power law: $\mathrm{P}_{\text {out }}=1.23 \mathrm{~V} * \mathrm{I}$. However, since we need to invest an overpotential the generation of hydrogen costs $P_{\text {in }}=(1.23 \mathrm{~V}+\eta){ }^{*} \mathrm{I}$. From this it can be simply observed that $P_{\text {lost }}=\eta$ * $\mathrm{I}$. The bulk of this energy loss is as heat due to resistances, such as cable resistances, interfacial resistances in the electrochemical cell, and mass diffusion.

Mass diffusion occurs on several levels in an electrochemical system. ${ }^{[24,57]}$ There should be diffusion in the bulk to maintain concentrations. This diffusion is a function of bulk concentration and usually (solutions of $\geq 1 \mathrm{M}$ ) not a big issue. The more interesting mass diffusion occurs in what is called the double layer, or the Helmholtz layer. ${ }^{[41,42,57]}$ Since the electrodes are charged, oppositely charged ions adsorb on the surface. This results in a double layer, a capacitive layer of e.g. a negatively charged electrode and a layer of adsorbed positive ions. No electron transfer occurs here, known as a nonFaradaic current. ${ }^{[58-61]}$ The built-up capacitance is known as the double layer capacitance and is a measure of surface area and surface composition according to, $C_{D L}=\left(I_{D L} / v\right) / C_{s}$, where $C_{D L}$ is the double layer capacitance, $I_{D L}$ is the double layer current, $\mathrm{v}$ is the scan speed $(\mathrm{V} / \mathrm{s})$ of the experiment and $\mathrm{C}_{\mathrm{s}}$ is the specific capacitance of the material. This last number is a material- 
specific parameter. If $\mathrm{C}_{\mathrm{S}}$ is known and constant, the current $\mathrm{I}_{\mathrm{DL}}$, is solely dependent on the amount of surface on which positive ions can adsorb. Thus, the double layer capacitance is often used as a measure of surface area. ${ }^{[58-61]}$

The necessity for an electrocatalyst to be conductive by definition means that there are limits in the choice of materials. ${ }^{[4]}$ Understandably, this results in most reported catalysts being metals or oxides. ${ }^{[4]}$ There are also other materials such as sulfides, phosphides, nitrides, and carbides, which are found as efficient catalysts, but these are less studied. ${ }^{[8,24,41,42]}$

\subsection{Electrocatalysts for the Hydrogen Evolution Reaction}

Out of the monometallic materials, platinum is the most efficient in the hydrogen evolution reaction, while ruthenium is the most efficient oxygen evolution catalyst. ${ }^{[4,24,41,42]}$ The main reason for the efficiency of these materials is based on the Sabatier principle: they bind intermediates (like adsorbed hydrogen) neither too strongly, nor too weakly. ${ }^{[24,41,42,62]}$ Considering hydrogen evolution, which is the focus of this thesis: on one hand, a material that would be too strongly binding would form hydrides. ${ }^{[23,24,63,64]}$ On the other hand, too weakly bonding materials would not adsorb hydrogen and thus not act as a catalyst. ${ }^{[24,41,42]}$ This resulted in the well-known shape of the volcano plot, as shown in Figure 1.9. These results from Trassati are under heavy debate since the metals on the descending branch are covered in oxides under HER conditions, which can have a significant impact on the activity. ${ }^{[41,42,62]}$
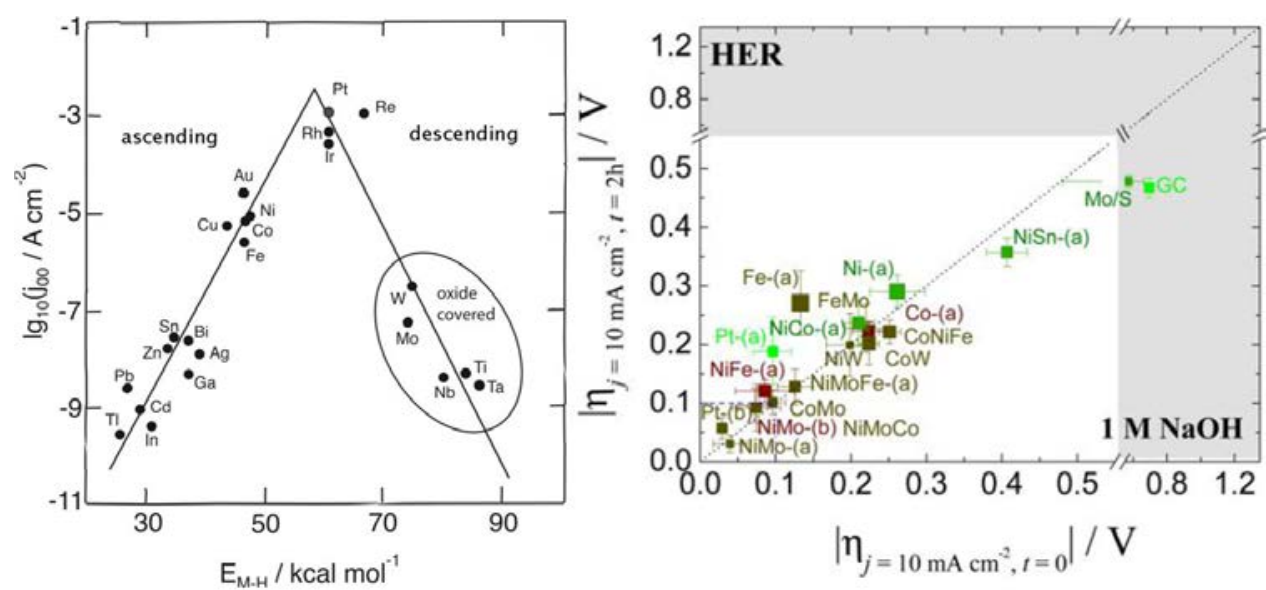

Figure 1.9: Left: The much-debated volcano plot of mono-metallic electrocatalysts with their activity (in acidic media) on the $y$-axis and $\mathrm{M}-\mathrm{H}$ bond strength on the $\mathrm{x}$-axis. It shows Pt as the most active, Mo as too weakly binding and Ni as too strongly binding. Reproduced from ref 62. Right: A plot showing various electrocatalysts tested in literature and comparing their initial overpotential ( $x$-axis) versus their overpotential after $2 h$ (y-axis) in alkaline media. It can be seen that Ni-Mo has comparable activity to Pt. Reproduced from Ref. 4. 
Yet there is a search for alternatives to $\mathrm{Pt}$ and $\mathrm{Ru}$. The simple reasons are thus: these noble metals are scarce and expensive. ${ }^{[4,24]}$ To get the technology of electrolysis as an energy storage method off the ground on a large scale it needs to be economically viable. This means there is a need for cheap and stable materials to be able to compete with, for example, the oil industry; in the end, most consumers will buy the cheapest product and thus there is a target that needs to be reached. ${ }^{[4,24]}$

Despite the controversy, this plot is what sparked the search for bimetallic and multimetallic alloys for the HER ${ }^{[4,24]}$ As is also shown in Figure 1.9 most materials that are reported to have similar or even superior activity compared to Pt are alloys. The most common elements in these alloys are $\mathrm{Ni}, \mathrm{Co}, \mathrm{W}$, and Mo. One of the main reasons hailed for the activity of these materials is the synergy between a material on the ascending branch (too strongly binding) like $\mathrm{Ni}$ or $\mathrm{Co}$, with a material on the descending branch (too weakly binding) like $\mathrm{W}$ or Mo. $[23,53,63,65,66]$ This is not the case for all the materials in the graph, however, such as NiFe or NiCoFe, where all materials are on the ascending branch. ${ }^{[4]}$

Such reasons add to the debate about whether the volcano plot is correct since making such plots depend greatly on experimental conditions. Note that the shown volcano plot was generated in acidic media, while the activity plot on the right is made in $1 \mathrm{M} \mathrm{NaOH}$. Though discussed heavily, all plots made, to the author's knowledge, show that the plotted trends stay roughly the same in either acidic or alkaline media. ${ }^{[2,41,42,62]}$ Despite all this discussion, however, it is clear that materials like Ni-Mo are highly efficient in the HER.

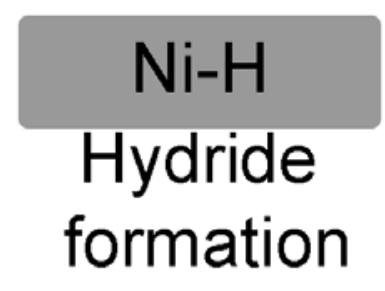

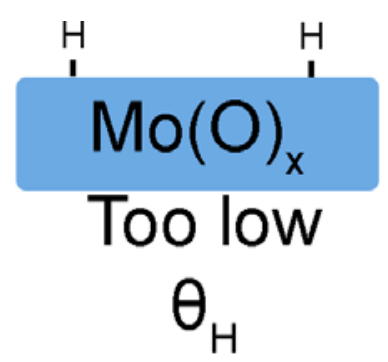
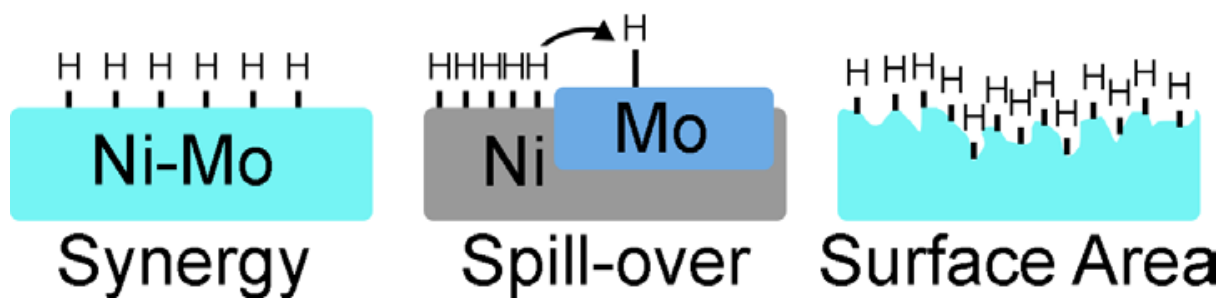

Figure 1.10: Top: Schematics showing why metallic Ni and Mo electrodes do not perform exceptionally as separate materials. Bottom: Schematics showing possible mechanisms through which Ni-Mo has increased performance. 
It does make one ask: is the synergy of strong and weakly binding materials the real reason for this high activity? Several reasons can be found in literature and the main descriptions are summarized in Figure 1.10. It is known that $\mathrm{Ni}$ forms hydrides under HER conditions, and while it is still one of the most active monometallic materials, this hampers its activity. ${ }^{[23,24,63,64]} \mathrm{Mo}$, on the other hand, is, as mentioned before, covered in oxides at typical HER conditions. ${ }^{[4,23,24,67,68]}$ Furthermore, it is known it has a low $\theta_{H}$, meaning that hydrogen formation is slow. The most proposed reason for the activity in the literature is the synergy of $\mathrm{Ni}$ and $\mathrm{Mo}$, in part because the discussion on the volcano plot was only sparked relatively recently. ${ }^{[23,53,63,65,66]}$ This reasoning assumes that the hydrogen binding energy, $\mathrm{E}_{\mathrm{M}-\mathrm{H}}$, is averaged between the two materials and thus results in an alloy, which is basically on top of the volcano plot. Another discussed mechanism is the spill-over effect. This assumes an alloy, which is not perfectly mixed but has a more domain-like structure. Here $\mathrm{Ni}$ would fully cover its surface in a hydride-like state. As it gets covered, adsorbed hydrogen spills towards the Mo domains. Since Mo has a much lower $\mathrm{E}_{\mathrm{M}-\mathrm{H}}$ the hydrogen there easily desorbs to form $\mathrm{H}_{2} \cdot{ }^{[23,66]}$

The final main description of the high activity of Ni-Mo is its tendency to form high surface area materials, giving rise to a high electrochemically active surface area (ECSA). ${ }^{[23,24,43,53,65,66]}$

The surface area is an important descriptor in electrocatalysis (and catalysis in general). ${ }^{[4,24,45]}$ Electrochemical literature can often be difficult to compare since it is not always clear what is used as a surface area when reporting the current density $\left(\mathrm{j}, \mathrm{mA} / \mathrm{cm}^{2}\right)$. It has a significant impact if the geometric surface area is used, as is the case in Figure 1.9, where only the substrate electrode area is reported. If the ECSA is used, on the other hand, Pt is still undebated as the best catalyst per surface site. ${ }^{[4,24,41,42]}$

It should come as no surprise that increasing the surface area of a catalyst is one of the main methods to improve the activity of electrocatalysts. ${ }^{[23,24,43,53,65,66]}$ There are many reports on high surface area NiMo with exceptional activity due to high surface area. This is a common approach found in many fields of catalysis, however, in electrochemistry literature making comparisons is often difficult because often only currents and not turn-over frequencies (TOF; i.e., activity, expressed as the number of molecules converted per active site per time unit) or like-wise turn-over numbers (TON) are reported. ${ }^{[4]}$

The surface area determination of electrodes is experimentally challenging. ${ }^{[4,58-}$ 61] Double layer capacitance measurements are generally used, yet depend on not only the surface area but surface composition as well. ${ }^{[4,58-61]}$ Furthermore, porosity is not always properly probed due to mass transport limitations. Techniques, such as gas physisorption, are often not available due to size constraints. Surface techniques, like scanning electron microscopy (SEM), transmission electron microscopy (TEM) or atomic force microscopy (AFM) also struggle with visualizing pores properly. All these reasons make it hard to report an actual TOF for which the number of active surface sites needs to be 
accurately known. ${ }^{[61]}$ However, it should be clear that this challenge is not limited to electrocatalysis, but holds for the entire field of heterogeneous catalysis.

As shown in Figure 1.11 surface area can be increased in several ways, e.g. by using high surface area substrates, such as metal foams (panel b) ${ }^{[68]}$, by forming high surface area materials, such as nanorods (panel c) ${ }^{[69,70]}$, or by increasing the mass loading of the catalytically active material when using particles (panel e) ${ }^{[71]}$.

Since Ni-Mo is an alloy the ratio of the elements is studied as well (panel a) and it is found that $\mathrm{Ni}_{0.6} \mathrm{Mo}_{0.4}$ is the most active phase. ${ }^{[63]}$ As already shown in Figure 1.9 there are also reports on trimetallic alloys, such as NiCoMo or NiFeMo.
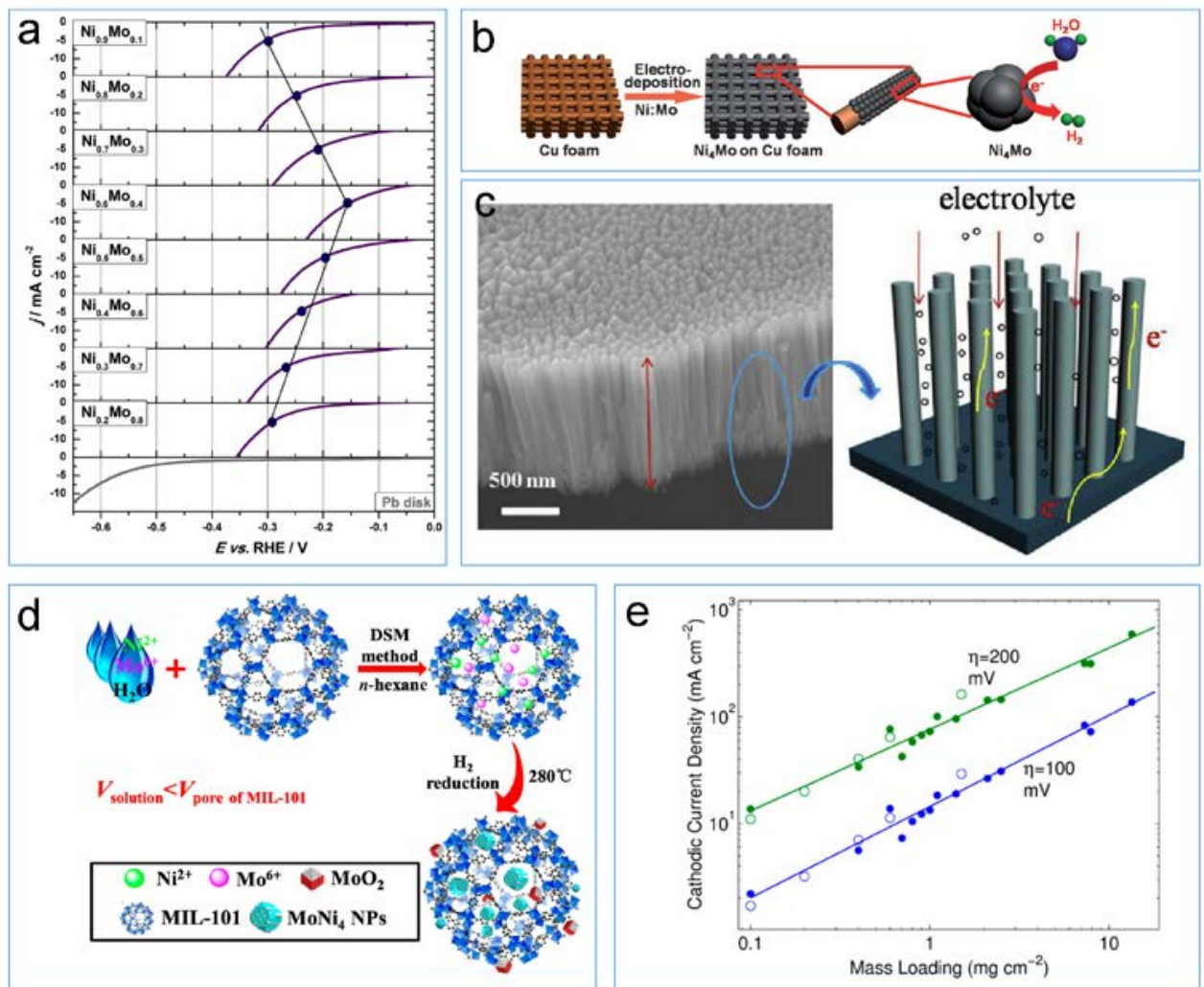

Figure 1.11: A selection from literature showing strategies for improving Ni-Mo activity. a) Optimizing the Ni:Mo ratio, with the optimum at Nio.6 Mo 0.4 . Reproduced from ref. 63. b) Synthesizing Ni-Mo on high surface area substrates such as metal foams. Reproduced from ref. 68. c) Synthesizing Ni-Mo in a high surface area configuration, such as nanorods. Reproduced from ref. 69. d) Combining Ni-Mo with photo-catalysts such as the metal-organic framework MIL-101. Reproduced from ref. 72. e) Increasing the catalyst loading when using particles. Reproduced from ref. 71. 
While these score lower in this large-scale test by McCrory et al., especially NiFeMo can still be an interesting material. ${ }^{[4]}$ Even though there is a loss in activity replacing $\mathrm{Ni}$ or Mo with the significantly cheaper Fe could be a huge benefit if the overpotential is not too significant cost-wise.

A more exotic approach is combining electrocatalysts with photo-catalytic (panel d) or photo-electrochemical materials. ${ }^{[2]}$ This allows for theoretically higher (economic) efficiency since fewer steps are required: energy capture and conversion are done in one reactor instead of having to have energy capture technologies such as solar panels and windmills and a separate reactor for energy conversion. Earlier mentioned challenges accompanying photocatalysts and photo-electrodes still hold: many properties are required to be suitable for such a system to work.

\subsection{Scope and Outline of the PhD Thesis}

The goals of this PhD Thesis are outlined in a cartoon in Figure 1.12. The main goal is to produce hydrogen from renewable electricity via water electrolysis

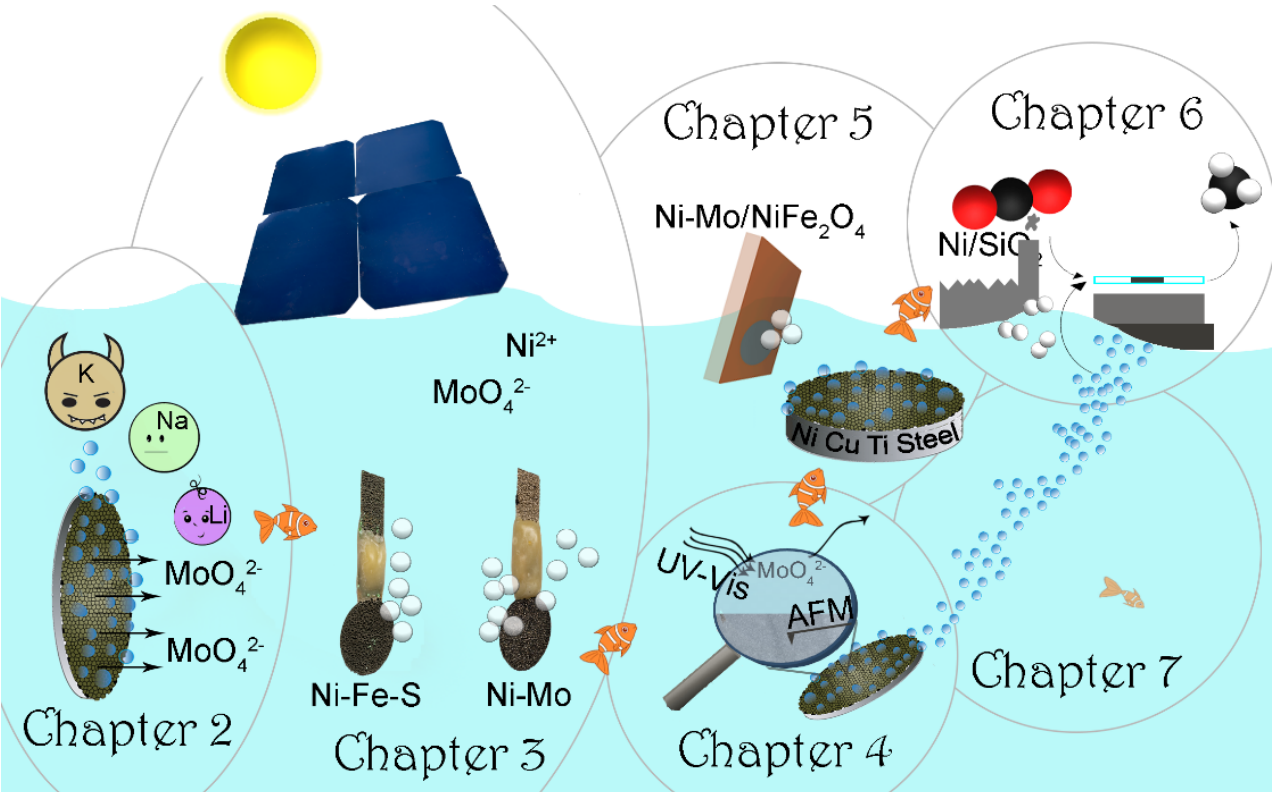

Figure 1.12: Cartoon illustrating the scope of this PhD Thesis. Chapter 2, discussing the leaching of $\mathrm{Mo}$ as $\mathrm{MoO}_{4}{ }^{2-}$ and the effects of electrolytes. Chapter 3, discussing integration of a high-performing OER catalyst (Ni-Fe-S) with the Ni-Mo HER catalyst and the optimization of the electrodeposition synthesis. Chapter 4, discussing the leaching of $\mathrm{MoO}_{4}{ }^{2-}$ as a function of current and potential and introducing AFM and UV-Vis spectroscopy as in situ techniques for these systems. Chapter 5: discussing the possibility of combining $\mathrm{Ni}-\mathrm{Mo}$ with $\mathrm{NiFe}_{2} \mathrm{O}_{4}$ photo-absorbers. Chapter 6 , discussing the integration of solar driven electrochemical water splitting with $\mathrm{CO}_{2}$ hydrogenation to store the energy in methane. Finally, there's Chapter 7 to conclude and summarize the thesis as well as present an outlook on future research. 
using Ni-Mo electro-catalysts. It aims to establish knowledge on the stability of the Ni-Mo system and subsequently stabilizing it. Finally, it explores the use of $\mathrm{Ni}-\mathrm{Mo}$ catalysts in various configurations such as part of photo-electrodes, in two-electrode electrolyzers and as the hydrogen production catalyst in cascaded $\mathrm{CO}_{2}$ hydrogenation.

First, some instability was found on the Ni-Mo cathode and further explored in Chapter 2. Here the leaching of the Mo component of Ni-Mo was further explored and the mechanism of leaching was found. The mechanism was found where Mo leaches as $\mathrm{MoO}_{4}{ }^{2-}$, producing a surplus of $\mathrm{H}_{2}$ as well, without consuming electrons. The reaction was found to be driven by $\mathrm{OH}^{-}$and thus the effects of $\mathrm{pH}$ are discussed in this PhD chapter. Furthermore, the effect of the cations in the electrolyte, usually seen as spectator species, are discussed and found to play a role in Mo leaching. The findings show that the activity of $\mathrm{Ni}-\mathrm{Mo}$ is a combination of synergetic as well as surface area effects.

A system will be established, in Chapter 3, combining Ni-Mo HER catalysts with a more recently discovered Ni-Fe-S OER catalysts to form a system capable of splitting water solely driven by solar cells. This PhD chapter then focusses in more detail on Ni-Fe-S catalysts and discusses the roles of Fe and $\mathrm{S}$ in improving the activity of $\mathrm{Ni}$ towards OER. It was found that Fe mostly serves to increase surface area, where $\mathrm{S}$ synergizes with $\mathrm{Ni}$ towards a better activity. The activity of these materials was furthermore improved by increasing their surface area, using high surface area Ni foam supports. High stability over the course, maintaining a low operating overpotential was found.

In Chapter 4, we utilize in situ AFM and in situ UV-Vis spectroscopy to study the effect of potential, and of metallic substrates, on the stability of Ni-Mo. Ti, $\mathrm{Cu}, \mathrm{Ni}$, and stainless steel are explored as potential metallic substrates for $\mathrm{Ni}$ Mo. In this PhD Chapter, it is found that these materials have significantly different behavior with respect to Mo leaching. This substrate dependency also results in differences in potential dependency of the leaching effects. Either low or high overpotentials were found to reduce Mo leaching in most cases, which shows that there are at least two mechanisms through which the potential influenced Mo leaching.

$\mathrm{Ni}$-Mo was then applied as a co-catalyst to $\mathrm{NiFe}_{2} \mathrm{O}_{4}$ photo-cathodes. In Chapter 5 , this combined material is discussed, where $\mathrm{NiFe}_{2} \mathrm{O}_{4}$ is a suitable photoabsorber for hydrogen evolution, but lacking redox stability renders it impractical for use. Combining it, however, with Ni-Mo through cathodic electrodeposition formed a stable system, where Ni-Mo was bifunctional as a catalyzing layer and a protective coating for the photo-absorber. The use of a different substrate did incite the question of what the effect of substrates on NiMo stability would be, as well as the effect of potential, which led us to study that in more detail.

In Chapter 6, we tackle another challenge of water splitting: hydrogen storage. Here the development and study of a cascaded setup are discussed. Here solar cell driven electrochemical water splitting is combined by thermal $\mathrm{CO}_{2}$ 
hydrogenation using supported Ni nanoparticle catalysts. We find it is indeed possible to form $\mathrm{CH}_{4}$ using only $\mathrm{CO}_{2}$ and $\mathrm{H}_{2} \mathrm{O}$ as resources, and further find and discuss practical implications which follow from combining said reactions. The formation of hydroxide containing aerosols was found, and these deposit on the hydrogenation catalysts, influencing their performance. We explore how this can either be exploited or prevented.

Finally, the PhD Thesis ends with Chapter 7, providing a summary of the main findings, followed by some concluding remarks and an outlook on potential future experiments.

\subsection{References}

[1] Acar, C. \& Dincer, I., Int. J. Hydrogen Energy 2014, 39, 1-12

[2] Allen, M. R., Barros, V. R., Broome, J., Cramer, W., Christ, R., Church, J. A., Clarke, L., Dahe, Q., Dasgupta, P., Dubash, N. K., Edenhofer, O., Elgizouli, I., Field, C. B., Forster, P., Friedlingstein, P., Fuglestvedt, J., Gomez-Echeverri, L., Hallegatte, S., Hegerl, G., Howden, M., Jiang, K., Cisneros, B. J., Kattsov, V., Lee, H., Mach, K. J., Marotzke, J., Mastrandrea, M. D., Minx, L. M. J., Mulugetta, Y., O'Brien, K., Oppenheimer, M., Pachauri, R. K., Pereira, J. J., Pichs-Madruga, R., Plattner, G.-K., Pörtner, H.-O., Power, S. B., Preston, B., Ravindranath, N. H., Reisinger, A., Riahi, K., Rusticucci, M., Scholes, R., Seyboth, K., Sokona, Y., Stavins, R., Stocker, T. F., Tschakert, P., van Vuuren, D. van \& van Ypersele, J.-P., IPCC Fifth Assess. Synth. Rep., November 2014

[3] Lewis, N. S., Science 2016, 351, 353; Lewis, N.S., Science 2016, 351, aad1920

[4] McCrory, C. C. L., Jung, S., Ferrer, I. M., Chatman, S. M., Peters, J. C. \& Jaramillo, T. F., J. Am. Chem. Soc. 2015, 137, 4347-4357

[5] Rand, D. A. J., J. Solid State Electrochem. 2011, 15, 1579-1622

[6] Schlögl, R., Angew. Chem. Int. Ed. 2015, 54, 4436-4439

[7] Schlögl, R., Angew. Chem. Int. Ed. 2017, 56, 11019-11022

[8] Vesborg, P. C. K., Seger, B. \& Chorkendorff, I., J. Phys. Chem. Lett. 2015, 6, 951-957

[9] Walter, M. G., Warren, E. L., McKone, J. R., Boettcher, S. W., Mi, Q., Santori, E. A. \& Lewis, N. S., Chem. Rev. 2010, 110, 6446-6473

[10] Heide, D., von Bremen, L., Greiner, M., Hoffmann, C., Speckmann, M. \& Bofinger, S., Renew. Energy 2010, 35, 2483-2489

[11] Mikayilov, J. I., Galeotti, M. \& Hasanov, F. J., J. Clean. Prod. 2018, 197, 1558-1572

[12] Fresno, F., Portela, R., Suárez, S. \& Coronado, J. M., J. Mater. Chem. A 2014, 2, 2863-2888

[13] Benson, E. E., Kubiak, C. P., Sathrum, A. J. \& Smieja, J. M., Chem. Soc. Rev. 2009, 38, 89-99

[14] Kim, S. H., Kim, K. H. \& Hong, S. H., Angew. Chem. Int. Ed. 2014, 53, 771-774 
[15] Kiss, A. A., Pragt, J. J., Vos, H. J., Bargeman, G. \& de Groot, M. T., Chem. Eng. J. 2016, 284, 260-269

[16] Kumar, B., Llorente, M., Froehlich, J., Dang, T., Sathrum, A. \& Kubiak, C. P., Annu. Rev. Phys. Chem. 2012, 63, 541-569

[17] Qiao, J., Liu, Y., Hong, F. \& Zhang, J., Chem. Soc. Rev. 2014, 43, 631675

[18] Sumida, K., Rogow, D. L., Mason, J. A., McDonald, T. M., Bloch, E. D., Herm, Z. R., Bae, T. H. \& Long, J. R., Chem. Rev. 2012, 112, 724-781

[19] Creel, E. B. \& McCloskey, B. D., Nat. Catal. 2018, 1, 6-7

[20] Gao, P., Li, S., Bu, X., Dang, S., Liu, Z., Wang, H., Zhong, L., Minghuang, Q., Yang, C., Cai, J., Wei, W. \& Sun, Y., Nat. Chem. 2017, 9, 1019-1024

[21] Bloomberg NEF, World Reaches 1000GW of Wind and Solar, Keeps Going 2018, Available at: https://about.bnef.com/blog/world-reaches$1000 \mathrm{gw}$-wind-solar-keeps-going/.

[22] Anderson, D. L., J. Geophys. Res. 1983, 88, B41-B52

[23] Schalenbach, M., Speck, F. D., Ledendecker, M., Kasian, O., Goehl, D., Mingers, A. M., Breitbach, B., Springer, H., Cherevko, S. \& Mayrhofer, K. J. J., Electrochim. Acta 2018, 259, 1154-1161

[24] Sapountzi, F. M., Gracia, J. M., Weststrate, C. J., Fredriksson, H. O. A. \& Niemantsverdriet, J. W., Prog. Energy Combust. Sci. 2017, 58, 1-35

[25] Balat, M. \& Balat, M., Int. J. Hydrogen Energy 2009, 34, 3589-3603

[26] Billone, M., Yan, Y., Burtseva, T. \& Daum, R., U.S. NRC 2008, Cladding Embrittlement During Postulated Loss-of-Coolant Accidents

[27] Kandemir, T., Schuster, M. E., Senyshyn, A., Behrens, M. \& Schlogl, R., Angew. Chem. Int. Ed. 2013, 52, 12723-12726

[28] Olah, G. A. \& Molnar, A., Hydrocarbon Chemistry, John Wiley \& Sons, New Jersey, 2003

[29] Brunet, S., Mey, D., Pe, G., Bouchy, C. \& Diehl, F., Appl. Catal.: A Gen. 2005, 278, 143-172

[30] Prado, G. H. C., Rao, Y. \& De Klerk, A., Energy Fuels 2017, 31, 14-36

[31] De Smit, E. \& Weckhuysen, B. M., Chem. Soc. Rev. 2008, 37, 27582781

[32] Takeshita, T. \& Yamaji, K., Energy Policy 2008, 36, 2773-2784

[33] Du, F., Warsinger, D. M., Urmi, T. I., Thiel, G. P., Kumar, A. \& V, J. H. L., Environ. Sci. Technol. 2018, 52, 5949-5958

[34] Greenwood, N. N. \& Earnshaw, A., Chemistry of the Elements, Elsevier Ltd., New York, 1997

[35] Diaz, L. A., Diaz, L. A., Dufek, E. J. \& Lister, T. E., Green Chem. 2018, 20, 620-626

[36] Lin, L., Hall, J., Lippmann-pipke, J., Ward, J. A., Lollar, B. S., DeFlaun, M., Rothmel, R., Moser, D., Gihring, T. M., Mislowack, B. \& Onstott, T. C., Geochemistry Geophys. Geosystems 2005, 6, Q07003

[37] Lin, L., Wang, P., Rumble, D., Lippmann-pipke, J., Boice, E., Pratt, L. M., Lollar, B. S., Brodie, E. L., Hazen, T. C., Andersen, G. L., Desantis, T. Z., Moser, D. P., Kershaw, D. \& Onstott, T. C., Science 2006, 314, 479-483 
[38] Xu, D., Dong, L. \& Ren, J., Introduction of Hydrogen Routines, Chapter 2, in: Hydrogen Economy (Eds.: Scipioni, A., Manzardo, A. \& Ren, J.), Elsevier Ltd., London, 2017

[39] Rajeshwar, K., Encycl. Electrochem. 2001, 6, 3-53

[40] Safizadeh, F., Ghali, E. \& Houlachi, G., Int. J. Hydrogen Energy 2014, 40, 256-274

[41] Zeng, K. \& Zhang, D., Prog. Energy Combust. Sci. 2010, 36, 307-326

[42] Zeng, M. \& Li, Y., J. Mater. Chem. A 2015, 3, 14942-14962

[43] Abdel-Karim, R., Halim, J., El-Raghy, S., Nabil, M. \& Waheed, A., J. Alloys Compd. 2012, 530, 85-90

[44] Horiuchi, Y., Toyao, T., Takeuchi, M., Matsuoka, M. \& Anpo, M., Phys. Chem. Chem. Phys. 2013, 15, 13243-13253

[45] Chorkendorff, I. \& Niemantsverdriet, J. W., Concepts of Modern Catalysis and Kinetics, Wiley-VCH, Weinheim, 2017

[46] Banerjee, S., Pillai, S. C., Falaras, P., O'Shea, K. E., Byrne, J. A. \& Dionysiou, D. D., J. Phys. Chem. C 2014, 5, 2543-2554

[47] Djurišić, A. B., Leung, Y. H. \& Ching Ng, A. M., Mater. Horizons 2014, 1, 400-410

[48] Linsebigler, A. L., Lu, G. \& Yates, J. T., Chem. Rev. 1995, 95, 735-758

[49] Seitz, L. C., Chen, Z., Forman, A. J., Pinaud, B. A., Benck, J. D. \& Jaramillo, T. F., ChemSusChem 2014, 7, 1372-1385

[50] Weber, M. F., J. Electrochem. Soc. 1984, 131, 1258-1265

[51] Weber, M. F. \& Dignam, M. J., Int. J. Hydrog. Energy 1986, 11, 225232

[52] Kaninski, M. P. M., Saponjic, D. P., Nikolic, V. M., Zugic, D. L. \& Tasic, G. S., Int. J. Hydrogen Energy 2011, 36, 8864-8868

[53] Tasic, G. S., Maslovara, S. P., Zugic, D. L., Maksic, A. D. \& Kaninski, M. P. M., Int. J. Hydrogen Energy 2011, 36, 11588-11595

[54] Abdi, F. F., Han, L., Smets, A. H. M., Zeman, M., Dam, B. \& van de Krol, R., Nat. Commun. 2013, 4, 2195

[55] Kudo, A. \& Miseki, Y., Chem. Soc. Rev. 2009, 38, 253-278

[56] Liu, B., Zhao, X., Terashima, C., Fujishima, A. \& Nakata, K., Phys. Chem. Chem. Phys. 2014, 16, 8751-8760

[57] Nozik, A. J. \& Memming, R., J. Phys. Chem. 1996, 100, 13061-13078

[58] Csernica, P. M., Mckone, J. R., Mulzer, C. R., Dichtel, W. R., Abruna, H. D. \& DiSalvo, J., ACS Catal. 2017, 7, 3375-3383

[59] Gileadi, E., Physical Electrochemistry, Wiley-VCH, Weinheim, 2011

[60] Janssen, M., Griffioen, E., Biesheuvel, P. M., Roij, R. Van \& Erné, B., Phys. Rev. Lett. 2017, 119, 166002

[61] Trasatti, S. \& Petrii, O. A., J. Electroanal. Chem. 1992, 327, 353-376

[62] Zeradjanin, A. R., Grote, J., Polymeros, G. \& Mayrhofer, K. J. J., Electroanalysis 2016, 28, 2256-2269

[63] Gutic, S. J., Jovanovic, A. Z., Dobrota, A. S., Metarapi, D., Rafailovic, L. D., Pasti, I. A. \& Mentus, S. V, Int. J. Hydrogen Energy 2017, 43, 16846-16858

[64] Krstajic, N. V, Jovic, V. D., Gajic-Krstajic, L., Jovic, B. M., Antozzi, A. L. \& Martelli, G. N., Int. J. Hydrogen Energy 2008, 33, 3676-3687

[65] Gonzalez-Buch, C., Herraiz-Cardona, I., Ortega, E., Garcia-Anton, J. \& Perez-Herranz, V., J. Appl. Electrochem. 2016, 46, 791-803 
[66] Mckone, J. R., Marinescu, S. C., Brunschwig, B. S., Winkler, J. R. \& Gray, H. B., Chem. Sci. 2014, 5, 865-878

[67] Wang, Y., Woodward, C., Zhou, S. H., Liu, Z. K. \& Chen, L. Q., Scr. Mater. 2005, 52, 17-20

[68] Wang, Y., Zhang, G., Xu, W., Wan, P., Lu, Z. \& Li, Y., ChemElectroChem 2014, 1, 1138-1144

[69] Zhao, S., Huang, J., Liu, Y., Shen, J., Wang, H., Yang, X., Zhu, Y. \& Li, C., J. Mater. Chem. A Mater. Energy Sustain. 2017, 5, 4207-4214

[70] Zhang, L., Xiong, K., Nie, Y., Wang, X., Liao, J. \& Wei, Z., J. Power Sources 2015, 297, 413-418

[71] Mckone, J. R., Sadtler, B. F., Werlang, C. A., Lewis, N. S. \& Gray, H. B., ACS Catal. 2013, 3, 166-169

[72] Zhen, W., Gao, H., Tian, B., Ma, J. \& Lu, G., ASC Appl. Mater. Interfaces 2016, 8, 10808-10819 
General Introduction 
We are driving for the space museum. I am looking out of the car window, bored by the long travel The crystal-clear blue water of a river rushes by. Dad stops the car next to a clearing and tells me to get out. "Son, do you know what the strongest thing in the universe is?" Annoyed I answer, just wanting to get this long drive over with. "Metal, of course."

"That's where you're wrong." I am intrigued and watch my dad gesture out towards the large river rumbling in front of us. "It is water." "Water?" I ask surprised. "Yes, the biggest mountain, or the strongest metal, water will, in time, beat either."

I look at the river with wide eyes, "But it is liquid, how does that beat a solid?" "Just look son, it corrodes metal, and over time this river even ate its way through the earth, leaving this gorge." Water beating metal? Never before had I thought about it. It takes my dad a while to get me back into the car, and never again did I underestimate water. 


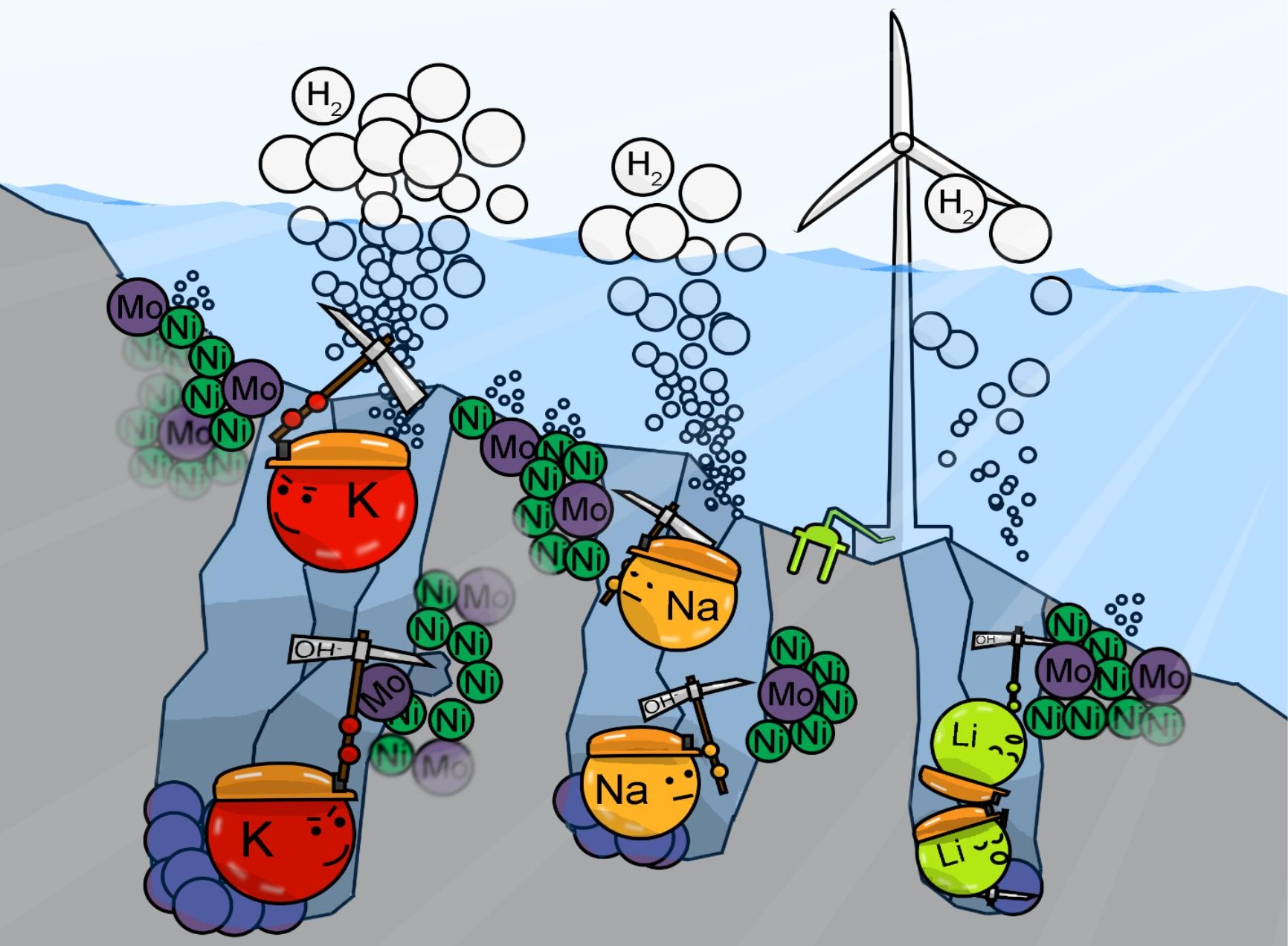




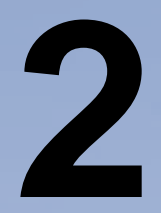

\section{Electrolyte Effects on the Stability of Nickel- Molybdenum Cathodes for the Hydrogen Evolution Reaction}

Water electrolysis to form hydrogen as a solar fuel requires its catalysts to be highly effective. Nickel-Molybdenum (Ni-Mo) is known as such a material. In this Chapter, we have performed theoretical and experimental studies on the activity and stability of Ni-Mo cathodes. Density functional theory studies show various Ni-Mo facets to be active for the hydrogen evolution reaction, Ni segregation to be thermodynamically favorable, and Mo vacancy formation to be favorable even without an applied potential. Electrolyte effects on the long-term stability of $\mathrm{Ni}$-Mo cathodes have been determined. We have compared Ni-Mo before and after up to $100 \mathrm{~h}$ of continuous operation. We show that Ni-Mo is unstable in alkaline media due to Mo leaching in the form of $\mathrm{MoO}_{4}{ }^{2-}$, ultimately leading to a decrease in absolute overpotential. We found that the electrolyte, the alkali cations, and $\mathrm{pH}$ all influence Mo leaching. Changing from $\mathrm{Li}$ to $\mathrm{Na}$ to $\mathrm{K}$ influences the surface segregation of $\mathrm{Mo}$, and pushes the reaction towards Mo dissolution. Lowering the $\mathrm{pH}$ decreases the $\mathrm{OH}$ concentration and in this manner inhibits Mo leaching. Of the electrolytes studied, in terms of stability, the best to use is $\mathrm{LiOH}$ at a $\mathrm{pH}$ of 13. Thus, we present a mechanism for Mo leaching as well as ways to influence the stability and make the Ni-Mo material more viable for renewable energy storage in chemical bonds. 


\subsection{Introduction}

A lot of work is done studying the synthesis of Ni-Mo cathodes for hydrogen production from water by changing their morphology and altering their chemical composition. ${ }^{[1-4]} \mathrm{A}$ Ni content of $60-80 \%$ in these metal alloys has been found to be optimal for the activity and stability. ${ }^{[1,5-7]}$ However, while some previous research works show that Ni-Mo is unstable in alkaline media, the origins of this instability are as of yet not extensively studied, except for one key work by Schalenbach et al. ${ }^{[5]}$ showing that Ni-Mo can form multiple crystal phases depending on the ratio between $\mathrm{Ni}$ and Mo. Furthermore, they report that Mo can leach from the material during electrocatalysis. ${ }^{[5,8,9]}$

In this Chapter, we present a combined theoretical-experimental study of the activity and stability of Ni-Mo as hydrogen evolution reaction (HER) electrocatalyst. Using density functional theory (DFT) and a simple thermodynamic model of HER activity, we predict a model Ni-Mo system to be highly active towards the HER on several facets. ${ }^{[10]}$ Since Mo leaches, the nature of the electrolyte is expected to play a key role. To this end, we studied different commonly used electrolytes: $\mathrm{NaOH}$ and $\mathrm{KOH}$ as well as $\mathrm{LiOH}$, and show that the choice can play a significant role in HER performance. ${ }^{[6]}$ Our calculated energies suggest $\mathrm{Ni}$ segregation as well as Mo vacancy formation to be favorable. ${ }^{[11-13]}$ Experimentally, using scanning electron microscopy in combination with X-ray spectroscopy (SEM-EDX), atomic force microscopy (AFM), X-ray photoelectron spectroscopy (XPS), inductively coupled plasmaatomic emission spectroscopy (ICP-AES) and UV-Vis spectroscopy, we have characterized the stability of Ni-Mo materials in a variety of electrolytes and $\mathrm{pH}$ 's. We confirm that Mo leaches, as recently shown by Schalenbach et al. ${ }^{[5]}$, and found that $\mathrm{Mo}$ leaches as $\mathrm{MoO}_{4}{ }^{2-}$. Roughening and changes in electrocatalytic activity were a result of Mo leaching. The cation in the electrolyte, being either $\mathrm{K}^{+}, \mathrm{Na}^{+}$, or $\mathrm{Li}^{+}$, as well as the solution $\mathrm{pH}$ significantly influence these effects. With this work, we present an understanding of the Mo leaching phenomenon through both experiment and theory.

\subsection{Results and Discussion}

\subsubsection{Electrolyte Effects: The Cation Matters}

To study Ni-Mo alloy surfaces in detail the material was synthesized by electrodeposition on $\mathrm{Ti}$ substrates. ${ }^{[14-16]}$ The materials generally form amorphous, granular structures with cracks on the surface on a $\mu \mathrm{m}$ scale, as shown in the SEM micrographs in Figure 2.1. These are typical structures found for electrodeposited materials ${ }^{[17]}$ an observation, which is more general as can be deduced from the SEM micrographs in Figures 2.2 and 2.3. 

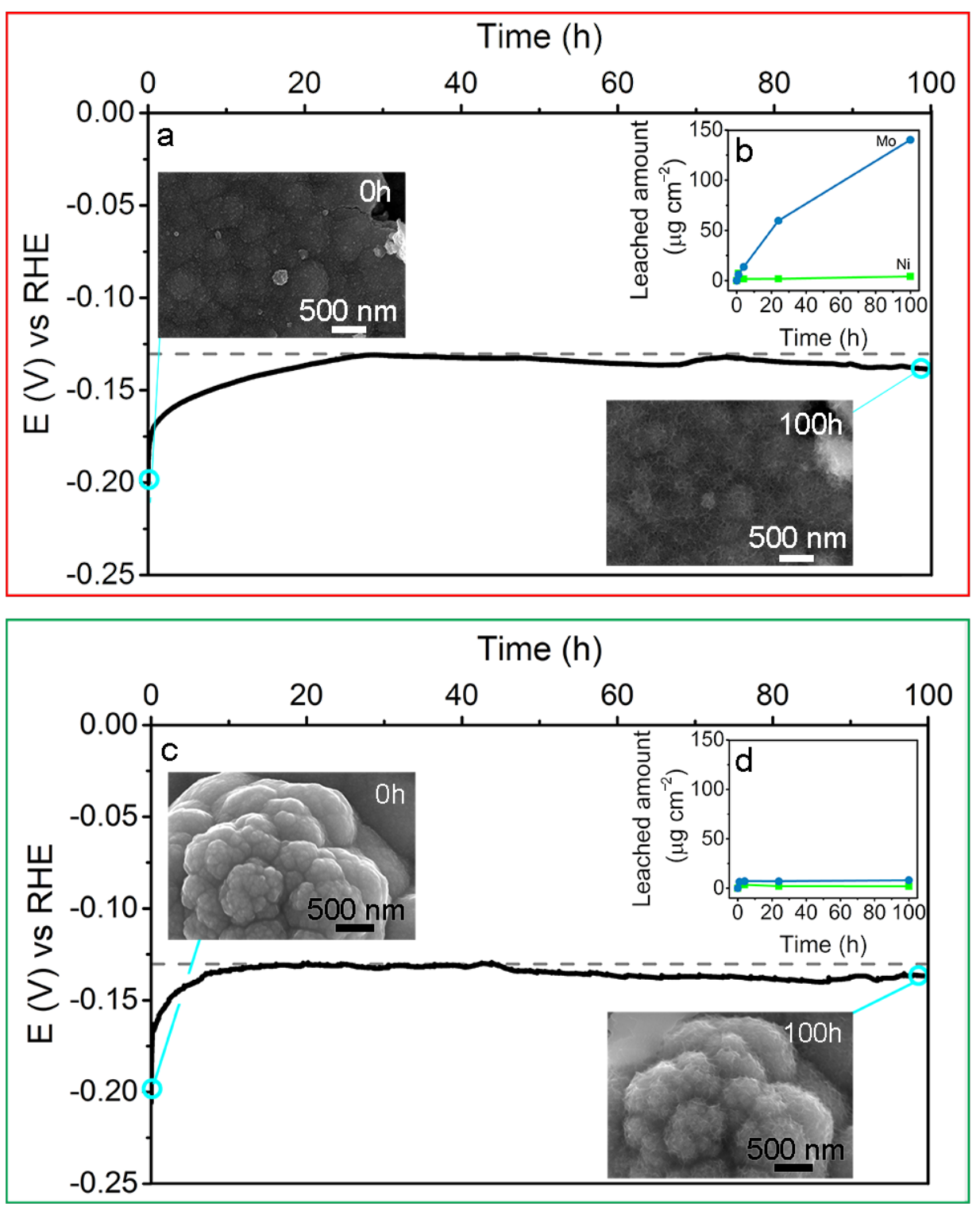

Figure 2.1: Boxed in red are the experiments performed in $1 \mathrm{MKOH}$ : a) Chronopotentiometric curve obtained at $-10 \mathrm{~mA} / \mathrm{cm}^{2}$ for Ni-Mo electrodeposits. The SEM images show the Ni-Mo surfaces after different times of catalysis, with $\mathrm{O} h$ and $100 \mathrm{~h}$ taken on the same sample. b) Amount of Ni and Mo found in spent electrolytes as determined by ICP-AES per $\mathrm{cm}^{2}$ of electrode. Boxed in green are the experiments performed in $1 \mathrm{M} \mathrm{NaOH}$ : c) Chronopotentiometric curve obtained at $-10 \mathrm{~mA} / \mathrm{cm}^{2}$ for $\mathrm{Ni}$ Mo electrodeposits. The SEM images show the Ni-Mo surfaces after different times of catalysis, with $\mathrm{O} h$ and $100 \mathrm{~h}$ taken on the same sample. d) Amount of Ni and Mo found in spent electrolytes as determined by ICP-AES per $\mathrm{cm}^{2}$ of electrode. 
These samples were subjected to electrocatalysis via chronopotentiometry at $10 \mathrm{~mA} / \mathrm{cm}^{2}$ in $1 \mathrm{M}$ hydroxide solutions; note that all calculations are done on basis of the substrate surface area. The behavior is similar for the materials employed in $1 \mathrm{M} \mathrm{KOH}$ (Figure 2.1a) or $1 \mathrm{M} \mathrm{NaOH}$ (Figure 2.1c). One difference,

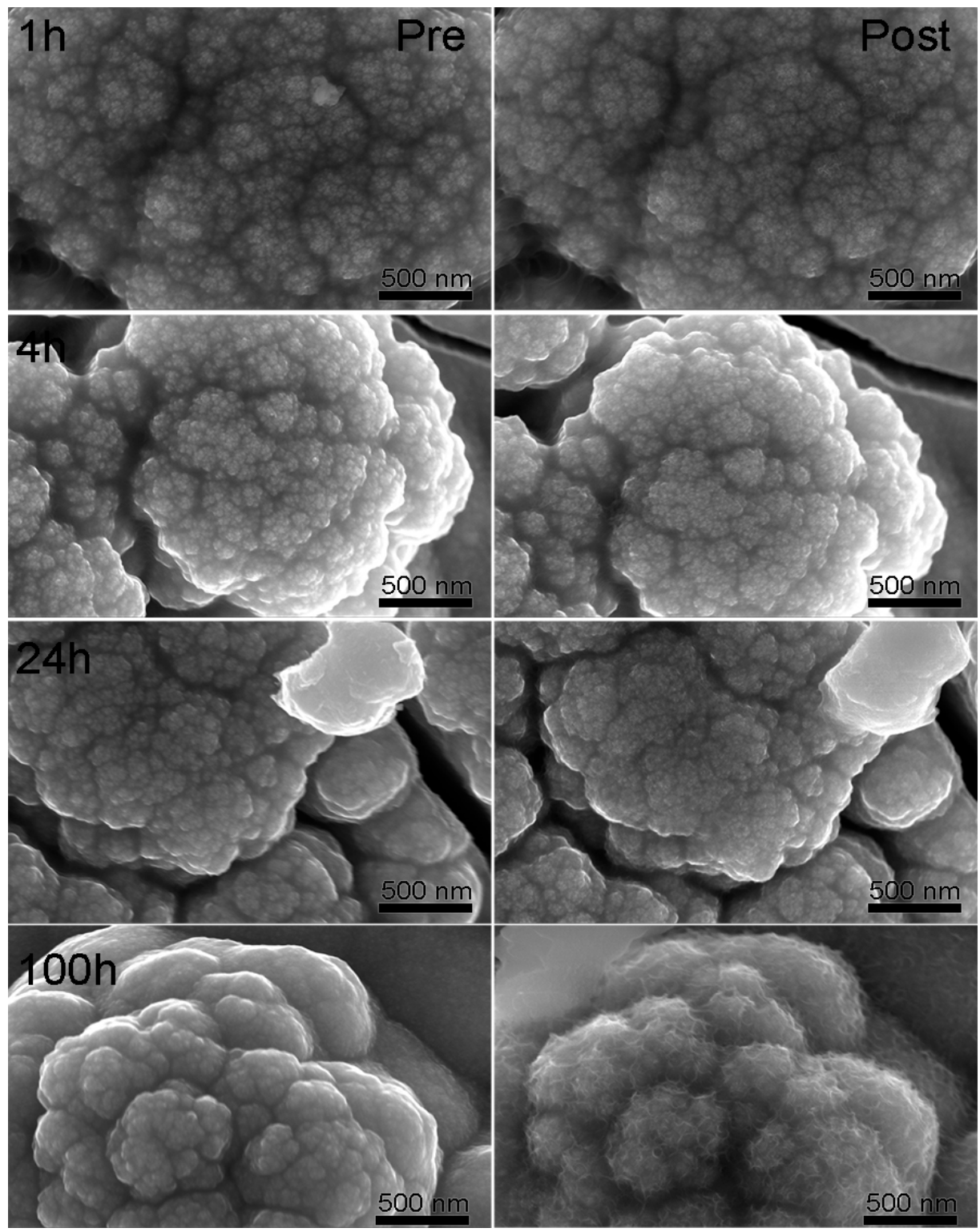

Figure 2.2: SEM images prior to (left) and after (right) catalysis in $1 \mathrm{M} \mathrm{NaOH}$ for various times (top to bottom $1 \mathrm{~h}, 4 \mathrm{~h}, 24 \mathrm{~h}, 100 \mathrm{~h}$ ). 
however, is that the catalyst in $1 \mathrm{M} \mathrm{KOH}$ takes a longer time to activate towards the optimum overpotential at about $30 \mathrm{~h}$, compared to $15 \mathrm{~h}$ in $1 \mathrm{M} \mathrm{NaOH}$. The absolute overpotential changes from $0.18 \mathrm{~V}$ to $0.13 \mathrm{~V}$, it then stays stable for

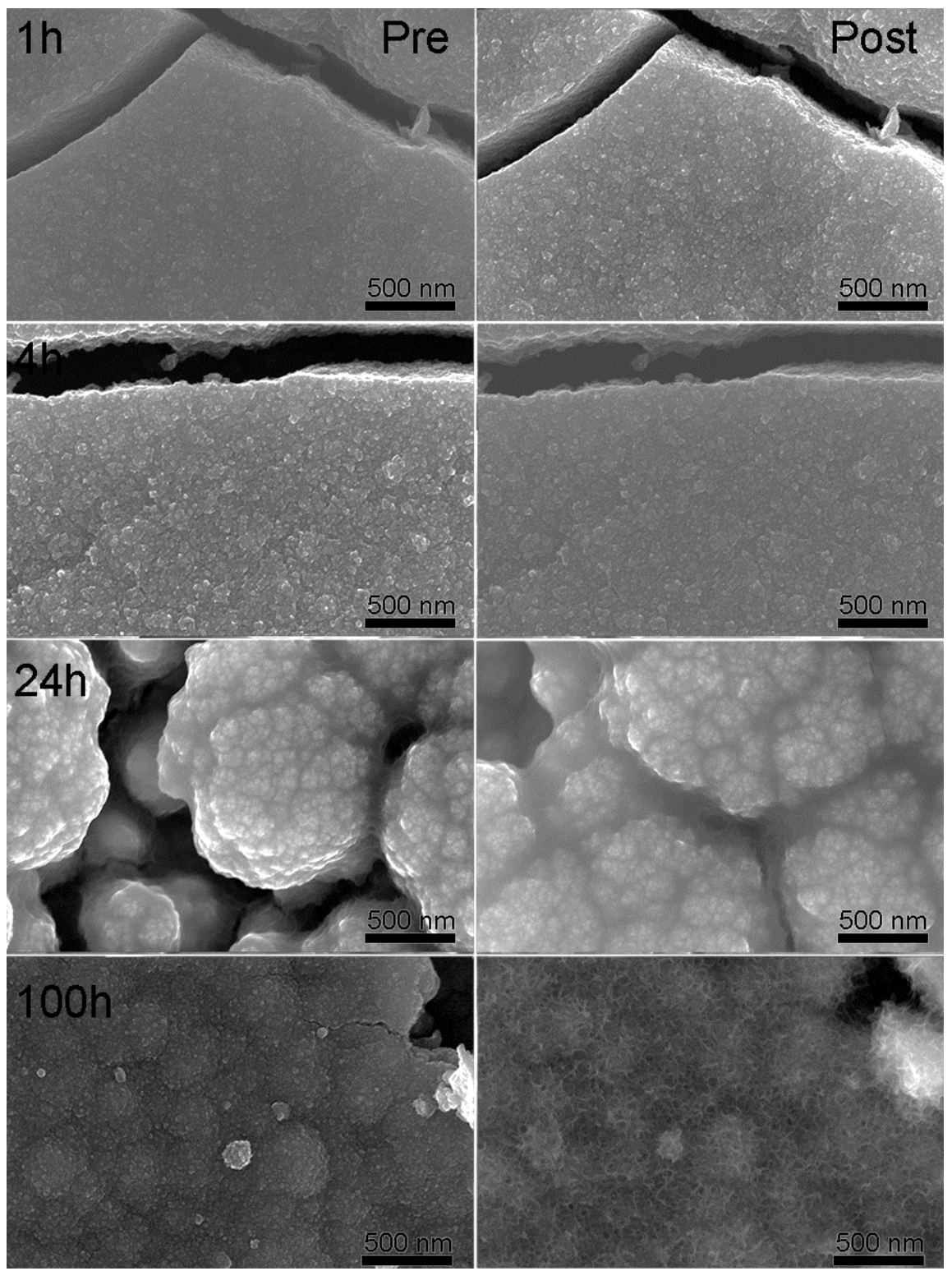

Figure 2.3: SEM images prior to (left) and after (right) catalysis in $1 \mathrm{M} \mathrm{KOH}$ for various times (top to bottom $1 \mathrm{~h}, 4 \mathrm{~h}, 24 \mathrm{~h}, 100 \mathrm{~h}$ ). 
several days before increasing again. The low overpotential shows it is indeed active as suggested by theory (section 2.2 .4 ) and previous studies. ${ }^{[1-4,6,18-22]}$

Leaching of Mo was further confirmed experimentally. On a larger scale SEM was performed on the samples at several time intervals. In both the case of $\mathrm{NaOH}$ and of $\mathrm{KOH}$, after a long time $(100 \mathrm{~h})$ of operation, edges and other nanoscaled features form on the material, which can be linked to the vacancy formation, as described in more detail in Section 2.2.4. This effect is similar to that observed during anisotropic etching of noble metals, and thus could be linked to Mo leaching. ${ }^{[23,24]}$

Table 2.1: ICP-AES values found in electrolytes after catalysis. Values in red were below the detection limit.

\begin{tabular}{|c|c|c|}
\hline Experiment & $\mathrm{Ni}(\mathrm{mg} / \mathrm{L})$ & Mo (mg/L) \\
\hline $\mathrm{Na}-\mathrm{Na} 1 \mathrm{~h}$ & 0.056 & 0.083 \\
\hline $\mathrm{Na}-\mathrm{Na} 4 \mathrm{~h}$ & 0.044 & 0.090 \\
\hline $\mathrm{Na}-\mathrm{Na} 24 \mathrm{~h}$ & 0.026 & 0.089 \\
\hline Na-Na $100 \mathrm{~h}$ & 0.025 & 0.102 \\
\hline Na-Na $24 \mathrm{~h} \mathrm{pH}=8 \mathrm{H}$-cell & 0.117 & 1.859 \\
\hline $\mathrm{Na}-\mathrm{Na} 24 \mathrm{~h} \mathrm{pH}=11 \mathrm{H}$-cell & 0.020 & 1.144 \\
\hline $\mathrm{Na}-\mathrm{Na} 24 \mathrm{~h} \mathrm{pH}=14 \mathrm{H}$-cell & 0.014 & 3.895 \\
\hline $\mathrm{Na}-\mathrm{Na} 24 \mathrm{~h} \mathrm{pH}=14.8 \mathrm{H}$-cell & -0.007 & 0.312 \\
\hline Na-K $1 \mathrm{~h}$ & 0.093 & 0.072 \\
\hline $\mathrm{Na}-\mathrm{K} 4 \mathrm{~h}$ & 0.021 & 0.170 \\
\hline $\mathrm{Na}-\mathrm{K} 24 \mathrm{~h}$ & 0.022 & 0.749 \\
\hline $\mathrm{Na}-\mathrm{K} 100 \mathrm{~h}$ & 0.053 & 1.762 \\
\hline Na-K 24 h pH = 8 H-cell & 0.121 & 0.208 \\
\hline Na-K $24 \mathrm{~h} \mathrm{pH}=11 \mathrm{H}$-cell & -0.007 & 0.912 \\
\hline Na-K $24 \mathrm{~h} \mathrm{pH}=14 \mathrm{H}$-cell & 0.048 & 3.349 \\
\hline Na-K $24 \mathrm{~h} \mathrm{pH}=14.8 \mathrm{H}$-cell & 0.028 & 0.233 \\
\hline K-Na 24 h & 0.048 & 0.165 \\
\hline K-Na $100 \mathrm{~h}$ & 0.017 & 0.098 \\
\hline K-K $24 \mathrm{~h}$ & 0.211 & 0.061 \\
\hline K-K $100 \mathrm{~h}$ & 0.081 & 0.381 \\
\hline $\mathrm{Na}-\mathrm{K} 24 \mathrm{~h}$ without catalysis & 0.011 & 0.613 \\
\hline Ti 96 h $(\mathrm{KOH}) \mathrm{pH}=14 \mathrm{H}$-cell & 0.024 & -0.006 \\
\hline Na-Li 24 h pH = 13 & -0.004 & 0.035 \\
\hline $\mathrm{Na}-\mathrm{Na} 24 \mathrm{~h} \mathrm{pH}=13$ & 0.025 & 0.352 \\
\hline $\mathrm{Na}-\mathrm{K} 24 \mathrm{~h} \mathrm{pH}=13$ & 0.013 & 0.166 \\
\hline $\mathrm{Na}-\mathrm{Li} 24 \mathrm{~h} \mathrm{pH}=13 \mathrm{H}$-Cell & 0.010 & 0.352 \\
\hline $\mathrm{Na}-\mathrm{Na} 24 \mathrm{~h} \mathrm{pH}=13 \mathrm{H}$-Cell & -0.006 & 1.693 \\
\hline Na-K 24 h pH = 13 H-Cell & -0.006 & 1.000 \\
\hline
\end{tabular}


The similarity with anisotropic etching led us to perform ICP-AES analysis, of which the results are summarized in Table 2.1, of the electrolytes after catalysis, to observe possible Mo or Ni leaching. These results are also plotted in Figure 2.1b and 2.1d for $1 \mathrm{M} \mathrm{KOH}$ and $1 \mathrm{M} \mathrm{NaOH}$, respectively. Indeed, Mo leaches, most obviously when using $\mathrm{KOH}$ as an electrolyte. Leaching in $\mathrm{KOH}$ starts slower than in $\mathrm{NaOH}$ during the first hour but continues to higher values of $1.84 \mu \mathrm{mol}$ Mo after $100 \mathrm{~h}$. In the case of $\mathrm{NaOH}$, it leaches to a value of 0.09 $\mu \mathrm{mol}$ Mo after just $1 \mathrm{~h}$, but after that no more leaching takes place. In either situation, both activity and stability are superior to pure $\mathrm{Ni}$ and Mo electrodes (Figure 2.4).

Despite the significant difference in Mo leaching between $\mathrm{KOH}$ and $\mathrm{NaOH}$ electrolytes, we observe that the chronopotentiometry does not change much after about $30 \mathrm{~h}$ of operation, suggesting a steady state is achieved. Furthermore, as will be shown in Section 2.2.4, according to DFT neither $\mathrm{Na}^{+}$ or $\mathrm{K}^{+}$adsorbs suggesting that this is not the pathway via which leaching is influenced. The apparent roughening observed in SEM is a suitable explanation for the slight decrease in overpotential observed during the beginning of the chronopotentiometry: the available surface area increases and thus activity increases. To quantify the roughening process, double layer capacitance measurements and AFM are employed. First, this capacitance is not only a function of surface area: the specific capacitance of a material depends on the composition as well. ${ }^{[25-27]}$ Previous research shows that the $\mathrm{Ni}^{2+} / \mathrm{Ni}^{3+}$ redox couple can also be used to determine surface areas ${ }^{[5]}$, but we find, that since the surface concentration of $\mathrm{Ni}$ changes, that this approach likewise is limited. Furthermore, to be able to study in detail what happens during HER catalysis, applying oxidizing potentials might result in electrochemical processes that are usually not found for the Ni-Mo system under HER conditions, such as anodic etching.

Since neither approach of determining the surface area is ideal, we attempt to, at least, exclude the possibility that differences in capacitance values are due to small differences between samples, by performing experiments where every 30 min of catalysis alternates with double layer capacitance measurements
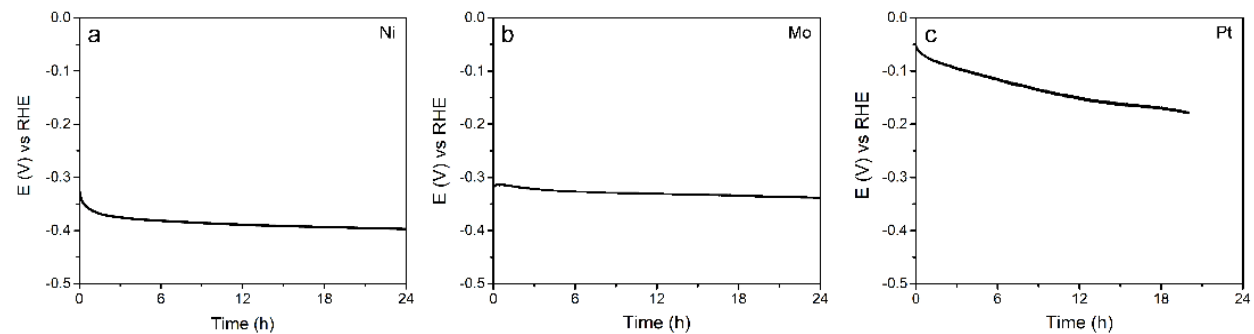

Figure 2.4: Chronopotentiometry for $24 \mathrm{~h}$ at $-10 \mathrm{~mA} / \mathrm{cm}^{2}$ in $1 \mathrm{M} \mathrm{KOH}$ of a) polished $\mathrm{Ni}$, b) polished Mo, c) Pt mesh (20 h). 

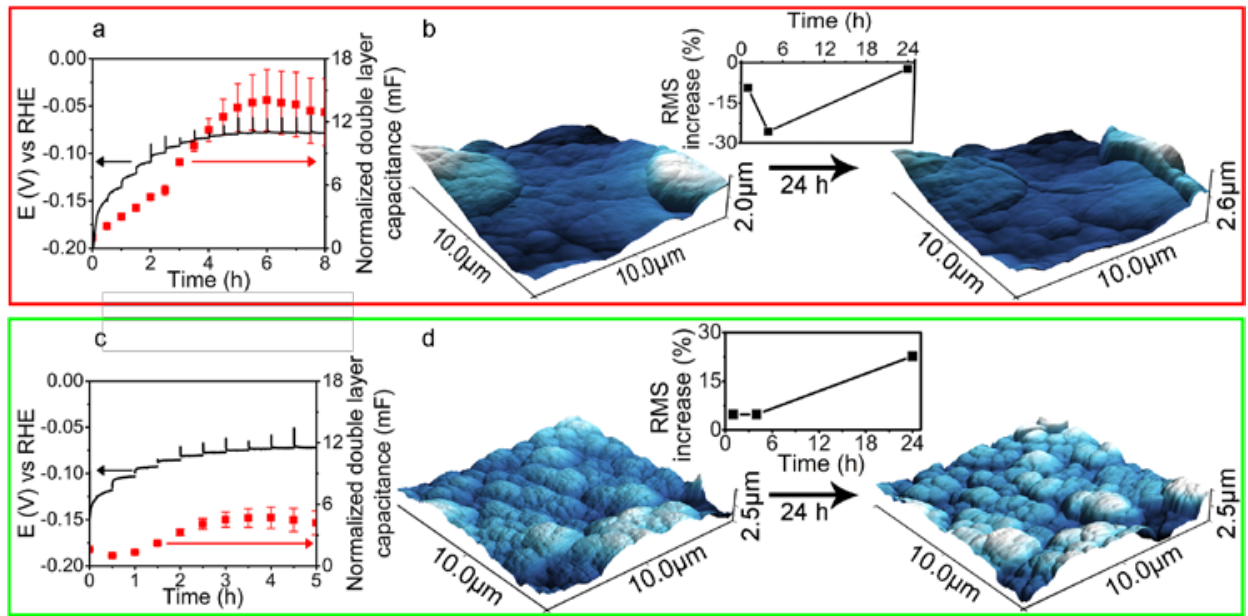

Figure 2.5: a) stepped chronopotentiometry in $\mathrm{KOH}$ (black, left axis) alternated with double layer capacitance measurements (red squares, right axis). b) AFM images obtained prior (left) and post (right) catalysis in $\mathrm{KOH}$ for $24 \mathrm{~h}$. Above the image the increase in RMS is shown, where negative values correspond to a decrease. $c$ ) stepped chronopotentiometry in $\mathrm{NaOH}$ (black, left axis) alternated with double layer capacitance measurements (red squares, right axis). d) AFM images obtained prior (left) and post (right) catalysis in $\mathrm{NaOH}$ for $24 \mathrm{~h}$. Above the arrow the increase in RMS is shown, where neqative values correspond to a decrease.

(Figure 2.5). Immediately, it is clear that there is an influence of electrolyte. In $\mathrm{KOH}$ it takes longer for the catalyst to reach the optimum in overpotential (take note of the different $x$-axes). During this process, the capacitance increases with a rate of $2.3 \mathrm{mF} / \mathrm{h}$ before leveling off at a normalized capacitance of 13 $\mathrm{mF}$, while in $\mathrm{NaOH}$ this rate is only $1.3 \mathrm{mF} / \mathrm{h}$ and it levels off at only $4 \mathrm{mF}$. While these data cannot be directly related to roughness it shows the change of the material is gradual during HER catalysis and that it occurs on the same timescale as the change in overpotential. With AFM we found that the increase in surface area after $24 \mathrm{~h}$ is $23 \%$ when using $\mathrm{NaOH}$ (Figure 2.5d). This is significantly less than the factor 4 increase found with the capacitance measurements, immediately proving that the capacitance cannot be directly linked to surface roughness. In the case of $\mathrm{KOH}$ (Figure 2.5b), it is even more extreme and a decrease in surface area is observed.

Change in the capacitance is also observed for the pure electrodes. A slight increase in capacitance was observed from $0.51 \mathrm{mF}$ to $1.33 \mathrm{mF}$ after this process for Ni. For Mo, a decrease of capacitance is observed from $27.3 \mathrm{mF}$ to $1.74 \mathrm{mF}$. A small decline is observed from $0.32 \mathrm{~V}$ towards an overpotential of $0.34 \mathrm{~V}$. It should be noted that the polishing of Mo was far from optimal due to the brittleness of the material. 
It should be noted that the root-mean-square (RMS) determination (see Figures 2.25 and 2.26 in Section 2.4) is difficult due to the presence of features on the micrometer scale, the cracks. Furthermore, features on the nanometer scale, such as possible pores having formed are not taken into consideration on this scale. We selected spots based on their relative lack of large features at the beginning. Nevertheless, as seen in the AFM images of Figure 2.5b, large changes can occur due to cracking or removal of whole grains due to flaking, which will influence the determined RMS significantly. Furthermore, experiments on pure $\mathrm{Ni}$ and pure Mo show that the specific capacitance of Mo $(27.3 \mathrm{mF})$ is higher than that of $\mathrm{Ni}(0.51 \mathrm{mF})$ meaning this can be related to more Mo being present at the surface.

On the other hand, the large change in surface capacitance and the observed leaching led us to study the surface in more detail. As mentioned before, with SEM-EDX it was possible to determine that $\mathrm{Na}$ is present at the surface, and furthermore, after catalysis, this amount is either increased $(\mathrm{NaOH})$ or replaced by $\mathrm{K}(\mathrm{KOH})$, as summarized in Table 2.2. To find what is really occurring on the surface itself and in the first few $100 \mathrm{~nm}$, we used XPS depth profiling (see Figure 2.6a). Prior to catalysis, the samples contain $\mathrm{Na}$, $\mathrm{Ni}$ and $\mathrm{Mo}$ homogeneously dispersed throughout the first $600 \mathrm{~nm}$, with only the surface being significantly higher in $\mathrm{Na}$ and Mo content. Furthermore, the Mo content is higher depth, for these several micrometer thick samples. The substrate could be observed usually, showing that probing was possible beyond the

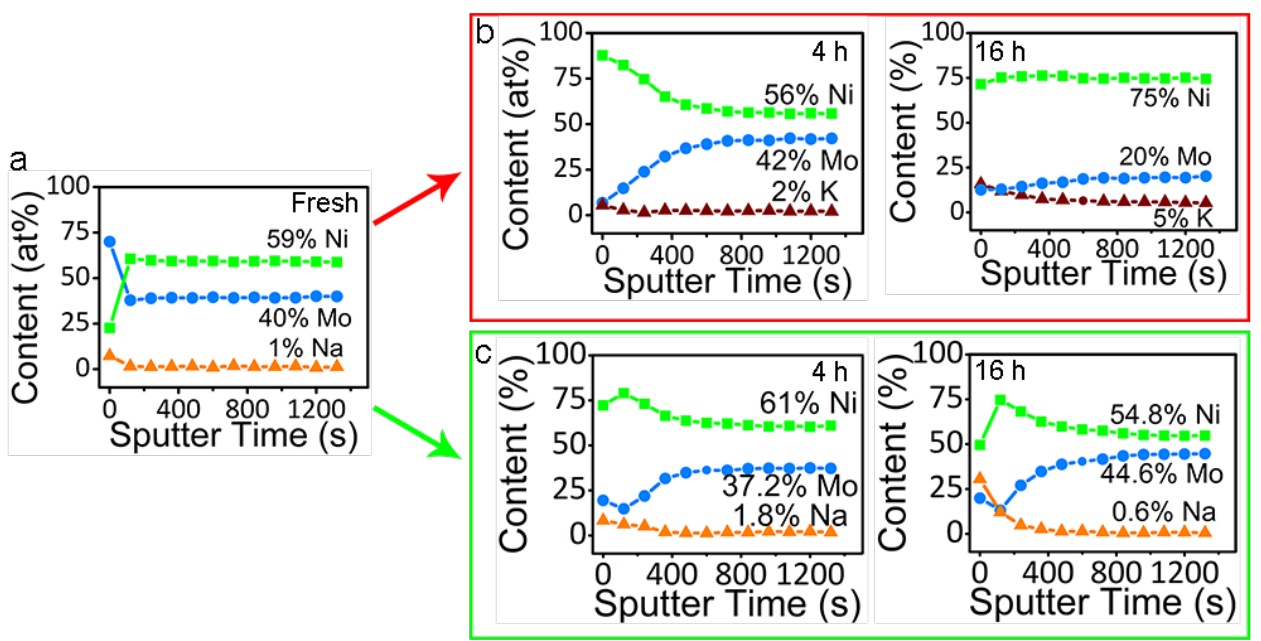

Figure 2.6: a) XPS depth profile of a fresh Ni-Mo surface. In all cases a sputter rate of $0.50 \mathrm{~nm} / \mathrm{s}$ was assumed (based of $\mathrm{Ta}_{2} \mathrm{O}_{5}$ ). b) XPS depth profile of Ni-Mo spent in $1 \mathrm{M}$ $\mathrm{KOH}$ after $4 \mathrm{~h}$ and $16 \mathrm{~h}$. c) XPS depth profile of Ni-Mo spent in $1 \mathrm{M} \mathrm{NaOH}$ after $4 \mathrm{~h}$ and $16 \mathrm{~h}$. In all Ni (green squares), Mo (blue circles), and Na (orange triangles) or K (purple triangles) are shown. Other elements $(O, C)$ have not been taken into account in the calculation of the ratios. 
electrodeposited layer, and thus that likely most of the sample was measured. The observation of Mo being more concentrated on the surface points towards surface segregation, as is reported before in the literature. ${ }^{[11,12]}$

On one hand, after chronopotentiometry in $1 \mathrm{M} \mathrm{KOH}$ (Figure 2.6b), already after $4 \mathrm{~h}$, the Mo content has decreased significantly in the first $400 \mathrm{~nm}$ (from $40 \%$ to $15 \%$ at $60 \mathrm{~nm}$ depth). This is more near the surface (40\%) than what was found with SEM-EDX (25\%), which is effectively a bulk technique, with a micrometer scale penetration significant even after $16 \mathrm{~h}$ reaching beyond the probing depth of $660 \mathrm{~nm}$. At the same time, Na was completely gone already after $4 \mathrm{~h}$ and instead $\mathrm{K}$ is found, most prominently on the surface. In $\mathrm{NaOH}$ (Figure 2.6c), on the other hand, the same effect occurs, but the extent of the leaching of $\mathrm{Mo}$ is less. Mo contents decrease over time as well in $\mathrm{NaOH}$, mostly from the top layers, but in contrast with $\mathrm{KOH}$ electrolytes; even after $16 \mathrm{~h}$ leaching barely occurred after $500 \mathrm{~nm}$.

Table 2.2: SEM-EDX results found for samples after catalysis. Only $\mathrm{Na}, \mathrm{Ni}, \mathrm{Mo}$ and $\mathrm{K}$ are considered and put at a total of $100 \%$.

\begin{tabular}{|c|c|c|c|c|}
\hline Experiment & $\mathrm{Na}(\mathrm{at} \%)$ & $\mathrm{Ni}(\mathrm{at} \%)$ & Mo (at $\%)$ & $\mathrm{K}(\mathrm{at} \%)$ \\
\hline $\mathrm{Na}-\mathrm{Na} 1 \mathrm{~h}$ & 4.2 & 73.9 & 21.9 & - \\
\hline $\mathrm{Na}-\mathrm{Na} 4 \mathrm{~h}$ & 3.9 & 77.3 & 18.8 & - \\
\hline $\mathrm{Na}-\mathrm{Na} 24 \mathrm{~h}$ & 4.0 & 75.0 & 20.7 & - \\
\hline $\mathrm{Na}-\mathrm{Na} 100 \mathrm{~h}$ & 3.0 & 72.2 & 24.8 & - \\
\hline $\mathrm{Na}-\mathrm{K} 1 \mathrm{~h}$ & - & 70.1 & 28.8 & 1.1 \\
\hline $\mathrm{Na}-\mathrm{K} 4 \mathrm{~h}$ & - & 72.2 & 25.9 & 1.9 \\
\hline $\mathrm{Na}-\mathrm{K} 24 \mathrm{~h}$ & 0.8 & 83.7 & 14.3 & 1.3 \\
\hline $\mathrm{Na}-\mathrm{K} 100 \mathrm{~h}$ & - & 73.0 & 25.4 & 1.7 \\
\hline K-Na 24 h & 4.1 & 82.2 & 13.6 & 0.1 \\
\hline K-Na $100 \mathrm{~h}$ & 15.0 & 66.6 & 18.4 & - \\
\hline K-K $24 \mathrm{~h}$ & - & 76.0 & 23.0 & 1 \\
\hline K-K $100 \mathrm{~h}$ & - & 75.6 & 22.0 & 2.4 \\
\hline $\mathrm{Na}-\mathrm{Li}(\mathrm{pH}=13) 24 \mathrm{~h}$ & 0.6 & 68.5 & 30.9 & - \\
\hline $\mathrm{Na}-\mathrm{Na}(\mathrm{pH}=13) 24 \mathrm{~h}$ & 13.6 & 57.6 & 13.6 & - \\
\hline $\mathrm{Na}-\mathrm{K}(\mathrm{pH}=13) 24 \mathrm{~h}$ & 0.7 & 67.1 & 29.8 & 2.4 \\
\hline
\end{tabular}

In $\mathrm{NaOH}$ as well as in $\mathrm{KOH}$ the alkali cation has infiltrated the surface in higher numbers than was the case prior to catalysis. Its presence, however, is much more contained to the surface for $\mathrm{Na}$ than for $\mathrm{K}$, being higher at the top layers but almost absent after $200 \mathrm{~nm}$, while for $\mathrm{K}$ it is more homogeneously present after $16 \mathrm{~h}$ up to at least $660 \mathrm{~nm}$. This implies there is a different rate of the formation of porosity into which the electrolyte infiltrates. This agrees with the formation of Mo vacancies according to DFT and the different Mo leaching rates 

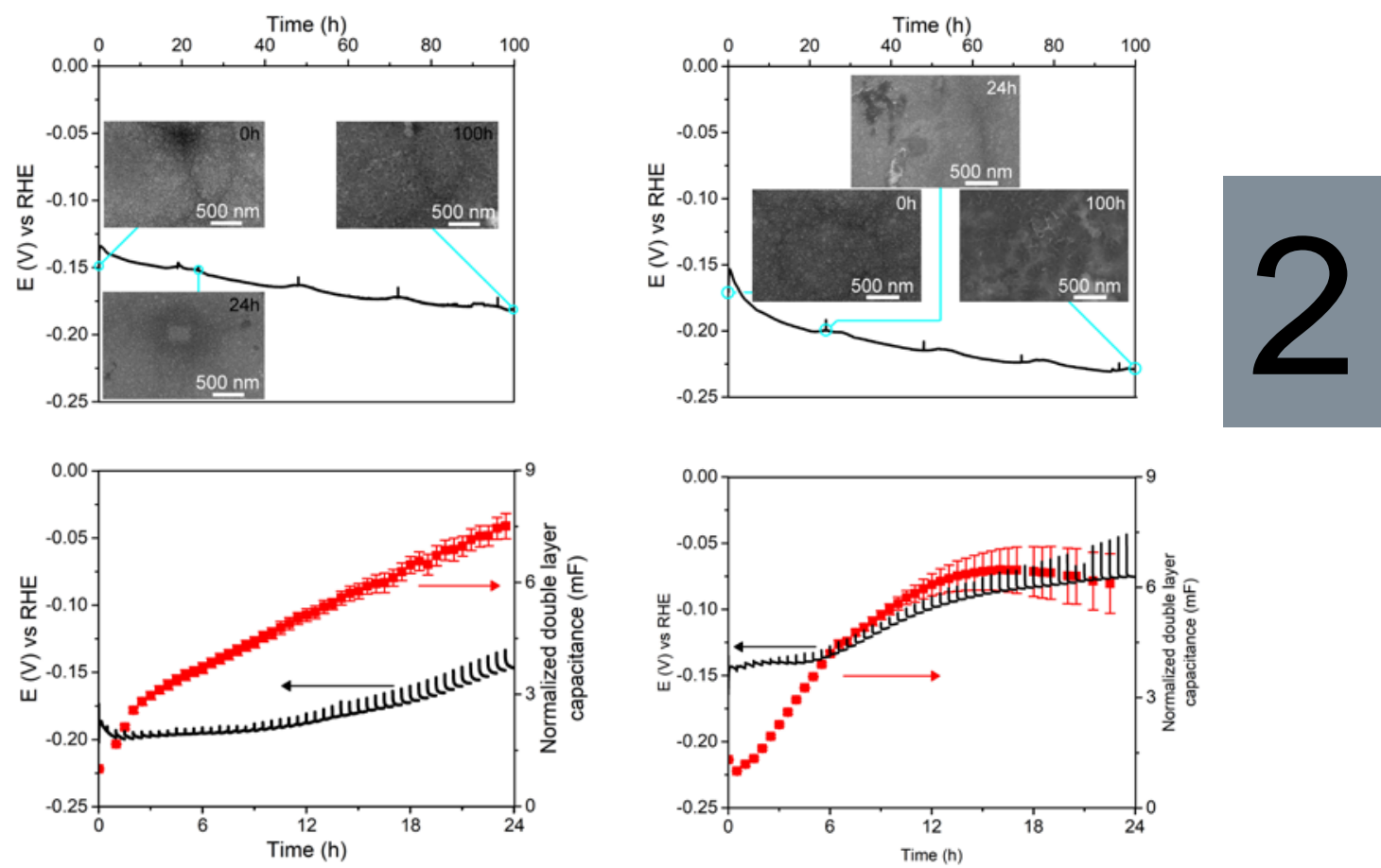

Figure 2.7: Sample synthesized using K- Figure 2.8: Sample synthesized using Kbased precursors $\left(\mathrm{K}_{2} \mathrm{MoO}_{4}, \mathrm{~K}_{3}\right.$ Citrate) and based precursors $\left(\mathrm{K}_{2} \mathrm{MoO}_{4}, \mathrm{~K}_{3}\right.$ Citrate) and used for electrochemistry in $1 \mathrm{M} \mathrm{NaOH}$. used for electrochemistry in $1 \mathrm{M} \mathrm{KOH}$. Chronopotentiometry and progress of Chronopotentiometry and progress of sample surface morphology (top). sample surface morphology (top). Evolution of the double layer capacitance Evolution of the double layer capacitance (red) and chronopotentiometry (black) (red) and chronopotentiometry (black) (bottom). (bottom).

found. The higher values for $\mathrm{Na}$ in the top layer than for $\mathrm{K}$ can be related to the difference in ion size $\left(\mathrm{Na}^{+}\right.$is smaller than $\mathrm{K}^{+}$and thus more would fit in a pore of the same size). Furthermore, the samples tested in $\mathrm{NaOH}$ retain the property that the Mo content directly at the surface is slightly higher than in the layer beneath it. Thus, the presence of $\mathrm{Na}$ or $\mathrm{K}$ influences Mo surface segregation. These observations agree with the capacitance measurements, where $\mathrm{Ni}$ and Mo atoms influence the specific capacitance more than $\mathrm{Na}$ and $\mathrm{K}$, since the surface ratio of Ni:Mo changes much more in $\mathrm{KOH}$ than in $\mathrm{NaOH}$. Due to the role of the cations we also made catalysts from K-based electrodeposition baths, but due to their poor performance we decided not to study them in detail (see Figures 2.7 and 2.8).

Prior to catalysis the surface consists mostly of $\mathrm{Ni}(\mathrm{II})$ hydroxide, while most of the $\mathrm{Mo}$ is $\mathrm{Mo}(\mathrm{VI})$ with a small amount of $\mathrm{Mo}(\mathrm{IV})$ and a few percents of metallic 
Mo. After catalysis, in either electrolyte, the Ni retains its phase, while Mo is (almost) fully oxidized to $\mathrm{Mo}(\mathrm{VI})$ after exposure to air, as shown in Figure 2.9. Information on the deeper layers regarding oxidation states is disregarded, as the sputtering to measure deeper layers is a reducing process, possibly reducing the Mo to the metallic state as well. $\mathrm{Ni}$ is present mostly in its hydroxide phase with traces of the metallic phase $(7 \%)$ prior to catalysis. Mo is mostly oxidized into its $\mathrm{Mo}(\mathrm{VI})$ state. Only prior to catalysis Mo is partially present in its metallic (7\%) and Mo(IV) (26 \%) phases. The peaks at $229.4 \mathrm{eV}$ and $232.5 \mathrm{eV}$ are labeled $\mathrm{MoO}_{2}$, but could also be Ni4Mo since both are reported at those binding energies. ${ }^{[28]}$ Finally, there is also a component visible which is previously reported as belonging to $\mathrm{Mo}^{5+}$ species. ${ }^{[29]}$

\subsubsection{Elucidation of the Mo Leaching Mechanism}

To explore more in-depth the mechanism of Mo leaching we performed UV-Vis spectroscopy on spent electrolytes and the results are shown in Figure 2.10. In both $\mathrm{KOH}$ and $\mathrm{NaOH}, \mathrm{UV}$-Vis bands are visible, characteristic for the presence of $\mathrm{MoO}_{4}{ }^{2-}$ species, effectively proving that the leaching indeed occurs by the
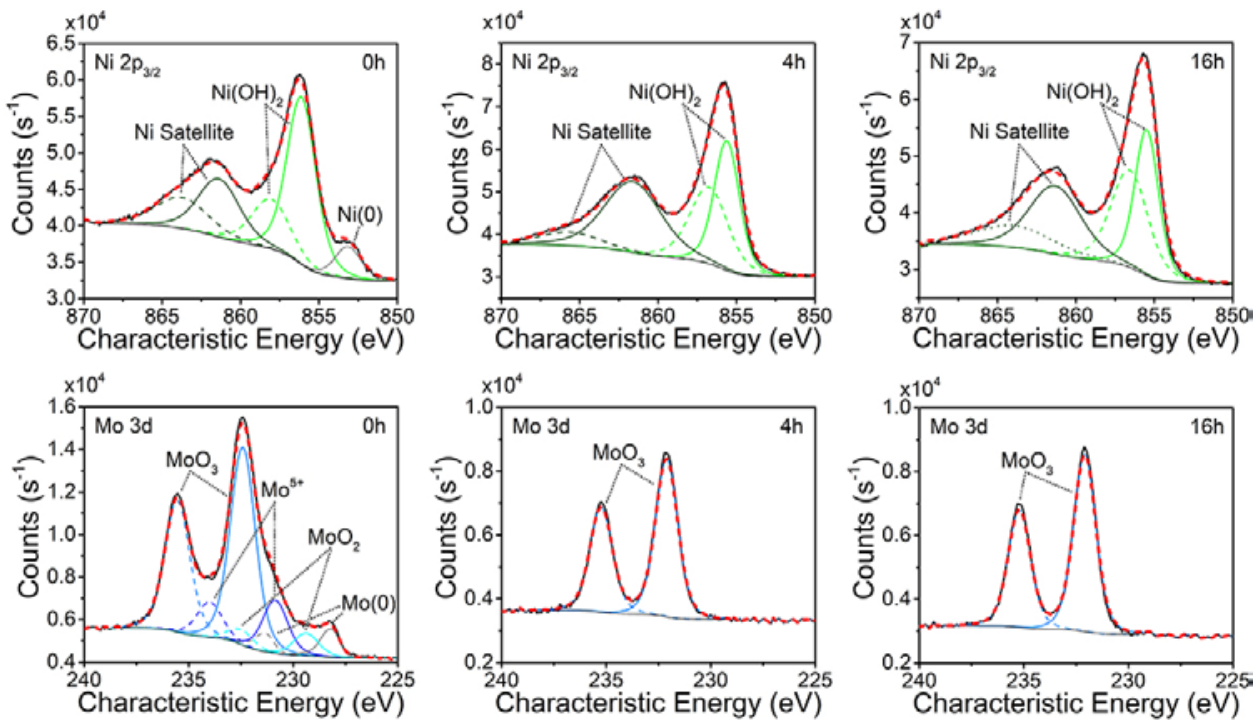

Figure 2.9: XPS spectra of Ni and Mo found at the surface of Ni-Mo surfaces prior to catalysis and after $4 \mathrm{~h}$ and $16 \mathrm{~h}$ of catalysis in $1 \mathrm{M} \mathrm{KOH}$. 
formation of $\mathrm{MoO}_{4}{ }^{2-}$. Leaching even occurs without applied potential (Table 2.1) thus we suggest $\mathrm{Mo}+2 \mathrm{OH}^{-}+2 \mathrm{H}_{2} \mathrm{O} \rightarrow \mathrm{MoO}_{4}{ }^{2-}+3 \mathrm{H}_{2}$ to be the leaching mechanism. Since Mo leaches as $\mathrm{MoO}_{4}{ }^{2-}$ the difference between $\mathrm{K}$ and $\mathrm{Na}$ could be explained by the solubility constants of $\mathrm{K}_{2} \mathrm{MoO}_{4}$ and $\mathrm{Na}_{2} \mathrm{MoO}_{4}$ on top of the observed influence of surface segregation. To ensure the solubility constants we use are relevant, these were determined in the electrolytes used. The solubility of $\mathrm{K}_{2} \mathrm{MoO}_{4}(0.76 \mathrm{~g} / \mathrm{L})$ is significantly higher than that of $\mathrm{Na}_{2} \mathrm{MoO}_{4}$ $(0.39 \mathrm{~g} / \mathrm{L})$ independent of the $\mathrm{pH}$ used $(\mathrm{pH} 8,11$ \& 14), except for $6 \mathrm{M}$ solutions. In the case of $6 \mathrm{M}$ solutions, the solubility was found to be lower $(0.43 \mathrm{~g} / \mathrm{mL}$ and $0.13 \mathrm{~g} / \mathrm{mL}$ for $\mathrm{K}_{2} \mathrm{MoO}_{4}$ and $\mathrm{Na}_{2} \mathrm{MoO}_{4}$, respectively), which is likely due to the higher concentration of $\mathrm{K}^{+}$or $\mathrm{Na}^{+}$ions in the electrolyte. ${ }^{[30]}$ This can explain the difference in the behavior despite the lack of differences in the calculations.

To confirm that the suggested reaction takes place and that it is a non-Faradaic process as is thermodynamically suggested, the Faradaic efficiency (FE) was
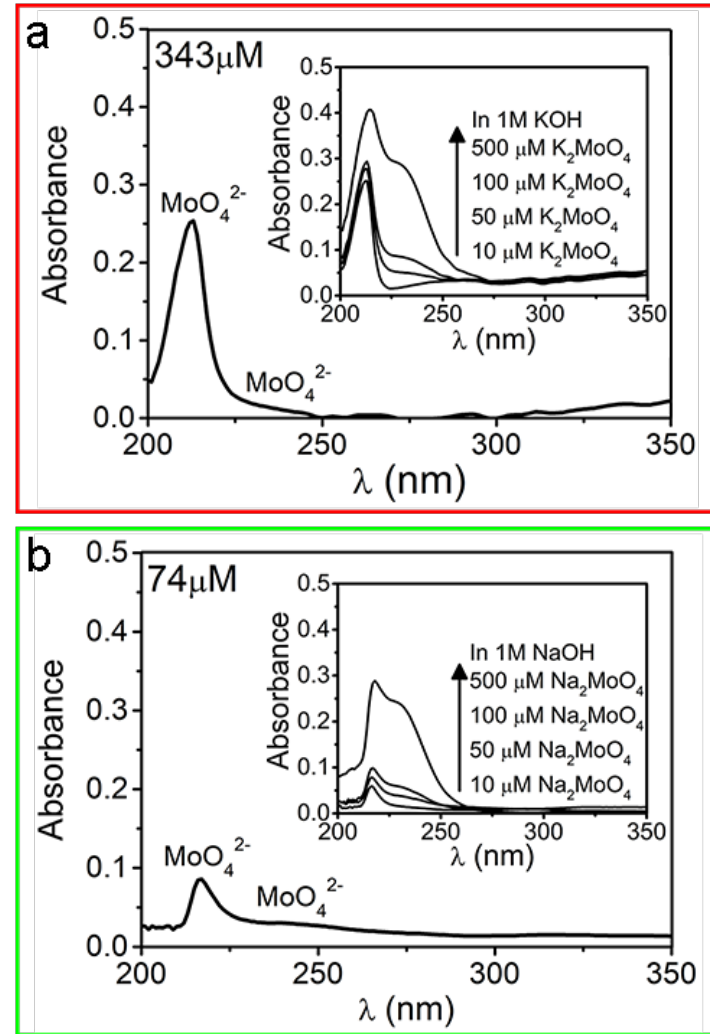

Figure 2.10: a) UV-Vis spectrum after $100 \mathrm{~h}$ of catalysis in $1 \mathrm{M} \mathrm{KOH}$, the inset shows spectra of $\mathrm{K}_{2} \mathrm{MoO}_{4}$ in $1 \mathrm{M} \mathrm{KOH}$ as references. b) UV-Vis spectrum after $100 \mathrm{~h}$ of catalysis in $1 \mathrm{M} \mathrm{NaOH}$, the inset shows spectra of $\mathrm{Na}_{2} \mathrm{MoO}_{4}$ in $1 \mathrm{M} \mathrm{NaOH}$. 

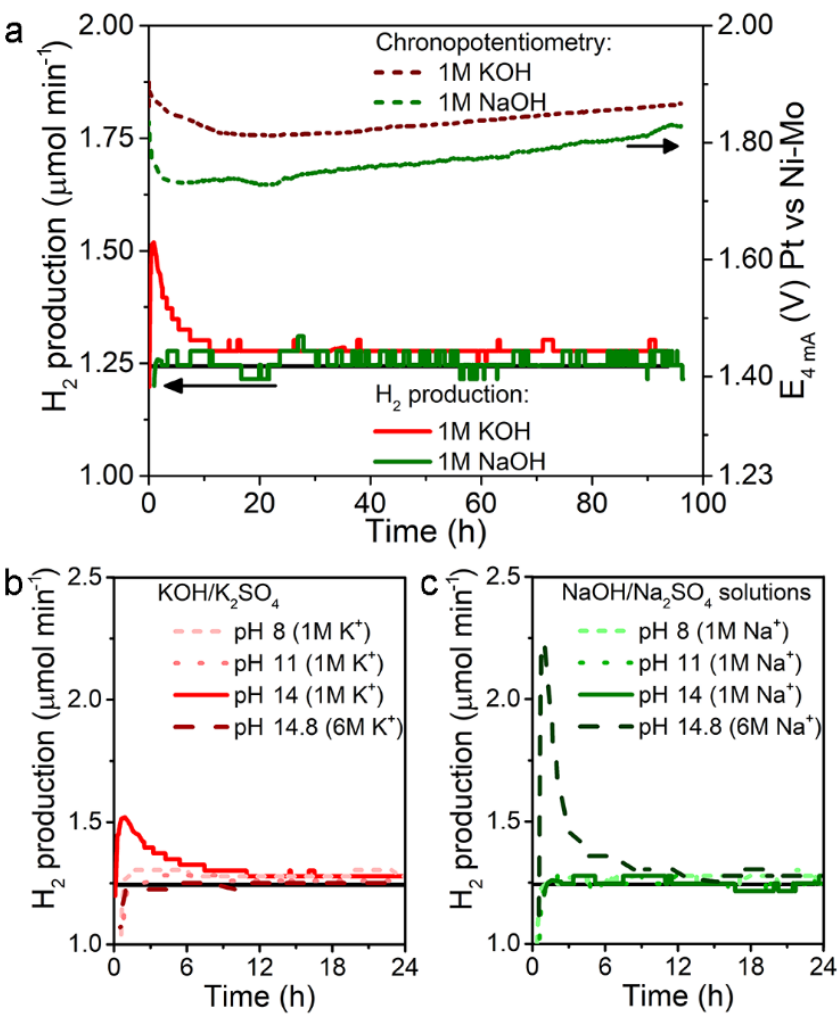

Figure 2.11: a) Hydrogen production found for $\mathrm{Ni}-\mathrm{Mo}$ in $1 \mathrm{M} \mathrm{KOH}$ (Red) or $1 \mathrm{M} \mathrm{NaOH}$ (green) at $4 \mathrm{~mA}$; the black line shows the theoretical amount expected. The dashed lines show the chronopotentiometric curves of these experiments. b) Hydrogen production in $\mathrm{KOH}$ at different $\mathrm{pH}$ values. c) Hydrogen production in $\mathrm{NaOH}$ at different $\mathrm{pH}$ values.

determined. Using gas chromatography (GC) we find that during the first few hours of HER catalysis in hydroxide solutions the FE is higher than $100 \%$ in the case of $1 \mathrm{M} \mathrm{KOH}$. This is shown in Figure 2.11a. This agrees with the proposed reaction mechanism where hydrogen forms without consuming electrons from the circuit, thus forming more hydrogen than the applied current would suggest. For $1 \mathrm{M} \mathrm{KOH}$ it tops at $122 \%$ after which it drops slowly to a value corresponding to $103 \% \mathrm{FE}$. In $1 \mathrm{M} \mathrm{NaOH}$ on the other hand, no such peak in FE is observed and it is constant at a FE of $101 \%$, corresponding to the lower extent of Mo leaching.

\subsubsection{Electrolyte Effects: Stabilization by pH Tuning}

In the case of $\mathrm{KOH}$ it is possible to suppress the additional formation of hydrogen by lowering the $\mathrm{pH}$, making the Mo leaching reaction less likely to occur. This is shown in Figure 2.11b. Meanwhile, increasing the pH for $1 \mathrm{M}$ 

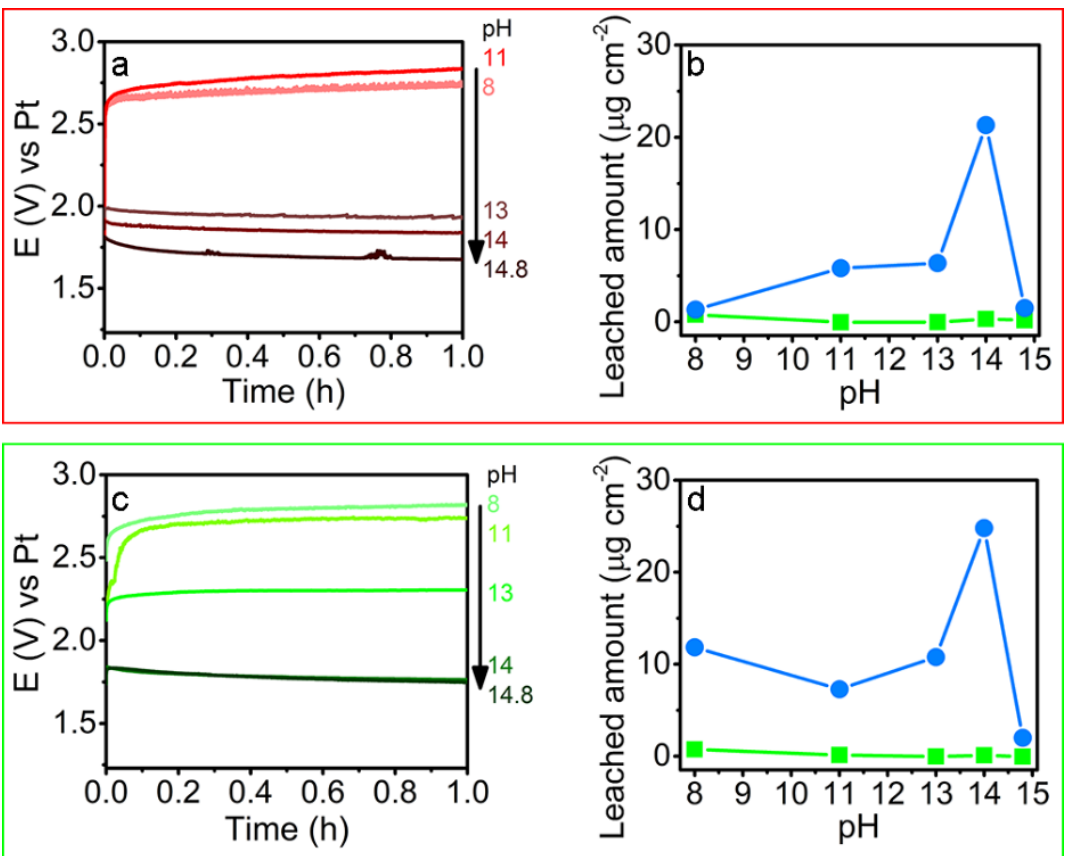

Figure 2.12: a) The first hour of the chronopotentiometric curves in $1 \mathrm{M} \mathrm{K}^{+}$ $\left(\mathrm{KOH} / \mathrm{K}_{2} \mathrm{SO}_{4}\right.$ ) solutions of varying $\mathrm{pH}$. b) The observed Mo (blue circles) and Ni (green squares) leaching after $24 \mathrm{~h}$ of operation at $-10 \mathrm{~mA} / \mathrm{cm}^{2}$ in $\mathrm{K}^{+}$solutions of varying $\mathrm{pH}$. c) The first hour of the chronopotentiometric curves in $1 \mathrm{M} \mathrm{Na}^{+}\left(\mathrm{NaOH} / \mathrm{Na}_{2} \mathrm{SO}_{4}\right)$ solutions of varying $\mathrm{pH}$. d) The observed Mo (blue circles) and Ni (green squares) leaching after $24 \mathrm{~h}$ of operation at $-10 \mathrm{~mA} / \mathrm{cm}^{2}$ in $\mathrm{Na}^{+}$solutions of varying $\mathrm{pH}$.

$\mathrm{NaOH}$, due to the higher concentration of hydroxide ions, results in the peak in FE coming up as well for that electrolyte (Figure 2.11c). Interestingly, in $6 \mathrm{M}$ $\mathrm{KOH}$, the peak in hydrogen production is absent. The explanation we propose is that in the case of $6 \mathrm{M} \mathrm{KOH}$ the material leaches directly from the $\mathrm{Ni}-\mathrm{MoO}_{3}$ phase resulting in the reaction being $\mathrm{MoO}_{3}+2 \mathrm{OH}^{-} \rightarrow \mathrm{MoO}_{4}{ }^{2-}+\mathrm{H}_{2} \mathrm{O}$. In the other solutions leaching takes place from the metallic phase, which is present due to the reducing potential being applied during these experiments. ${ }^{[31]}$ In contrast, the Mo leaching observed with ICP-AES (Figure 2.12) is significantly lower in $6 \mathrm{M} \mathrm{NaOH}$ and $6 \mathrm{M} \mathrm{KOH}$, although it should be noted that the higher concentration of easily ionizable alkali ions (6 M versus $1 \mathrm{M}$ ) can significantly suppress the signal of other analytes. ${ }^{[30]}$ From ICP-AES we also observe that at $\mathrm{pH} 8$ the leaching of $\mathrm{Ni}$ becomes significant as well, as can be seen in Figure 2.12. Interestingly, while the Mo leaching decreasing with decreasing $\mathrm{pH}$ we also observed that this effect was far less significant for $\mathrm{NaOH}$ compared to $\mathrm{KOH}$, meaning that the stability is less at lower $\mathrm{pH}$ values for $\mathrm{NaOH}$ than for $\mathrm{KOH}$ (Figure 2.12). 

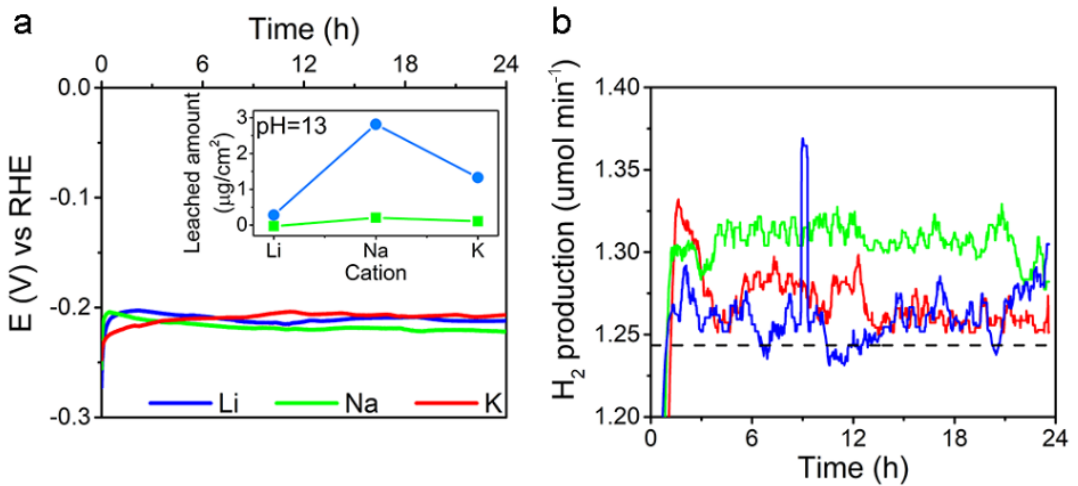

Figure 2.13: a) Chronopotentiometric curves in different $1 \mathrm{MM}$ + solutions at $\mathrm{pH} 13$ $\left(\mathrm{MOH} / \mathrm{M}_{2} \mathrm{SO}_{4}\right)$ with $\mathrm{Li}$ (blue), $\mathrm{Na}$ (green), $\mathrm{K}(\mathrm{red})$, showing nearly no variation. The inset shows Mo (blue circles) and Ni (green squares) leaching. b) $\mathrm{H}_{2}$ production as observed by in-line GC. The dotted line shows the expected value based on the applied current.

Furthermore, for $\mathrm{NaOH}$, at a $\mathrm{pH}$ of 8 , the Mo leaching increases again. This might relate to the increased $\mathrm{Ni}$ leaching which makes more Mo surface available. ${ }^{[31]}$ This is related to the earlier observations of leaching in $\mathrm{Na}$ being faster but less deeply penetrating. More Mo becomes available due to $\mathrm{Ni}$ leaching and in $\mathrm{NaOH}$ this increase in available Mo leaches faster than in $\mathrm{KOH}$. In the case of the experiments performed at lower $\mathrm{pH}$ values, the electrolytes acidify due to the Mo being leached to a concentration of about $20 \mu \mathrm{M}$. This also results in $40 \mu \mathrm{M}$ of $\mathrm{OH}^{-}$to be consumed, resulting in $\mathrm{pH} 4-5$. This also explains why $\mathrm{Ni}$ leaching started at electrolytes starting from $\mathrm{pH}$ 8. However, the potential role of $\mathrm{SO}_{4}{ }^{2-}$ ions in this acidification cannot be excluded; these ions result from $\mathrm{M}_{2} \mathrm{SO}_{4}$, which was added to maintain a constant alkali cation concentration.

Mo leaches even less in $\mathrm{LiOH}$ than in $\mathrm{KOH}$ and $\mathrm{NaOH}$ (Figure 2.13). While, as mentioned before, the leaching is more prominent in $\mathrm{NaOH}$ than in $\mathrm{KOH}$ on a timescale of $24 \mathrm{~h}$ at lower $\mathrm{pH}$ values, in $\mathrm{LiOH}$ this is appreciably less. The FE
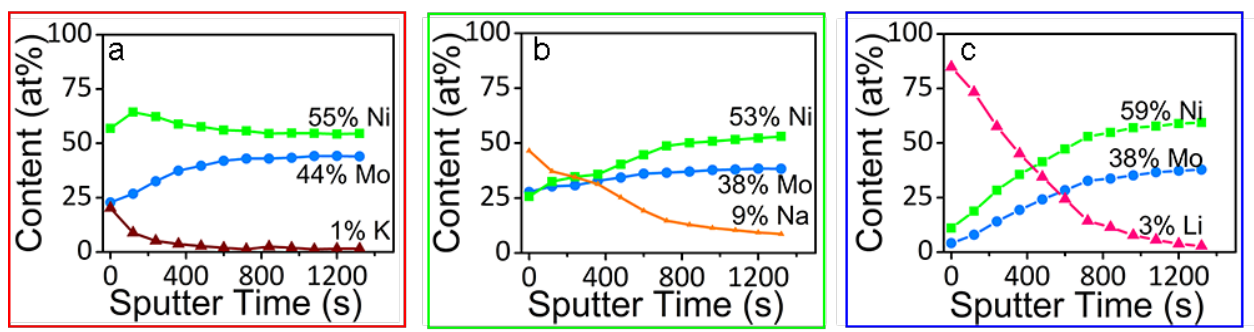

Figure 2.14: Elemental ratios up to $660 \mathrm{~nm}$ into the material from the surface as determined by XPS after $24 \mathrm{~h}$ of catalysis in $1 \mathrm{M} \mathrm{M}^{+}$solutions at $\mathrm{pH}=13$ for a) $\mathrm{M}=\mathrm{K}^{+}$, b) $M=\mathrm{Na}^{+}$and c) $M=\mathrm{Li}^{+}$. A sputter rate of $0.50 \mathrm{~nm} / \mathrm{s}$ (based on $\mathrm{Ta}_{2} \mathrm{O}_{5}$ ) was assumed for determining the $x$-axis. 
as observed with GC confirms this: $101.5 \%$ of the theoretical value over the course of $24 \mathrm{~h}$ in $\mathrm{Li}$, while for $\mathrm{K}$ and $\mathrm{Na}$ this is $102.1 \%$ and $105.0 \%$, respectively. Furthermore, the shape of leaching differs between the materials: on one hand, a sharp peak is observed for $\mathrm{KOH}$, similar to other $\mathrm{pH}$ values. On the other hand, a broad, low peak forms for $\mathrm{NaOH}$ and no observable peaking results in the case of $\mathrm{LiOH}$. Nevertheless, the chronopotentiometric curves look similar in all cases and the morphological changes are observed in all cases as well (Figure 2.15).

In Figure 2.14 the XPS depth profiles confirm the earlier statement that lighter alkaline elements infiltrate more easily into the alloy, since Li contents reach 85 $\%$ directly on the surface while this is $47 \%$ and $20 \%$ respectively for $\mathrm{Na}$ and $\mathrm{K}$. From these data the difference in leaching behavior at $\mathrm{pH} 13$ compared to

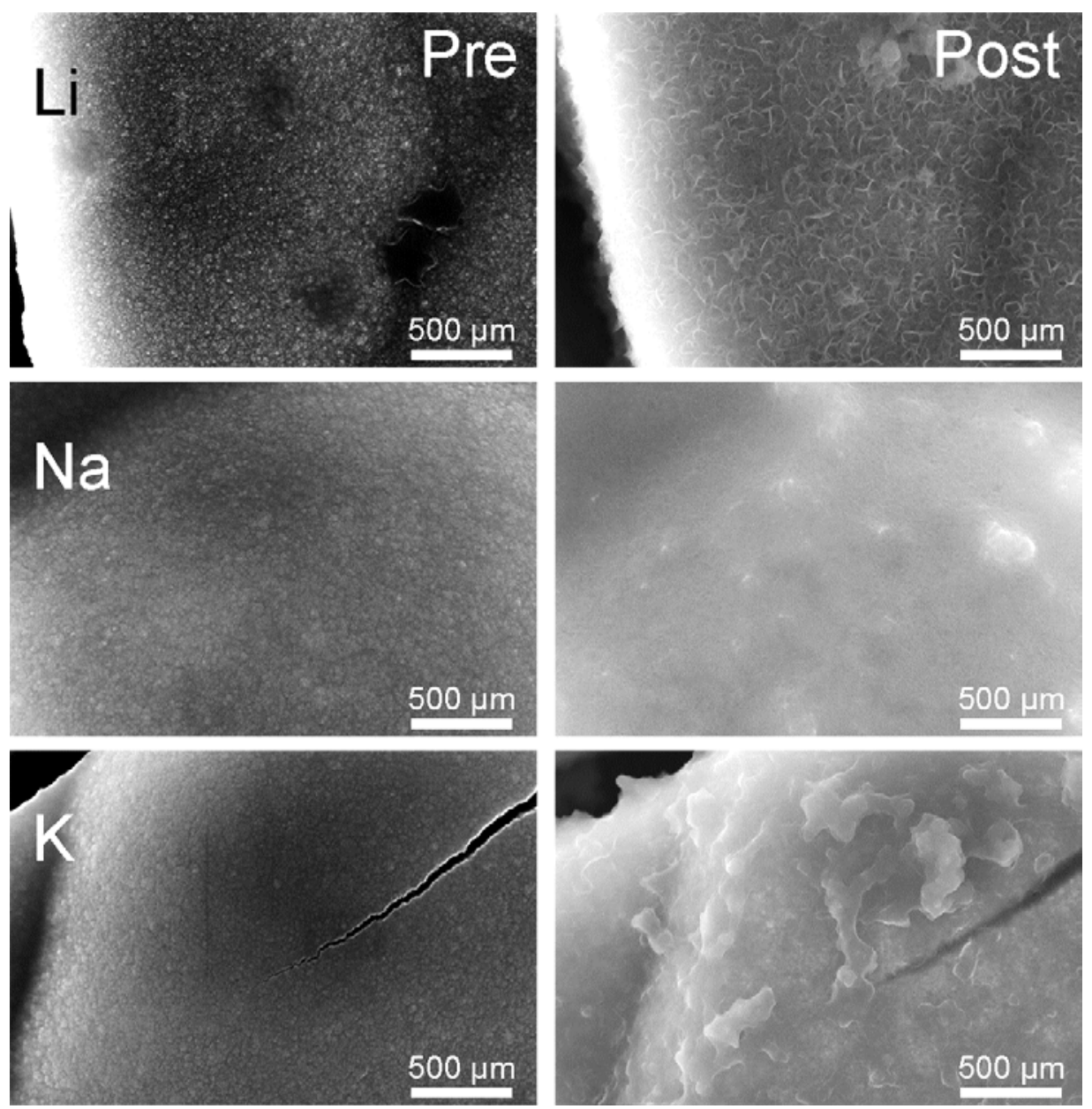

Figure 2.15: SEM images of Ni-Mo before (left) and after (right) electrocatalysis for $24 \mathrm{~h}$ in $1 \mathrm{M} \mathrm{MOH}$ solutions where $\mathrm{M}=\mathrm{Li}, \mathrm{Na}$, or $\mathrm{K}$ from top to bottom. 

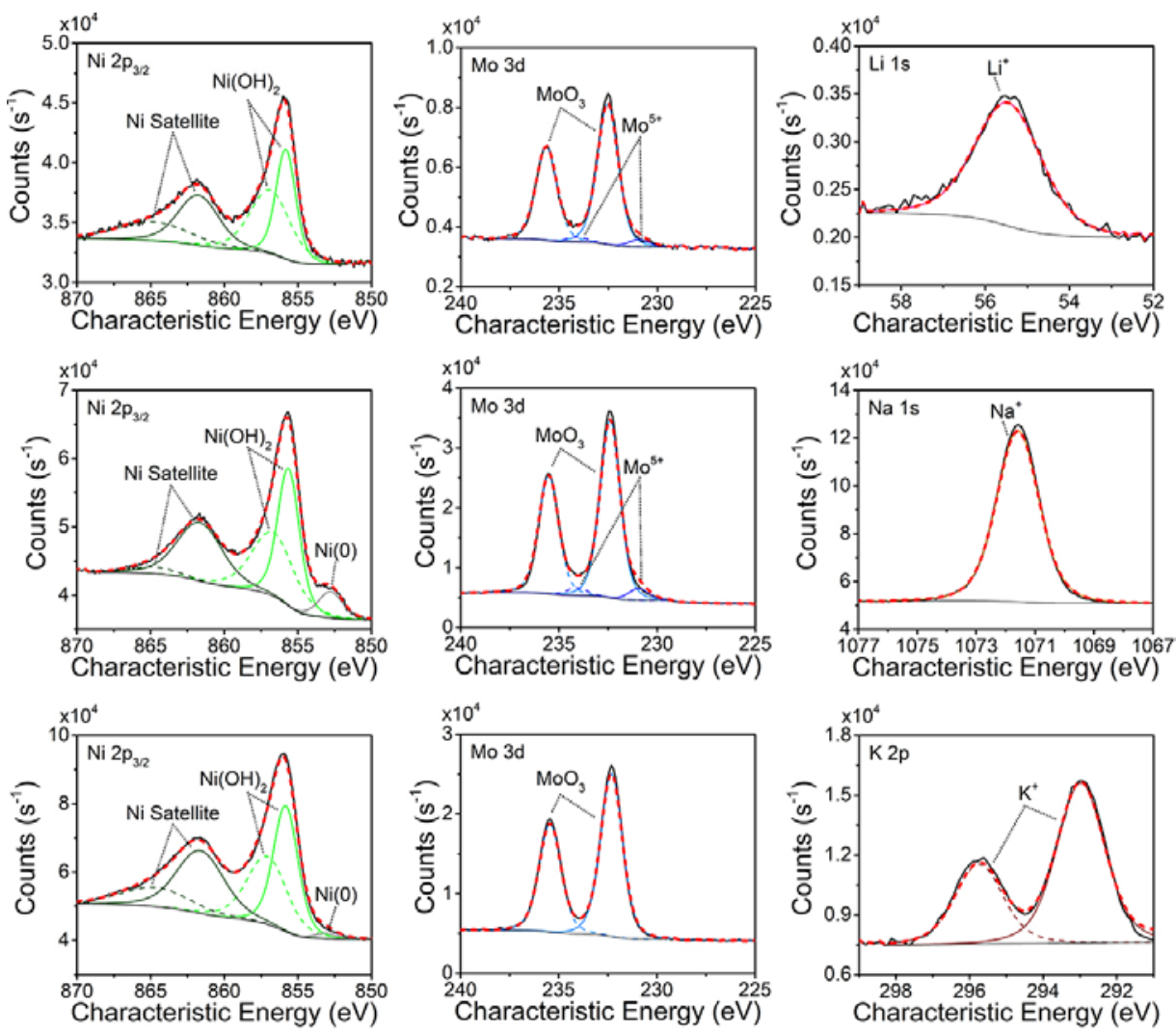

Figure 2.16: XPS spectra of Ni (left), Mo (middle) and alkali metal (right) of samples spent in $\mathrm{pH}$ 13, $1 \mathrm{M} \mathrm{M}^{+}$solutions. The samples spent in $\mathrm{LiOH}$ (top), $\mathrm{NaOH}$ (middle) and $\mathrm{KOH}$ (bottom) are shown.

$\mathrm{pH} 14$ can be explained as well: the highest leaching experiment was performed in $\mathrm{NaOH}$ and in contrast with $\mathrm{KOH}$ and $\mathrm{LiOH}$, in this case, the $\mathrm{Mo} / \mathrm{Ni}$ ratio increases instead of decreases. This is expected to be a result of Mo surface segregation which is described previously. ${ }^{[11,12]}$ In the cases of $\mathrm{KOH}$ and $\mathrm{LiOH}$, the $\mathrm{Mo} / \mathrm{Ni}$ decreases towards the surface, as was also the case for the experiments at $\mathrm{pH}$ 14. This means that Mo transport to the surface is less in these cases, as seen by the elemental ratios stabilizing earlier into the material. This lessened segregation left less Mo exposed to leach into the electrolyte. The same species were found with XPS after electrolysis as they were found at $\mathrm{pH}$ 14. This is listed in Figure 2.16. 


\subsubsection{Surface Segregation and Adsorbates as Revealed by Theory}

Density functional theory (DFT) was used to investigate hydrogen and cation adsorption, $\mathrm{Ni}$ and Mo surface segregation, and vacancy formation energies. Differential Gibbs free energies of hydrogen adsorption, $\Delta G_{H}$, were calculated as it has been shown previously to be a good descriptor for the HER activity on a variety of materials. ${ }^{[10,13,32-34]}$ Further details regarding the calculation of $\Delta \mathrm{G}_{\mathrm{H}}$ can be found in the Experimental Section. We use the limiting potential, determined theoretically as the potential at which all steps in the HER mechanism become exergonic, as an estimate of activity. For the HER, this limiting potential is simply defined as $U_{L}=-\left|\Delta G_{H}\right| / e$ and so the theoretical prediction of activity is maximized for $U_{L}=0$ and hence $\Delta G_{H}=0 \mathrm{eV}$. This theoretically determined limiting potential has been shown to correlate well with experimental activity for several processes. ${ }^{[10,13,32-35]}$ We chose $\mathrm{Ni}_{3} \mathrm{Mo}$ as the model Ni-Mo system due to the similarity in stoichiometry to the experimental system. Figure 2.17 shows $\Delta G_{H}$ as a function of the surface hydrogen coverage, $\theta_{H}$ for the three terrace facets of $\mathrm{Ni}_{3} \mathrm{Mo}$. At moderate surface coverages, $\Delta G_{H}$ approaches zero, indicating high predicted activity towards the HER for all studied surface facets.

To investigate the origin of the changing overpotential, we investigated the stability of the Ni-Mo system under HER conditions. Cation and hydroxyl adsorption free energies, $\Delta \mathrm{G}_{\mathrm{ads}}$ and $\Delta \mathrm{GO}_{\mathrm{H}}$ respectively, were calculated under

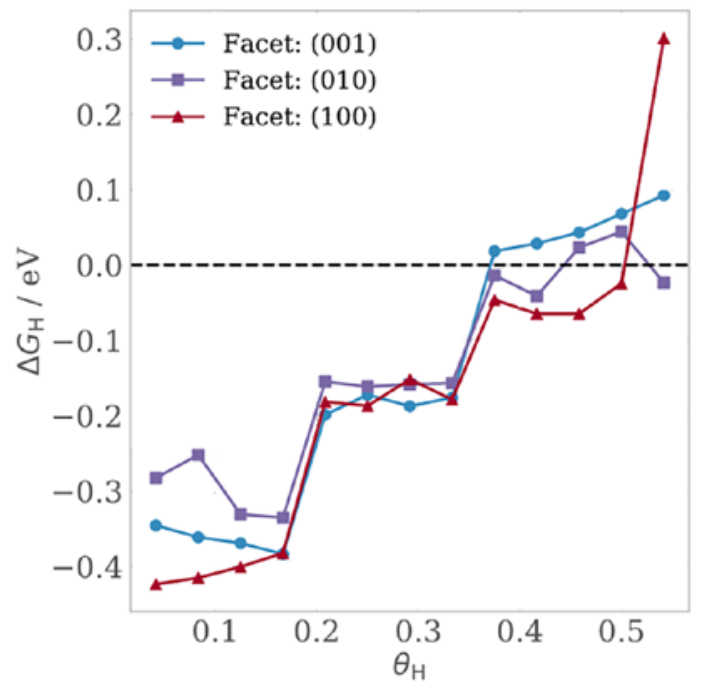

Figure 2.17: $\Delta G_{H}$ as a function of surface hydrogen coverage, $\theta_{H}$. 

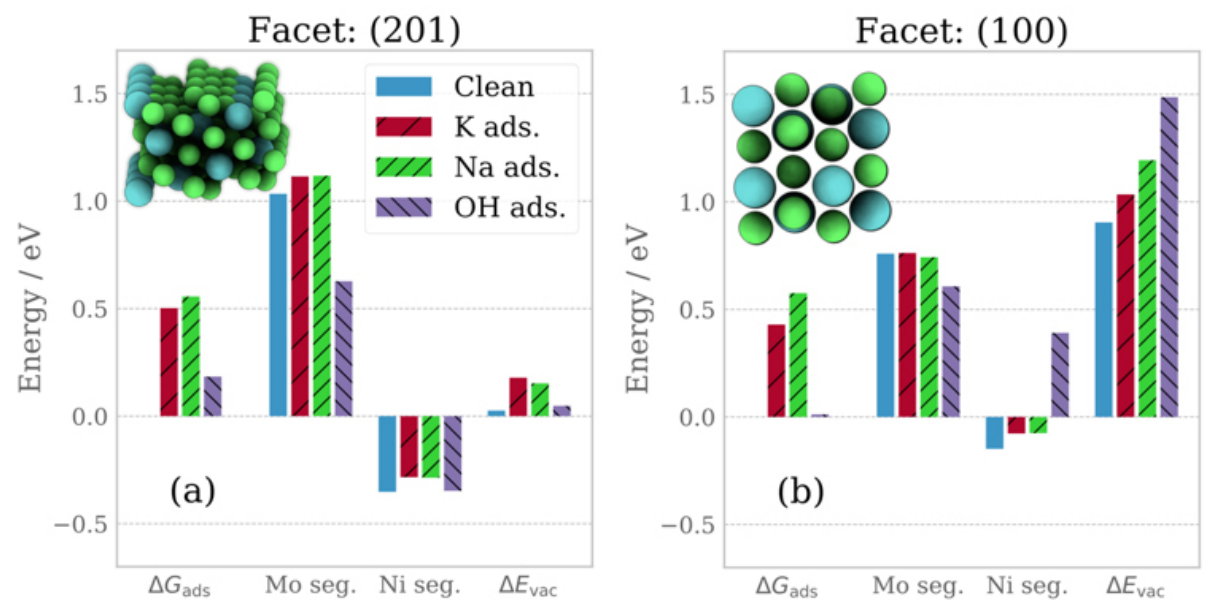

Figure 2.18: DFT investigation into the thermodynamics of surface restructuring, calculated under operating conditions $(U=-0.15 \mathrm{~V}$ vs $R H E, p H=13)$. (a) illustrates the energetics at a stepped $\mathrm{Ni}_{3} \mathrm{Mo}$ surface, while (b) illustrates the energetics for a terrace $\mathrm{Ni}_{3} \mathrm{Mo}$ surface.

operating conditions $(\mathrm{U}=-0.15 \mathrm{~V}$ vs $\mathrm{RHE}, \mathrm{pH} 13)$ to determine if they play a role in changes of surface morphology.

Figure 2.18 illustrates these energies for a step and terrace termination of $\mathrm{Ni}_{3} \mathrm{Mo}$. Similar plots for terrace facets (010) and (001) can be found in Figure 2.19. We find that cations bind unfavorably to both steps and terraces. Assuming a Boltzmann distribution, the expected coverage of cations $\theta_{\text {ion }}$ is therefore effectively 0 . However, solvent stabilization may allow cations to adsorb at small coverages at more negative potentials. Similarly, ${ }^{*} \mathrm{OH}$ binds unfavorably on the step, and weakly on the terrace. Solvent stabilization again may allow some small coverage of ${ }^{*} \mathrm{OH}$.

The energy to segregate Mo to the surface was then calculated as follows:

$$
\Delta E_{\text {seg, } M o}=E_{\text {seg }}-E_{\text {clean }}-\left(E_{M o}-E_{N i}\right)
$$

where $E_{\text {seg }}$ is the energy of a surface where one surface Ni atom is replaced with one bulk Mo atom, $E_{c l e a n}$ is the clean surface, $E_{M o}$ is the energy of one Mo atom in $\mathrm{Ni}_{3} \mathrm{Mo}$ relative to bulk $\mathrm{Ni}$, and $\mathrm{E}_{\mathrm{Ni}}$ is the energy of one $\mathrm{Ni}$ atom in $\mathrm{Ni}_{3} \mathrm{Mo}$ relative to bulk Mo.

Similarly, segregation energies for bringing $\mathrm{Ni}$ to the surface from bulk $\mathrm{Ni}_{3} \mathrm{Mo}$, while sending a surface Mo atom to a solvated molybdate ion, were determined:

$$
\Delta E_{\text {seg, Ni }}=E_{\text {seg }}-E_{\text {clean }}-\left(E_{\mathrm{Ni}}-\left(E_{M o(s)}+\Delta E_{M o, d i s s}\right)\right)
$$


Facet: (010)

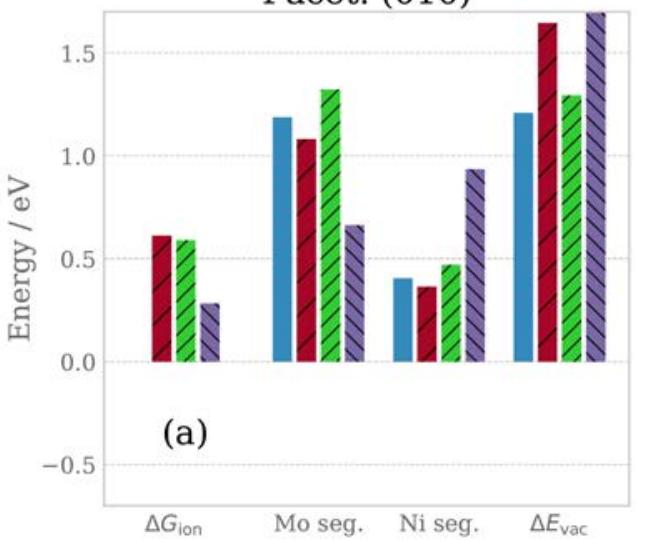

Facet: (001)

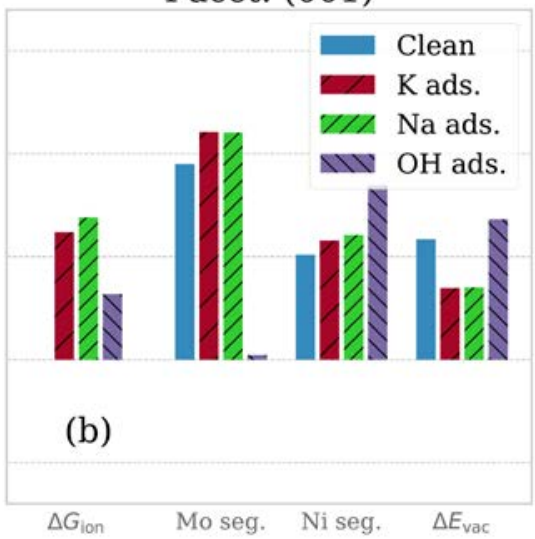

Figure 2.19: a) Bar chart of ion binding energy, Mo segregation energy, Ni segregation energy and energy for vacancy information through Mo solution of (010) terraces. b) Bar chart of ion binding energy, Mo segregation energy, Ni segregation energy and energy for vacancy information through Mo solution of (001) terraces.

where, $\mathrm{E}_{\mathrm{Mo}(\mathrm{s})}$ is the energy of a molybdenum atom in its pure solid phase, and $\Delta \mathrm{E}_{\mathrm{Mo} \text {,diss }}$ is the energy of the dissolution reaction which converts $\mathrm{Mo}(\mathrm{s})$ into a molybdate ion. Molybdate is considered since it is the most likely to form at $\mathrm{pH}$ 14 , under the studied potentials, according to the Pourbaix diagram. ${ }^{[31]}$

From literature data ${ }^{[36]}$, we have the equilibrium potential of the following reaction:

$$
\mathrm{Mo}(\mathrm{s})+8 \mathrm{OH}^{-}(\mathrm{aq}) \rightarrow \mathrm{MoO}_{4}{ }^{2-}(\mathrm{aq})+4 \mathrm{H}_{2} \mathrm{O}(\mathrm{l})+6 \mathrm{e}^{-}, \mathrm{U}_{0}=+0.913 \mathrm{~V}
$$

We can then add to this the HER at pH 14 as follows:

$$
6\left(\mathrm{e}^{-}+\mathrm{H}_{2} \mathrm{O} \rightarrow 1 / 2 \mathrm{H}_{2}+\mathrm{OH}^{-}\right), \mathrm{U}_{0}=0.0-14{ }^{*}-0.059 \mathrm{~V}
$$

Giving a net reaction and equilibrium potential:

$$
2 \mathrm{H}_{2} \mathrm{O}+\mathrm{Mo}(\mathrm{s})+2 \mathrm{OH}^{-} \rightarrow 3 \mathrm{H}_{2}+\mathrm{MoO}_{4}{ }^{2-}, \mathrm{U}_{0}=+0.087 \mathrm{~V}
$$

Using the Nernst equation, we see that the free energy of this reaction is then:

$$
\Delta \mathrm{G}_{\mathrm{Mo}, \text { dissolution }}=-\mathrm{nF} \mathrm{U}_{0}=-0.522 \mathrm{eV}
$$

The energy required to form a Mo vacancy on the surface via dissolution of Mo, $\Delta \mathrm{E}_{\mathrm{vac}}$, was calculated:

$$
\Delta \mathrm{E}_{\mathrm{vac}}=\mathrm{E}_{\mathrm{vacancy}}-\mathrm{E}_{\text {clean }}-\left(\mathrm{E}_{\mathrm{Mo}(\mathrm{s})}+\Delta \mathrm{E}_{\mathrm{Mo}, \text { diss }}\right)
$$


(100)

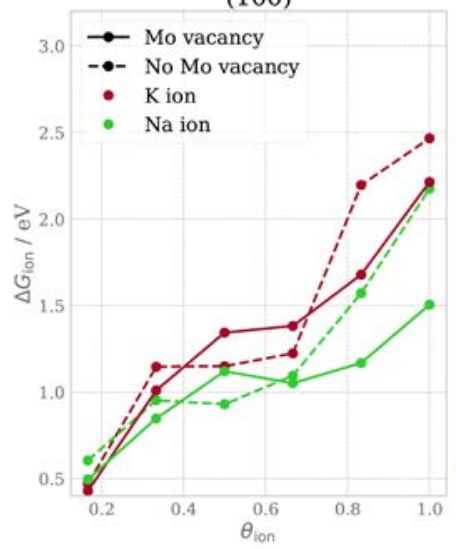

(010)

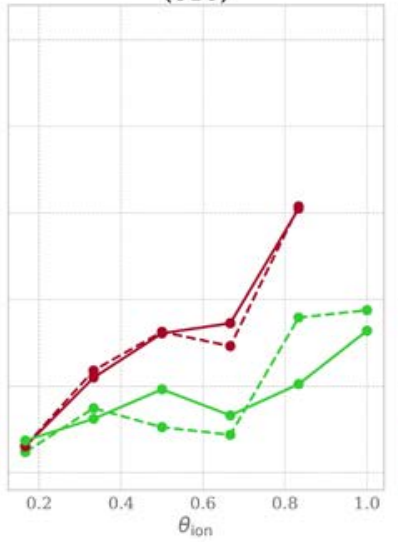

(001)

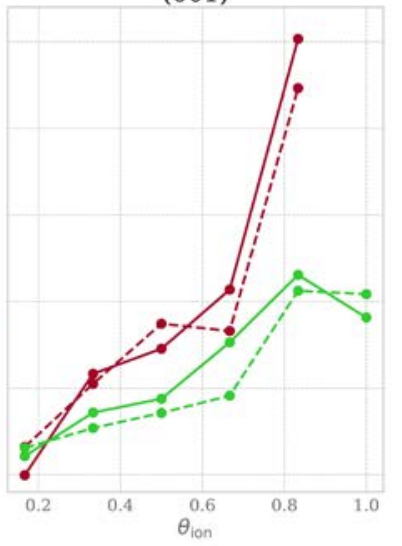

Figure 2.20: Ion adsorption energies as a function of ion coverage where $\theta_{\text {ion }}=1$ corresponds to four ions adsorbed on a single unit cell on different terrace facets.

Here $E_{\text {vacancy }}$ is the energy of the surface with a vacancy, and $E_{c l e a n}$ is the clean surface. The segregation and vacancy formation energies were calculated both on clean slabs and in the presence of cations and $\mathrm{OH}^{\star}$. These are tabulated in Figure 2.18.

We find that it is energetically unfavorable to enrich the surface in Mo, while enriching the bulk in $\mathrm{Ni}$, regardless of cation adsorption. Additional results for cation adsorption can be found in Figure 2.20. We do find however that ${ }^{*} \mathrm{OH}$ can significantly stabilize Mo surface enrichment, though it is still unfavorable energetically. This is likely due to molybdenum's high oxophilicity. Ni enrichment, however, is generally energetically favorable, consistent with experimental observation, discussed in what follows. We find that the formation of a Mo vacancy on the surface via dissolution to molybdate is feasible on the step, but not on the terrace. Because the films in this study are highly amorphous and are likely to contain sites less coordinated than the step presented here, we expect the Mo conversion to molybdate to occur without an applied potential.

\subsection{Conclusions}

Ni-Mo as material performs exceptionally well as a hydrogen evolution reaction (HER) catalyst and its performance stability is high since the overpotential of operation only changes slightly during $100 \mathrm{~h}$ of catalysis. Density functional theory (DFT) calculations show Ni-Mo low index facets to have nearly thermoneutral $\mathrm{H}$ adsorption free energy, which is consistent with the observed high Ni-Mo activity. Furthermore, the theoretical calculations also suggest both $\mathrm{Ni}$ segregation and Mo vacancy formation to be favorable even without the influence of an applied potential. This observation was confirmed by catalyst 
characterization results. The activation observed at the start of HER operation is due to some Mo leaching via the reaction: $\mathrm{Mo}+2 \mathrm{OH}^{-}+2 \mathrm{H}_{2} \mathrm{O} \rightarrow \mathrm{MoO}_{4}{ }^{2-}+$ $3 \mathrm{H}_{2}$. This results in an overall increase of surface area and thus an apparent decrease in absolute overpotential. Although the material operates stably for at least a week, future research on longer timescales should show if the leaching would not be detrimental for real long-term performance stability. Furthermore, the leaching results in undesired contaminants in operating systems and we have shown, as summarized in Figure 2.21, how simple changes to the electrolyte (by changing the monovalent cation) can already significantly suppress the Mo leaching without hugely influencing the overall HER performance.

The influence, we found, can be directly related to the observed mechanism of leaching. Changing from $\mathrm{Li}$ to $\mathrm{Na}$ to $\mathrm{K}$ influences the surface segregation of Mo, and so pushes the reaction towards Mo dissolution by increasing the surface concentration of Mo. Decreasing the $\mathrm{pH}$ decreases the concentration of $\mathrm{OH}^{-}$ and in this manner inhibits the leaching reaction. This is, however, only valid down to a certain value since the leaching reaction consumes $\mathrm{OH}^{-}$and acidifies the solution, which becomes significant at $\mathrm{pH}$ values closer to neutral. The acidification destabilizes Ni instead, similarly destroying the HER material. Of the electrolytes studied, in terms of stability, the best to use is $\mathrm{LiOH}$ at a pH of 13.

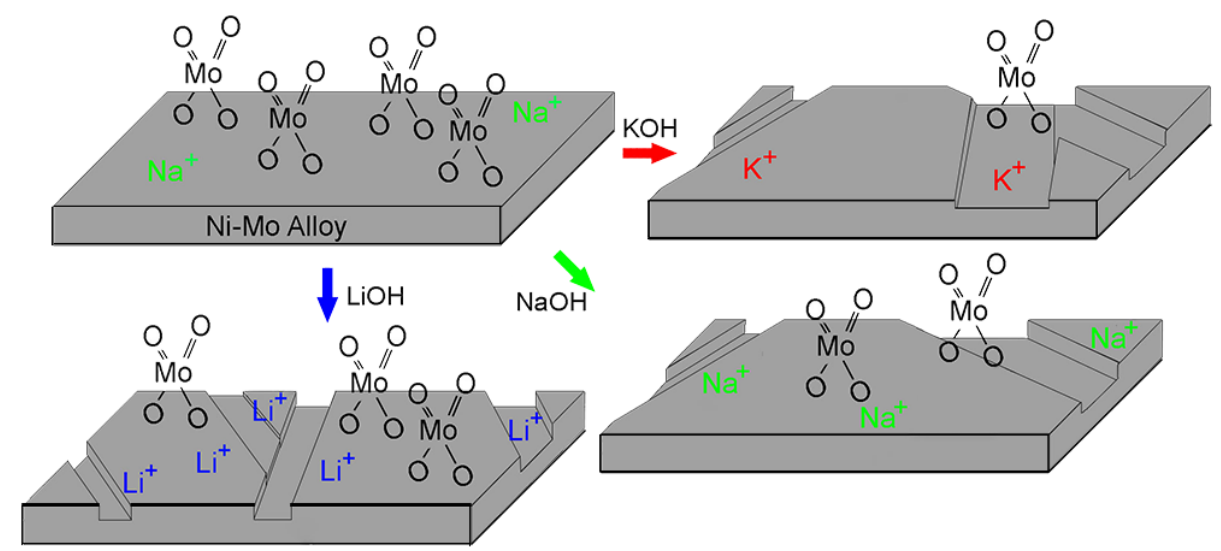

Figure 2.21: Schematic overview of the results obtained in this PhD Chapter, showing the Ni-Mo alloy with surface $\mathrm{MoO}_{x}$, which, after HER catalysis, is etched by a loss of Mo and infiltrated by the monovalent cations present in the electrolyte. 


\subsection{Experimental}

\subsubsection{Chemicals and Materials}

All materials were used as received without further purification. $\mathrm{NiSO}_{4} \cdot 6 \mathrm{H}_{2} \mathrm{O}$ (ReagentPlus, $>99 \%$ pure), $\mathrm{NaMoO}_{4} \cdot 2 \mathrm{H}_{2} \mathrm{O}$ (ACS reagent, $>99 \%$ pure), $\mathrm{NaOH}$ (99.99\% trace metals, semiconductor grade), $\mathrm{KOH}$ (ACS reagent, >85\% pure), $\mathrm{LiOH} \mathrm{H}_{2} \mathrm{O}$ (99.95\% trace metals), $\mathrm{Na}_{2} \mathrm{SO}_{4}$ (ACS reagent, $\geq 99.0 \%$ ), $\mathrm{K}_{2} \mathrm{SO}_{4} \quad$ (ReagentPlus $\geq 99.0 \%$ ), $\quad \mathrm{Li}_{2} \mathrm{SO}_{4} \cdot \mathrm{H}_{2} \mathrm{O} \quad$ (BioUltra $\geq 99.0 \%$ ) and $\mathrm{Na}_{3} \mathrm{C}_{6} \mathrm{H}_{5} \mathrm{O}_{7} \cdot 2 \mathrm{H}_{2} \mathrm{O}$ (sodium citrate, ACS reagent, > $99 \%$ pure) were received from Sigma Aldrich. $\mathrm{NH}_{3} 28-30 \%$ (ACS reagent, ph. Eur. for analysis) was obtained from Emsure. In all experiments, deionized water was used.

\subsubsection{Electrodeposition}

Ti stubs (99.99+ \%, Goodfellow) are machined to $1.257 \mathrm{~cm}^{2}$ round substrates of similar shape as SEM stubs (Figure 2.22a-b) and were fixed in a threeelectrode cell for electro-deposition (Figure 2.22c-e). Prior to electrodeposition these were polished on SiC paper with increasing grit $(500,1200,4000)$, they were then cleaned by sonication in three steps of 15 min each, first in 1:1 Ethanol:Acetone, then $2 \mathrm{M} \mathrm{HNO}_{3}$, and finally deionized water. Electrodeposition was performed galvanostatically using an Ivium Compactstat at a current of $-100 \mathrm{~mA}$ for $1200 \mathrm{~s}$, while stirring at $400 \mathrm{rpm}$. As a counter electrode a Pt mesh (Mateck, 99.9+ \%) was used and as a reference electrode a $3 \mathrm{M}$ $\mathrm{Ag} / \mathrm{AgCl}(\mathrm{BASi})$ was used. Since it is good practice to control the stability of the
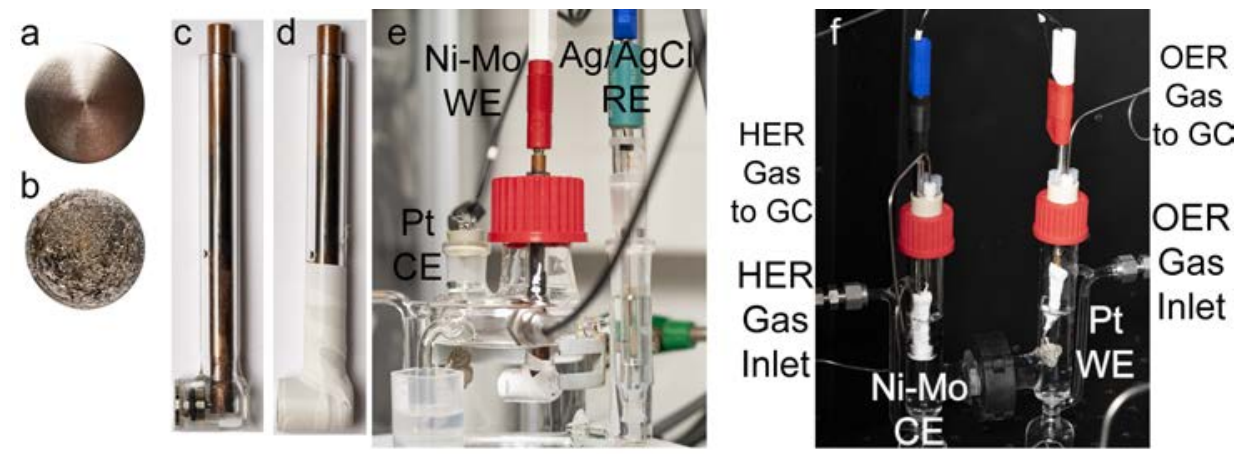

Figure 2.22: a) Photograph of a Ti stub after polishing. b) Photograph of a Ti stub coated with Ni-Mo. c) Photograph of sample holder with copper tubing for electrical connection, the stub fixated with a rubber O-ring on the bottom. All of this is in a glass tube. d) Photograph of the sample holder made water tight with Teflon tape to have only the top part $1.257 \mathrm{~cm}^{2}$ exposed. e) Overview photograph of the three-electrode cell with a Pt mesh counter electrode (CE), Ni-Mo/Ti working electrode (WE) and $\mathrm{Ag} / \mathrm{AgCl} 3 \mathrm{M} \mathrm{KCl}$ reference electrode (RE). The RE is connected to the main cell by a Luggin capillary. Gas inlets are closed off by rubber stoppers and a water lock is used to prevent pressure build-up and to prevent ambient air from re-entering the cell. f) $\mathrm{H}$ cell with left the Ni-Mo as counter electrode (CE) and right a Pt mesh as working electrode (WE). A Nafion membrane is placed in the bridge of the H-cell. Gas inlets flow through glass frits to have fine bubbles flow through the cell at all times. 

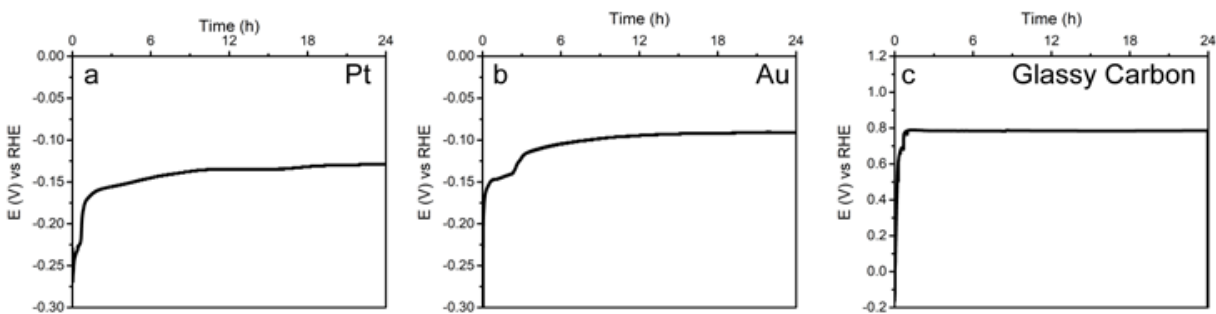

Figure 2.23: Chronopotentiometry of Ni-Mo versus a) Pt, b) Au, c) glassy carbon. Note the different $y$-axis in the case of c) glassy carbon.

counter electrode, the possibility of Pt leaching ${ }^{[37]}$ and analogous counter electrodes (Au, Goodfellow 99.99+\%, Glassy Carbon, BASi) was studied (Figure 2.23). Pt was found to be stable and the better counter electrode of the three for this system, no Pt was found by EDX ( $0 \%$ in all tested cases) or XPS (Figure 2.24). Glassy carbon was destroyed during the electrolysis, as was expected. ${ }^{[38]}$ The plating bath used contained $0.3 \mathrm{M} \mathrm{NiSO}_{4}, 0.2 \mathrm{M} \mathrm{Na}_{2} \mathrm{MoO}_{4}$ and $0.3 \mathrm{M} \mathrm{Na}_{3} \mathrm{C}_{6} \mathrm{H}_{5} \mathrm{O}_{7}$ in $100 \mathrm{~mL}$ deionized water. To this, $10 \mathrm{~mL} \mathrm{NH}_{3}$ was added to obtain a pH of 9.2. First, the metal precursors were dissolved in water through stirring, and then $\mathrm{NH}_{3}$ was added to adjust the $\mathrm{pH}$. Prior to the syntheses, the baths were purged with Ar for 15 min, and a gentle Ar flow was kept over the solution during electro-deposition. As summarized in Table 2.3 the composition of the electrodes approached $\mathrm{Ni}_{3} \mathrm{Mo}(71 \% \pm 3 \% \mathrm{Ni}, 26 \% \pm 3 \% \mathrm{Mo}, 3 \% \pm 1 \%$ $\mathrm{Na}$ ) when synthesized from Na-based precursors. When synthesized from Kbased precursors it approached $\mathrm{Ni}_{4} \mathrm{Mo}(82 \% \pm 7 \% \mathrm{Ni}, 17 \% \pm 7 \% \mathrm{Mo}, 0.3 \%$ $\pm 0.1 \% \mathrm{~K})$.

\subsubsection{Electrochemical characterization}

Electrochemical testing on samples was done as follows. The samples were loaded in three-electrode cells with a Pt mesh counter electrode and a $3 \mathrm{M}$ $\mathrm{Ag} / \mathrm{AgCl}$ (Metrohm, shielded, $-0.207 \mathrm{~V}$ vs SHE, which is $-1.033 \mathrm{~V}$ vs RHE (pH 14) and $-0.974 \mathrm{~V}$ vs $\mathrm{RHE}(\mathrm{pH}$ 13)) reference electrode. $1 \mathrm{M} \mathrm{MOH}$ is used as an electrolyte at $\mathrm{pH}$ values of 14 . Other electrolytes were made with $\mathrm{MOH}$ and $\mathrm{M}_{2} \mathrm{SO}_{4}$ to maintain a concentration of $1 \mathrm{M}$ alkali cations $\left(\mathrm{M}^{+}\right)$. First, double layer capacitance measurements were performed between $-0.7 \mathrm{~V}$ and $-0.9 \mathrm{~V}$ vs $\mathrm{Ag} / \mathrm{AgCl}$ at 100, 200, 300, 400 and $500 \mathrm{mV} / \mathrm{s}$ for 3 cycles each. Following this a linear sweep was performed at $50 \mathrm{mV} / \mathrm{s}$ from $-1 \mathrm{~V}$ to $-1.3 \mathrm{~V} \mathrm{vs} \mathrm{Ag} / \mathrm{AgCl}$ to confirm no polluting electrochemical processes take place (data not shown). Finally, chronopotentiometry was performed for varying lengths of time $(1,4$, 24 or $100 \mathrm{~h})$ at $-12.57 \mathrm{~mA}\left(-10 \mathrm{~mA} / \mathrm{cm}^{2}\right)$. The linear sweep and double layer capacitance measurements were performed again. Double layer capacitance values were obtained by taking the difference between the forward and backward current of the third scan. Data was averaged between 0.795-0.805 V for each point. The resulting double layer thickness was then plotted versus the 

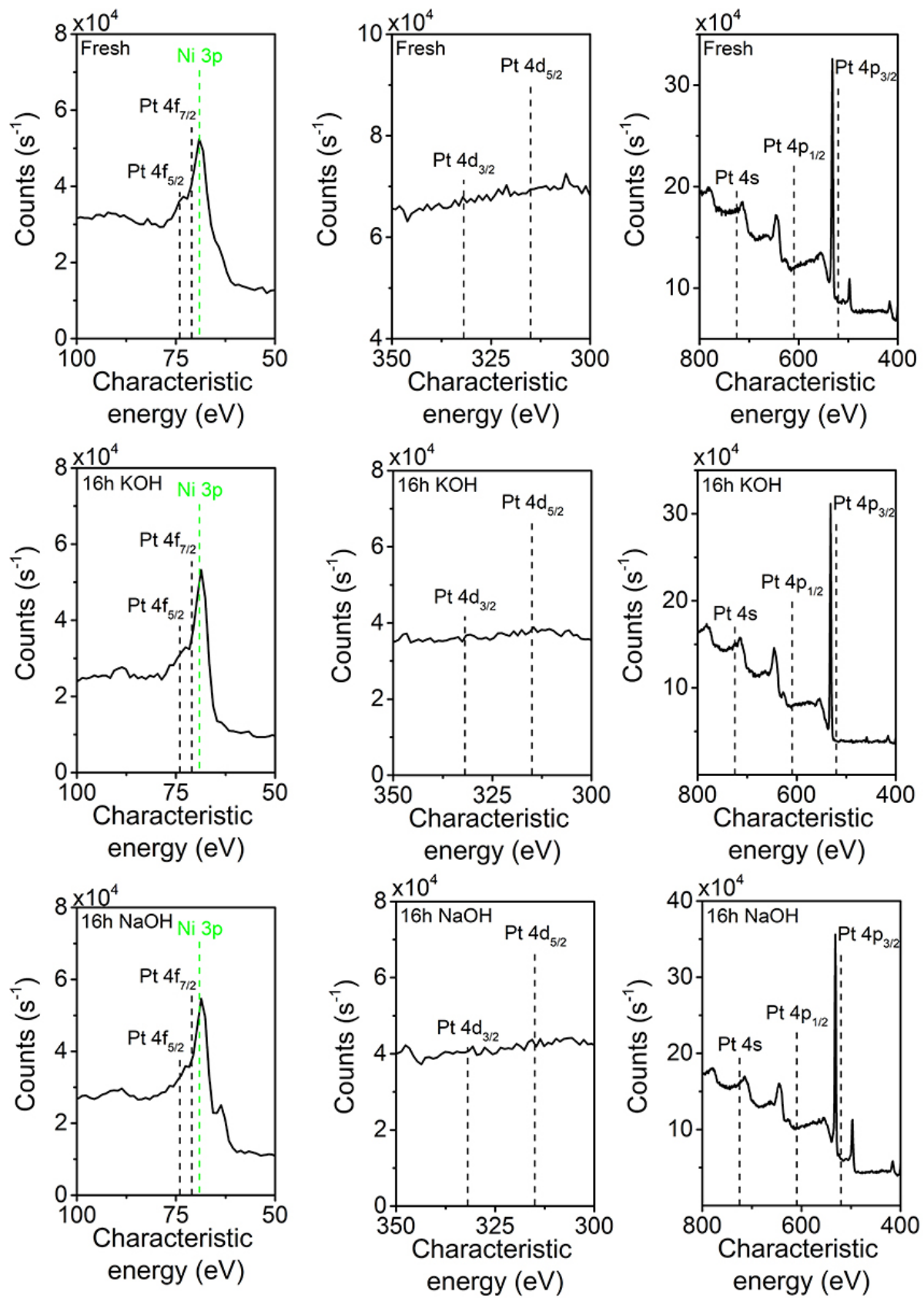

Figure 2.24: XPS spectra of the Pt $4 f$ (left), Pt $4 d$ (middle) and Pt $4 p$ and $4 s$ (right) peaks of unspent (top), $16 \mathrm{~h}$ in $1 \mathrm{M} \mathrm{KOH}$ (middle) and spent $16 \mathrm{~h}$ in $1 \mathrm{M} \mathrm{NaOH}$ (lower). As can be observed in the spectra, both before and after catalysis no Pt is present above the detection limit of XPS in the surface of the samples. 
scan rate. The linear fit of these points yields the capacitance. The stepped capacitance measurements were performed by alternating 30 min long chronopotentiometric measurements with the five cyclic voltammetry measurements. This was done over the course of $24 \mathrm{~h}$. The data after the capacitance value levels off is not shown as linear fitting beyond that point could no longer be called satisfactory as the points were approaching a second order function. Gas Chromatography (GC) analysis was done with a H-cell with a Nafion perfluorinated membrane (Nafion 117, 0.007 inches thick, Sigma Aldrich) loaded with the electrodes and $1 \mathrm{M} \mathrm{KOH}$. This was purged with 2 $\mathrm{mL} / \mathrm{min} \mathrm{N}_{2}$ (5.0), $0.1 \mathrm{~mL} / \mathrm{min} \mathrm{Kr}$ (5.0) on the $\mathrm{O}_{2}$ side and $2 \mathrm{~mL} / \mathrm{min} \operatorname{Ar}(5.0), 0.1$ $\mathrm{mL} / \mathrm{min} \mathrm{Kr}$ on the $\mathrm{H}_{2}$ side. This was bubbled past the samples through a glass frit. The $\mathrm{O}_{2}$ electrode was the working electrode (WE), the $\mathrm{H}_{2}$ electrode was the counter electrode (CE)/reference electrode (RE). A current of $4 \mathrm{~mA} / \mathrm{cm}^{2}$ was maintained for $96 \mathrm{~h}$. GC was obtained using Global Analyzer Solutions Compact GC 4.0 from Interscience with separate channels for $\mathrm{H}_{2}$ and $\mathrm{O}_{2} . \mathrm{H}_{2}$ was analyzed via a $75 \mu \mathrm{L}$ sample loop injecting into a $5 \mathrm{~m} \cdot 0.53 \mathrm{~mm}$ MXT-Qbond then a $10 \mathrm{~m} \cdot 0.53 \mathrm{MXT}$-Msieve column and detected on a TCD. $\mathrm{O}_{2}$ was injected via a $50 \mu \mathrm{L}$ loop through different columns of the same type and analyzed on a separate TCD. An injection was done each minute, with about $10 \mathrm{~s}$ delay between each injection. For each injection, $\mathrm{Kr}$ was used as an internal standard.

Table 2.3: SEM-EDX results found for samples prior to catalysis. Only $\mathrm{Na}, \mathrm{Ni}, \mathrm{Mo}$ and $K$ are considered and put at a total of $100 \%$.

\begin{tabular}{|c|c|c|c|c|}
\hline Experiment & $\mathrm{Na}(\mathrm{at} \%)$ & $\mathrm{Ni}(\mathrm{at} \%)$ & Mo (at\%) & K (at\%) \\
\hline $\mathrm{Na}-\mathrm{Na} 1 \mathrm{~h}$ & 3.7 & 73.0 & 23.4 & - \\
\hline $\mathrm{Na}-\mathrm{Na} 4 \mathrm{~h}$ & 3.1 & 73.9 & 23.1 & - \\
\hline $\mathrm{Na}-\mathrm{Na} 24 \mathrm{~h}$ & 2.3 & 74.3 & 23.4 & - \\
\hline $\mathrm{Na}-\mathrm{Na} 100 \mathrm{~h}$ & 2.3 & 69.3 & 28.4 & - \\
\hline Na-K 1 h & 2.0 & 68.5 & 29.4 & - \\
\hline $\mathrm{Na}-\mathrm{K} 4 \mathrm{~h}$ & 2.6 & 65.1 & 32.2 & - \\
\hline $\mathrm{Na}-\mathrm{K} 24 \mathrm{~h}$ & 6.0 & 71.4 & 22.5 & - \\
\hline $\mathrm{Na}-\mathrm{K} 100 \mathrm{~h}$ & 1.3 & 73.8 & 24.9 & - \\
\hline K-Na 24 h & - & 78.7 & 20.9 & 0.4 \\
\hline K-Na $100 \mathrm{~h}$ & - & 78.0 & 21.6 & 0.3 \\
\hline K-K 24 h & - & 94.6 & 5.3 & 0.1 \\
\hline K-K $100 \mathrm{~h}$ & - & 77.4 & 22.1 & 0.5 \\
\hline $\mathrm{Na}-\mathrm{Li}(\mathrm{pH}=13) 24 \mathrm{~h}$ & 3.3 & 67.2 & 29.5 & - \\
\hline $\mathrm{Na}-\mathrm{Na}(\mathrm{pH}=13) 24 \mathrm{~h}$ & 7.6 & 64.0 & 28.4 & - \\
\hline $\mathrm{Na}-\mathrm{K}(\mathrm{pH}=13) 24 \mathrm{~h}$ & 3.6 & 66.9 & 29.5 & - \\
\hline
\end{tabular}

\subsubsection{Structural characterization}

UV-Vis spectroscopy was performed using an Avantes DH-2000-BAL Deuterium lamp and an Avantes StarLine AvaSpec-2048L spectrometer using 
a liquid immersed probe head. The spectra were obtained in the range of 200$500 \mathrm{~nm}$ using $1 \mathrm{M} \mathrm{KOH}$ or $1 \mathrm{M} \mathrm{NaOH}$ as a reference. ICP-AES was performed using an Optima 8300 instrument from Perkin Elmer and an average of three samples was used. Electrodeposited samples were dissolved in $10 \mathrm{~mL} 2 \%$ $\mathrm{HNO}_{3}$ before oxidation. These were diluted with $2 \% \mathrm{HNO}_{3}$ to achieve optimal measurement ranges. Electrolytes were decreased in $\mathrm{pH}$ to add $1 \mathrm{~mL} 65 \%$ $\mathrm{HNO}_{3}$ per $10 \mathrm{~mL}$ electrolyte, resulting in ca. $2 \% \mathrm{HNO}_{3}$. Ni (231.604 nm), $\mathrm{K}$ $(766.491 \mathrm{~nm}), \mathrm{Na}(589.592 \mathrm{~nm}), \mathrm{Ti}(334.187 \mathrm{~nm})$ and Mo $(202.095 \mathrm{~nm})$ were then measured. SEM-EDX was performed on a FEI Helios nanolab 600 DualBeam with an Oxford instruments Silicon Drift Detector X-Max energy dispersive spectroscope. EDX mapping was performed with an electron beam of $15 \mathrm{kV}$ and $0.8 \mathrm{nA}$. All SEM imaging was done using secondary electrons at $15 \mathrm{kV}$ and $0.8 \mathrm{nA}$. Wide images were first shot to ensure the larger magnifications were taken at representative areas of the material (data not shown for brevity). XPS measurements were carried out with a Thermo Scientific K-Alpha instrument, equipped with a monochromatic small-spot X-ray source and a $180^{\circ}$ double focusing hemispherical analyzer with a 128-channel detector. Spectra were obtained using an aluminum anode (Al Ka $=1486.6 \mathrm{eV}$ ) operating at $72 \mathrm{~W}$ and a spot size of $400 \mu \mathrm{m}$. Scans were measured in snapshot mode. The background pressure was $2 \times 10^{-8} \mathrm{mbar}$ and during the measurement $3 \times 10^{-7}$ mbar Argon because of the charge compensation dual beam source. The sputtering parameters were as following: ion energy $=2000$ $\mathrm{eV}$, high current, sputter rate estimate $\left(\mathrm{Ta}_{2} \mathrm{O}_{5}\right)=0.50 \mathrm{~nm} / \mathrm{s}$, sputter Time $=120$ s/level, number of levels $=12$. Binding energy calibration for all samples was performed by setting the C1s (sp3) binding energy of adventitious carbon to $285.0 \mathrm{eV}$. Fitting of the spectra (BE, FWHM, peak shape, asymmetry, number of species) was performed with CasaXPS. Content percentages of $\mathrm{Ni}, \mathrm{Mo}, \mathrm{Na}$, and $\mathrm{K}$ were determined by finding the area of their respective spectra and dividing this by the sensitivity factor that is specific to the element. This gives the relative area for each element. All relative areas of the elements of interest (excluding $\mathrm{C}$ and $\mathrm{O}$ ) together are defined as $100 \%$. AFM measurements were performed on a NT-MDT NTEGRA Spectra instrument, using silicon NSC-16 tips $\left(F=45 \mathrm{~N} / \mathrm{m}\right.$, $\left.f_{\text {res }}=190 \mathrm{kHz}\right)$ in tapping mode. Samples were marked using a scalpel, and an optical system was used to find the same scanning spots preand post-catalysis. Flattening and masking were done using Gwyddion. ${ }^{[39]}$ Surface roughnesses (as root-mean-square, RMS) were determined using the programs "Statistical quantities" on exclusively the masked areas (Figures 2.25 and 2.26).

\subsubsection{Computational details}

All calculations were performed using the Vienna Ab-Initio Simulation Package (VASP) ${ }^{[40-42]}$ Core electrons were described by PAW pseudopotentials ${ }^{[43,44]}$, 

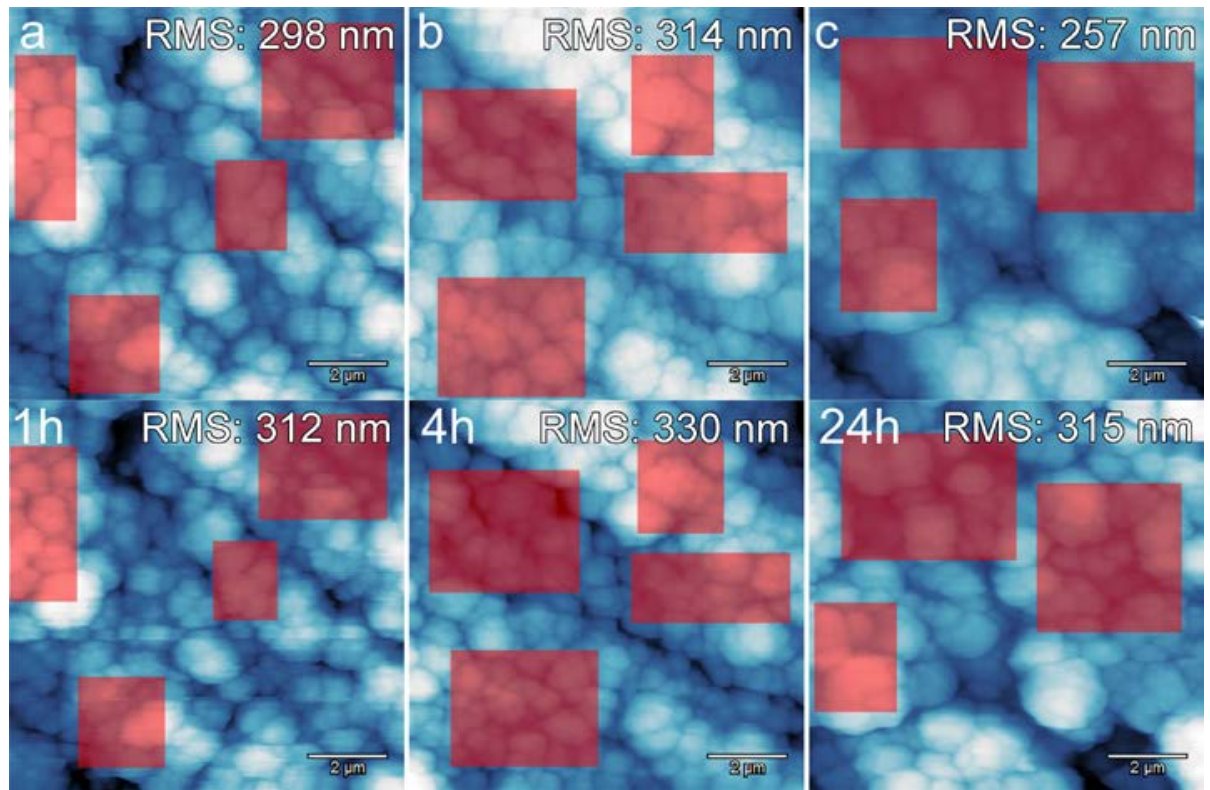

Figure 2.25: AFM images of Ni-Mo on Ti prior to (top line) and after (bottom line) electrocatalysis in $1 \mathrm{M} \mathrm{NaOH}$ for $1 \mathrm{~h}$ (a), $4 \mathrm{~h}$ (b) and $24 \mathrm{~h}$ (c). The red masked areas are the areas of which the averaged RMS value is given as noted in the images.

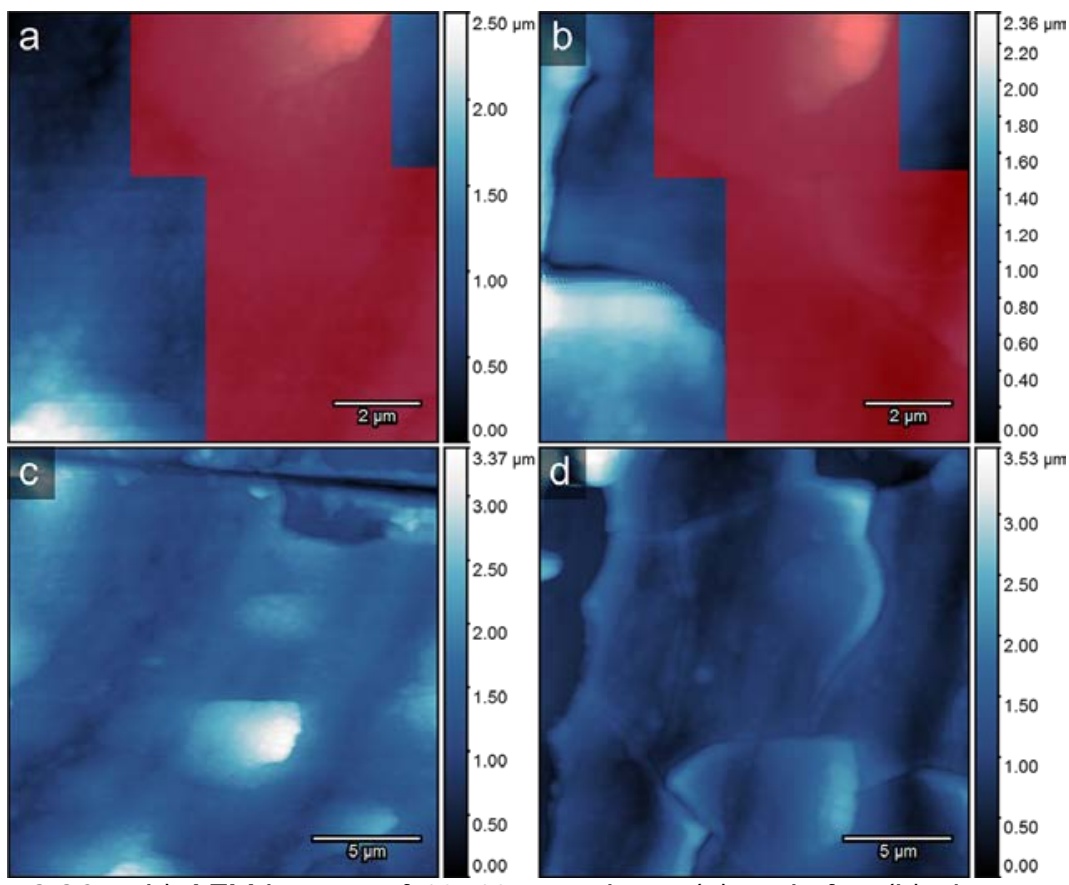

Figure 2.26: $a-b)$ AFM images of $10 \times 10 \mu m$ prior to (a) and after (b) electrocatalysis in $1 \mathrm{M} \mathrm{KOH}$. The red marked areas are the areas in which the RMS is determined. $\mathrm{c}$ d) AFM images of $20 \times 20 \mu \mathrm{m}$ illustrating the more significant changes of this sample, it shows significant cracking and chipping of the sample in the probed area. 
cut-off of $500 \mathrm{eV}$. Exchange-correlation interactions were described using the RPBE functional. ${ }^{[45]}$ For surface calculations, the Brillouin zone was sampled using a $4 \times 4 \times 1 \Gamma$-centered Monkhorst-Pack ${ }^{[46]}$ k-point mesh (6x6x6 was used for bulk $\mathrm{Ni}_{3} \mathrm{Mo}$, and $12 \times 12 \times 12$ was used for bulk Ni, Mo, $\mathrm{K}$, and $\mathrm{Na}$ ). $\mathrm{Ni}_{3} \mathrm{Mo}$ was chosen as a model system due to the 3:1 ratio found by SEM-EDX. Crystalline unit cells were used, considering it is likely microcrystalline domains are present. ${ }^{[47,48]}$ Predominant surface terminations and facets of $\mathrm{Ni}_{3} \mathrm{Mo}$ were determined using the Bravais-Friedel-Donnay-Harker (BFDH) algorithm. ${ }^{[49]}$ The facets (001), (010), and (100) were found to be equally likely, and so all three facets were considered in our theoretical studies. To consider the polycrystalline nature of the films, a stepped surface was also considered for vacancy formation, cation adsorption, and segregation energies.

Following the development of the computational hydrogen electrode ${ }^{[50]}$, we apply an analogous reference electrode for $\mathrm{Na}$ and $\mathrm{K}$. Metallic $\mathrm{Na}$ and $\mathrm{K}$ are in equilibrium with their ion electron pair at $-2.71 \mathrm{~V}$ vs SHE and $-2.93 \mathrm{~V}$ vs SHE, respectively. ${ }^{[51]}$ We can then simply write the free energy of the ion electron pair as follows:

$$
\begin{array}{cr}
\mathrm{Na}(\mathrm{s}) \rightarrow \mathrm{Na}^{+}+\mathrm{e}^{-} & \mathrm{U}_{0}=-2.71 \mathrm{~V} \text { vs SHE } \\
\mathrm{K}(\mathrm{s}) \rightarrow \mathrm{K}^{+}+\mathrm{e}^{-} & \mathrm{U}_{0}=-2.93 \mathrm{~V} \text { vs SHE } \\
\mu\left(\mathrm{K}^{+}\right)+\mu\left(\mathrm{e}^{-}\right)=\mu(\mathrm{K}(\mathrm{s}))-\mathrm{e}\left(\mathrm{U}-\mathrm{U}_{0}\right) \\
\mu\left(\mathrm{Na}^{+}\right)+\mu\left(\mathrm{e}^{-}\right)=\mu(\mathrm{Na}(\mathrm{s}))-\mathrm{e}\left(\mathrm{U}-\mathrm{U}_{0}\right)
\end{array}
$$

where $\mu$ refers to the chemical potential. The energy of $\mathrm{K}(\mathrm{s})$ and $\mathrm{Na}(\mathrm{s})$ can be trivially calculated using DFT, and so in this way we calculate the free energy of the ion electron pair.

\subsection{Author Contributions and Acknowledgements}

This Chapter is based on the following manuscript: Electrolyte Effects on the Stability of Nickel-Molybdenum Cathodes for the Hydrogen Evolution Reaction, J.H.J. Wijten, R.L. Riemersma, J. Gauthier, L.D.B. Mandemaker, M.W.G.M. Verhoeven, J.P. Hofmann, K. Chan, B.M. Weckhuysen, ChemSusChem 2019, 12, 3491-3500.

Jochem Wijten and Bert Weckhuysen conceived the research plans. Jochem Wijten and Romy Riemersma executed the experimental work under the supervision of Bert Weckhuysen. Joe Gauthier (Stanford School of Engineering \& SLAC) executed the theoretical work under the supervision of Karen Chan (DTU). Laurens Mandemaker performed the AFM measurements, while Tiny 
Verhoeven (TU/e) performed the XPS measurements under the supervision of Jan Philipp Hofmann (TU/e). Jochem Wijten wrote the work with the input of all co-authors and feedback and corrections by Bert Weckhuysen.

The following people are gratefully acknowledged: Coen Mulder (UU) and Christa van Oversteeg (UU) are thanked for the ICP-AES measurements and Oscar Kerkenaar (UU), Pascal Wijten (UU), and Herrick Schaink (UU) are gratefully acknowledged for the technical support related to the GC measurements.

\subsection{References}

[1] Krstajic, N. V, Jovic, V. D., Gajic-Krstajic, L., Jovic, B. M., Antozzi, A. L. \& Martelli, G. N., Int. J. Hydrogen Energy 2008, 33, 3676-3687

[2] Bigos, A., Beltowska-Lehman, E. \& Kot, M., Surf. Coat. Technol. 2017, 317, 103-109

[3] Abdel-Karim, R., Halim, J., El-Raghy, S., Nabil, M. \& Waheed, A., J. Alloys Compd. 2012, 530, 85-90

[4] Halim, J., Abdel-Karim, R., El-Raghy, S., Nabil, M. \& Waheed, A., J. Nanomater. 2012, 2012, 845673

[5] Schalenbach, M., Speck, F. D., Ledendecker, M., Kasian, O., Goehl, D., Mingers, A. M., Breitbach, B., Springer, H., Cherevko, S. \& Mayrhofer, K. J. J., Electrochim. Acta 2018, 259, 1154-1161

[6] McCrory, C. C. L., Jung, S., Ferrer, I. M., Chatman, S. M., Peters, J. C. \& Jaramillo, T. F., J. Am. Chem. Soc. 2015, 137, 4347-4357

[7] Gutic, S. J., Jovanovic, A. Z., Dobrota, A. S., Metarapi, D., Rafailovic, L. D., Pasti, I. A. \& Mentus, S. V, Int. J. Hydrogen Energy 2017, 43, 16846-16858

[8] Zhao, S., Huang, J., Liu, Y., Shen, J., Wang, H., Yang, X., Zhu, Y. \& Li, C., J. Mater. Chem. A 2017, 5, 4207-4214

[9] Wang, Y., Woodward, C., Zhou, S. H., Liu, Z. K. \& Chen, L. Q., Scr. Mater. 2005, 52, 17-20

[10] M., Jaramillo, T. F., Jørgensen, K. P., Bonde, J., Nielsen, J. H., Horch, S. \& Chorkendorff, I., Science 2007, 317, 100-103

[11] Yu, Y., Zhang, J., Xiao, W., Wang, J. \& Wang, L., Phys. Status Solidi Basic Res. 2017, 254, 1600810

[12] Yu, Y., Hu, Q., Xiao, W., Wang, J. \& Wang, L., Intermetallics 2018, 94, 99105

[13] Greeley, J., Nørskov, J. K., Kibler, L. A., El-aziz, A. M. \& Kolb, D. M., ChemPhysChem 2006, 7, 1032-1035

[14] Murase, K., Ogawa, M., Hirato, T. \& Awakura, Y., J. Electrochem. Soc. 2004, 151, C798-C805

[15] Sanches, L. S., Domingues, S. H., Marino, C. E. B. \& Mascaro, L. H., Electrochem. Commun. 2004, 6, 543-548

[16] Podlaha, E. J. \& Landolt, D., J. Electrochem. Soc. 1996, 143, 885-892

[17] Djokic, S., Electrodeposition and Surface Finishing, Springer, New York, 2014

[18] Kaninski, M. P. M., Saponjic, D. P., Nikolic, V. M., Zugic, D. L. \& Tasic, G. S., Int. J. Hydrogen Energy 2011, 36, 8864-8868

[19] Zhao, S., Huang, J., Liu, Y., Shen, J., Wang, H., Yang, X., Zhu, Y. \& Li, C., J. Mater. Chem. A Mater. Energy Sustain. 2017, 5, 4207-4214

[20] Kawashima, A., Sakaki, T., Habazaki, H. \& Hashimoto, K., Mater. Sci. Eng. 1999, 267, 246-253 
[21] Gonzalez-Buch, C., Herraiz-Cardona, I., Ortega, E., Garcia-Anton, J. \& PerezHerranz, V., J. Appl. Electrochem. 2016, 46, 791-803

[22] Tasic, G. S., Maslovara, S. P., Zugic, D. L., Maksic, A. D. \& Kaninski, M. P. M., Int. J. Hydrogen Energy 2011, 36, 11588-11595

[23] Hersbach, T. J. P., Mints, V. A., Calle-Vallejo, F., Yanson, A. I. \& Koper, M. T. M., Faraday Discuss. 2016, 193, 207-222

[24] Hersbach, T. J. P., Yanson, A. I. \& Koper, M. T. M., Nat. Commun. 2016, 7, 12653

[25] Csernica, P. M., Mckone, J. R., Mulzer, C. R., Dichtel, W. R., Abruna, H. D. \& DiSalvo, J., ACS Catal. 2017, 7, 3375-3383

[26] Janssen, M., Griffioen, E., Biesheuvel, P. M., van Roij, R. \& Erné, B., Phys. Rev. Lett. 2017, 119, 166002

[27] Trasatti, S. \& Petrii, O. A., J. Electroanal. Chem. 1992, 327, 353-376

[28] Hu L., Jeong S., Wakisaka M., Fujita J., Ito Y., Metals, 2018, 8, 83-91

[29] Liu K., Huang X., Pidko E. A., Hensen E. J. M., Green Chem. 2017, 17, 30143022

[30] Olivares, J. A. \& Houk, R. S., Anal. Chem. 1986, 58, 20-25

[31] Materialsproject.org 2018, Ni, Mo, K, Na

[32] Nørskov, J. K., Bligaard, T., Logadottir, A., Kitchin, J. R., Chen, J. G., Pandelov, S. \& Stimming, U., J. Electrochem. Soc. 2005, 152, J23-J26

[33] Hinnemann, B., Moses, P. G., Bonde, J., Jørgensen, K. P., Nielsen, J. H., Horch, S., Chorkendorff, I. \& Nørskov, J. K., J. Am. Chem. Soc. 2005, 127, 5308-5309

[34] Kibsgaard, J., Tsai, C., Chan, K., Benck, J. D., Nørskov, J. K., Abild-pedersen, F. \& Jaramillo, T. F., Energy Environ. Sci. 2015, 8, 3022-3029

[35] Greeley, J., Jaramillo, T. F., Bonde, J., Chorkendorff, I. \& Nørskov, J. K., Mater. Sus. Energy 2010, 280-284

[36] O'Hare, P. A. G., J. Chem. Thermo. 1974, 6, 425-434.

[37] Clark E. L., Resasco J., Landers A., Lin J., Chung L. T., Walton A., Hahn C., Jaramillo T. F. \& Bell A. T., ACS Catal. 2018, 8, 6560-6570

[38] Yi Y., Weinberg G., Prenzel M., Greiner M., Heumann S., Becker S. \& Schlögl R., Catal. Today, 2017, 295, 32-40

[39] Nečas, D. \& Klapetek, P., Open Phys. 2012, 10, 181-188

[40] Kresse, G. \& Hafner, J., Phys. Rev. B 1993, 47, 558-561

[41] Kresse, G. \& Furthmuller, J., Comp. Mater. Sci. 1996, 6, 15-50

[42] Kresse, G. \& Furthmuller, J., Phys. Rev. B 1996, 54, 11169-11186

[43] Kresse, G. \& Hafner, J., J. Phys. Condens. Matter. 1994, 6, 8245-8257

[44] Kresse, G. \& Joubert, D., Phys. Rev. B 1999, 59, 1758-1775

[45] Hammer, B., Hansen, L. B. \& No, J. K., Phys Rev B 1999, 59, 7413-7421

[46] Monkhorst, H. J. \& Pack, J. D., Phys Rev B 1976, 13, 5188-5192

[47] Hirotsu, Y., Uehara, M. \& Ueno, M., J. Appl. Phys. 1986, 59, 3081-3086

[48] Ichinose, H. \& Ishida, Y., Trans. Jpn. Inst. Met. 1983, 24, 405-412

[49] Dochertyt, R., Clydesdale, G., Roberts, K. J. \& Bennema, P., J. Phys. D Appl. Phys. 1991, 24, 89-99

[50] Nørskov, J. K., Rossmeisl, J., Logadottir, A., Lindqvist, L., Kitchin, J. R., Bligaard, T. \& Jonsson, H., J. Phys. Chem. B 2004, 108, 17886-17892

[51] Rumble, J., CRC Handbook of Chemistry \& Physics, 99th Ed., 2018, CRC Press, Boca Raton. 
"Dad? I was wondering about that water as a fuel thing you said." "What about it, son?"

I twiddle my thumbs a bit, "Well, I was wondering, how does it work?" "You use electricity to split it into hydrogen and oxygen, instead of, for example, powering that thing." He says, pointing at my laptop. "But you always said that combining water and electricity is dangerous." Dad chuckles: "It certainly is son, but with the proper techniques and handling it can be done, and safely to boot." "Really?" He gets up, "Really. You know what? There's a place where I can show you if you want; a son and dad trip?" Curiously, I get up as well. "Sure, why not." 


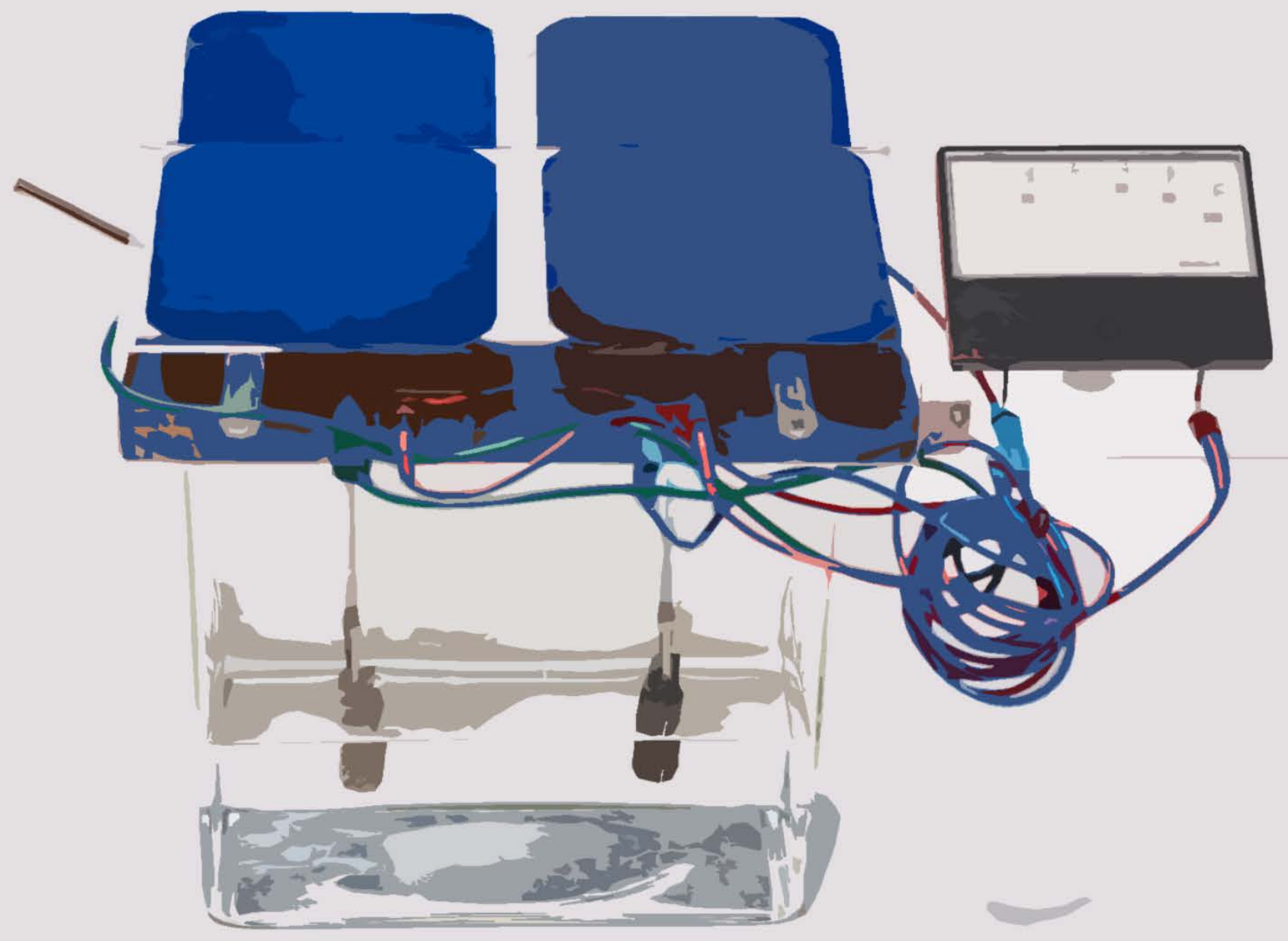




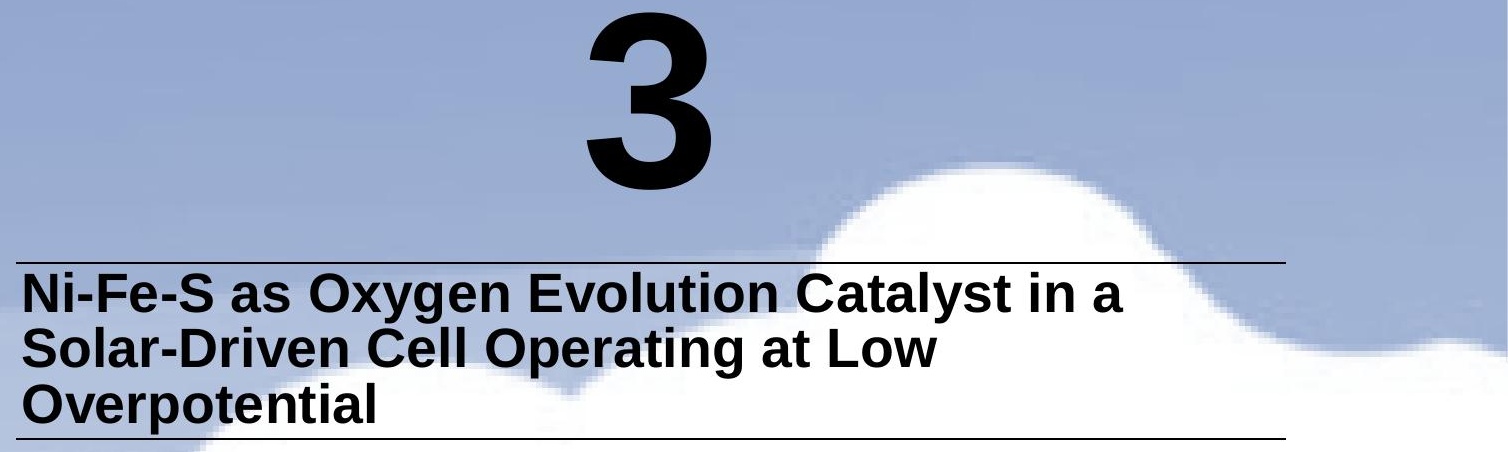

Non-noble metal electro-catalysts for water splitting are highly desired when we are moving towards a society where green electrons are becoming abundantly available, offering clear prospects to make our society more sustainable. In this PhD Chapter, Ni-Fe-S is reported as a high performing anode material for the water splitting reaction, operating at low overpotentials and showing high apparent stability. Furthermore, Ni-Mo electrodes are developed on metallic foam substrates and optimized in terms of their performance. The NiFe-S material as anode, combined and integrated with $\mathrm{Ni}-\mathrm{Mo}$ as cathode in a cell configuration, splits water at $10 \mathrm{~mA} / \mathrm{cm}^{2}$ and a potential of $1.55 \mathrm{~V}$. This configuration could be solely driven by solar panels with simple electrode size optimization. We confirm that Mo leaches from $\mathrm{Ni}-\mathrm{Mo} / \mathrm{Ni}$ foam electrodes similar to previous reports. Cycling tests and ICP-AES measurements show that the stability of $\mathrm{Ni}-\mathrm{Fe}-\mathrm{S}$ is apparent and that in reality, $\mathrm{S}$ is leaching from the material as was already suggested in literature. We expand on this knowledge and show that the leaching of $\mathrm{S}$ is dependent on both $\mathrm{pH}$ and the cation used during electrocatalysis. Furthermore, we find that applying an oxidative potential is in truth stabilizing towards $S$ and that the alkalinity causes leaching. $S$ was furthermore mobile and found to segregate towards the surface. Finally, using too low pH values (11 and lower) results in the passivating hydroxide metal layers being destroyed and the Ni-Fe-S completely dissolves. 


\subsection{Introduction}

One of the targets described in literature for solar-driven water splitting cells to achieve $10 \%$ solar-to-hydrogen (STH) efficiency is obtaining a combination of the hydrogen evolution reaction (HER) and the oxygen evolution reaction (OER) electrocatalysts, which operate at $10 \mathrm{~mA} / \mathrm{cm}^{2}$ (geometric surface area) with a total overpotential $\left(\eta_{10}\right)$ lower than $450 \mathrm{mV} \cdot{ }^{[1-4]} 10 \mathrm{~mA} / \mathrm{cm}^{2}$ is described as the current density output, which is typically found for solar driven water electrolyzers at 1 sun illumination. ${ }^{[1]}$

Importantly, the catalysts should maintain this low overpotential over an extended period of time to be viable to be used in water electrolyzers. ${ }^{[1]}$ Furthermore, it is desirable to produce catalysts based on earth-abundant materials. For example, Pt is the best known mono-metallic HER electrocatalyst [1], however, its scarcity and cost render it unsuitable for large-scale water splitting applications. Based on literature one of the best performing HER electrocatalysts is Ni-Mo, which approaches the activity of Pt-based catalysts. ${ }^{[1,5,6]}$ Whereas for OER, Ni-S ${ }^{[7-11]}$ and Ni-Fe ${ }^{[1,12]}$ have been found as good electrocatalysts, which usually have an overpotential at about 300-400 $\mathrm{mV}$ at $10 \mathrm{~mA} / \mathrm{cm}^{2}$. These materials still get trumped by $\mathrm{Ir}$ and $\mathrm{Ru}$ oxide catalysts; the latter of which reaches overpotentials of only $290 \mathrm{mV}$ at 10 $\mathrm{mA} / \mathrm{cm}^{2}{ }^{[1,713,14]} \mathrm{Ni}-\mathrm{Fe}-\mathrm{S}$ is recently studied as a promising water splitting anode material reaching lower reported overpotential values for OER down to 65 $m V{ }^{[15-19]}$ It should be noted that this low overpotential was, in part, due to the use of high surface area substrates ( $\mathrm{Ni}$ foam). ${ }^{[15]}$ Literature is currently in disagreement on the stability of Ni-Fe-S, however. ${ }^{[15-19]}$ Many state that the
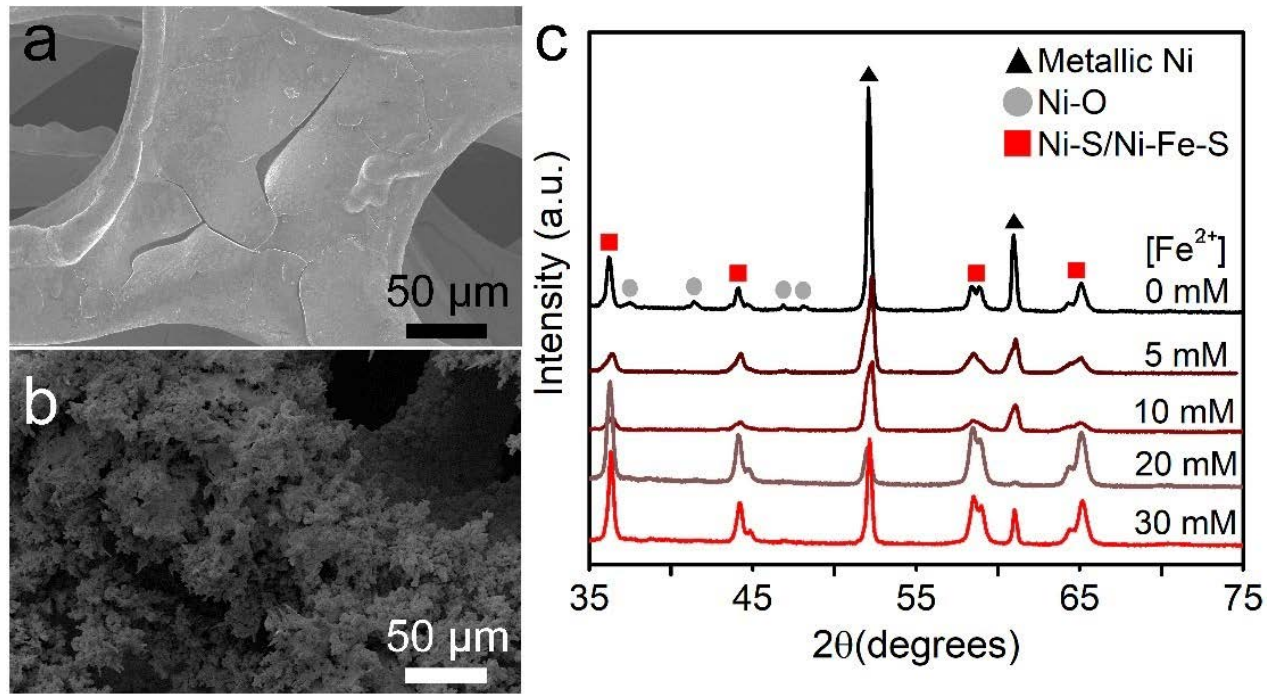

Figure 3.1: a) SEM of Ni-Mo coated on Ni foam. b) SEM of Ni-Fe-S coated on Ni foam from $20 \mathrm{mM} \mathrm{Fe}{ }^{2+}$ solutions. c) XRD patterns of Ni-Fe-S on Ni foam synthesized at varying $\left[\mathrm{Fe}^{2+}\right]$. Peaks are indicated for metallic Ni (black triangles), NiO (grey circles) and Ni-S/Ni-Fe-S (red squares). 
material is stable ${ }^{[16-19]}$, though despite the claims of stability a significant increase of about $150 \mathrm{mV}$ is seen over $200 \mathrm{~h}$ of continuous operation. ${ }^{[16]}$ The described mode of instability is $S$ destabilization in alkaline media. ${ }^{[15]}$ This mode of destabilization is also underlined by the fact that dissolving $\mathrm{Na}_{2} \mathrm{~S}$ in the electrolyte stabilizes the material. ${ }^{[19]}$

In this PhD Chapter, we combine HER and OER electrocatalysts operating at low overpotentials. We show that Ni-Mo as a HER electrocatalyst and Ni-Fe-S as an OER electrocatalyst can achieve a current density of $10 \mathrm{~mA} / \mathrm{cm}^{2}$ with an overpotential of only $320 \mathrm{mV}$, easily reaching the described target of overpotentials below $450 \mathrm{mV} .^{[1-4]}$ This goal is achieved by combining large surface areas per $\mathrm{cm}^{2}$ electrode through the use of metal foams with electrocatalysts. ${ }^{[9]}$ The catalysts are formed with simple and cheap one-step methods, being electrodeposition (Ni-Mo) and hydrothermal treatment (Ni-FeS). ${ }^{[7,9,11]}$ With scanning electron microscopy (SEM), energy dispersive

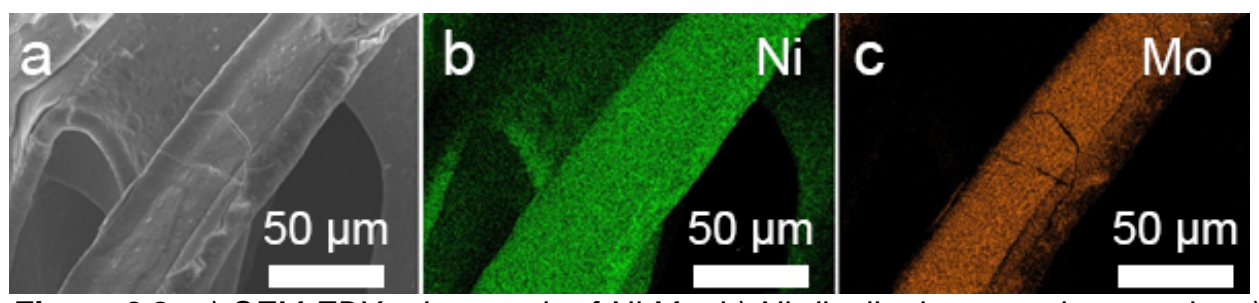

Figure 3.2: a) SEM-EDX micrograph of Ni-Mo. b) Ni distribution over the sample. c) Mo distribution over the sample.
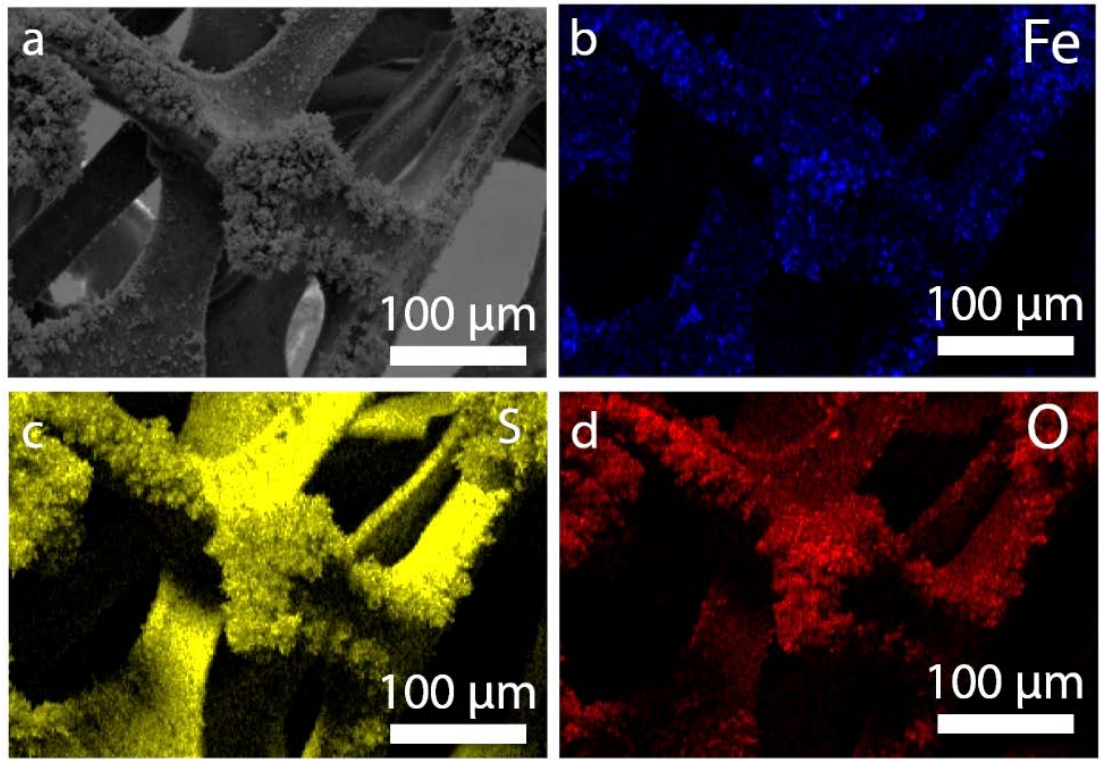

Figure 3.3: a) SEM-EDX micrograph of Ni-Fe-S. b) Fe distribution over the sample. c) $S$ distribution over the sample. d) O distribution over the sample. 
spectroscopy (EDX) and X-ray diffraction (XRD) we observe the desired phases. The performance is stable for a week in $1 \mathrm{M}$ alkaline solutions. Gas chromatography (GC) is used to confirm the Faradaic efficiency. Material stability was studied in detail and we found that $S$ leaches from the Ni-Fe-S material as a function of $\mathrm{pH}$ and electrolyte cations. Finally, we show the capability of this water splitting cell to be driven by actual photovoltaic (PV) cells.

\subsection{Results and Discussion}

\subsubsection{Ni-Mo vs Ni-Fe-S Water Splitting}

For Ni-Mo, homogeneous, amorphous coatings are formed via electrodeposition on high surface area $\left(5400 \mathrm{~m}^{2} / \mathrm{m}^{3}\right)$ Ni foams with a granular morphology containing several large cracks (Figure 3.1a), which is a typical morphology for these materials. ${ }^{[20-22]}$ With EDX an elemental distribution of 2:1 $\mathrm{Ni}$ :Mo was found; to minimize the contribution of the Ni foam substrate the $\mathrm{Ni}$ L-edge peak is used to determine this ratio (Figure 3.2). ${ }^{[23]} \mathrm{Ni}-\mathrm{Fe}-\mathrm{S}$ was prepared via a hydrothermal synthesis procedure (Figure 3.3). Sharp pyramidal morphologies (Figure 3.1b) form during synthesis. They form as a result of the addition of $\mathrm{Fe}$ and grew more prominent with increasing Fe concentrations during the synthesis (Figure 3.4). The increase of surface area, that is a result of these morphologies forming, is likely the reason that Fe improves the
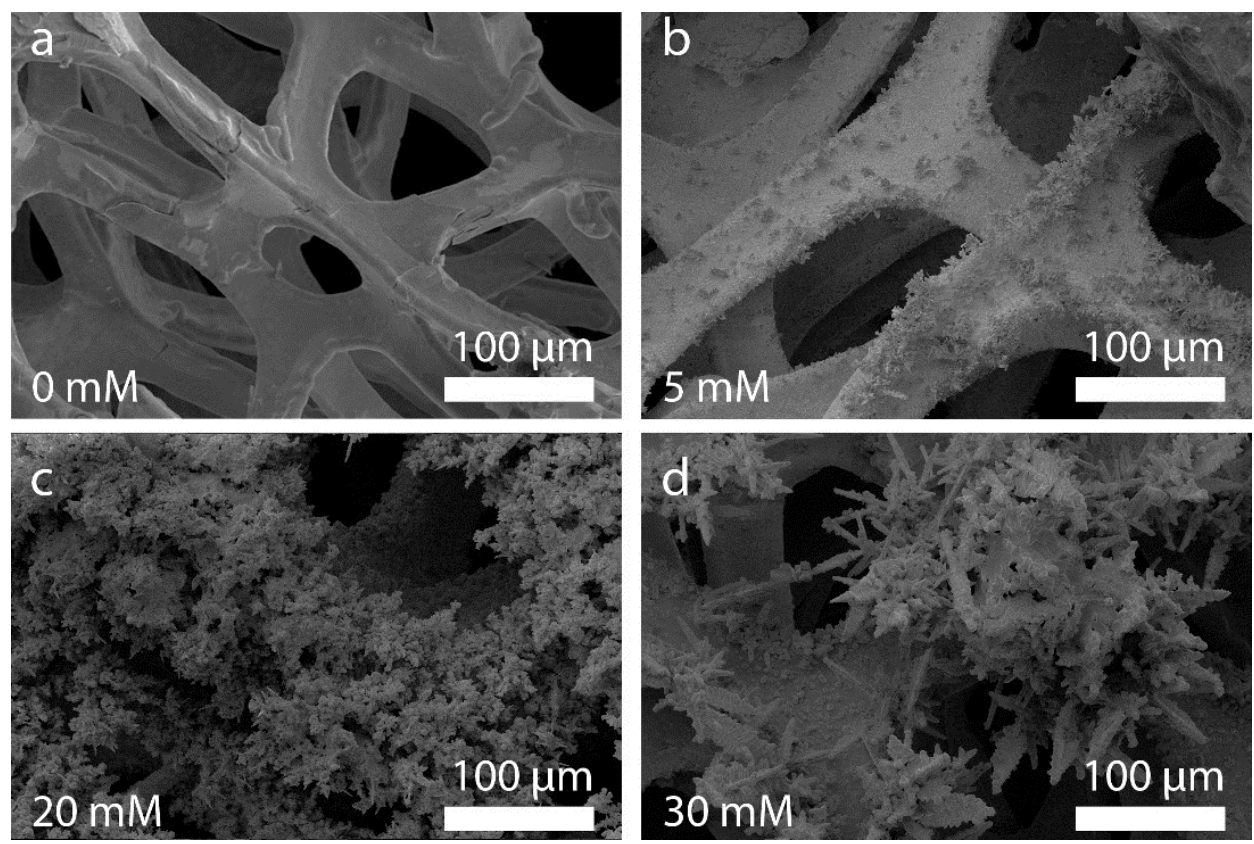

Figure 3.4: Effect of $\mathrm{FeSO}_{4}$ concentration, a) $0 \mathrm{mM}$, b) $5 \mathrm{mM}$, c) $20 \mathrm{mM}$, and d) 30 $m \mathrm{M}$, on the morphology of Ni-Fe-S. 

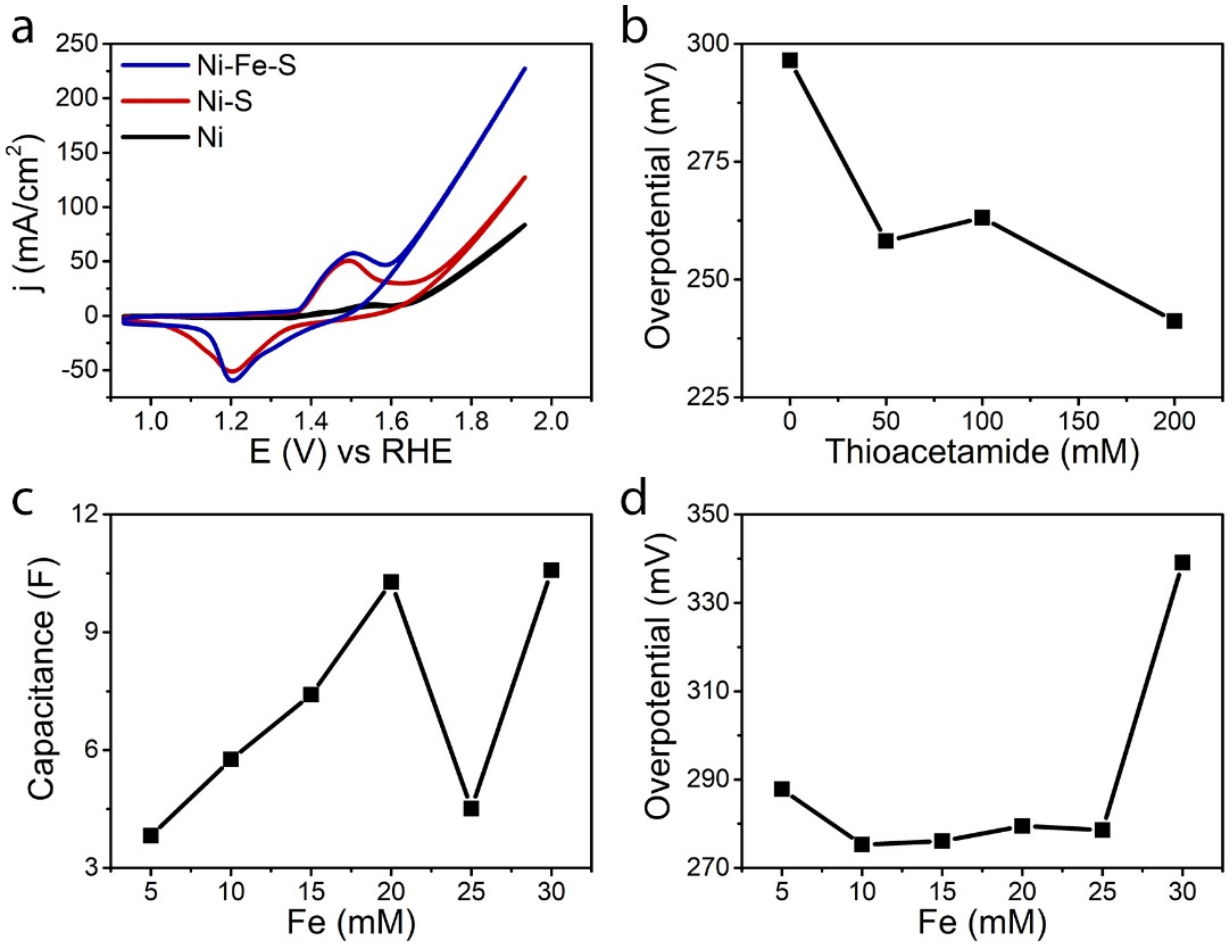

Figure 3.5: a) Comparison of CV's taken on bare Ni foam (black), Ni-S (red) and Ni-Fe$S$ (blue). b) The overpotential at $10 \mathrm{~mA} / \mathrm{cm}^{2}$ with increasing thioacetamide concentrations (10 $\mathrm{mM} \mathrm{FeSO}_{4}$ ). c) Increase of surface area, represented as the double layer capacitance slope, as a function of $\mathrm{FeSO}_{4}$ concentration during synthesis $(50 \mathrm{mM}$ thioacetamide). d) Behavior of the overpotential as a function of $\mathrm{FeSO}_{4}$ concentration (50 mM thioacetamide).

performance of these materials ${ }^{[24-28]}$. Fe is concentrated in the pyramids, as shown by EDX, while $\mathrm{S}$ and $\mathrm{Ni}$ are homogeneously distributed over the material (Figure 3.3).

Using XRD (Figure 3.1c) it was found the formed Ni-Fe-S anodes are crystalline. The XRD peaks belonging to metallic Ni decrease in intensity with increasing Fe concentration, while XRD peaks ascribed to the Ni-Fe-S phase increase in intensity with increasing Fe concentration. This material forms the same crystal structure as Ni-S but with a slightly smaller unit cell as observed by the peaks being at slightly higher diffraction angles. ${ }^{[29]}$

Various experimental parameters for the synthesis of Ni-Fe-S were varied to optimize the performance (Figure 3.5). Figure 3.5a shows that Ni-Fe-S outperforms Ni-S which in turn outperforms bare Ni foam. In each case, a reversible peak is seen at $1.49 \mathrm{~V}\left(\mathrm{Ni}^{2+} \rightarrow \mathrm{Ni}^{3+}\right)$ and $1.20 \mathrm{~V}\left(\mathrm{Ni}^{3+} \rightarrow \mathrm{Ni}^{2+}\right)$. The observed overpotential towards OER for this material decreased with 

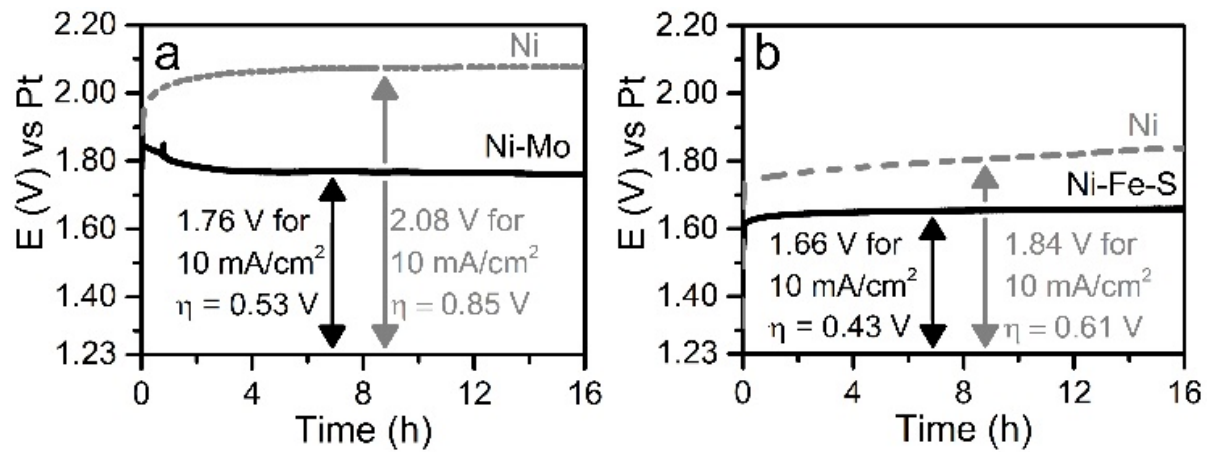

Figure 3.6: a) Chrono-potentiometry of Ni (grey, dashed) and Ni-Mo (black, solid) at $10 \mathrm{~mA} / \mathrm{cm}^{2}$ for $16 \mathrm{~h}$ using the materials as cathode with a Pt mesh as anode in a 2electrode cell configuration. b) Chrono-potentiometry of Ni (grey, dashed) and Ni-Fe$\mathrm{S}$ (black, solid) at $10 \mathrm{~mA} / \mathrm{cm}^{2}$ for $16 \mathrm{~h}$ using the materials as anode with a Pt mesh as cathode. Both experiments are performed in $1 \mathrm{M} \mathrm{NaOH}$ in a 2-electrode cell configuration.

increasing S content, as shown by the amount of thioacetamide added (Figure 3.5b). Adding more thioacetamide than $210 \mathrm{mM}$ resulted in significant embrittlement of the foam, however, and yielded electrodes not usable in electrochemistry. On the other hand, adding more $\mathrm{Fe}^{2+}$ into the electrode resulted in an increase in the capacitive slope found with double layer capacitance measurements (Figure 3.5c), suggesting an increase of surface area, agreeing with SEM (Figure 3.4). It had little influence on the overpotential up to $30 \mathrm{mM} \mathrm{FeSO}_{4}$ where a large loss of efficiency was observed (Figure 3.5d). This tells us that the $S$ acts as a synergetic compound, increasing the activity whereas Fe serves to increase the surface area of the material.

The materials were then tested towards their respective reactions and, as shown in Figure 3.6, compared to bare, uncoated Ni foam. Ni-Mo vs Pt (Figure 3.6a) increased significantly in performance, reaching $\eta_{10}$ values as low as 530 $\mathrm{mV}$, compared to $850 \mathrm{mV}$ when testing Ni vs Pt; an improvement of $320 \mathrm{mV}$. The Ni-Mo material has a short activation time of $2 \mathrm{~h}$, which is a result of Mo leaching and a resulting increase of electrochemically active surface area. ${ }^{[30]}$ The anode: Ni-Fe-S, when tested vs Pt (Figure 3.6b) operates at an overpotential of $430 \mathrm{mV}$, compared to $610 \mathrm{mV}$ for bare $\mathrm{Ni}$ vs Pt, improving by $180 \mathrm{mV}$. The tests with Pt as cathode have a significantly lower overpotential since Pt performs better towards the HER than the OER. ${ }^{[1]}$ In the case of NiFe-S, there is a small increase in overpotential during the first hours of operation, being a result of oxidation to $\mathrm{Ni}(\mathrm{Fe}, \mathrm{S}) \mathrm{OOH}$ surfaces. ${ }^{[31-33]}$

The OER and HER materials were combined in an integrated manner to test the performance of the combined setup for an entire week. As can be observed in Figure 3.7a the materials perform at a stable overpotential of $320 \mathrm{mV}$. The combination of these materials also shows an activation period like the 

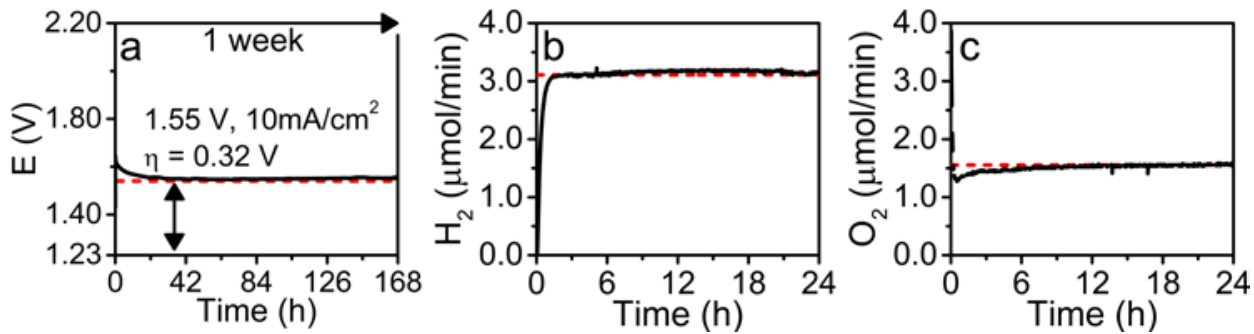

Figure 3.7: a) Chrono-potentiometry in $1 \mathrm{M} \mathrm{NaOH}$ of Ni-Mo (HER) versus Ni-Fe-S $(O E R)$ and the corresponding stability over the course of $168 \mathrm{~h}$ in a 2-electrode cell configuration, the red dashed line is set at $1.55 \mathrm{~V}$. b) Hydrogen evolution in $\mu \mathrm{mol} / \mathrm{min}$ (black) showing also the expected amount (Faradaic Efficiency of $101 \%$, red dashed) measured in the $\mathrm{H}$-cell. c) Oxygen evolution in $\mu \mathrm{mol} / \mathrm{min}$ (black) showing also the expected amount (Faradaic Efficiency of $100 \%$, red dashed) measured in the H-cell.

Table 3.1: Amounts of $\mu$ mol leached into $1 \mathrm{M} \mathrm{NaOH}$ electrolytes as found by ICP-AES for $\mathrm{Ni}, \mathrm{Fe}, \mathrm{S}$ and Mo for various combinations of electrodes after $16 \mathrm{~h}$ of operation (168 $h$ for Ni-Mo vs Ni-Fe-S).

\begin{tabular}{l|l|l|l|l} 
HER vs OER & $\begin{array}{l}\text { Ni }(\mu \mathrm{mol} \\
\text { leached })\end{array}$ & $\begin{array}{l}\text { Fe }(\mu \mathrm{mol} \\
\text { leached })\end{array}$ & $\begin{array}{l}\mathrm{S}(\mu \mathrm{mol} \\
\text { leached })\end{array}$ & $\begin{array}{l}\text { Mo }(\mu \mathrm{mol} \\
\text { leached })\end{array}$ \\
\hline Ni Vs Pt $(16 \mathrm{~h})$ & 0.084 & 0.003 & -0.050 & 0.069 \\
\hline Pt vs Ni $(16 \mathrm{~h})$ & 0.084 & 0.012 & 0.048 & 0.017 \\
\hline Pt vs Ni-Fe-S $(16 \mathrm{~h})$ & 0.073 & 0.004 & 5.999 & 0.010 \\
\hline Ni-Mo vs Pt $(16 \mathrm{~h})$ & 0.081 & 0.000 & -0.102 & 3.189 \\
\hline Ni-Mo vs Ni-Fe-S (168 h) & 0.064 & 0.035 & 12.319 & 2.724
\end{tabular}

separate materials, however, it is observable over a much longer timescale of $30 \mathrm{~h}$. Faradaic Efficiency (FE) experiments show that we reach a value of 101.2 $\%$ for HER (Figure 3.7b) and a value of $99.7 \%$ for OER (Figure 3.7c); both values are very close to the aimed value of $100 \%$. However, there was some small leaching of Mo and S from the respective samples, as observed by ICP-
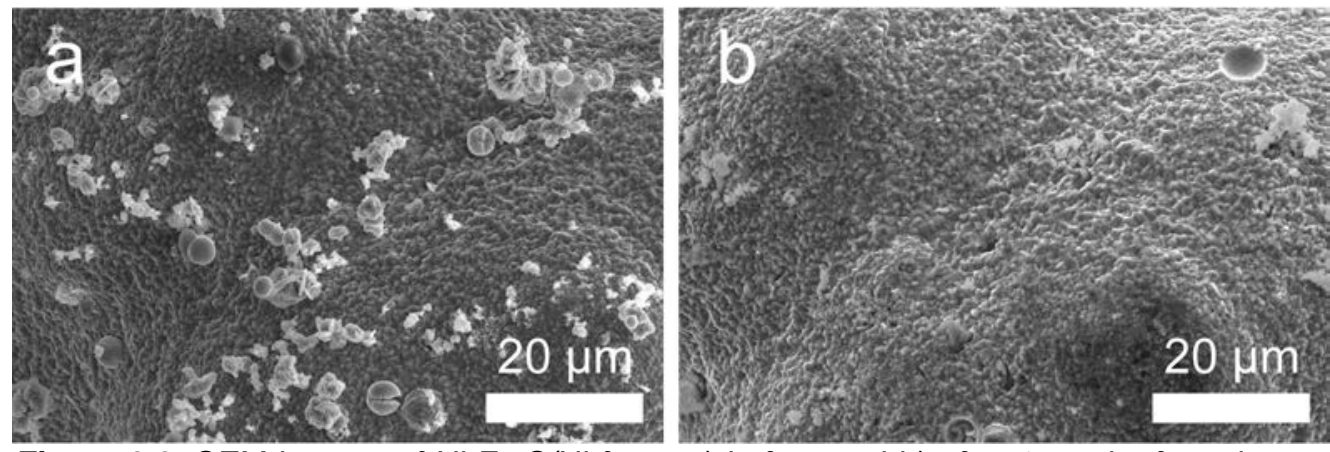

Figure 3.8: SEM images of Ni-Fe-S/Ni foam a) before and b) after 1 week of continuous operation at $10 \mathrm{~mA} / \mathrm{cm}^{2}$ in $1 \mathrm{M} \mathrm{KOH}$ vs Ni-Mo/Ni foam. 
AES (Table 3.1). ${ }^{[30]}$ As can be observed, no significant amounts of $\mathrm{Ni}$ or $\mathrm{Fe}$ leach in any of the combinations of materials. $S$ does leach somewhat from the $\mathrm{Ni}-\mathrm{Fe}-\mathrm{S}$ material, most significant in the first $16 \mathrm{~h}$ of electrolysis, but continues for longer timescales to $12 \mu \mathrm{mol}$ after 1 week. Mo also leaches, as was previously found ${ }^{[30]}$, and it leaches predominantly in the first hours of operation since no increase in leaching is found after 1 week of operation compared to $16 \mathrm{~h}$. Values were measured as $\mathrm{mg} / \mathrm{kg}$ and corrected to take into account the 1.1x dilution with $\mathrm{HNO}_{3}$ and the total volume of $100 \mathrm{~mL}$.

In Figure 3.8 SEM is shown of Ni-Mo/Ni foam and Ni-Fe-S/Ni foam after the test of a week. As can be seen, the main surface of the material does not change noticeably. The small particulate matter that is present prior to catalysis has mostly disappeared as was found to consist mostly of Fe with EDX, which explains the observed Fe in solution with ICP-AES.

The leaching of $\mathrm{S}$ and Mo at a continuous current led us to do a stability test via cyclic voltammetry, measuring 1000 cycles at a scan rate of $50 \mathrm{mV} / \mathrm{s}$ to simulate current intermittency at a sped up rate. As can be seen in Figure 3.9 there is an obvious difference between the initial cycle and later cycles where the $\mathrm{Ni}^{2+} \rightarrow \mathrm{Ni}^{3+}$ peak at $1.4 \mathrm{~V}$ grew significantly, after which slow growth

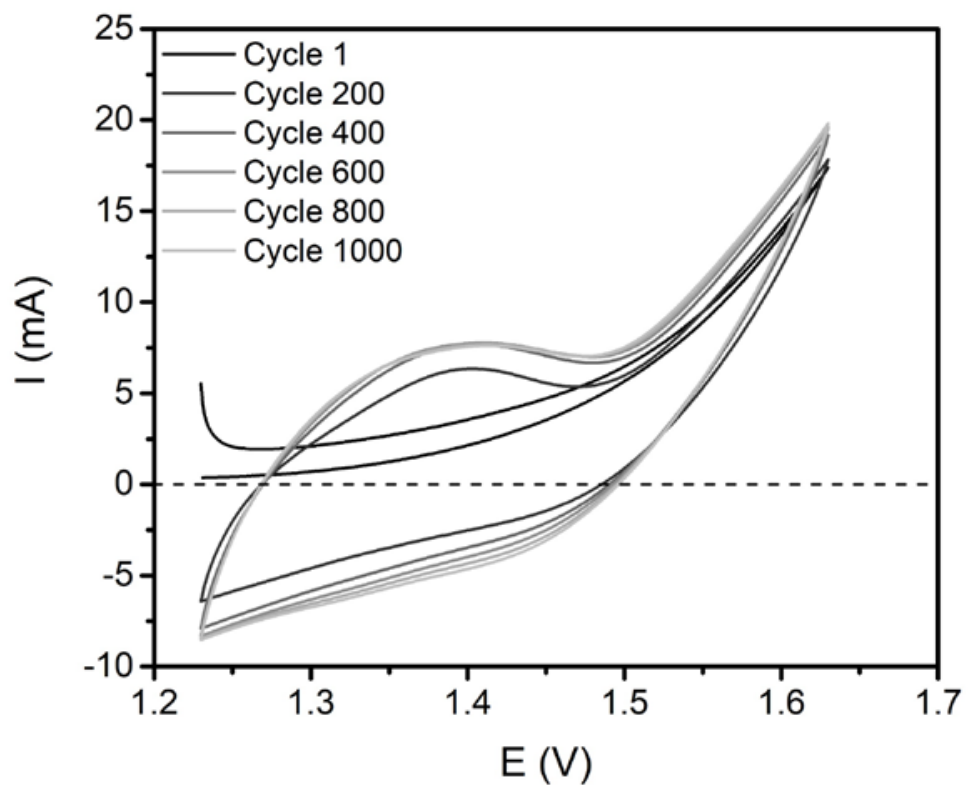

Figure 3.9: Cyclic voltammograms of continuous cycling for 1000 cycles of Ni-Mo vs $\mathrm{Ni}$-Fe-S. Cycles are shown every 200 cycles. A large change was seen in the first few cycles, where the $\mathrm{Ni}^{2+} \rightarrow \mathrm{Ni}^{3+}$ peak became more prominent which was fairly stable after. Nevertheless a slow increase of this peak as well as the OER current was observed over the course of cycling. 
continued during the cycling. The OER current increased slowly likewise but was predominantly stable. This shows us that though the material is clearly unstable it has a stable performance.

\subsubsection{Electrolyte effects on Ni-Fe-S Stability}

The observation of the material being unstable, without significantly changing the OER performance led us to believe that the $S$ leaching behaves similar to the Mo leaching observed in Chapter 2. Likewise, we chose to study whether this leaching is dependent on the electrolyte. In Figure 3.10 the effect of $\mathrm{pH}$, as well as the cation, is studied. As can be seen, the activity of these materials is mostly independent on the cation used. The $\mathrm{pH}$, expectedly influences the activity: higher $\mathrm{pH}$ means higher activity. To exclude this being an ion density effect we also tested the materials in $0.1 \mathrm{M} \mathrm{MOH}$ with $0.45 \mathrm{M} \mathrm{M}_{2} \mathrm{SO}_{4}$ electrolytes, maintaining $1 \mathrm{M}$ of $\mathrm{M}^{+}$and though these samples perform better, as could be expected, it does not bring them to the level of those operated in 1 $\mathrm{M} \mathrm{MOH}$. It is well studied that the $\mathrm{OH}^{-}$concentration improves the OER, since it reacts via $4 \mathrm{OH}^{-} \rightarrow 2 \mathrm{H}_{2} \mathrm{O}+\mathrm{O}_{2}+4 \mathrm{e}^{-[1]}$ Furthermore, employing $\mathrm{M}_{2} \mathrm{SO}_{4}$ allowed us to study if $\mathrm{SO}_{4}{ }^{2-}$ could have a stabilizing function similar to $\mathrm{S}^{2-} .{ }^{[19]}$

In Figure 3.10 the change in double layer capacitance is shown as well. As already explained in Chapter 2, the capacitance is often used as a measure of surface area. We opt, however, to use it as a measure of surface change, as we already found that changing surface composition has a large impact as well. Whereas the activity was not visibly influenced the change in capacitance is. First of all, we see a significant increase in capacitance in all samples, which is in the order of a tenfold increase. However, it can clearly be observed that the final capacitance found in $\mathrm{KOH}$ is significantly lower than the one found for $\mathrm{NaOH}$ and $\mathrm{LiOH}$. Especially at $\mathrm{pH} 14$ the difference in $\mathrm{K}$ and $\mathrm{Na}$ containing electrolytes is clear. Interestingly, at $\mathrm{pH} 14.8$ the materials end up at a similar value of $1.57 \mathrm{mF}(\mathrm{KOH})$ and $1.83 \mathrm{mF}(\mathrm{NaOH})$, despite the vast difference in starting capacitance $(0.16 \mathrm{mF}$ for $\mathrm{KOH}, 0.93 \mathrm{mF}$ for $\mathrm{NaOH})$. This strongly suggests that $\mathrm{pH}$ and cation have a significantly stronger effect on the catalyst surface than the starting point for said surface.

As was the case with Ni-Mo HER electro-catalysts, this observation of a changing catalyst surface led us to suspect that leaching occurs. In Table 3.2 we listed the values found for $\mathrm{Ni}$, Fe and $\mathrm{S}$ after $24 \mathrm{~h}$ of catalysis. Interestingly, for the catalysts operated at $\mathrm{pH} 14.8$ a metallic plating was found on the Au counter electrode. This plating was dissolved and measured separately as shown in Table 3.2. It was found to mostly consist of Fe and $\mathrm{S}$ with traces of Ni. Unfortunately, the $\mathrm{pH} 14.8 \mathrm{KOH}$ electrolyte crystallized upon preparation for ICP-AES, resulting in it being unmeasurable by ICP-AES. Assuming the ratio 

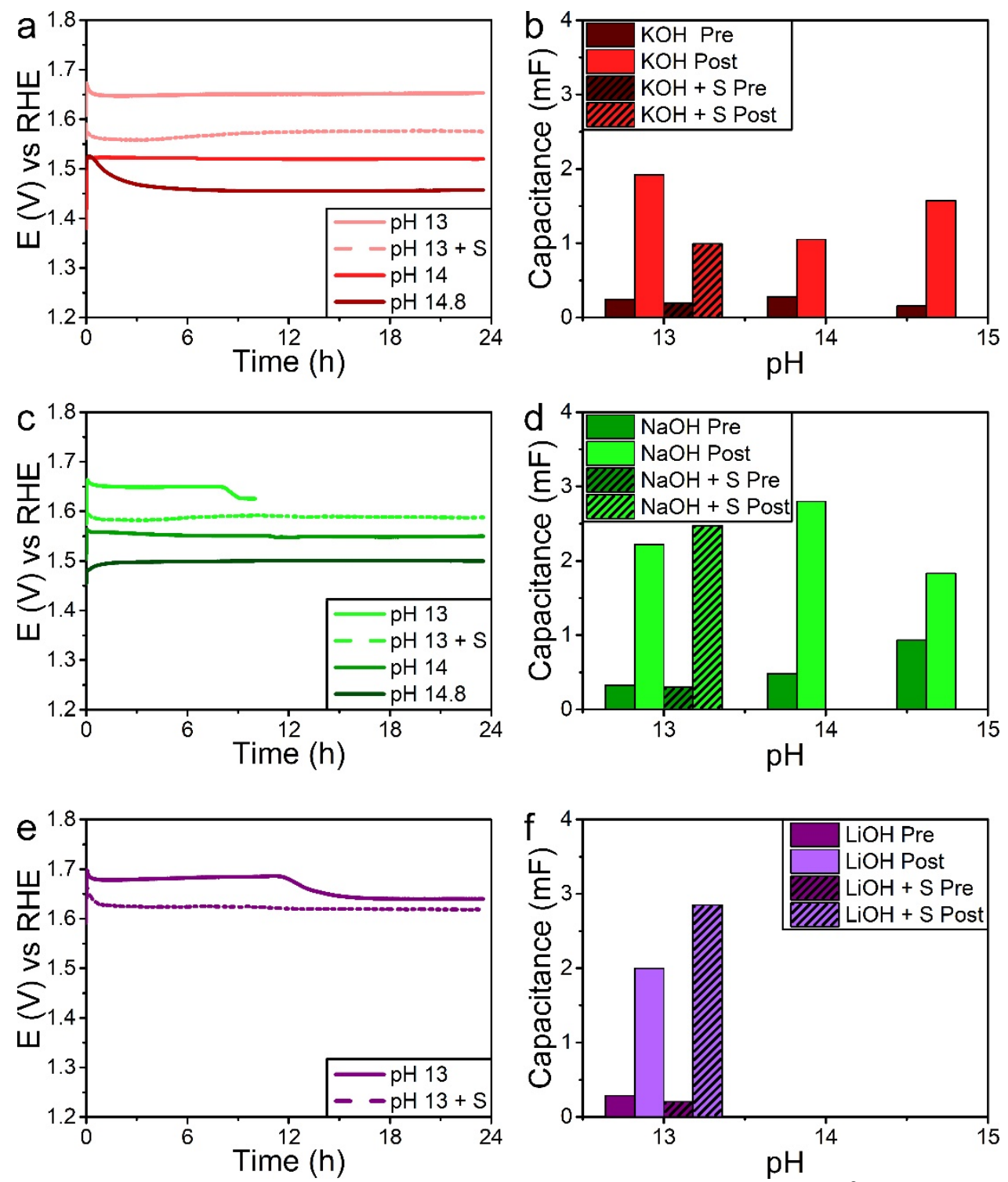

Figure 3.10: a) Chrono-potentiometry of $\mathrm{Ni}-\mathrm{Fe}-\mathrm{S} / \mathrm{Ni}$ foam at $10 \mathrm{~mA} / \mathrm{cm}^{2}$ operated in $\mathrm{KOH}$ electrolytes of different $\mathrm{pH}$. b) Double layer capacitance found before (dark red) and after (bright red) $24 \mathrm{~h}$ at $10 \mathrm{~mA} / \mathrm{cm}^{2}$ at different $\mathrm{pH}$ values in $\mathrm{KOH}$ electrolytes. $\mathrm{c}$ ) Chrono-potentiometry of $\mathrm{Ni}-\mathrm{Fe}-\mathrm{S} / \mathrm{Ni}$ foam at $10 \mathrm{~mA} / \mathrm{cm}^{2}$ operated in $\mathrm{NaOH}$ electrolytes of different $\mathrm{pH}$. For $\mathrm{pH} 13$ data collection stopped after $10 \mathrm{~h}$, but it was confirmed water electrolysis continued for the full $24 \mathrm{~h}$. d) Double layer capacitance found before (dark green) and after (bright green) $24 \mathrm{~h}$ at $10 \mathrm{~mA} / \mathrm{cm}^{2}$ at different $\mathrm{pH}$ values in $\mathrm{NaOH}$ electrolytes. e) Chrono-potentiometry of Ni-Fe-S/Ni foam at $10 \mathrm{~mA} / \mathrm{cm}^{2}$ operated in $\mathrm{LiOH}$ electrolytes at $\mathrm{pH}$ 13. f) Double layer capacitance found before (dark purple) and after (bright purple) $24 \mathrm{~h}$ at $10 \mathrm{~mA} / \mathrm{cm}^{2}$ in $\mathrm{pH} 13 \mathrm{LiOH}$ electrolytes. In all figures the $\mathrm{pH}$ $13+S$ samples contain $0.45 \mathrm{M} \mathrm{M}_{2} \mathrm{SO}_{4}$ to maintain a $1 \mathrm{M} \mathrm{M}^{+}$concentration. 
of plating on $\mathrm{Au}$ and solutes in the electrolyte are similar we estimated the values as shown in Table 3.2. We find that, in line with the capacitance change, in $\mathrm{KOH}$ leaching occurs least in the order of $\mathrm{K}<\mathrm{Li}<\mathrm{Na}$ at $\mathrm{pH} 13$. The trend of leaching being $\mathrm{K}<\mathrm{Na}$ holds for $\mathrm{pH} 14$ as well. At $\mathrm{pH} 14.8$ there is more leaching into $\mathrm{KOH}$ than is into $\mathrm{NaOH}$, which is again in line with the capacitance. The trend of $\mathrm{pH}$ with leaching is similar to the one observed with the capacitance: $\mathrm{pH} 14.8 \mathrm{NaOH}$ being lowest, though it should be noted that the starting capacitance for this material was significantly higher than most samples. This is followed by $\mathrm{pH} 14 \mathrm{KOH}$ being low, as is seen in the capacitance as well. Going to lower $\mathrm{pH}$ values for $\mathrm{KOH}$ resulted in increased leaching. Going to even lower values than reported in Figure 3.10 and Table 3.2, namely pH 11, resulted in the $\mathrm{Ni}-\mathrm{Fe}-\mathrm{S} / \mathrm{Ni}$ foam being too unstable and the 'acidity' of the solution resulted in the entire exposed material, Ni foam included, to be dissolved, and subsequently precipitated as a slimy green solid. Almost no Fe $(0.012 \mu \mathrm{mol})$ was found in the solution, while relatively high amounts of $\mathrm{Ni}(0.215 \mu \mathrm{mol})$ remained. No comments can be made on $\mathrm{S}$ as $0.5 \mathrm{M} \mathrm{K}_{2} \mathrm{SO}_{4}$ was present to maintain electrolyte conductivity. Both the $\mathrm{Ni}$, nor $\mathrm{Fe}$, amounts in solution were high enough to account for the entire material to be dissolved, and thus the precipitation contains both, likely being the hydroxides of both.

Interestingly, when no current is applied while the Ni-Fe-S catalyst is in the electrolyte leaching is approximately double for all three elements present after

Table 3.2: Amount of Ni, Fe, S, and Mo leached into the electrolyte as detected by ICPAES after electrocatalysis for 24 hours unless noted otherwise. ${ }^{a}$ These values are estimated based on the ratio of plating and electrolyte concentration of $\mathrm{NaOH}$ at ph 14.8. ${ }^{b}$ In this electrolyte both a Ni-Fe-S/Ni foam and Ni-Mo/Ni foam sample were present.

\begin{tabular}{l|l|l|l|l} 
& $\begin{array}{l}\text { Ni }(\mu \mathrm{mol} \\
\text { leached) }\end{array}$ & $\begin{array}{l}\text { Fe }(\mu \mathrm{mol} \\
\text { leached })\end{array}$ & $\begin{array}{l}\mathrm{S} \quad(\mu \mathrm{mol} \\
\text { leached) }\end{array}$ & $\begin{array}{l}\text { Mo }(\mu \mathrm{mol} \\
\text { leached })\end{array}$ \\
\hline $\mathrm{KOH} \mathrm{pH} \mathrm{13}$ & 0.026 & 0.113 & 7.104 & - \\
\hline $\mathrm{KOH} \mathrm{pH} \mathrm{14}$ & 0.019 & 0.134 & 4.226 & - \\
\hline $\mathrm{KOH} \mathrm{pH} \mathrm{14.8}$ & 0.046 & 0.850 & 16.336 & - \\
\hline $\begin{array}{l}\mathrm{KOH} \mathrm{pH} \mathrm{14.8} \\
\text { plating on Au }\end{array}$ & 0.180 & 9.430 & 18.684 & - \\
\hline $\begin{array}{l}\mathrm{KOH} \mathrm{pH} \mathrm{14,} \mathrm{24} \mathrm{h,} \\
\text { no current }\end{array}$ & 0.030 & 0.330 & 8.918 & - \\
\hline $\begin{array}{l}\mathrm{KOH} \mathrm{pH} \mathrm{14,} \mathrm{1} \\
\text { week, no current }\end{array}$ & 0.103 & 0.306 & 31.209 & 2.345 \\
\hline \hline $\mathrm{NaOH} \mathrm{pH} \mathrm{13}$ & 0.012 & 0.133 & 9.730 & - \\
\hline $\mathrm{NaOH} \mathrm{pH} \mathrm{14}$ & 0.008 & 0.215 & 17.264 & - \\
\hline $\mathrm{NaOH} \mathrm{pH} \mathrm{14.8}$ & 0.018 & 0.345 & 3.141 & - \\
\hline $\begin{array}{l}\mathrm{NaOH} \mathrm{pH} \mathrm{14.8} \\
\text { plating on Au }\end{array}$ & 0.070 & 3.826 & 3.592 & - \\
\hline \hline $\mathrm{LiOH} \mathrm{pH} \mathrm{13}$ & 0.007 & 0.072 & 8.38 & -
\end{tabular}



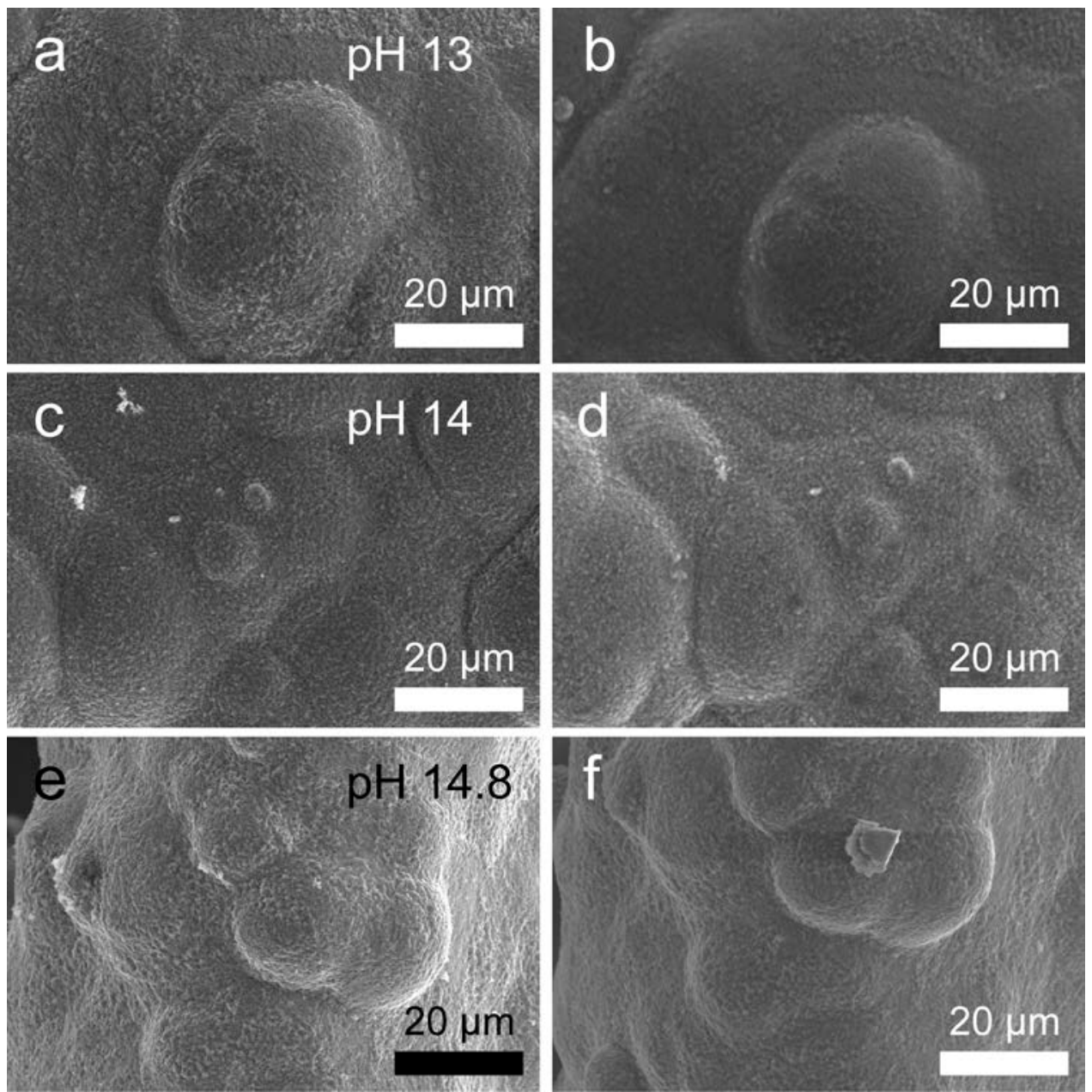

Figure 3.11: SEM micrographs of Ni-Fe-S/Ni foam of a) fresh and b) spent in $\mathrm{pH} 13$ $\mathrm{KOH}$ for $24 \mathrm{~h}, \mathrm{c}$ ) fresh and d) spent in $\mathrm{pH} 14 \mathrm{KOH}$ for $24 \mathrm{~h}$, and e) fresh and f) spent in $\mathrm{pH} 14.8 \mathrm{KOH}$ for $24 \mathrm{~h}$.

$24 \mathrm{~h}$. Similarly, when the sample is submerged for 1 week, the leaching is higher for all elements (compared to Table 3.1) except for Mo, which comes from the Ni-Mo sample also present in this experiment. Mo leaching being increased slightly by the application of current was already found in Chapter 2 and thus in line with previous results. This observation strongly suggests that the application of an oxidative potential on the system suppresses the leaching. The expected modes of leaching for $\mathrm{Ni}$ and $\mathrm{Fe}$ are oxidative $\left(\mathrm{M} \rightarrow \mathrm{M}^{\mathrm{x}+}+\mathrm{x}^{-}\right)$. This leaching mode is likely why it destabilized at pH 11 and subsequently precipitated as hydroxides. At higher $\mathrm{pH}$ values it is well known from corrosion studies that passivating oxide/hydroxide layers $\left(\mathrm{MOOH}, \mathrm{M}(\mathrm{OH})_{2}\right)$ are formed. ${ }^{[34-36]} \mathrm{S}$ leaching is likely to occur via $\mathrm{H}_{2} \mathrm{O}\left(\mathrm{S}+2 \mathrm{H}_{2} \mathrm{O} \rightarrow \mathrm{S}^{2-}+2 \mathrm{OH}^{-}\right)$ 


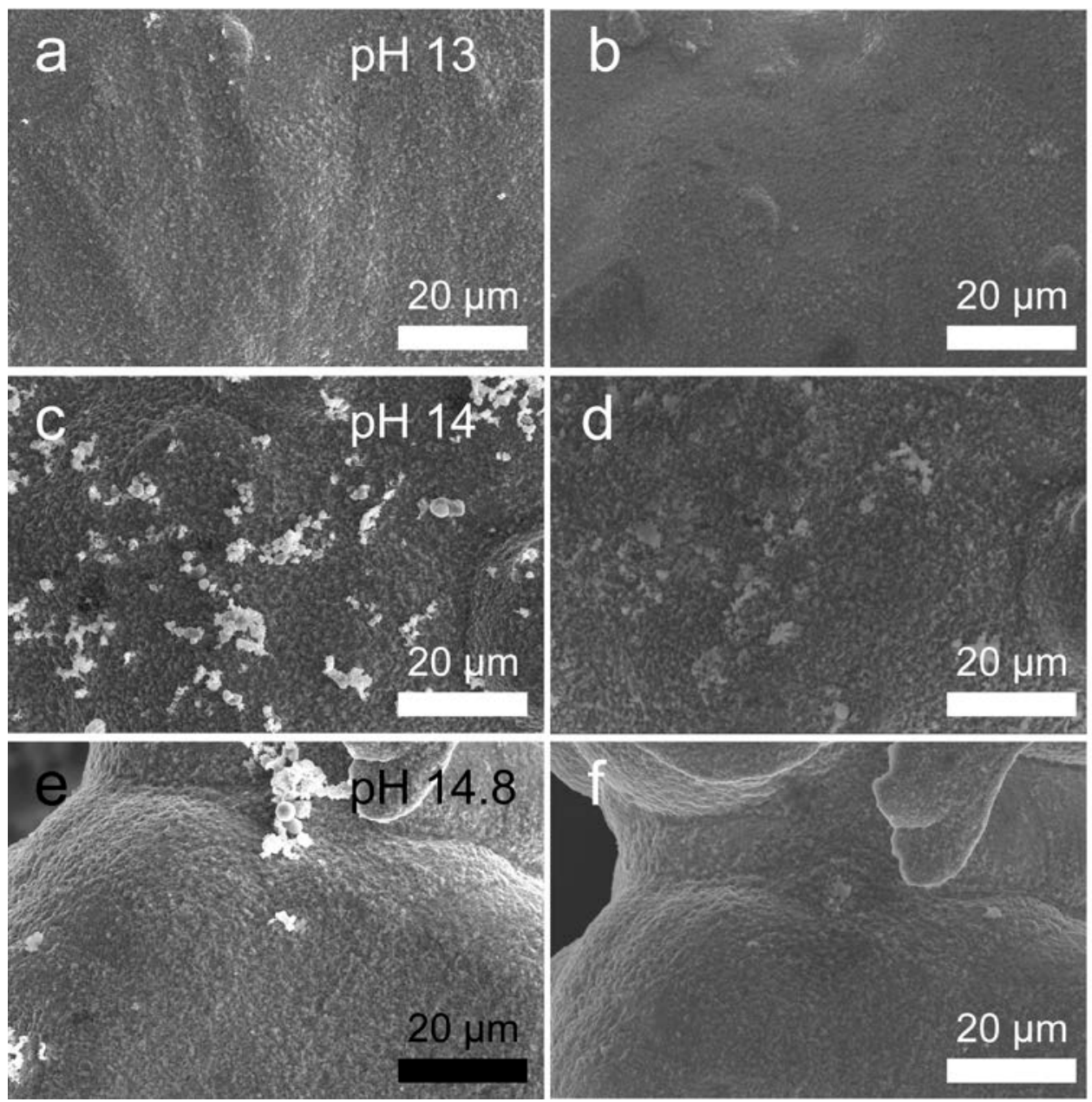

Figure 3.12: SEM micrographs of Ni-Fe-S/Ni foam of a) fresh and b) spent in pH 13 $\mathrm{NaOH}$ for $24 \mathrm{~h}, \mathrm{c}$ ) fresh and d) spent in $\mathrm{pH} 14 \mathrm{NaOH}$ for $24 \mathrm{~h}$, and e) fresh and f) spent in $\mathrm{pH} 14.8 \mathrm{NaOH}$ for $24 \mathrm{~h}$.

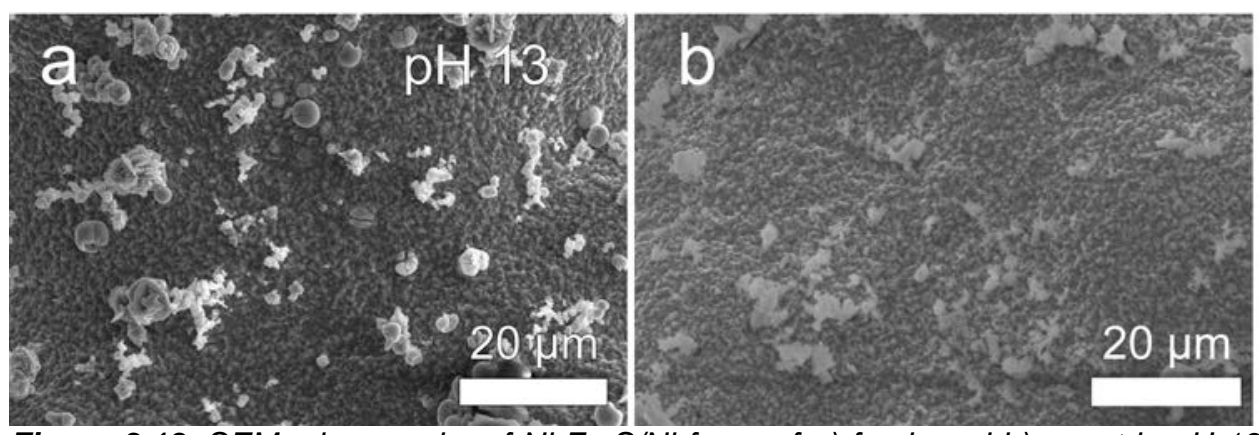

Figure 3.13: SEM micrographs of Ni-Fe-S/Ni foam of a) fresh and b) spent in $\mathrm{pH} 13$ $\mathrm{LiOH}$ for $24 \mathrm{~h}$. 
and is reported to be first order in $\mathrm{H}^{+}$(effectively present as $\mathrm{H}_{2} \mathrm{O}$ at high $\mathrm{pH}$ ). ${ }^{[37]}$

This explains the observation that leaching of $S$ is reduced when an oxidative potential is applied (as $\mathrm{S}+2 \mathrm{e}^{-} \rightarrow \mathrm{S}^{2-}$ is a reduction) and why lower leaching is found for $\mathrm{KOH}$ at $\mathrm{pH} 14$ compared to $\mathrm{pH}$ 13. It does not, however, explain the higher leaching at $\mathrm{pH} 14.8$ in $\mathrm{KOH}$.

To explore if the observed values are a result of possible differences in the initial concentration of $S$ in the materials SEM-EDX was employed both prior to and after the $24 \mathrm{~h}$ electrocatalysis. As can be seen, for all 3 electrolytes, $\mathrm{KOH}$, $\mathrm{NaOH}$, and $\mathrm{LiOH}$ (Figures 3.11-3.13, respectively), the surface morphology doesn't change significantly on the micrometer scale. Larger magnifications were not explored due to significant charge build-up if the electron beam was focused further, which posed a risk to damage the SEM.

Table 3.3: Atomic ratios found by EDX of Ni, Fe, S, $K$ and Na before (normal) and after (bold) catalysis at $10 \mathrm{~mA} / \mathrm{cm}^{2}$ for $24 \mathrm{~h}$, unless noted otherwise. Other elements (adventitious $C, O$ ) were observed but are not included in the calculation. Li at\% values were not determined since it emits $X$-rays of too low energy to be quantified.

\begin{tabular}{|c|c|c|c|c|c|}
\hline & $\mathrm{Ni}(\mathrm{at} \%)$ & Fe (at $\%)$ & S (at $\%)$ & $\mathrm{K}(\mathrm{at} \%)$ & $\mathrm{Na}(\mathrm{at} \%)$ \\
\hline \multirow[t]{2}{*}{$\mathrm{KOH} \mathrm{pH} 13$} & 65.0 & 8.1 & 26.9 & - & - \\
\hline & 61.6 & 2.9 & 35.4 & 0.1 & - \\
\hline \multirow[t]{2}{*}{$\mathrm{KOH} \mathrm{pH} 13+\mathrm{S}$} & 72.1 & 0.1 & 27.8 & - & - \\
\hline & 60.6 & 0.1 & 38.9 & 0.5 & - \\
\hline \multirow[t]{2}{*}{$\mathrm{KOH} \mathrm{pH} 14$} & 73.5 & 0.1 & 26.4 & - & - \\
\hline & 62.0 & 0.1 & 37.0 & 0.9 & - \\
\hline \multirow[t]{2}{*}{$\mathrm{KOH}$ pH 14.8} & 73.6 & 0.2 & 26.2 & - & - \\
\hline & 63.0 & 0.2 & 34.3 & 2.6 & - \\
\hline \multirow{2}{*}{$\begin{array}{c}\mathrm{KOH} \text { pH } 14,24 \mathrm{~h}, \\
\text { no current }\end{array}$} & 66.5 & 7.7 & 25.8 & - & - \\
\hline & 53.3 & 9.2 & 34.7 & 2.8 & - \\
\hline \multirow{2}{*}{$\begin{array}{c}\mathrm{KOH} \mathrm{pH} 14,1 \\
\text { week, no current }\end{array}$} & 64.5 & 6.7 & 28.9 & - & - \\
\hline & 67.8 & 5.4 & 25.0 & 1.8 & - \\
\hline \multirow[t]{2}{*}{$\mathrm{NaOH} \mathrm{pH} 13$} & 73.2 & 0.0 & 26.8 & - & - \\
\hline & 57.5 & 0.1 & 42.2 & - & 0.2 \\
\hline \multirow[t]{2}{*}{$\mathrm{NaOH}$ pH $13+\mathrm{S}$} & 75.7 & 7.9 & 16.5 & - & - \\
\hline & 61.2 & 1.2 & 34.4 & - & 3.2 \\
\hline \multirow[t]{2}{*}{$\mathrm{NaOH} \mathrm{pH} 14$} & 72.0 & 3.6 & 24.4 & - & - \\
\hline & 58.1 & 0.7 & 36.5 & - & 4.7 \\
\hline \multirow[t]{2}{*}{$\mathrm{NaOH}$ pH 14.8} & 71.3 & 1.4 & 27.3 & - & - \\
\hline & 57.7 & 0.3 & 35.2 & - & 6.7 \\
\hline \multirow[t]{2}{*}{$\mathrm{LiOH}$ pH 13} & 63.1 & 9.2 & 27.7 & - & - \\
\hline & 55.6 & 2.8 & 41.6 & - & - \\
\hline \multirow[t]{2}{*}{$\mathrm{LiOH}$ pH 13 + S } & 72.2 & 1.9 & 25.9 & - & - \\
\hline & 60.2 & 2.4 & 37.4 & - & - \\
\hline
\end{tabular}


Interestingly, when comparing EDX values before and after catalysis we observe a clear trend: the Ni/S ratio decreases. This means, that despite the clear leaching of $\mathrm{S}$, the surface concentration of said $\mathrm{S}$ increases. Similar to NiMo described in Chapter 2 this suggests we have surface segregation resulting in higher $\mathrm{S}$ surface concentrations. This is again a clear sign that electrocatalysts are indeed not static under operation conditions. Furthermore, we find $\mathrm{K}$ and $\mathrm{Na}$ on the samples after catalysis, where the concentration increases with $\mathrm{pH}$ and $\mathrm{M}^{+}$concentration in the solution. This is not a result of flushing; differences in flushing time with deionized water after catalysis does not change the observed surface concentration. Also worth to be noted is that before catalysis rather reproducible values of $\mathrm{Ni}(70.2 \pm 4.1 \mathrm{at} \%)$ and $\mathrm{S}(25.9 \pm 3.0$ at\%) are found, whereas Fe inclusion nearly has an error of $100 \%$ (3.9 \pm 3.6 at\%). It has to be noted that all the samples reported in Table 3.3 have been made at the same time in a single vessel. In other words, the treatment was constant. Likely $\mathrm{Fe}$ in the solution aids the formation of roughness as was already described in Section 3.2.1. It is not included in the material itself it seems but sooner present as a residue after synthesis, giving a wide spread in its atomic contribution to the material. Indeed, with EDX mapping we find that Fe is mostly present in the particulate matter which is, for example, seen in Figure 3.12c and Figure 3.13a.

\subsubsection{Solar Driven Water Splitting Demonstration}

$\mathrm{Ni}$-Mo forms a slightly darker material on the Ni foam, while Ni-Fe-S forms a nearly black compound. On one hand, these can be combined in a controlled system and perform exceptionally at $10 \mathrm{~mA} / \mathrm{cm}^{2}$ and stay stable on $1.55 \mathrm{~V}$ for at least one week. On the other hand, we also present a system driven solely by a solar module consisting of four solar cells. These deliver $2.1 \mathrm{~V}$ and $1 \mathrm{~A}$

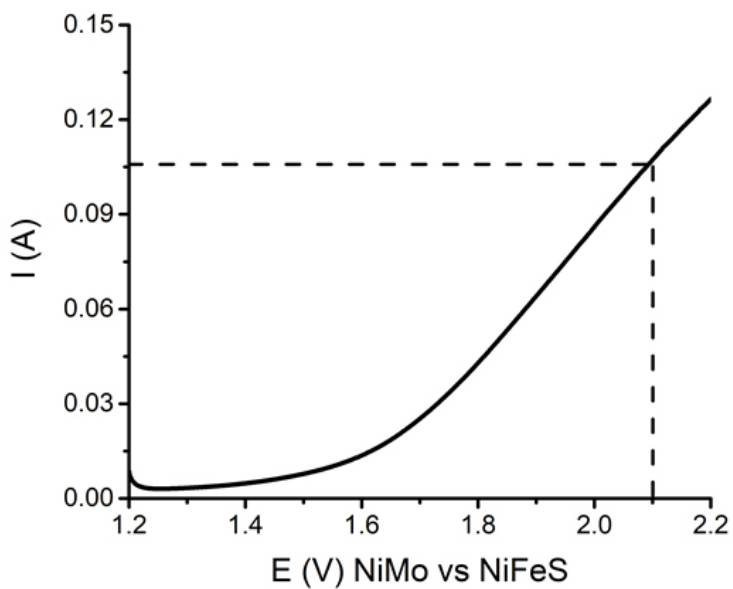

Figure 3.14 Ni-Fe-S vs Ni-Mo linear sweep with each electrode consisting of $1 \mathrm{~cm}^{2} \mathrm{Ni}$ foam. Dotted lines show the measured $2.1 \mathrm{~V}$ of the solar module resulting in 0.105 $\mathrm{A} / \mathrm{cm}^{2}$. 

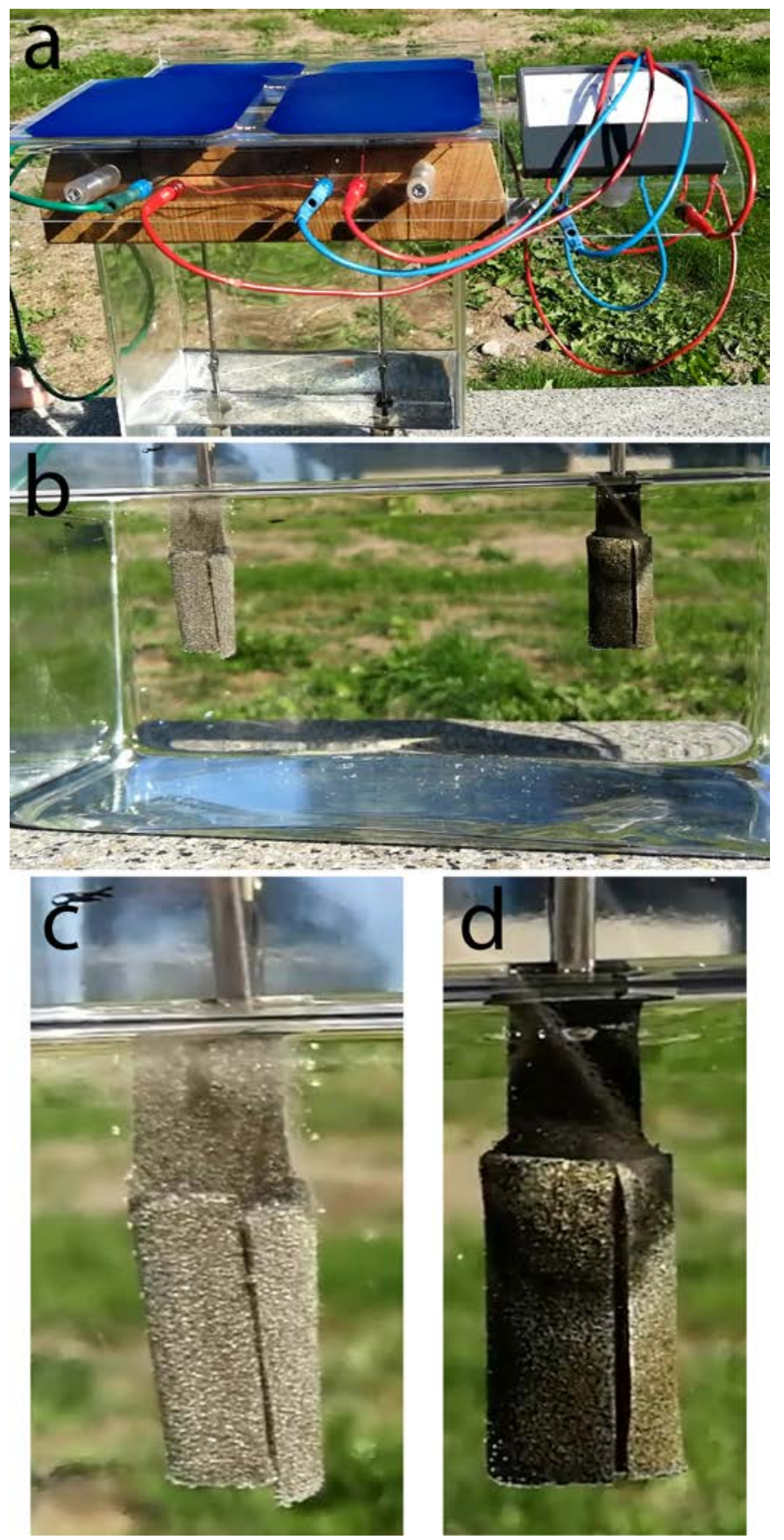

Figure $\quad 3.15$ :

Snapshots of a movie made while running the solar cell driven demonstration setup outside in the sun. a) Overview showing the solar cells connected to the electrodes. b) Picture of the electrodes with $\mathrm{Ni}$ $\mathrm{Mo} / \mathrm{Ni}$ foam on the left performing HER and Ni-Fe-S/Ni foam on the right performing OER. c) Zoomed-in picture of the $\mathrm{Ni}-\mathrm{Mo} / \mathrm{Ni}$ foam HER electrode. d) Zoomed-in picture of the $\mathrm{Ni}-\mathrm{Fe}-\mathrm{S} / \mathrm{Ni}$ foam OER electrode. 
under 1 sun (1.5 AM) illumination. To accommodate these values, we tested the materials in $0.1 \mathrm{M} \mathrm{KOH}$, since at $2.1 \mathrm{~V} \mathrm{Ni}-\mathrm{Fe}-\mathrm{S}$ oxidizes to $\mathrm{Ni}^{2+}$ and subsequently precipitates as $\mathrm{NiO}$ in a $1 \mathrm{M}$ hydroxide solutions. From this resulted that $10 \mathrm{~cm}^{2}$ is the optimal electrode size to accommodate the full current (Figure 3.14).

Snapshots of a movie, made of the demonstration setup are given in Figure 3.15. For practical purposes, an electrode size of $15 \mathrm{~cm}^{2}$ is chosen to relieve electrochemical strain on the electrodes, in case the light intensity is higher than 1.5 AM. It can be observed that indeed extensive bubble formation occurs when the setup is running in the sun. Furthermore, as is expected, the number of bubbles formed at the HER side are larger than those at OER. Interestingly the bubbles formed at the HER are visibly smaller than the bubbles at OER, suggesting that $\mathrm{H}_{2}$ releases from the material more readily than $\mathrm{O}_{2}$, though more research is needed to explore if this is a result from the difference in

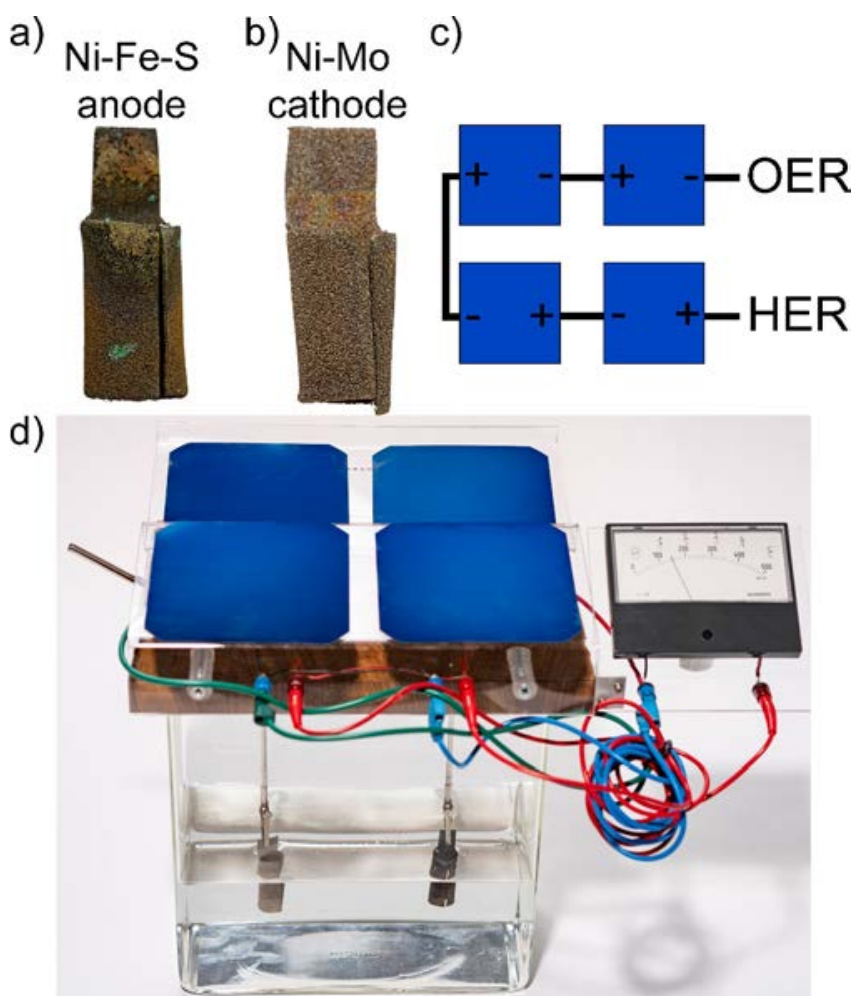

Figure 3.16: a) Photograph of a $15 \mathrm{~cm}^{2} \mathrm{Ni}$-Fe-S electrode. b) Photograph of a $15 \mathrm{~cm}^{2}$ $\mathrm{Ni}$-Mo electrode. c) Schematic representation of the electrical connection of the four solar panels in series and their connection to the HER and OER reactions. d) Photograph of the demonstration setup outside with four solar panels mounted on top of a wooden top. The electrolyte is $0.1 \mathrm{M} \mathrm{KOH}$. There are furthermore connections to a voltmeter showing $2.1 \mathrm{~V}$ potential. 
surface morphology of the catalysts or a result of the different physical properties of the gasses.

\subsection{Conclusions}

We have demonstrated, as also illustrated in Figure 3.16, that hydrogen and oxygen can be produced from water solely with renewable energy using highly performing electrocatalysts, i.e., Ni-Mo and Ni-Fe-S, deposited on high surface area substrates. Furthermore, we have identified that the high activity of Ni-Fe$\mathrm{S}$ stems from two different effects: synergy between $\mathrm{Ni}$ and $\mathrm{S}$ and a surface area increase caused by the addition of Fe. High performance stability was found for these materials at a set current and they operate stably for the course of a week at $1.55 \mathrm{~V}$ and $10 \mathrm{~mA} / \mathrm{cm}^{2}$. The system is, however, more sensitive to intermittency in potential and cycling shows a large change in performance after the first few cycles, after which the change is slowed down significantly.

Deeper studies into the Ni-Fe-S material showed that $\mathrm{S}$ leaches from the material and segregates towards the surface to result in a surface of $\mathrm{Ni}_{60} \mathrm{~S}_{40}$ compared to the $\mathrm{Ni}_{72} \mathrm{~S}_{28}$ ratio found beforehand. Fe was found to function mostly to increase the surface area was seems to be not included in the material but only sometimes present as particles on top of the material, which in most cases are no longer found after catalysis. Changes in capacitance and leaching of $S$ show the same trends, though could not be directly linked, showing that for Ni-Fe-S electrodes surface composition is also a significant contributor to the capacitance value.

The $\mathrm{pH}$ of the electrolyte played a significant role in the stability of $\mathrm{Ni}-\mathrm{Fe}-\mathrm{S}$. Too low $\mathrm{pH}$ values result in the destabilization of the metal hydroxide passivating layers. Furthermore, $\mathrm{S}$ leaching is influenced by acidity as well and oxidative potentials stabilized the $S$ in the electrodes compared to electrodes being immersed in the electrolyte without applied potential. The cation of the electrolyte was found in the material after operation, where $\mathrm{Na}$ is present in significantly larger numbers than $\mathrm{K}$.

At continuous operation at $10 \mathrm{~mA} / \mathrm{cm}^{2}$ the $\mathrm{Ni}-\mathrm{Fe}-\mathrm{S}$ electrodes were found to be most stable in $1 \mathrm{M} \mathrm{KOH}$ solutions of all tested electrolytes. When higher potential values were applied (e.g. via the solar module) the window of stable operation seems to shift towards lower $\mathrm{pH}$.

\subsection{Experimental}

\subsubsection{Chemicals and Materials}

All materials were used as received without further purification. $\mathrm{NiSO}_{4} \cdot 6 \mathrm{H}_{2} \mathrm{O}$ (ReagentPlus, $>99 \%$ pure), $\mathrm{FeSO}_{4} \cdot 7 \mathrm{H}_{2} \mathrm{O}$ (ReagentPlus, $>99 \%$ pure), 
$\mathrm{NaMoO}_{4} \cdot 2 \mathrm{H}_{2} \mathrm{O}$ (ACS reagent, $>99 \%$ pure), $\mathrm{NaOH}(99.99 \%$ trace metals, semiconductor grade), $\mathrm{KOH}$ (ACS reagent, > $85 \%$ pure, ca. $15 \% \mathrm{H}_{2} \mathrm{O}$ ), Thioacetamide (ACS reagent, $>99 \%$ pure), $\mathrm{NaOH}(99.99 \%$, trace metals, semiconductor grade), $\mathrm{LiOH} \cdot \mathrm{H}_{2} \mathrm{O}$ (99.95\%, trace metals), $\mathrm{Na}_{2} \mathrm{SO}_{4}$ (ACS reagent, $\geq 99.0 \%$ ), $\mathrm{K}_{2} \mathrm{SO}_{4}$ (ReagentPlus, $\geq 99.0 \%$ ), $\mathrm{Li}_{2} \mathrm{SO}_{4} \cdot \mathrm{H}_{2} \mathrm{O}$ (BioUltra, $\geq 99.0$ $\%$ ) and $\mathrm{Na}_{3} \mathrm{C}_{6} \mathrm{H}_{5} \mathrm{O}_{7} \cdot 2 \mathrm{H}_{2} \mathrm{O}$ (sodium citrate, ACS reagent, $>99 \%$ pure) were received from Sigma Aldrich. $\mathrm{NH}_{3} 28-30 \%$ (ACS reagent, ph. Eur. for analysis) was obtained from Emsure. In all experiments deionized water was used.

\subsubsection{Ni foam preparation}

Ni foams were shaped into keyhole shapes (Figure 3.17) using a punch with a $2 \mathrm{~cm} \times 0.5 \mathrm{~cm}$ lip and a $1 \mathrm{~cm}^{2}$ circle. Epoxy (Loctite EA 3425) was used to cover the lower part of the lip to have a set area of the sample exposed. Application was done in two steps to ensure that the pores were filled with epoxy as well to prevent filling by capillary forces. They were then cleaned by sonication in 1:1:1 demiwater:ethanol:acetone, followed by sonication in $0.1 \mathrm{M} \mathrm{KOH}$, followed by sonication in water. Each sonication step took 15 min.

\subsubsection{Ni-Mo electrodeposition}

The foams were fixed in a three-electrode cell (Figure 3.18) for electrodeposition. Electro-deposition was performed galvano-statically using an Ivium Compactstat at a current of $-100 \mathrm{~mA}$ for $1200 \mathrm{~s}$ while stirring at $400 \mathrm{rpm}$. As a counter electrode a Pt mesh (Mateck, 99.9+ \%) was used and as a reference electrode a $3 \mathrm{M} \mathrm{Ag/AgCl}$ electrode (BASi) was used. The plating bath used

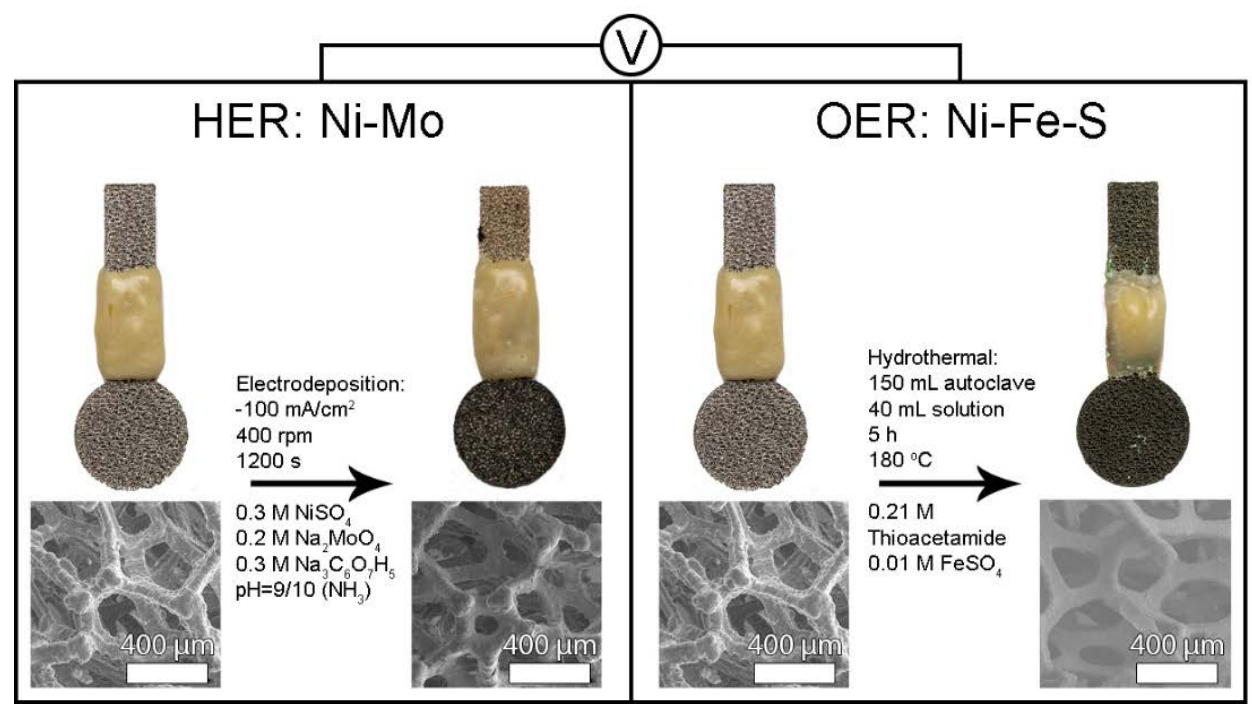

Figure 3.17: On the left are photographs and SEM images of Ni foams before and after electrodeposition of Ni-Mo. On the right are photographs and SEM images of Ni foams before and after hydrothermal synthesis of Ni-Fe-S. 


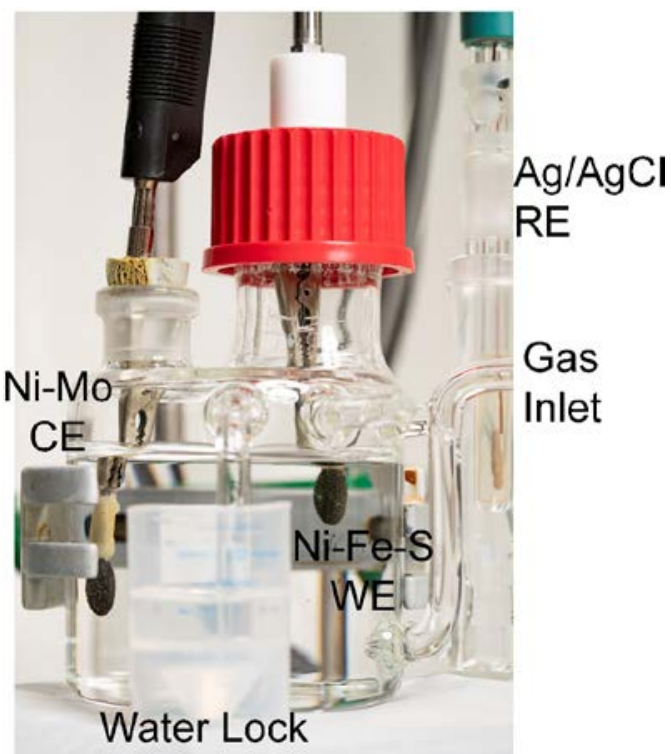

Figure 3.18: Photograph of the three-electrode electrochemical cell used in this work. There are two gas inlets: one for bubbling before an experiment and one for a constant Ar flow during the experiment. A gas outlet through a water lock prevents ambient air from infiltrating the cell. The electrodes are attached as follows: Ni-Fe-S anodes are the working electrode, $\mathrm{Ni}-\mathrm{Mo}$ cathodes are the counter electrode. $\mathrm{Ag} / \mathrm{AgCl}(3 \mathrm{M} \mathrm{KCl})$ is sometimes used as a reference electrode (3-electrode configuration, as shown in the picture). When a 2-electrode configuration was used the compartment separated by the Luggin capillary was closed off with a stopper.

contained $0.3 \mathrm{M} \mathrm{NiSO}_{4}, 0.2 \mathrm{M} \mathrm{Na}_{2} \mathrm{MoO}_{4} \& 0.3 \mathrm{M} \mathrm{Na}_{3} \mathrm{C}_{6} \mathrm{H}_{5} \mathrm{O}_{7}$ in $100 \mathrm{~mL}$ demineralized water. To this, $10 \mathrm{~mL} \mathrm{NH}_{3}$ was added to obtain a pH of 9.2. First, the metals were dissolved in water through stirring, and then $\mathrm{NH}_{3}$ was added to adjust the $\mathrm{pH}$. Prior to the syntheses, the baths were purged with $\mathrm{Ar}$ for 15 min, and a gentle Ar flow was kept over the solution during electro-deposition.

\subsubsection{Ni-Fe-S hydrothermal synthesis}

A $150 \mathrm{~mL}$, Teflon-lined autoclave was filled with $40 \mathrm{~mL}$ of solution containing $210 \mathrm{mM}$ thioacetamide, $10 \mathrm{mM} \mathrm{FeSO}_{4} \cdot 6 \mathrm{H}_{2} \mathrm{O}$ and a Ni foam were heated to 180 ${ }^{\circ} \mathrm{C}$ in an oven. This was left there for $5 \mathrm{~h}$ and then cooled slowly in air before being opened.

\subsubsection{Electrochemistry}

$100 \mathrm{~mL} 1 \mathrm{M} \mathrm{KOH}$ electrolyte is loaded in a three-electrode electrochemical cell then deoxygenated for at least $15 \mathrm{~min}$ by a flow of $20 \mathrm{~mL} / \mathrm{min}$ of $\operatorname{Ar}$ ( 5.0 quality). Samples are immersed in the solution just past the beginning of the epoxy layer as a working electrode. Depending on the experiment, the cell is loaded as a 


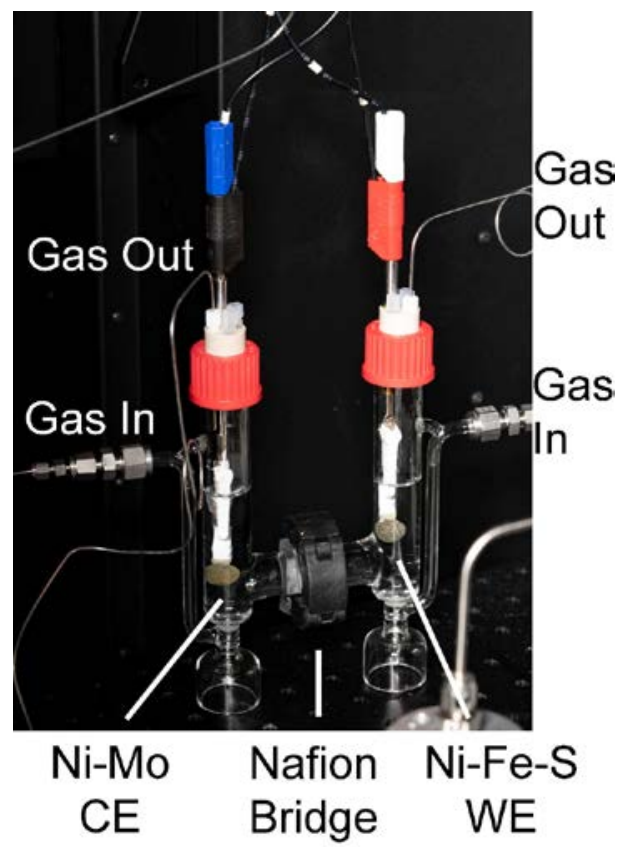

Figure 3.19: Photograph of the $\mathrm{H}$-cell used for Faradaic Efficiency measurements. Two compartments are separated by a Nafion proton exchange membrane so that $\mathrm{H}_{2}$ and $\mathrm{O}_{2}$ could be measured by separate channels in the GC. There are gas inlets through glass frits flowing 20:1, $2.1 \mathrm{~mL} / \mathrm{min}$ flows of $\mathrm{Ar} / \mathrm{Kr}$ (Cathode side) or $\mathrm{N}_{2} / \mathrm{Kr}$ (Anode side). No Ar was used on the anode side due to the overlap with $\mathrm{O}_{2}$ in the installed columns.

two-electrode cell (with the reference electrode compartment closed off) with another $\mathrm{Ni}$ foam, or a Pt mesh electrode as counter electrode. Optimization of $\mathrm{Ni}-\mathrm{Fe}-\mathrm{S}$ was done in a three-electrode configuration with a $3 \mathrm{M} \mathrm{KCl} \mathrm{Ag/AgCl}$ electrode (BASi, $-1.033 \mathrm{~V}$ vs NHE at $\mathrm{pH}$ 14). Chronoamperometry measurements are performed at $10 \mathrm{~mA} / \mathrm{cm}^{2}\left(-10 \mathrm{~mA} / \mathrm{cm}^{2}\right.$ in case the cathode was studied in a three-electrode configuration) with steps of $1 \mathrm{~s}$ with static electrolytes (no bubbling, no stirring). Gas Chromatography analysis was done with a H-cell with a Nafion perfluorinated membrane (Nafion 117, 0.007 inch thick, Sigma Aldrich) loaded with the electrodes and $1 \mathrm{M} \mathrm{KOH} \mathrm{(Figure} \mathrm{3.19).}$ This was purged with $2 \mathrm{~mL} / \mathrm{min} \mathrm{N}_{2}(5.0), 0.1 \mathrm{~mL} / \mathrm{min} \mathrm{Kr}(5.0)$ on the $\mathrm{O}_{2}$ side and $2 \mathrm{~mL} / \mathrm{min} \operatorname{Ar}(5.0), 0.1 \mathrm{~mL} / \mathrm{min} \mathrm{Kr}$ on the $\mathrm{H}_{2}$ side. This was bubbled past the samples through a glass frit. The $\mathrm{O}_{2}$ electrode was the WE, the $\mathrm{H}_{2}$ electrode was the CE/RE. A current of $10 \mathrm{~mA} / \mathrm{cm}^{2}$ was maintained for $24 \mathrm{~h}$. GC was obtained using Global Analyzer Solutions Compact GC 4.0 from Interscience with separate channels for $\mathrm{H}_{2}$ and $\mathrm{O}_{2}$. $\mathrm{H}_{2}$ was analyzed via a $75 \mu \mathrm{L}$ sample loop injecting into a $5 \mathrm{~m} \cdot 0.53 \mathrm{~mm}$ MXT-Q-bond then a $10 \mathrm{~m} \cdot 0.53 \mathrm{MXT}$-Msieve column and detected on a TCD. $\mathrm{O}_{2}$ was injected via a $50 \mu \mathrm{L}$ loop through different columns of the same type and analyzed on a separate TCD. An injection was done each minute, with about $10 \mathrm{~s}$ delay between each injection. 
For each injection $\mathrm{Kr}$ was used as an internal standard. Ni-Fe-S stability tests were done in $6 \mathrm{M} \mathrm{OH}^{-}$solutions, $1 \mathrm{M} \mathrm{OH}^{-}$solutions, and $0.1 \mathrm{M} \mathrm{OH}^{-}$solutions. The tests with $\mathrm{SO}_{4}{ }^{2-}$ were done in $0.1 \mathrm{M} \mathrm{MOH}$ with $0.45 \mathrm{M} \mathrm{M}_{2} \mathrm{SO}_{4}$. One test, in $0.001 \mathrm{M} \mathrm{KOH}$ with $0.5 \mathrm{M} \mathrm{K}_{2} \mathrm{SO}_{4}$ was done as well, but $\mathrm{pH} 11$ was found to be too low and the sample was fully digested, resulting in slimy green $\mathrm{NiO}$ precipitation. At pH 14 the tests were done as follows, with all voltages vs Ag/AgCl: 5 CV's from $0 \mathrm{~V}$ to $-0.2 \mathrm{~V}$ and back for 3 cycles at 100, 200, 300, 400, and $500 \mathrm{mV} / \mathrm{s}$, followed by linear sweep voltammetry from $0.23 \mathrm{~V}$ to $0.53 \mathrm{~V}$. Then chrono-potentiometry was performed at $10 \mathrm{~mA} / \mathrm{cm}^{2}$ for $86400 \mathrm{~s}$. Then the linear sweep was repeated, followed by a repeat of the CV's. At other pH values the same methodology was used, except that the used voltages were adjusted for the $\mathrm{pH}$ according to $-0.059 \mathrm{~V} / \mathrm{pH}$.

\subsubsection{Characterization}

X-ray diffraction (XRD) was measured using a Bruker D2 Phaser instrument with a cobalt anode. Scans were taken from $30-80{ }^{\circ} 2 \theta$ with $0.02{ }^{\circ} 2 \theta$ steps measuring $1 \mathrm{~s} /$ step while rotating at $15 \mathrm{~Hz}$. Scanning electron microscopy with energy dispersive X-ray spectroscopy (SEM-EDX) was performed on a FEI Helios nanolab 600 DualBeam with an Oxford instruments Silicon Drift Detector X-Max energy dispersive spectroscope. SEM imaging and EDX mapping was performed with an electron beam of $15 \mathrm{kV}$ and $0.8 \mathrm{nA}$. Inductively coupled plasma atomic emission spectroscopy (ICP-AES) was performed using an Optima 8300 instrument from Perkin Elmer and an average of three samples was used. Electrodeposited samples were dissolved in $10 \mathrm{~mL} 2 \% \mathrm{HNO}_{3}$ before oxidation. These were diluted with $2 \% \mathrm{HNO}_{3}$ to achieve optimal measurement ranges. Electrolytes were decreased in $\mathrm{pH}$ by adding $1 \mathrm{~mL} 65 \% \mathrm{HNO}_{3}$ per 10 $\mathrm{mL}$ electrolyte, resulting in ca. $2 \% \mathrm{HNO}_{3}$. Ni $(231.604 \mathrm{~nm})$, Fe (259.941 nm), $\mathrm{S}(182.034 \mathrm{~nm})$ and Mo $(202.095 \mathrm{~nm}, 203.909 \mathrm{~nm})$ were then measured.

\subsection{Author Contributions and Acknowledgements}

This Chapter is based on the following manuscript: Basicity and Electrolyte Composition Dependent Stability of Ni-Fe-S and Ni-Mo Electrodes during Water Splitting, J.H.J. Wijten, I. Garcia-Torregrosa, E.A. Dijkman, B.M. Weckhuysen, ChemPhysChem 2020.

Jochem Wijten, Iván Garcia-Torregrosa, and Bert Weckhuysen conceived the research plans. Jochem Wijten, Iván Garcia-Torregrosa, and Eva Dijkman executed the experimental work under the supervision of Bert Weckhuysen. Jochem Wijten wrote the work with the input of all co-authors and feedback and corrections by Bert Weckhuysen.

The following people are gratefully acknowledged: Oscar Kerkenaar (UU), Pascal Wijten (UU), and Herrick Schaink (UU) are thanked for their technical 
assistance with the GC measurements, Otto van de Beek and Peter de Graaf are acknowledged for their contribution in making the demonstration setup, Coen Mulder is acknowledged for the ICP-AES measurements, and Ivar Pel is thanked for making the photographs used in this PhD Chapter.

\subsection{References}

[1] McCrory, C. C. L., Jung, S., Ferrer, I. M., Chatman, S. M., Peters, J. C. \& Jaramillo, T. F., J. Am. Chem. Soc. 2015, 137, 4347-4357

[2] Weber, M. F., J. Electrochem. Soc. 1984, 131, 1258-1265

[3] Weber, M. F. \& Dignam, M. J., Int. J. Hydr. Energy 1986, 11, 225-232

[4] Walter, M. G., Warren, E. L., McKone, J. R., Boettcher, S. W., Mi, Q., Santori, E. A. \& Lewis, N. S., Chem. Rev. 2010, 110, 6446-6473

[5] Zeng, M. \& Li, Y., J. Mater. Chem. A 2015, 3, 14942-14962

[6] Safizadeh, F., Ghali, E. \& Houlachi, G., Int. J. Hydrogen Energy 2014, 40, 256-274

[7] Zhou, W., Wu, X. J., Cao, X., Huang, X., Tan, C., Tian, J., Liu, H., Wang, J. \& Zhang, H., Energy Environ. Sci. 2013, 6, 2921-2924

[8] Tang, C., Pu, Z., Liu, Q., Asiri, A. M., Luo, Y. \& Sun, X., Int. J. Hydr. Energy 2015, 40, 4727-4732

[9] Krishnamoorthy, K., Veerasubramani, G. K., Radhakrishnan, S. \& Kim, S. J., Chem. Eng. J. 2014, 251, 116-122

[10] Kessler, T., Triaca, W. E. \& Arvia, A. J., J. Appl. Electrochem. 1994, 24, 310-315

[11] Hu, P., Wang, T., Zhao, J., Zhang, C., Ma, J., Du, H., Wang, X. \& Cui, G., ACS Appl. Mater. Inter. 2015, 7, 26396-26399

[12] Friebel, D., Louie, M. W., Bajdich, M., Sanwald, K. E., Cai, Y., Wise, A. M., Cheng, M. J., Sokaras, D., Weng, T. C., Alonso-Mori, R., Davis, R. C., Bargar, J. R., Nørskov, J. K., Nilsson, A. \& Bell, A. T., J. Am. Chem. Soc. 2015, 137, 1305-1313

[13] Kanan, M. W. \& G, N. D., Science 2008, 321, 1072-1076

[14] Kauffman, D. R., Alfonso, D., Tafen, D. N., Lekse, J., Wang, C., Deng, X., Lee, J., Jang, H., Lee, J. S., Kumar, S. \& Matranga, C., ACS Catal. 2016, 6, 1225-1234

[15] Dong, B., Zhao, X., Han, G. Q., Li, X., Shang, X., Liu, Y. R., Hu, W. H., Chain, Y. M., Zhao, H., Liu, C. G., J. Mater. Chem. A 2016, 4, 1349913508

[16] Ganesan, P., Sivanantham, A., Shanmugam, S., J. Mater. Chem. A 2016, 4, 16394-16402

[17] Che, Q., Li, Q., Tan, Y., Chen, X., Xu, X., Chen, Y., Appl. Catal. B: Environ. 2019, 246, 337-348

[18] Zhang, J., Hu, Y., Liu, D., Yu, Y., Zhang, B., Adv. Sci. 2017, 4, 1600343

[19] Liu, Y., Jiang, S., Li, S., Zhou, L., Li, Z., Li, J., Shao, M., Appl. Catal. B: Environ. 2019, 247, 107-114 
[20] Krstajic, N. V, Jovic, V. D., Gajic-Krstajic, L., Jovic, B. M., Antozzi, A. L. \& Martelli, G. N., Int. J. Hydrogen Energy 2008, 33, 3676-3687

[21] Beltowska-Lehman, E., Bigos, A., Indyka, P. \& Kot, M., Surf. Coatings Technol. 2012, 211, 67-71

[22] Djokic, S., Electrodeposition and Surface Finishing, Springer, Berlin, 2014

[23] Goldstein, J. I., Newbury, D. E., Michael, J. R., Ritchie, N. W. M., Scott, J. H. J. \& Joy, D. C., Scanning Electron Microscopy and X-Ray Microanalysis, Springer, Berlin, 2018

[24] Jaśkaniec, S., Hobbs, C., Seral-Ascaso, A., Coelho, J., Browne, M. P., Tyndall, D., Sasaki, T. \& Nicolosi, V., Nat. Sci. Rep 2018, 8, 4179

[25] Gong, M., Li, Y., Wang, H., Liang, Y., Wu, J. Z., Zhou, J., Wang, J., Regier, T., Wei, F. \& Dai, H., J. Am. Chem. Soc. 2013, 135, 8452-8455

[26] Louie, M. W. \& Bell, A. T., J. Am. Chem. Soc. 2013, 135, 12329-12337

[27] Görlin, M., Chernev, P., De Araújo, J. F., Reier, T., Dresp, S., Paul, B., Krähnert, R., Dau, H. \& Strasser, P., J. Am. Chem. Soc. 2016, 138, 5603-5614

[28] Gorlin, M., De Araujo, J. F., Schmies, H., Bernsmeier, D., Dresp, S., Gliech, M., Jusys, Z., Chernev, P., Kraehnert, R., Dau, H. \& Strasser, P., J. Am. Chem. Soc. 2017, 139, 2070-2082

[29] PDF card. 01-078-4721, PDF card. 00-047-1740, PDF card. 01-0780165

[30] Schalenbach, M., Speck, F. D., Ledendecker, M., Kasian, O., Goehl, D., Mingers, A. M., Breitbach, B., Springer, H., Cherevko, S. \& Mayrhofer, K. J. J., Electrochim. Acta 2018, 259, 1154-1161

[31] Zhang, W., Wu, Y., Qi, J., Chen, M. \& Cao, R., Adv. Energy Mater. 2017, 7, 1602547

[32] Stevens, M. B., Trang, C. D. M., Enman, L. J., Deng, J. \& Boettcher, S. W., J. Am. Chem. Soc. 2017, 139, 11361-11364

[33] Barforoush, J. M., Jantz, D. T., Seuferling, T. E., Song, K. R., Cummings, L. C. \& Leonard, K. C., J. Mater. Chem. A 2017, 5, 1166111670

[34] Ai Z., Sun W., Jiang J., Song D., Ma H., Zhang J. \& Wang D., Materials, 2016, 9, 749

[35] Smith R.J., Hummel R.E. \& Ambrose J.R., Corr. Sci., 1987, 27, 815826

[36] Davies D.E. \& Barker W., Corrosion, 1964, 20, 47t-53t

[37] Crundwell F.K., Hydrometallurgy, 2014, 149, 71-81 
We continue driving and I keep on being distracted by the river. I accepted my father's words but believing them is still difficult. Eventually, the road takes us away from the river, but not before allowing me to see it flow into a cave into the mountain. It makes me wonder: did the river actually eat its way into the mountain like dad told me? My dad chuckles as he sees me look back at the cave and the river, sitting on my knees on the car seat. "It is always interesting to be able to see into something, isn't it?" He asks. "I... guess. I've never thought about it." I answer distractedly. "One day l'll take you to that cave. To truly convince you of the strength of water, seeing it happen in real-time yourself is the best argument I can make." Excitedly I sit down again, feeling like dad promised me to take me on more adventures. 


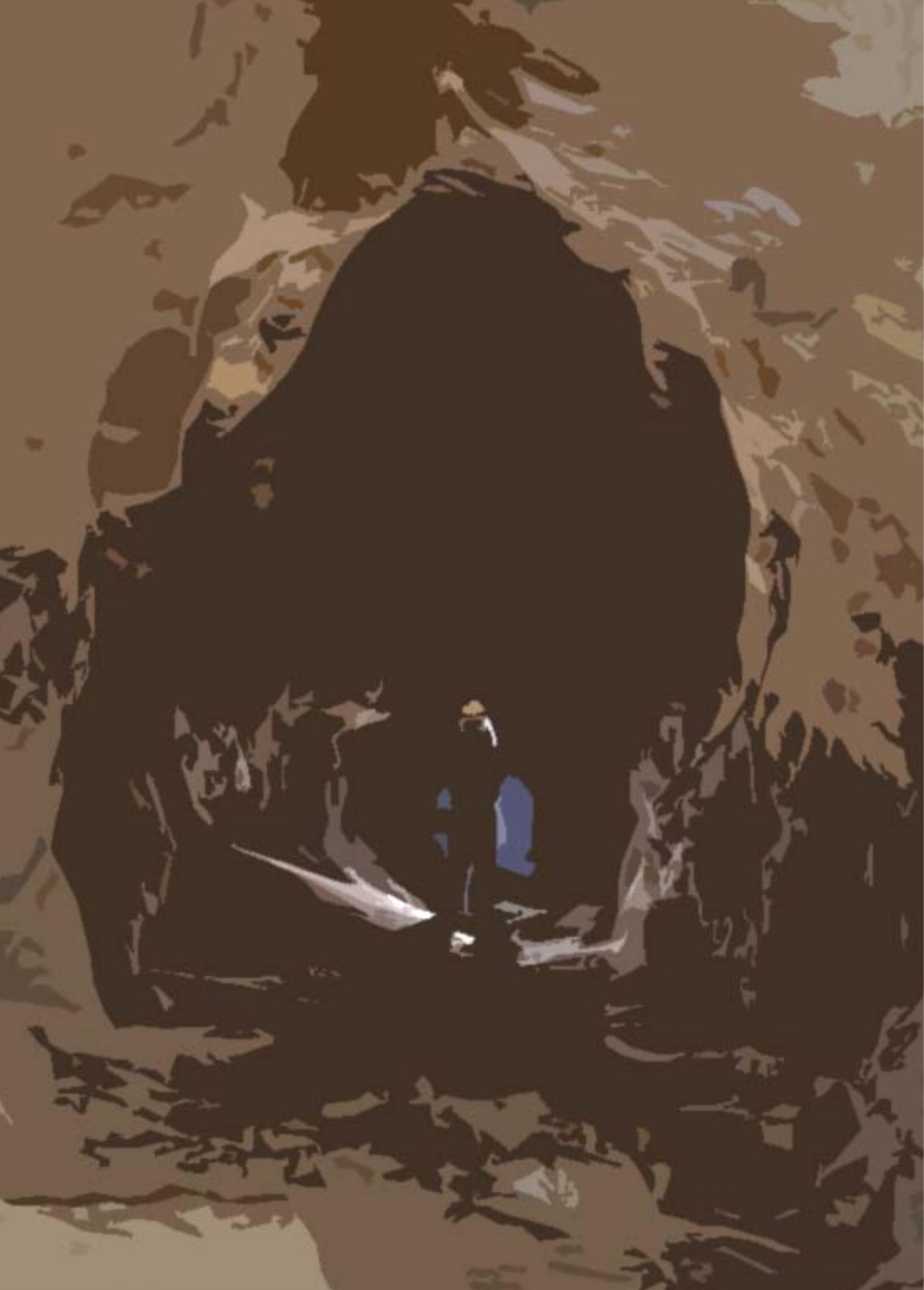




\section{4}

\section{In Situ Study of Ni-Mo Stability in a Solar Driven Water Splitting Device: Effect of Catalyst Substrate and Applied Potential}

Nickel-molybdenum (Ni-Mo) alloys are well-studied as highly effective water electrolysis electro-catalysts cathode materials. In this Chapter, we have performed in situ experiments with various techniques to study the stability and Mo leaching in detail. It was found that switching the potential towards higher overpotentials results in a non-linear change in leaching. Multiple processes are suggested to take place such as reducing the extent of Mo oxidation at the cathode by stronger reducing potentials while at the same time the increase of local $\mathrm{pH}$ at the cathode due to the hydrogen evolution reaction pushes towards more leaching. Morphology changes on the electrode materials are linked to the presence of $\mathrm{K}^{+}$in pores of the material, though it is uncertain if $\mathrm{K}^{+}$is the cause or a result hereof. It was found that the change in capacitance for these materials depends strongly on the change of surface composition and not only surface area. In situ UV-Vis spectroscopy shows that Mo leaching is a continuous process and it could not be directly linked to the change in overpotential during electrolysis. Finally, the effect of substrate on the material stability was studied and it was found that the substrate has a significant, albeit complex, influence on the stability and activity of Ni-Mo cathodes. In terms of stability in $1 \mathrm{M} \mathrm{KOH} \mathrm{Ni-Mo} \mathrm{was} \mathrm{found}$ to be best deposited on stainless steel substrates operated at low overpotentials $(-0.067 \mathrm{~V}$ vs RHE) showing nearly no change in capacitance (surface composition) and exhibiting low Mo leaching. 


\subsection{Introduction}

The stability of electro-catalysts is often tested by quickly cycling between two set potentials for thousand(s) of times. ${ }^{[1,2]}$ This is done to simulate the change of potential which is a result of using intermittent electricity following e.g. from solar cells and windmills. ${ }^{[1,3-5]}$ In most cases, this cycling shows that electrocatalysts are indeed much less stable when cycling than under constant potential. ${ }^{[1]}$ In the previous Chapters, we already touched on the stability of $\mathrm{Ni}$ $\mathrm{Mo}$ and $\mathrm{Ni}-\mathrm{Fe}-\mathrm{S}$ at a constant potential. For example, we found for $\mathrm{Ni}-\mathrm{Fe}-\mathrm{S}$ that high potentials result in oxide formation and thus catalyst degradation. ${ }^{[6-10]}$ This could effectively be halted by using lower concentrations of hydroxide ions when going to higher potentials as was the case with the solar cell driven demonstration (Chapter 3).

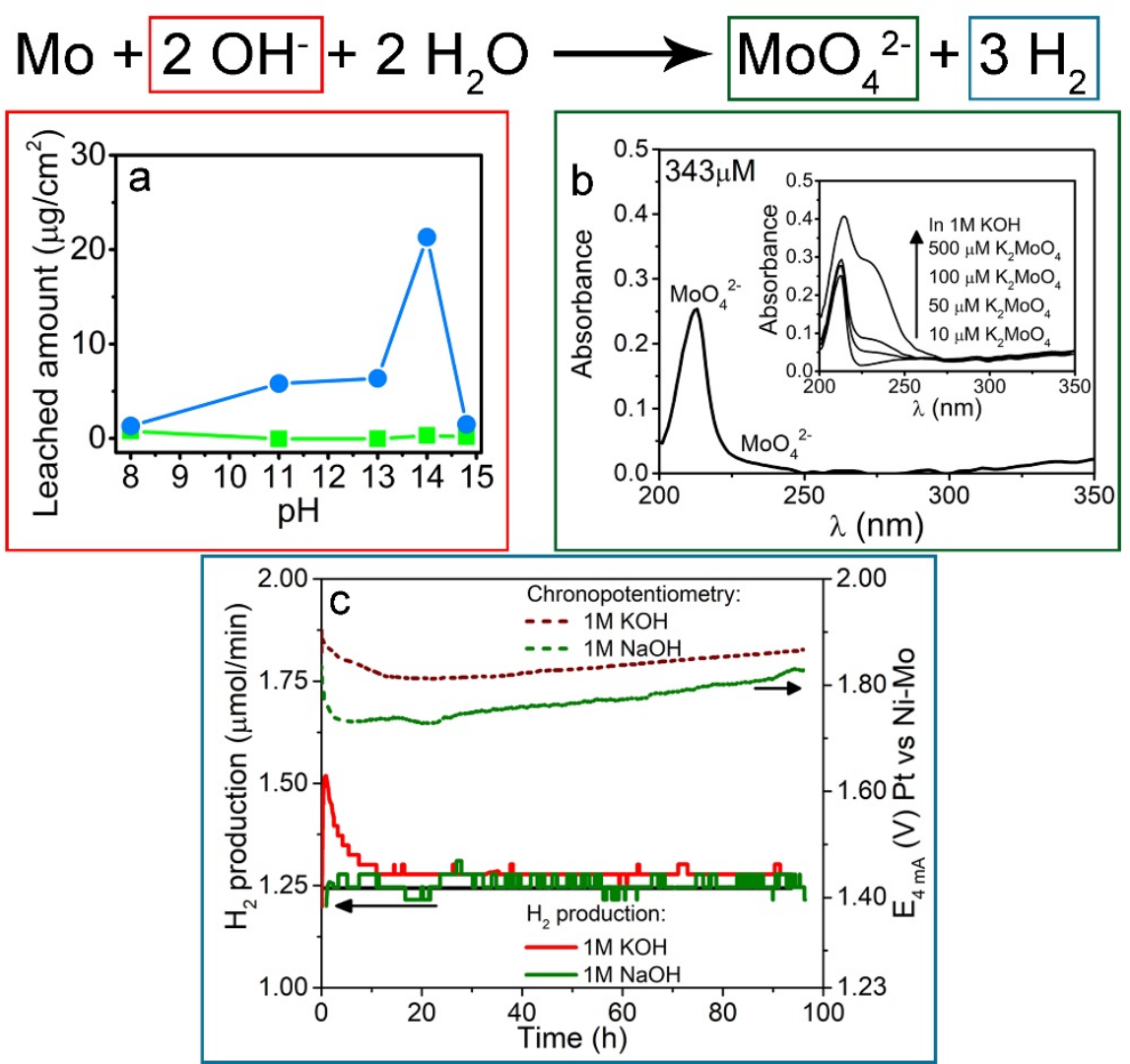

Figure 4.1: A summary of the findings found in Chapter $2 .^{[1]}$ a) The effect of $\mathrm{pH}$ in $K^{+}$-based electrolytes on Mo leaching as probed by ICP-AES, which shows the effect of $\mathrm{OH}^{-}$on leaching. b) UV-Vis spectra showing $\mathrm{MoO}_{4}{ }^{2-}$ to be the species that is formed. c) Faradaic efficiency as found by GC measurements showing higher than $100 \%$ efficiency which is owed to the $\mathrm{H}_{2}$ formed by Mo leaching. 
In this Chapter, the focus will be again on Ni-Mo and we will discuss the effect of potential/current and substrates on the stability of the material in more detail.[11] Using in situ UV-Vis spectroscopy ${ }^{[12-14]}$ and in situ atomic force microscopy ${ }^{[15-17]}$ (AFM), combined with ex situ elemental analyzes such as scanning electron microscopy with energy dispersive X-ray spectroscopy (SEM-EDX) and inductively coupled plasma atomic emission spectroscopy (ICP-AES) we follow Mo leaching as a function of these catalysis parameters and establish the use of these techniques for the study of operating Ni-Mo catalysts. ${ }^{[11,18]}$ Building forth on the knowledge gained in Chapter 2 (summarized in Figure 4.1) here we show potential limits for the stability of NiMo and find that the stability is highest at intermediary potentials. We explain how the potential/current influences multiple experimental parameters which contribute to the overall observed stability. ${ }^{[19,20]}$ Furthermore, taking inspiration from traditional heterogeneous catalysis we also study the metallic support for possibly influencing the stability. ${ }^{[21-24]}$ Aside from Ti, which we used before, we also studied $\mathrm{Ni}$, chosen since it likely supports the metallic growth of $\mathrm{Ni}-\mathrm{Mo}$, and furthermore $\mathrm{Cu}$ and stainless steel (AISI 316) which could be considered cheaper materials as supports and thus likely more attractive for up-scaling. With this work, we present a further understanding of Ni-Mo stability and its practical and physical limitations.

\subsection{Results and Discussion}

\subsubsection{Potential Effects on Ni-Mo/Ti}
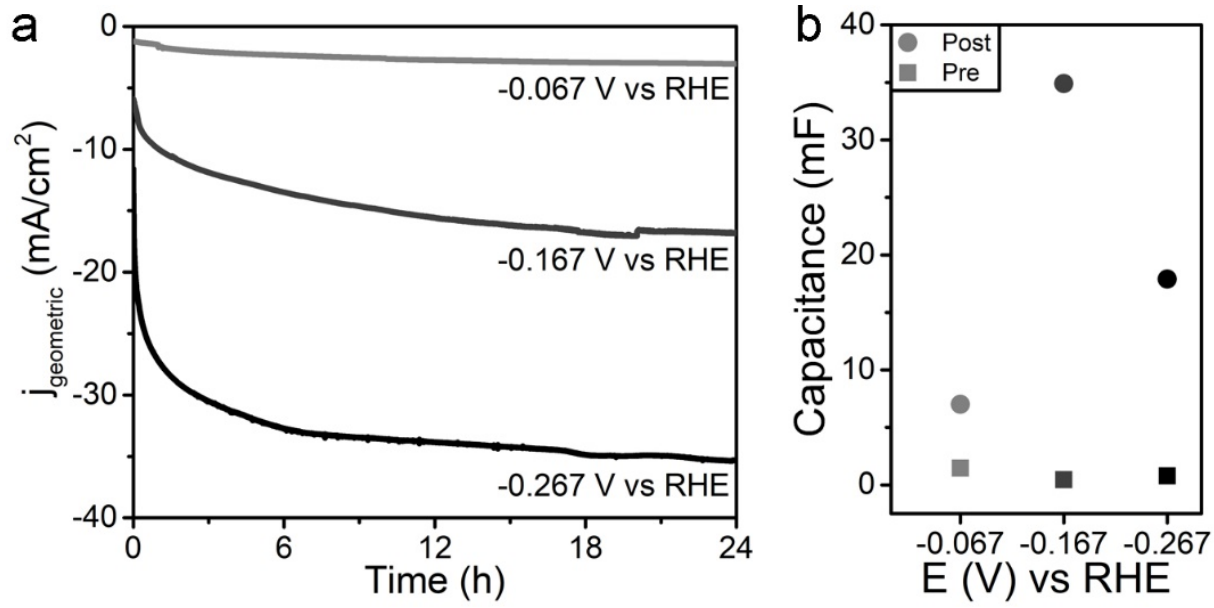

Figure 4.2: a) Chrono-amperometry of Ni-Mo/Ti in $1 \mathrm{M} \mathrm{KOH}$ showing the evolution of the current density at different applied potentials. b) Capacitance values found by double layer capacitance measurements before (squares) and after (circles) catalysis. 

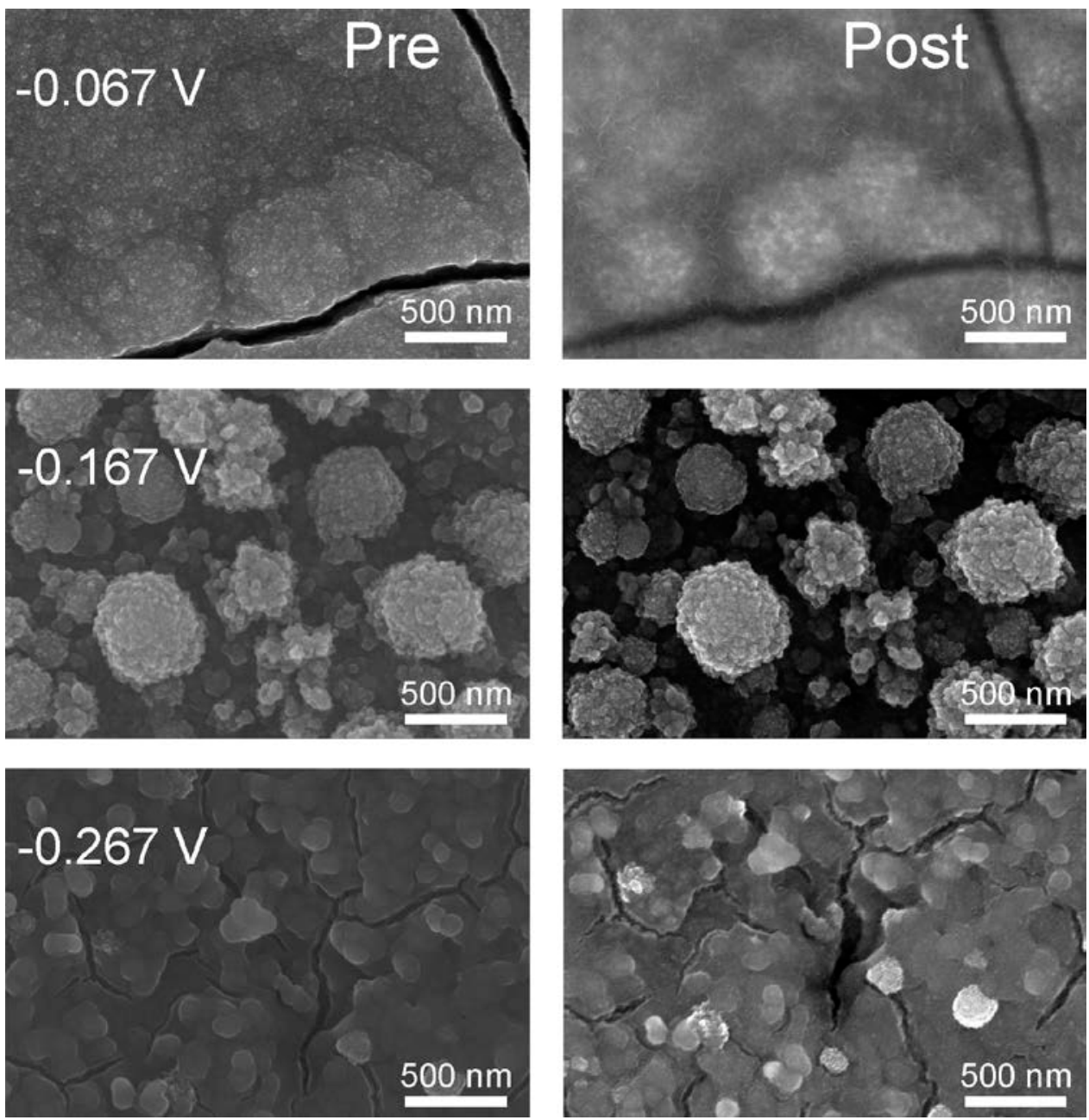

Figure 4.3: SEM micrographs of Ni-Mo/Ti before (left) and after (right) chronoamperometric catalysis for $24 \mathrm{~h}$ in $1 \mathrm{M} \mathrm{KOH}$ at different potentials.

To study the effect of potential on Ni-Mo, first the earlier studied $\mathrm{Ni}-\mathrm{Mo} / \mathrm{Ti}$ samples were used. In Figure 4.2a the chrono-amperometric curves can be found for the time span of $24 \mathrm{~h}$. It should be noted that for these curves the potential is at a set value of $-0.067 \mathrm{~V},-0.167 \mathrm{~V}$ or $-0.267 \mathrm{~V}$ vs RHE and thus the current varies over time. Like earlier results activation over time is observed on the hour timescale. As should be expected higher potential values resulted in higher currents. More interestingly, it was found that for $\mathrm{Ni}-\mathrm{Mo} / \mathrm{Ti}$, as shown in Figure $4.2 \mathrm{~b}$, the relative increase in surface capacitance is largest at intermediary values.

Contrary, as seen in Figure 4.3, we observed that the surface morphology according to SEM changed most for the sample that was run at $-0.067 \mathrm{~V}$. 
Meanwhile, for the two higher tested potential values no changes were observed after 24 h. EDX data, meanwhile, as shown in Table 4.1, shows us that the change in Ni/Mo ratio follows the same pattern as the surface capacitance. Furthermore, it shows us that $\mathrm{K}$ infiltration of the $-0.067 \mathrm{~V}$ sample was more significant than of the other two samples. Surprisingly, ICP-AES (Figure 4.4) shows that Mo leaching simply increases slightly with potential, meaning that a more negative potential results in slightly higher leaching from $\mathrm{Ni}-\mathrm{Mo} / \mathrm{Ti}$ samples.

Table 4.1: Atomic ratios as found by SEM-EDX before (regular) and after (bold) $24 \mathrm{~h}$ of chrono-amperometry. Only Ni, Mo, Na and K are considered and thus add up to 100 at\%. Other elements that were observed are (adventitious) C, O, Ti, and Si, the latter sometimes being present as SiC particles that had been stuck in grooves left by the sanding paper. The last column shows the ratio of Ni/Mo.

\begin{tabular}{l|c|c|c|c||c} 
& & & & & Ni/Mo \\
& Ni (at\%) & Mo (at\%) & Na (at\%) & K (at\%) & ratio \\
\hline $\mathrm{Ni}-\mathrm{Mo} / \mathrm{Ti}-0.067 \mathrm{~V}$ & 64.8 & 31.4 & 3.8 & - & 2.06 \\
\hline $\mathrm{Ni}-\mathrm{Mo} / \mathrm{Ti}-\mathbf{0 . 0 6 7} \mathrm{V}$ & $\mathbf{6 8 . 8}$ & $\mathbf{2 8 . 9}$ & - & $\mathbf{2 . 4}$ & $\mathbf{2 . 3 8}$ \\
\hline $\mathrm{Ni}-\mathrm{Mo} / \mathrm{Ti}-0.167 \mathrm{~V}$ & $\mathbf{7 3 . 2}$ & 22.8 & 3.9 & - & 3.21 \\
\hline $\mathrm{Ni}-\mathrm{Mo} / \mathrm{Ti}-\mathbf{- 0 . 1 6 7} \mathrm{V}$ & $\mathbf{8 8 . 5}$ & $\mathbf{9 . 6}$ & $\mathbf{1 . 0}$ & $\mathbf{1 . 0}$ & $\mathbf{9 . 2 2}$ \\
\hline $\mathrm{Ni}-\mathrm{Mo} / \mathrm{Ti}-0.267 \mathrm{~V}$ & 51.0 & 39.0 & 10.0 & 0 & 1.31 \\
\hline $\mathrm{Ni}-\mathrm{Mo} / \mathrm{Ti}-\mathbf{0 . 2 6 7} \mathrm{V}$ & $\mathbf{6 4 . 9}$ & $\mathbf{3 3 . 8}$ & - & $\mathbf{1 . 4}$ & $\mathbf{1 . 9 2}$
\end{tabular}

The data presented shows that there are multiple processes going on at the same time, as was already suggested in Chapter 2. Porosity formation is seen and can best be followed with the inclusion of $\mathrm{K}^{+}$into the surface, which is clearly highest at low potential values. Furthermore, it is likely from this data

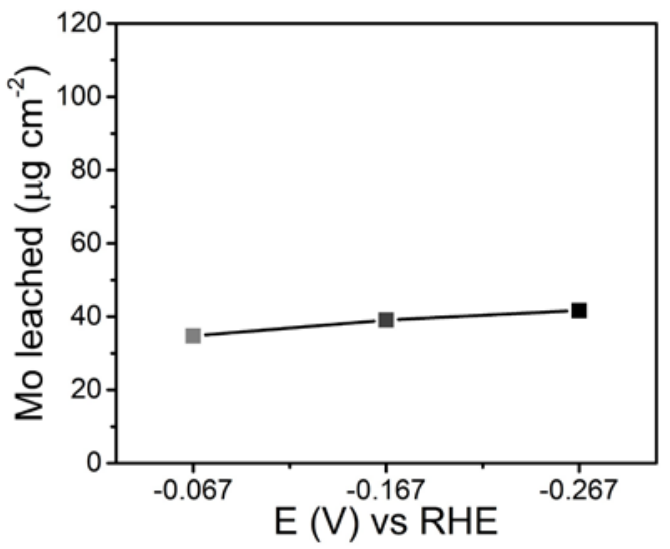

Figure 4.4: Amount of Mo leached into the electrolyte per $\mathrm{cm}^{2}$ of electrode as a function of applied potential after $24 \mathrm{~h}$ of chronoamperometric catalysis on $\mathrm{Ni}-\mathrm{Mo} / \mathrm{Ti}$ samples as probed by ICP-AES. that the observed differences in SEM are correlated to $\mathrm{K}^{+}$ infiltration, though at this point it cannot be said if $\mathrm{K}^{+}$ infiltration is a result of the morphology change or vice versa.

Meanwhile, the Ni/Mo ratio observed by SEM-EDX can clearly not directly be linked to the observed leaching by ICP-AES. This can be explained by surface segregation as was already discussed in depth in Chapter 2. ${ }^{11,25,26]} \mathrm{Ni}$ and Mo are moving through the bulk of the system, resulting in 
higher Ni/Mo ratio's near the surface, lowering the observed Mo content due to the limited penetration depth of the electron beam. Since the capacitance values follow the Ni/Mo trend observed in SEM-EDX (increases of 1.16, 2.87 and 1.47 respectively as a function of potential) and not the leaching trend observed by ICP-AES it can be concluded that the Ni/Mo is the main contributor to the observed capacitance and not the surface area. This underlines previous literature that care should be taken when linking the capacitance to the surface area. ${ }^{[27-29]}$

Furthermore, the link between capacitance and activity, which was found in Chapter 2, could lead to the hypothesis that the change in activity is mostly due to surface composition and not due to an increase in surface area. To test this hypothesis the rate of Mo leaching should be followed over time. In Figure 4.5a in situ UV-Vis spectroscopy data are shown, giving the evolution of the $\mathrm{MoO}_{4}{ }^{2-}$ peak over time. ${ }^{[11]}$ Note that from a practical point of view we used chronopotentiometry (Figure 4.5b) and not chrono-amperometry. This is due to bubble formation, which is assumed constant with chrono-potentiometry and thus minimizing the possible influence of scattering by bubbles on the results. ${ }^{[30]}$ Most importantly, as the chrono-potentiometry starts to level off, there seems to be no observable response yet in the evolution of the $\mathrm{MoO}_{4}{ }^{2-}$ peak, further agreeing with the hypothesis earlier stated that more processes are influencing the observed activity.

Interestingly, we see that the Mo leaching decreases with an increasing current in the UV-Vis spectroscopy experiments. The leaching changes with current as could be expected. A vital note is that the observed current-potential magnitude cannot be directly compared to the chrono-amperometry found in Figure 4.2a. The reason for this is that different electrochemical cells were used (Experimental Section 4.4) and thus different electrolyte resistances and kinetics are to be expected. ${ }^{[31,32]}$ From this, it can be determined that the ICPAES data presented in Figure 4.5c continues from the last point found in Figure 4.4. Furthermore, the same trend is observed in the in situ UV-Vis spectroscopy experiments and the ICP-AES experiments, suggesting that in situ UV-Vis
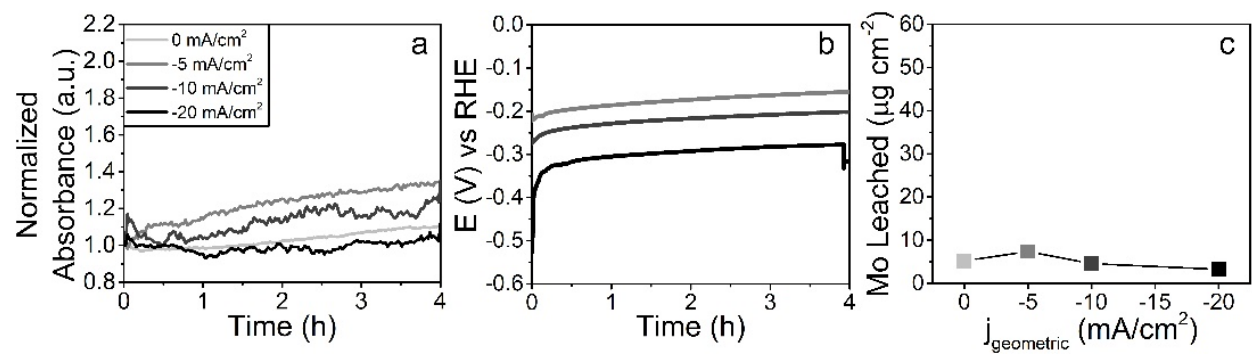

Figure 4.5: a) Normalized absorbance at $232 \mathrm{~nm}\left(\mathrm{MoO}_{4}{ }^{2-}\right)$ as probed with transmission UV-Vis and as a function of time. b) Chrono-potentiometric curves at $-5,-10$, and -20 $\mathrm{mA} / \mathrm{cm}^{2}$ respectively. c) Amount of Mo found in the electrolyte after $4 \mathrm{~h}$ of catalysis. 

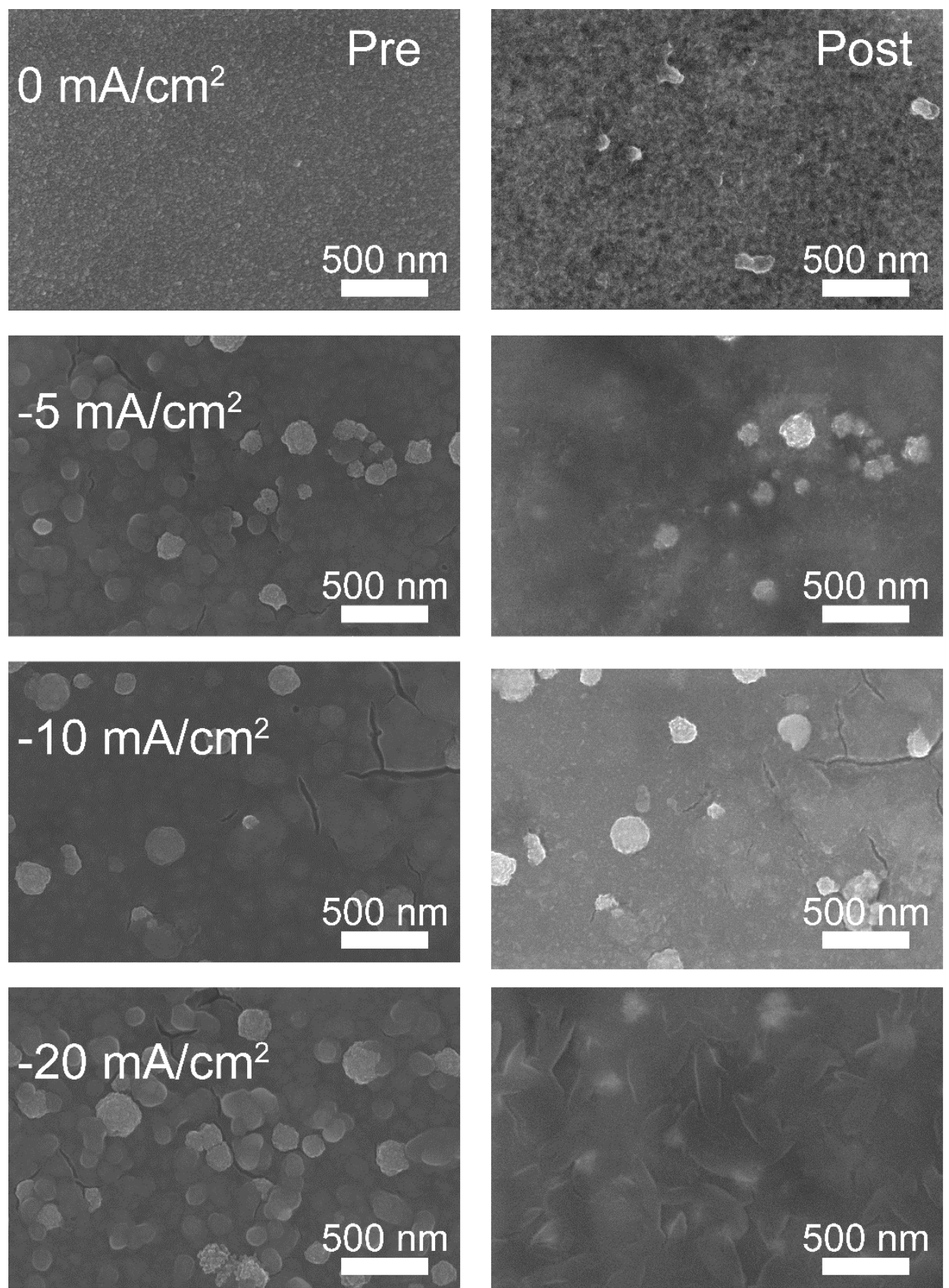

Figure 4.6: SEM micrographs of Ni-Mo/Ti before (left) and after (right) $4 \mathrm{~h}$ of chronopotentiometry at $0,-5,-10$ and $-20 \mathrm{~mA} / \mathrm{cm}^{2}$ respectively.

spectroscopy can indeed be used to follow $\mathrm{MoO}_{4}{ }^{2-}$ leaching in these systems. Seeing as Figure $4.5 \mathrm{c}$ is by approximation a continuation of Figure 4.4 it can 
be seen that Mo leaching is most extreme at intermediary potentials. Our proposed reasoning behind this observation is two-fold. On one hand HER (2 $\mathrm{H}_{2} \mathrm{O}+2 \mathrm{e}^{-} \rightarrow 2 \mathrm{OH}^{-}+\mathrm{H}_{2}$ ) forms one $\mathrm{OH}^{-}$ion locally for each electron consumed in the reaction. ${ }^{[31]}$ This results in a significantly higher $\mathrm{pH}$ directly at the surface. As was already described in Chapter $2\left(\mathrm{Mo}+2 \mathrm{OH}^{-}+2 \mathrm{H}_{2} \mathrm{O} \rightarrow \mathrm{MoO}_{4}{ }^{2-}+3 \mathrm{H}_{2}\right)$ the $\mathrm{OH}^{-}$increases $\mathrm{Mo}$ leaching. On the other hand, the half-reaction of leaching $\left(\mathrm{Mo}+8 \mathrm{OH}^{-} \rightarrow \mathrm{MoO}_{4}{ }^{2-}+4 \mathrm{H}_{2} \mathrm{O}+6 \mathrm{e}^{-}\right)$is oxidative, so thermodynamically it makes sense that the leaching is halted by strong, reducing potentials.

Similar to before we observed that the change in morphology (Figure 4.6) is correlated to the amount of $\mathrm{K}$ found in the material by SEM-EDX (Table 4.2). As before it is not possible to say from this data whether $\mathrm{K}$ is present due to the formation of porosity or is actually responsible for the change in morphology. It is also noted that the initial Ni/Mo ratio in these samples was relatively low but the impact on the performance or observations was minimal. The $\mathrm{Na}$ and $\mathrm{K}$ contents seem high due to the fact that there was a significant Ti signal in these samples causing high noise levels, which are significant in $\mathrm{Na}$ and $\mathrm{K}$ since they have low characteristic EDX signals.

Table 4.2: Atomic ratios as found by SEM-EDX before (regular) and after (bold) the in situ UV-Vis spectroscopy experiments. Only Ni, Mo, Na and $\mathrm{K}$ are considered and thus add up to $100 \mathrm{at} \%$. Other elements that were observed are (adventitious) C, O, Ti, and $\mathrm{Si}$, the latter sometimes being present as SiC particles that had been stuck in grooves left by the sanding paper. The last column shows the ratio of Ni/Mo.

\begin{tabular}{|c|c|c|c|c|c|}
\hline 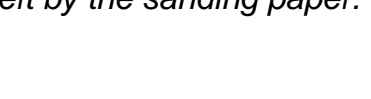 & $\mathrm{Ni}(\mathrm{at} \%)$ & Mo (at\%) & $\mathrm{Na}$ (at\%) & $\mathrm{K}(\mathrm{at} \%)$ & $\begin{array}{l}\mathrm{Ni} / \mathrm{Mo} \\
\text { ratio }\end{array}$ \\
\hline $\mathrm{Ni}-\mathrm{Mo} / \mathrm{Ti} 0 \mathrm{~mA} / \mathrm{cm}^{2}$ & 67.8 & 30.1 & 2.1 & - & 2.25 \\
\hline $\mathrm{Ni}-\mathrm{Mo} / \mathrm{Ti} 0 \mathrm{~mA} / \mathrm{cm}^{2}$ & 65.4 & 32.0 & 2.2 & 0.5 & 2.04 \\
\hline $\mathrm{Ni}-\mathrm{Mo} / \mathrm{Ti}-5 \mathrm{~mA} / \mathrm{cm}^{2}$ & 47.8 & 40.2 & 12.0 & - & 1.19 \\
\hline $\mathrm{Ni}-\mathrm{Mo} / \mathrm{Ti}$-5 mA/cm² & 39.4 & 24.3 & 8.7 & 27.6 & 1.62 \\
\hline $\mathrm{Ni}-\mathrm{Mo} / \mathrm{Ti}-10 \mathrm{~mA} / \mathrm{cm}^{2}$ & 44.6 & 40.6 & 14.8 & - & 1.10 \\
\hline Ni-Mo/Ti $-10 \mathrm{~mA} / \mathrm{cm}^{2}$ & 52.1 & 34.8 & 5.0 & 8.1 & 1.50 \\
\hline $\mathrm{Ni}-\mathrm{Mo} / \mathrm{Ti}-20 \mathrm{~mA} / \mathrm{cm}^{2}$ & 50.4 & 38.0 & 11.6 & - & 1.33 \\
\hline Ni-Mo/Ti - $20 \mathrm{~mA} / \mathrm{cm}^{2}$ & 40.5 & 11.8 & 7.9 & 39.8 & 3.43 \\
\hline
\end{tabular}

Furthermore, using in situ AFM we revisited probing the outer surface area. Earlier it was already explained that AFM proved unable to visualize the formation of pores in the Ni-Mo electro-catalysts. To find the role of porosity on the electrochemical activity the AFM data was compared to the evolution of the electrochemical curve. We studied the samples at different $\mathrm{pH}$ values of electrolyte without exposing them to an applied potential. In Figure 4.7 the data is presented for $\mathrm{KOH}$ concentrations of $0 \mathrm{M}, 1 \mathrm{M}$, and $6 \mathrm{M}$. It is observable that with increasing $\mathrm{pH}$ there are no visible differences in root-mean-square (RMS) values as found by AFM (Figure 4.8). The RMS values have been determined 

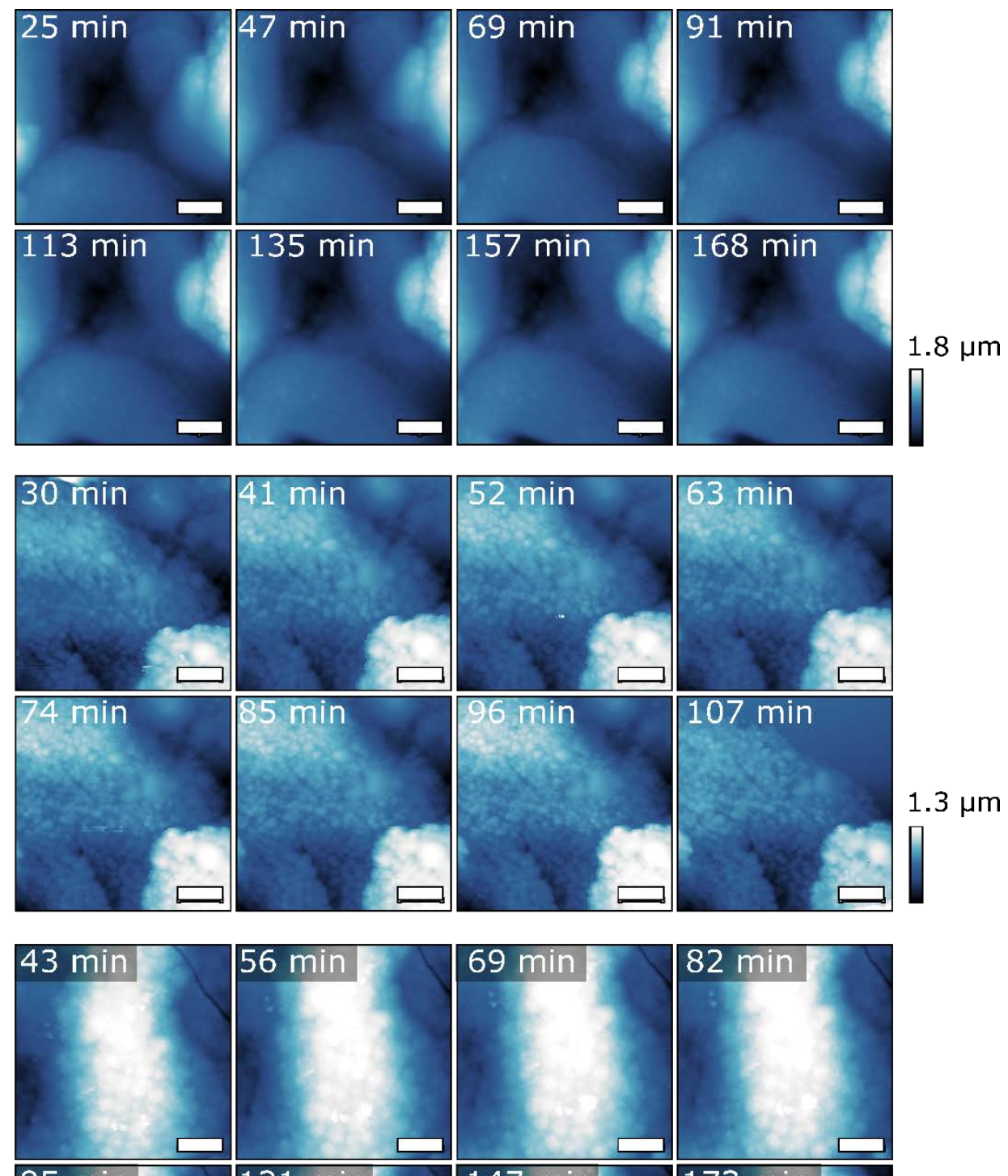

$1.8 \mu \mathrm{m}$
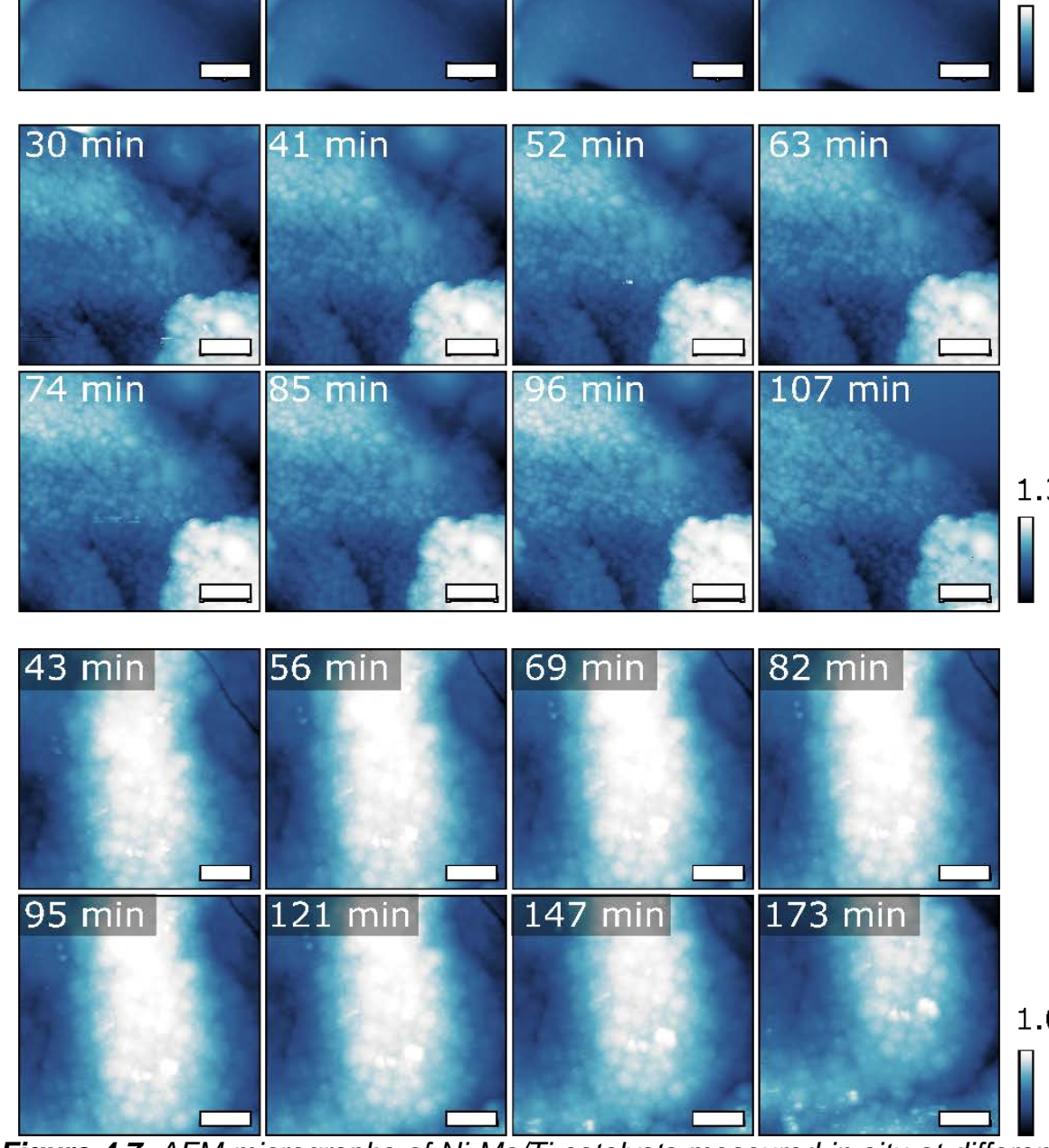

$1.0 \mu \mathrm{m}$

Figure 4.7: AFM micrographs of Ni-Mo/Ti catalysts measured in situ at different times at $0 \mathrm{M} \mathrm{KOH}$ (top), $1 \mathrm{M} \mathrm{KOH}$ (middle) and $6 \mathrm{M} \mathrm{KOH}$ (bottom). The scalebars are $2 \mu \mathrm{m}$.

after a specific flattening procedure as detailed in the experimental section (Section 4.4). From Figure 4.8 it can be observed that different spots on the 

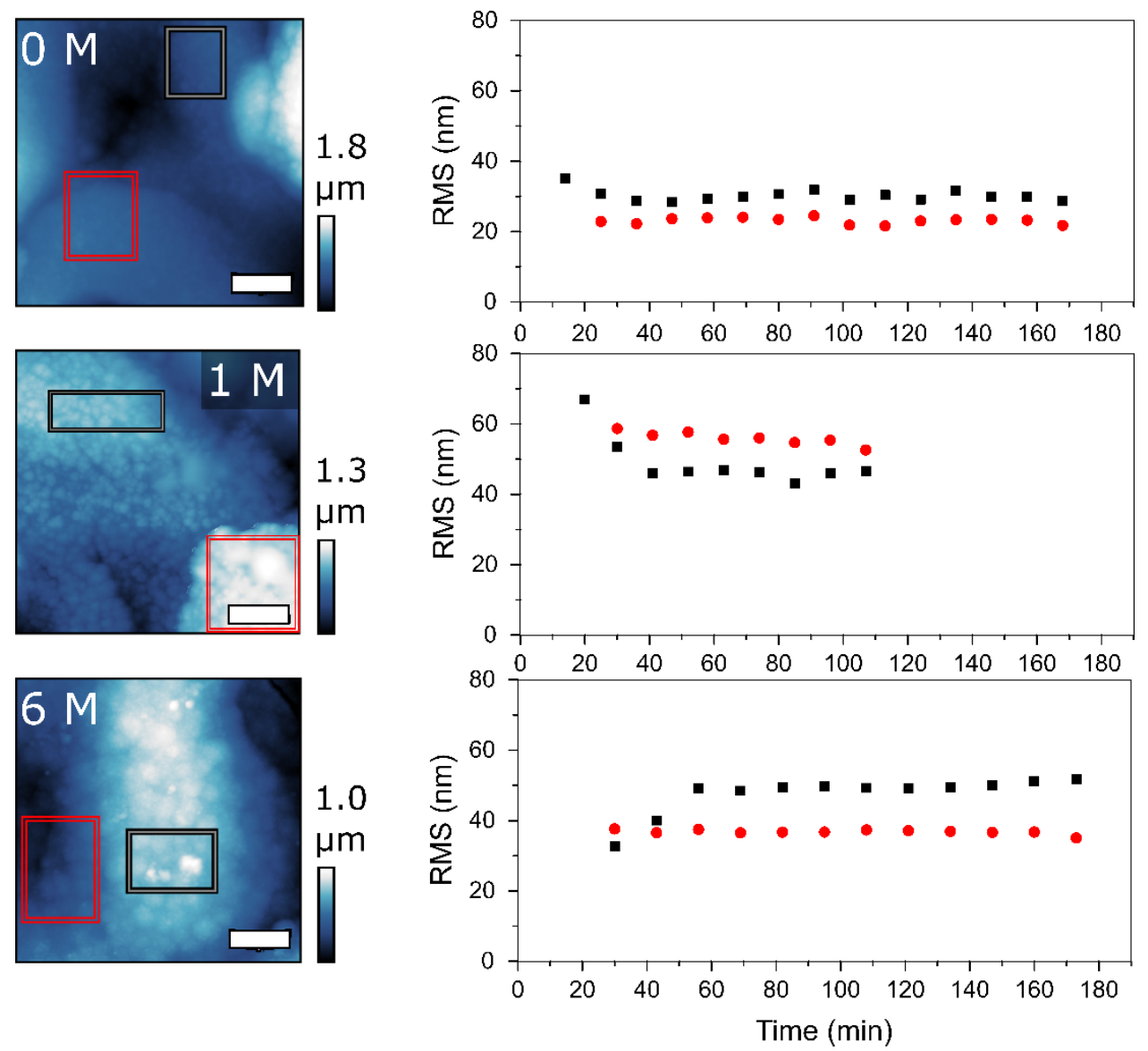

Figure 4.8: Left: AFM micrographs of the Ni-Mo/Ti catalysts with two selected spots on each material immersed in $0 \mathrm{M} \mathrm{KOH}$ (top), $1 \mathrm{M} \mathrm{KOH}$ (middle) and $6 \mathrm{M} \mathrm{KOH}$ (bottom). Right: progression of absolute RMS as a function of time of these samples at the two selected spots. The scalebars are $2 \mu \mathrm{m}$.

sample have different behaviour in terms of RMS. It can be expected that these relative rough and morphologically inhomogeneous (in terms of film materials) samples have different domains with different behavior. With in situ AFM, we show that this is indeed the case and that likely the particulate, rougher features, such as the large grains observed in the black-marked spot in the 6 $M$ experiment, are the most sensitive to roughening. This could be uninfluenced by the chemical processes taking place and might be solely due to dispersion in liquid. Overall this data suggests that morphological changes do not occur at a measurable scale without any applied electrochemistry over the course of 3 h. Furthermore, we can conclude AFM can be measured in situ over extended periods of time without any visible tip effects ( $\mathrm{Si}_{3} \mathrm{~N}_{4}$ tips) in extreme alkaline conditions, as this would also have a large influence on the observed features 
in Figures 4.7 and 4.8. This makes this a proof-of-concept for utilizing AFM in these conditions.

\subsubsection{Substrate Effects on Ni-Mo Stability}
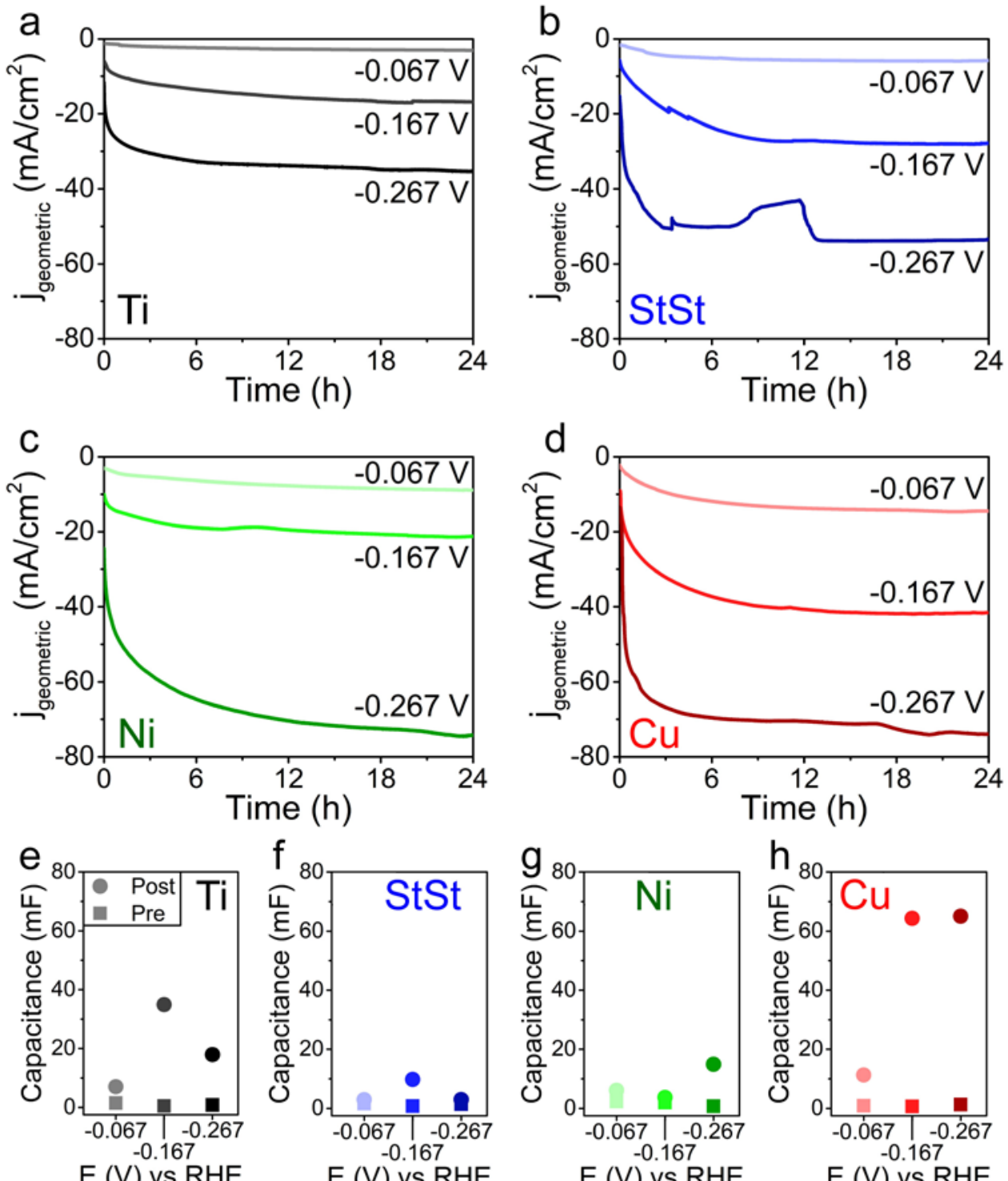

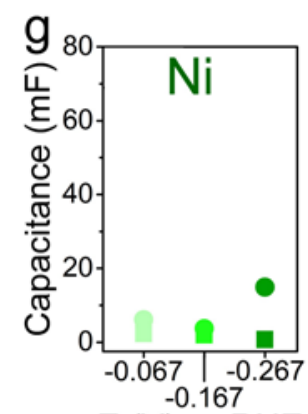

E (V) vs RHE

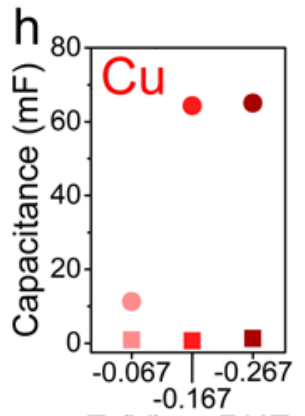

E (V) vs RHE

Figure 4.9: Chrono-amperometric curves at $-0.067 \mathrm{~V},-0.167 \mathrm{~V},-0.267 \mathrm{~V}$ on a) $\mathrm{Ni}$ $\mathrm{Mo} / \mathrm{Ti}$, b) $\mathrm{Ni}-\mathrm{Mo} / \mathrm{StSt}$, c) $\mathrm{Ni}-\mathrm{Mo} / \mathrm{Ni}$ and d) $\mathrm{Ni}-\mathrm{Mo} / \mathrm{Cu}$. The double layer capacitance values before (squares) and after (circles) are shown for Ni-Mo on the different substrates e) $\mathrm{Ti}$, f) StSt, g) $\mathrm{Ni}$ and h) $\mathrm{Cu}$. 
In this work, we study four different substrates: Ti, Ni, Cu and stainless steel (StSt). Ti is studied as a model substrate which was used previously due to its durability and practically non-existent HER activity. ${ }^{[33]} \mathrm{Ni}$ and $\mathrm{Cu}$ are chosen since they have a face-centered cubic (FCC) crystal structure ${ }^{[34]}$, which is the expected crystal structure for Ni-Mo as well. ${ }^{[35,36]}$ Finally, stainless steel is chosen since it's a readily available and durable material.

Shown in Figure 4.9 Ni-Mo behaves significantly differently on different substrates. As can be seen the performance of the materials is strongly dependent on the substrate as well. Activity-wise the performance increases $\mathrm{Cu}>\mathrm{Ni}>\mathrm{StSt}>\mathrm{Ti}$. It remains true for all cases that there is activation over time,
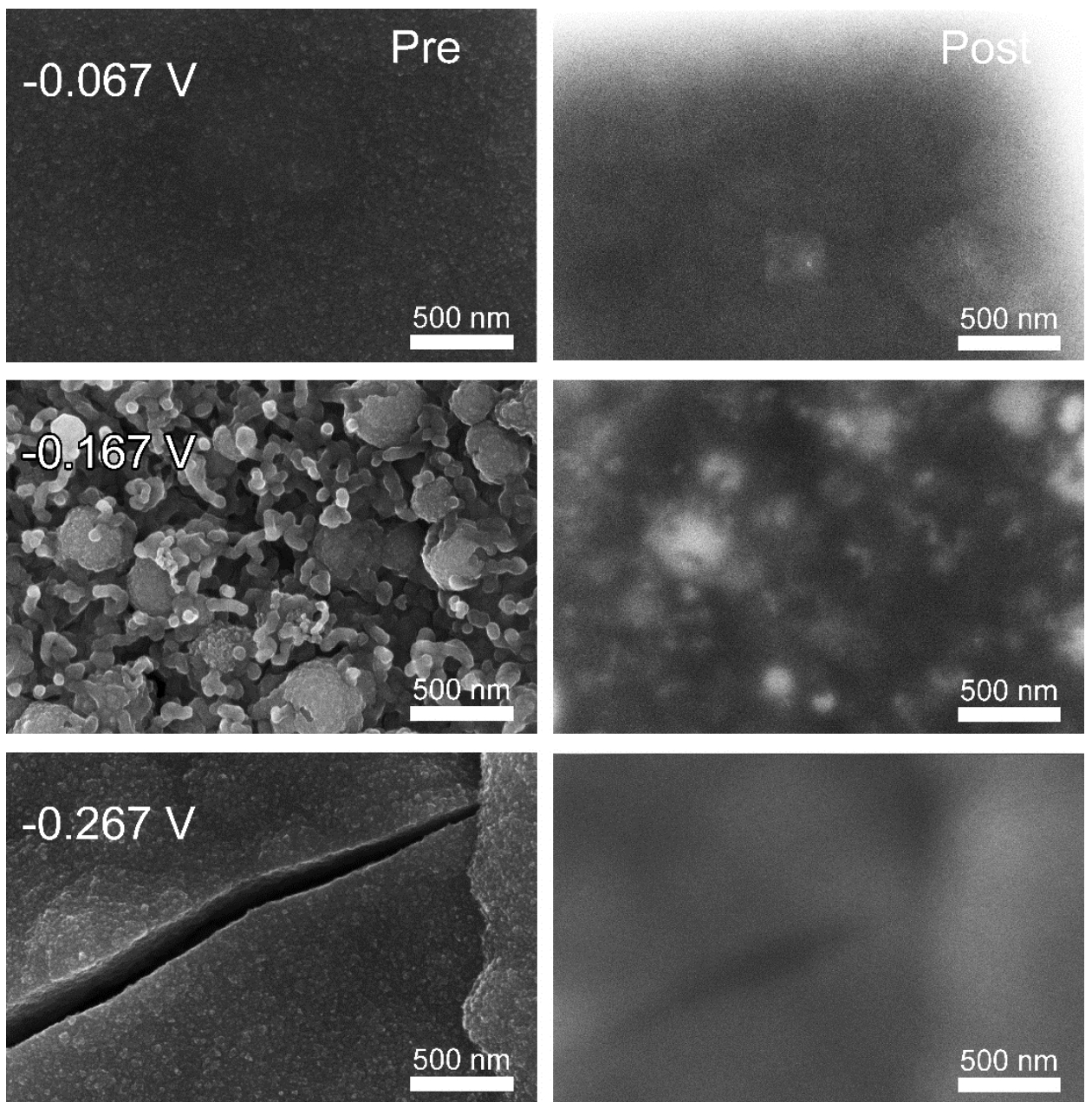

Figure 4.10: SEM micrographs of Ni-Mo/StSt before (left) and after (right) chronoamperometric catalysis for $24 \mathrm{~h}$ in $1 \mathrm{M} \mathrm{KOH}$ at different potentials. 
which can now be safely assumed to be an effect of Ni-Mo and not substrate related. It is furthermore not an effect of the catalytic activity of the substrates since it is well-known that StSt and Ni are significantly better at HER than $\mathrm{Cu}$. Meanwhile, there are interesting observations as well when considering the change in capacitance. StSt, like Ti, results in an intermediary potential at which the change is most significant. For $\mathrm{Ni}$ and $\mathrm{Cu}$, which are the $\mathrm{FCC}$ structures, we see that higher potentials (within the tested range) result in higher capacitance changes. This sparked the interest to explore in more detail these observed differences.

Studying the morphology of the Ni-Mo depositions showed us that similar morphologies form according to SEM (Figures 10-12 for $\mathrm{Ni}, \mathrm{Cu}$, and StSt
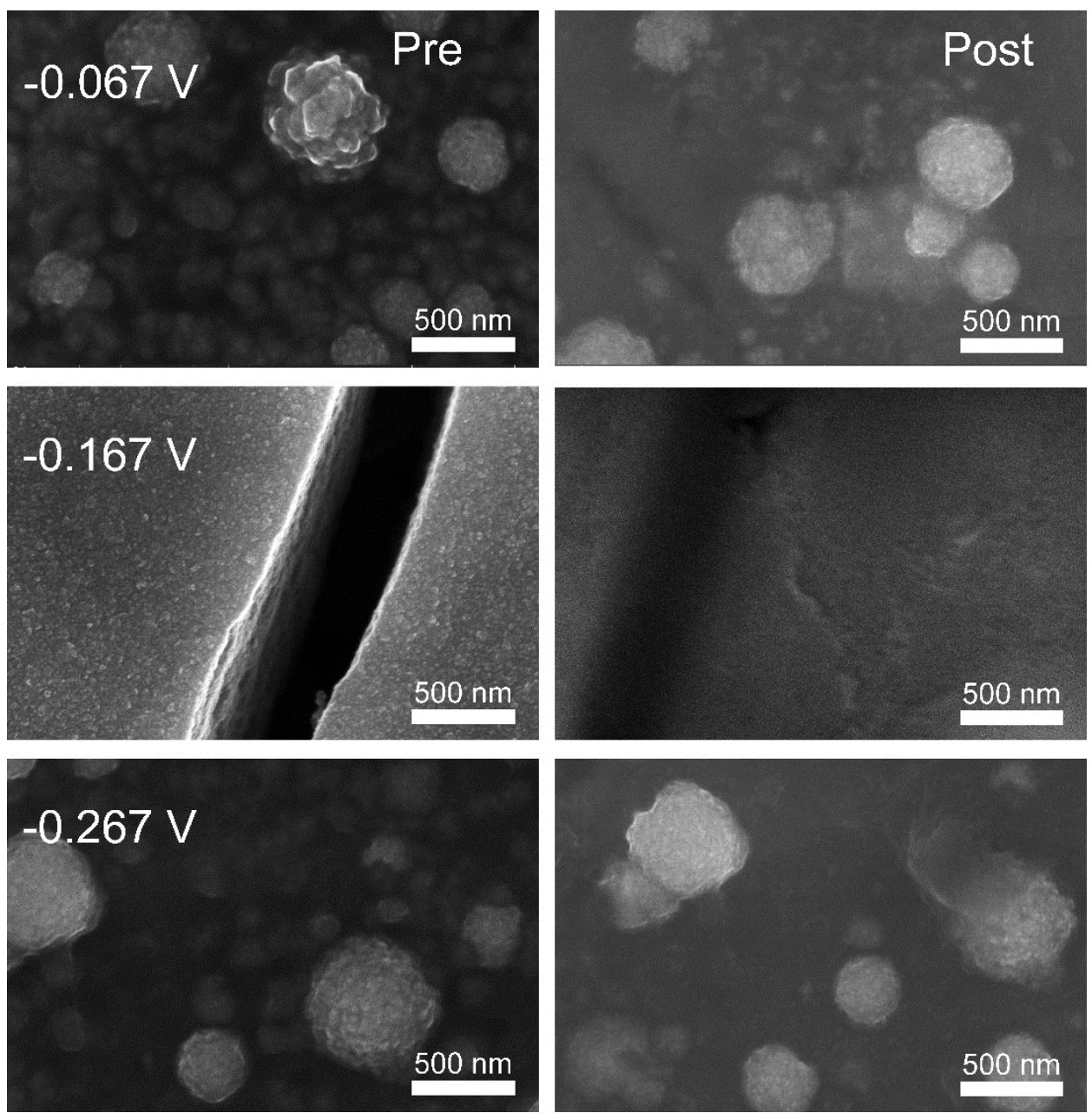

Figure 4.11: SEM micrographs of Ni-Mo/Ni before (left) and after (right) chronoamperometric catalysis for $24 \mathrm{~h}$ in $1 \mathrm{M} \mathrm{KOH}$ at different potentials. 

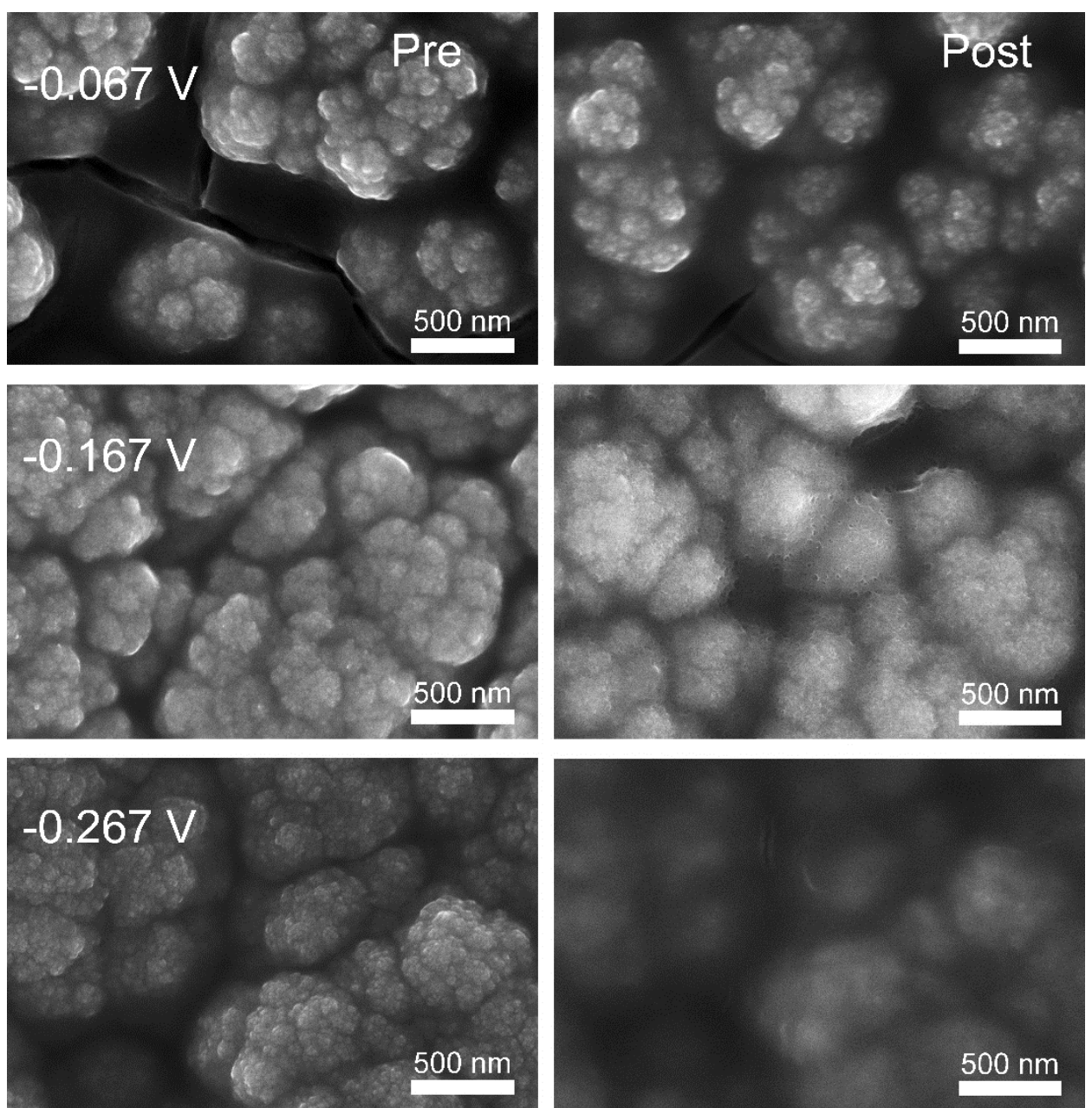

Figure 4.12: SEM micrographs of $\mathrm{Ni}-\mathrm{Mo} / \mathrm{Cu}$ before (left) and after (right) chronoamperometric catalysis for $24 \mathrm{~h}$ in $1 \mathrm{M} \mathrm{KOH}$ at different potentials.

respectively). Furthermore, studying these SEM micrographs and comparing them also with Figure 4.3 for Ni-Mo/Ti it can be said that morphologically these samples behave similarly. It should be noted that all micrographs are in focus, and in the cases it does not seem to be so it was due to a lack of contrast in the sample, in those cases cracks which were near the pre-measured spot were used to achieve optimal focus. All the samples show a similar morphological response to the presence of $K$ at the sample surfaces. As seen in Table 4.3 there is always a loss of Mo from all these samples. The extent of observed leaching/segregation, however, is significantly different and seems to depend on both potential and substrate. It is furthermore an interplay of these parameters as the potential dependency of leaching is different for each of the substrates. 

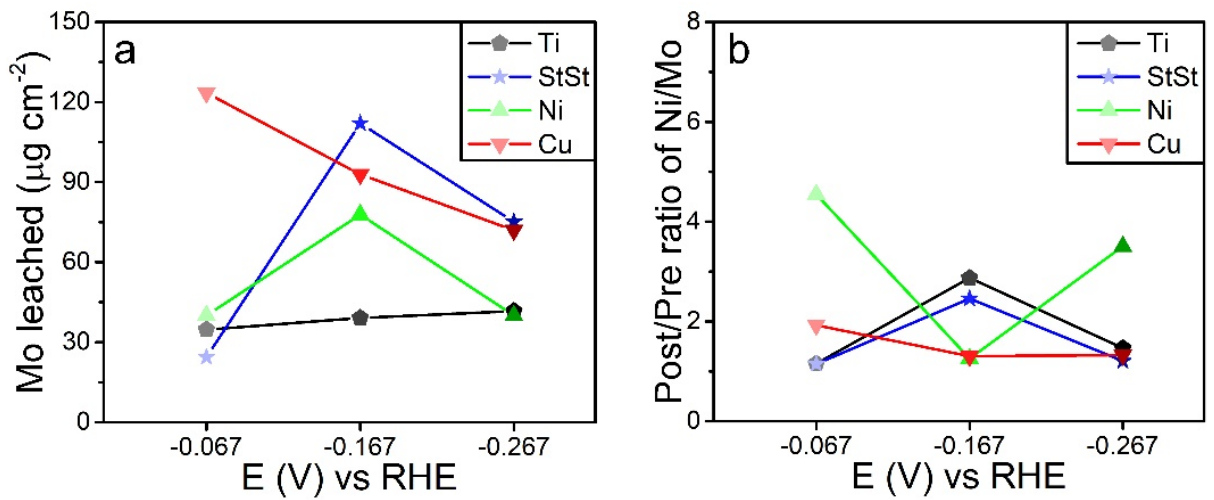

Figure 4.13: a) The amount of Mo leached as a function of applied potential after $24 \mathrm{~h}$ of chrono-amperometric catalysis on Ni-Mo on Ti (pentagons), StSt (stars), Ni (upward triangles), and $\mathrm{Cu}$ (downward triangles). b) The ratio of Ni/Mo ratios found by EDX before and after catalysis for the same materials.

Table 4.3: Atomic ratios as found by SEM-EDX before (regular) and after (bold) $24 \mathrm{~h}$ of chrono-amperometry. Only $\mathrm{Ni}, \mathrm{Mo}, \mathrm{Na}$ and $\mathrm{K}$ are considered and thus add up to 100 at\%. Other elements are (adventitious) C, O, and Si, the latter being present as SiC particles that had left by the sanding paper. For Ni-Mo/StSt Fe and $\mathrm{Cr}$ were also observed, for Ni-Mo/Cu Cu was observed. The last column shows the ratio of Ni/Mo. It should be noted that the Ni/Mo ratio for Ni-Mo/Ni and Ni-Mo/StSt is not representative due to the substrate also giving off signal which is very dependent on the thickness.

\begin{tabular}{|c|c|c|c|c|c|}
\hline 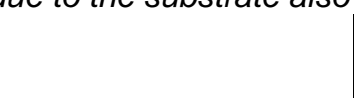 & Ni (at\%) & $\begin{array}{c}\text { Mo } \\
\text { (at\%) }\end{array}$ & $\mathrm{Na}(\mathrm{at} \%)$ & $\mathrm{K}(\mathrm{at} \%)$ & $\begin{array}{c}\mathrm{Ni} / \mathrm{Mo} \\
\text { ratio }\end{array}$ \\
\hline Ni-Mo/StSt -0.067 V & 65.0 & 30.3 & 4.9 & - & 2.15 \\
\hline Ni-Mo/StSt $-0.067 \mathrm{~V}$ & 68.8 & 27.9 & - & 3.3 & 2.47 \\
\hline Ni-Mo/StSt -0.167 V & 69.1 & 19.1 & 11.8 & - & 3.62 \\
\hline Ni-Mo/StSt $-0.167 \mathrm{~V}$ & 73.2 & 8.2 & - & 18.6 & 8.90 \\
\hline $\mathrm{Ni}-\mathrm{Mo} / \mathrm{StSt}-0.267 \mathrm{~V}$ & 68.5 & 29.6 & 1.9 & - & 2.31 \\
\hline Ni-MolStSt $-0.267 \mathrm{~V}$ & 70.0 & 25.1 & - & 4.9 & 2.79 \\
\hline Ni-Mo/Ni -0.067 V & 81.5 & 11.8 & 6.7 & - & 6.91 \\
\hline Ni-Mo/Ni $-0.067 \mathrm{~V}$ & 94.3 & 3 & - & 2.7 & 31.43 \\
\hline $\mathrm{Ni}-\mathrm{Mo} / \mathrm{Ni}-0.167 \mathrm{~V}$ & 65.5 & 31 & 3.5 & - & 2.11 \\
\hline Ni-Mo/Ni $-0.167 \mathrm{~V}$ & 70.7 & 26.7 & - & 2.6 & 2.65 \\
\hline $\mathrm{Ni}-\mathrm{Mo} / \mathrm{Ni}-0.267 \mathrm{~V}$ & 87.5 & 3.8 & 8.7 & - & 23.03 \\
\hline Ni-Mo/Ni $-0.267 \mathrm{~V}$ & 96.9 & 1.2 & - & 1.9 & 80.75 \\
\hline Ni-Mo/Cu $-0.067 \mathrm{~V}$ & 63.2 & 27 & 9.8 & - & 2.34 \\
\hline Ni-Mo/Cu -0.067 V & 81.1 & 18.0 & - & 0.8 & 4.51 \\
\hline Ni-Mo/Cu $-0.167 \mathrm{~V}$ & 72.9 & 24.9 & 2.1 & - & 2.93 \\
\hline Ni-Mo/Cu $-0.167 \mathrm{~V}$ & 76.3 & 20.0 & - & 3.8 & 3.82 \\
\hline $\mathrm{Ni}-\mathrm{Mo} / \mathrm{Cu}-0.267 \mathrm{~V}$ & 66.5 & 27.5 & 6 & - & 2.42 \\
\hline Ni-Mo/Cu $-0.267 \mathrm{~V}$ & 72.0 & 22.4 & 0.3 & 5.2 & 3.21 \\
\hline
\end{tabular}


If we compare the loss of Mo observed with EDX again with ICP-AES (Figure 4.13 ) it is clear also from this that the change in EDX signal follows from a combination of at least leaching and surface segregation both. Though in some cases, such as Ni-Mo/Cu the trends in EDX and ICP-AES are the same, the fact that the double layer capacitance does not agree takes away any doubt
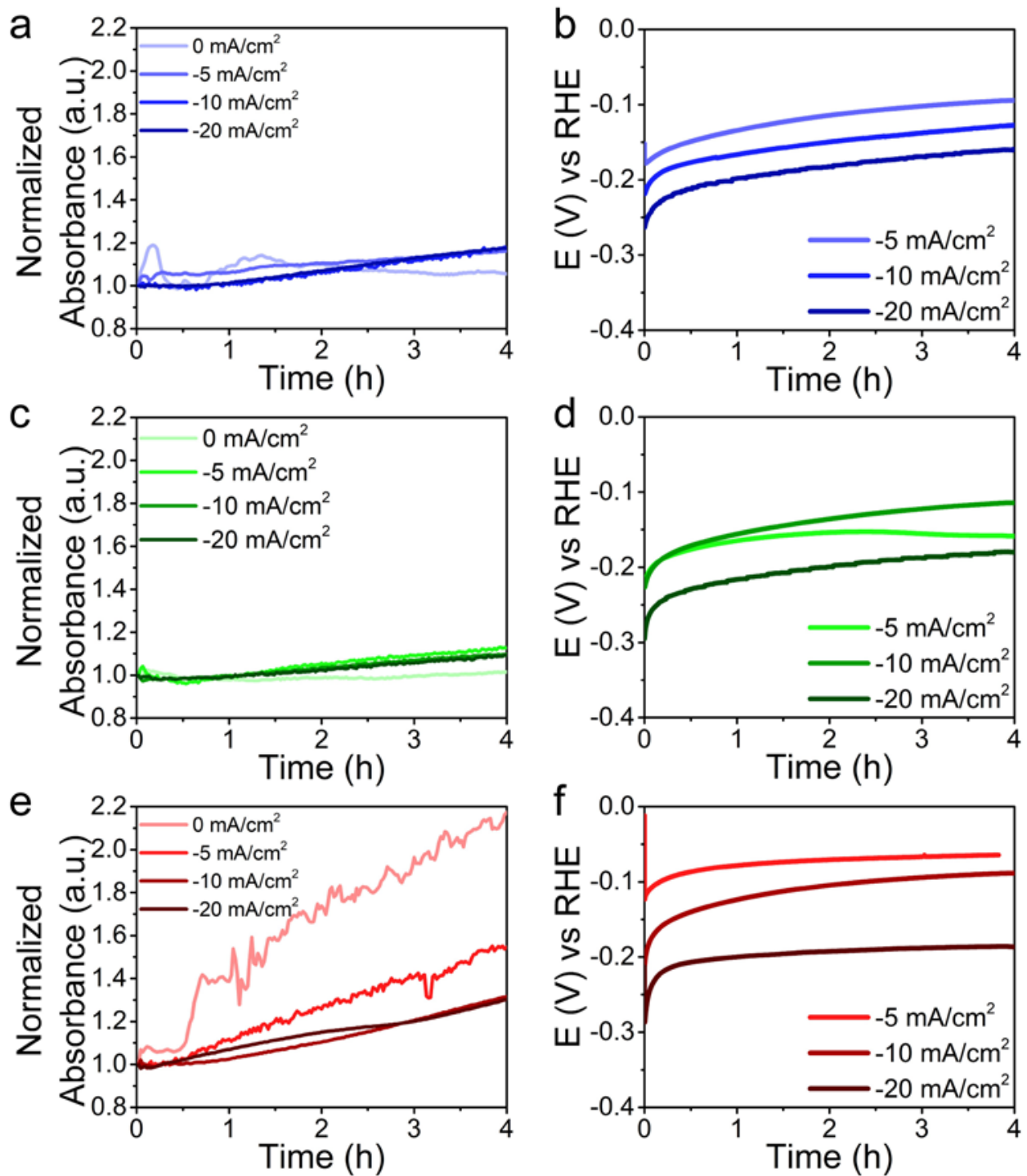

Figure 4.14: a) The normalized UV-Vis signal at $232 \mathrm{~nm}$ over time and b) the corresponding chrono-potentiometric curves on Ni-Mo/StSt. c) The normalized UV-Vis signal at $232 \mathrm{~nm}$ over time and d) the corresponding chrono-potentiometric curves on $\mathrm{Ni}-\mathrm{Mo} / \mathrm{Ni}$. e) The normalized UV-Vis signal at $232 \mathrm{~nm}$ over time and f) the corresponding chrono-potentiometric curves on $\mathrm{Ni}-\mathrm{Mo} / \mathrm{Cu}$. 


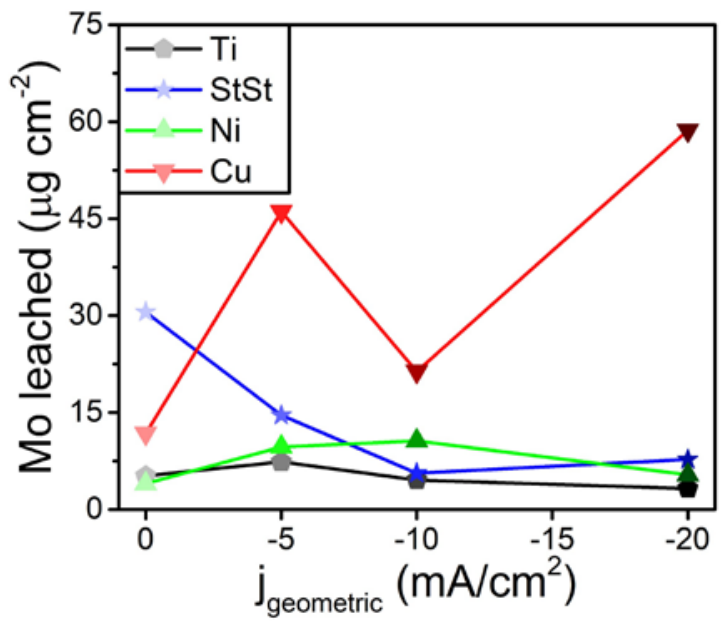

Figure 4.15: ICP-AES signal of Mo leaching after the in situ UV-Vis spectroscopy experiments as a function of applied current for $4 \mathrm{~h}$ on Ni-Mo at different substrates: Ti (pentagons), StSt (stars), Ni (upward triangles) and $\mathrm{Cu}$ (downward triangles). that there are indeed multiple processes influencing the data. Furthermore, the fact that EDX and capacitance measurements disagree for $\mathrm{Cu}$ tells us that morphology change is the most significant contributor in this case, which is in agreement with the significant changes seen in Figure 4.12 with SEM.

ICP-AES does tell us that leaching is strongly dependent not only on potential but also on the substrate used. Different behavior trends are observed with different substrates, where $\mathrm{Mo}$ is more stable in $\mathrm{Ni}-\mathrm{Mo} / \mathrm{Cu}$ at higher overpotentials and or has the strongest leaching at intermediary overpotentials as is the case for $\mathrm{Ni}-\mathrm{Mo} / \mathrm{StSt}$ and $\mathrm{Ni}-\mathrm{Mo} / \mathrm{Ni}$. Furthermore, the order of magnitude of leaching changes with the substrate. Mo is approximately more stable at the tested potentials in the order of $\mathrm{Ti}>\mathrm{Ni}>\mathrm{Cu}>\mathrm{StSt}$.

To exclude the possibility that the leaching pattern does not change with the substrate in situ UV-Vis was also performed (Figure 4.14). As was the case with $\mathrm{Ni}-\mathrm{Mo} / \mathrm{Ti}, \mathrm{Ni}, \mathrm{Cu}$, and $\mathrm{StSt}$ show the same leaching behavior, meaning a fairly constant leaching rate in at least the first $4 \mathrm{~h}$. The rates, however, are vastly different and StSt and Ni perform best in terms of leaching suppression at set currents, closely followed by $\mathrm{Ti}$ (Figure 4.5a) on $\mathrm{Cu}$ however we see significant $\mathrm{MoO}_{4}{ }^{2-}$ signals. Comparing it to ICP-AES data (Figure 4.15) on the spent electrolytes of those samples however we see that there are some disagreements. According to ICP-AES Ti suppresses leaching best, comparable to $\mathrm{Ni}$, whereas StSt substrates allow for significant leaching at lower currents but suppress it just as well at higher currents. $\mathrm{Cu}$, similar to the UV-Vis data gives us high Mo leaching signals.

The reason behind the discrepancy is that with in situ UV-Vis the electrolyte near the sample was being probed, whereas with ICP-AES the electrolyte is homogenized before it was sampled. This suggests that there is likely readsorption or even re-deposition of Mo during the tests. ${ }^{[37]}$ This would also explain the previous observation with depth-profile XPS in Chapter 2 that the 
direct surface concentration of Mo did not follow the trend and was higher. This re-deposition effect is also seen with SEM-EDX (Table 4.4) as the change in $\mathrm{Ni} / \mathrm{Mo}$ ratio disagrees with ICP-AES due to the inhomogeneity in depth of the material. Furthermore, in some cases we even observed the Ni/Mo ratio decreasing, even though in none of the tested samples Ni was found to leach. Possible explanations could thus be surface segregation and/or re-deposition. This effect is mostly seen for the Cu substrate and might be related to the fact that the in situ signal of $\mathrm{MoO}_{4}{ }^{2-}$ is so high, which suggests a lot of $\mathrm{MoO}_{4}{ }^{2-}$ dissolution and in extent high Mo mobility.

Table 4.4: Atomic ratios as found by SEM-EDX before (regular) and after (bold) the in situ UV-Vis spectroscopy experiments. Only Ni, Mo, Na and $\mathrm{K}$ are considered and thus add up to 100 at\%. Other elements that were observed are (adventitious) C, O, and Si, the latter sometimes being present as SiC particles that had been stuck in grooves left by the sanding paper. For Ni-Mo/StSt Fe and $\mathrm{Cr}$ were also observed, for $\mathrm{Ni}-\mathrm{Mo} / \mathrm{Cu} \mathrm{Cu}$ was observed. The last column shows the ratio of Ni/Mo. It should be noted that the $\mathrm{Ni} / \mathrm{Mo}$ ratio for Ni-Mo/Ni and Ni-Mo/StSt is not representative due to the substrate also giving off signal which is very dependent on the thickness.

\begin{tabular}{|c|c|c|c|c|c|}
\hline & $\mathrm{Ni}($ at\%) & $\begin{array}{c}\text { Mo } \\
\text { (at\%) }\end{array}$ & $\begin{array}{c}\mathrm{Na} \\
(\mathrm{at} \%)\end{array}$ & K (at\%) & $\begin{array}{l}\mathrm{Ni} / \mathrm{Mo} \\
\text { ratio }\end{array}$ \\
\hline $\mathrm{Ni}-\mathrm{Mo} / \mathrm{StSt} 0 \mathrm{~mA} / \mathrm{cm}^{2}$ & 66.1 & 31.1 & 2.9 & - & 2.13 \\
\hline $\mathrm{Ni}-\mathrm{Mo} / \mathrm{StSt} 0 \mathrm{~mA} / \mathrm{cm}^{2}$ & 61.9 & 32.0 & 2.7 & 3.4 & 1.93 \\
\hline $\mathrm{Ni}-\mathrm{Mo} / \mathrm{StSt}-5 \mathrm{~mA} / \mathrm{cm}^{2}$ & 63.1 & 34.4 & 2.5 & - & 1.83 \\
\hline Ni-MolStSt $-5 \mathrm{~mA} / \mathrm{cm}^{2}$ & 65.6 & 31.3 & - & 3.2 & 2.10 \\
\hline $\mathrm{Ni}-\mathrm{Mo} / \mathrm{StSt}-10 \mathrm{~mA} / \mathrm{cm}^{2}$ & 71.0 & 19.0 & 10 & - & 3.74 \\
\hline $\mathrm{Ni}-\mathrm{Mo} / \mathrm{StSt}-10 \mathrm{~mA} / \mathrm{cm}^{2}$ & 86.0 & 11.6 & - & 1.9 & 7.41 \\
\hline $\mathrm{Ni}-\mathrm{Mo} / \mathrm{StSt}-20 \mathrm{~mA} / \mathrm{cm}^{2}$ & 65.3 & 22.5 & 12.2 & - & 2.90 \\
\hline $\mathrm{Ni}-\mathrm{Mo} / \mathrm{StSt}-20 \mathrm{~mA} / \mathrm{cm}^{2}$ & 74.7 & 22.7 & - & 2.6 & 3.29 \\
\hline $\mathrm{Ni}-\mathrm{Mo} / \mathrm{Ni} 0 \mathrm{~mA} / \mathrm{cm}^{2}$ & 68.9 & 28.8 & 2.3 & - & 2.39 \\
\hline $\mathrm{Ni}-\mathrm{Mo} / \mathrm{Ni} 0 \mathrm{~mA} / \mathrm{cm}^{2}$ & 65.0 & 30.9 & 2.0 & 2.2 & 2.10 \\
\hline $\mathrm{Ni}-\mathrm{Mo} / \mathrm{Ni}-5 \mathrm{~mA} / \mathrm{cm}^{2}$ & 79.2 & 18.9 & 1.9 & - & 4.19 \\
\hline $\mathrm{Ni}-\mathrm{Mo} / \mathrm{Ni}-5 \mathrm{~mA} / \mathrm{cm}^{2}$ & 77.9 & 18.3 & 2.1 & 1.7 & 4.26 \\
\hline $\mathrm{Ni}-\mathrm{Mo} / \mathrm{Ni}-10 \mathrm{~mA} / \mathrm{cm}^{2}$ & 68.8 & 22.2 & 9 & - & 3.10 \\
\hline $\mathrm{Ni}-\mathrm{Mo} / \mathrm{Ni}-10 \mathrm{~mA} / \mathrm{cm}^{2}$ & 67.5 & 24.1 & 1.7 & 6.8 & 2.80 \\
\hline $\mathrm{Ni}-\mathrm{Mo} / \mathrm{Ni}-20 \mathrm{~mA} / \mathrm{cm}^{2}$ & 69.9 & 28.2 & 1.9 & - & 2.48 \\
\hline $\mathrm{Ni}-\mathrm{Mo} / \mathrm{Ni}-20 \mathrm{~mA} / \mathrm{cm}^{2}$ & 67.1 & 27.9 & 1.1 & 4 & 2.41 \\
\hline $\mathrm{Ni}-\mathrm{Mo} / \mathrm{Cu} 0 \mathrm{~mA} / \mathrm{cm}^{2}$ & 67 & 27.2 & 5.8 & - & 2.46 \\
\hline $\mathrm{Ni}-\mathrm{Mo} / \mathrm{Cu} 0 \mathrm{~mA} / \mathrm{cm}^{2}$ & 73.2 & 26.7 & - & 0.1 & 2.74 \\
\hline $\mathrm{Ni}-\mathrm{Mo} / \mathrm{Cu}-5 \mathrm{~mA} / \mathrm{cm}^{2}$ & 62.8 & 28.6 & 8.5 & - & 2.20 \\
\hline $\mathrm{Ni}-\mathrm{Mo} / \mathrm{Cu}-5 \mathrm{~mA} / \mathrm{cm}^{2}$ & 69 & 24.9 & - & 6.1 & 2.77 \\
\hline $\mathrm{Ni}-\mathrm{Mo} / \mathrm{Cu}-10 \mathrm{~mA} / \mathrm{cm}^{2}$ & 68.5 & 28.3 & 3.2 & - & 2.42 \\
\hline $\mathrm{Ni}-\mathrm{Mo} / \mathrm{Cu}-10 \mathrm{~mA} / \mathrm{cm}^{2}$ & 67.4 & 22.9 & - & 9.7 & 2.94 \\
\hline $\mathrm{Ni}-\mathrm{Mo} / \mathrm{Cu}-20 \mathrm{~mA} / \mathrm{cm}^{2}$ & 68.3 & 29.3 & 2.4 & - & 2.33 \\
\hline $\mathrm{Ni}-\mathrm{Mo} / \mathrm{Cu}-20 \mathrm{~mA} / \mathrm{cm}^{2}$ & 70.0 & 26.7 & - & 3.4 & 2.62 \\
\hline
\end{tabular}




\subsection{Conclusions}

To summarize in this work (Figure 4.16), on one hand, Ni-Mo/Ti stability was further explored and the effect of $\mathrm{K}^{+}$inclusion could be ascribed to porosity and both leaching and surface segregation were observed. The change in double layer capacitance that has been reported before for this material was found to be most sensitive to the change in Ni/Mo ratio on the surface and not surface roughening, showing that care is needed when using this value as a measure of surface area. This study was then extended to in situ UV-Vis spectroscopy and AFM measurements to further confirm surface roughening and Mo leaching as $\mathrm{MoO}_{4}{ }^{2-}$ and shows that leaching has a constant rate in the first $4 \mathrm{~h}$ and does not directly correspond to the change in activity.

The effect of potential was also studied and found to influence the stability on several levels. Since there is an optimum in the potential for $\mathrm{Ni}-\mathrm{Mo} / \mathrm{Ti}$ there is both a stabilizing and destabilizing effect of potential on the material. These were ascribed to the reducing potential hampering Mo oxidation towards $\mathrm{Mo}^{6+}$ (in the form of $\mathrm{MoO}_{4}{ }^{2-}$ ) whereas stronger reducing potentials also lead towards more HER and thus higher local $\mathrm{pH}\left(\mathrm{OH}^{-}\right.$concentrations) which increase Mo leaching as seen in the leaching mechanism $\mathrm{Mo}+2 \mathrm{OH}^{-}+2 \mathrm{H}_{2} \mathrm{O} \rightarrow \mathrm{MoO}_{4}{ }^{2-}+$ $3 \mathrm{H}_{2}$.

We showed in situ AFM measurements on Ni-Mo are possible and tracked the progress of leaching without applied potential as a function of $\mathrm{pH}$. It was observed that the behavior of the samples is not homogeneous and that the particulate rougher features seem to be more sensitive to leaching than the flatter morphology of the bulk. It also shows that the samples do not visibly roughen without applied potential over the course of $3 \mathrm{~h}$.

On the other hand, inspired by support effects often seen in classical heterogeneous catalysis, we studied the effect of the support. Using earlier established techniques such as SEM-EDX, in situ UV-Vis, double layer capacitance and ICP-AES the stability of Ni-Mo was studied on $\mathrm{Ti}, \mathrm{Cu}, \mathrm{Ni}$ and StSt (stainless steel). It was found that the substrate also is of significant influence when studying Ni-Mo and potentially other electrocatalysts as well. Activity-wise we found that the highest currents are found for $\mathrm{Ni}-\mathrm{Mo} / \mathrm{Cu}$ and $\mathrm{Ni}$ $\mathrm{Mo} / \mathrm{Ni}$ followed by Ni-Mo/StSt and finally Ni-Mo/Ti.

The response of Ni-Mo towards potential was also found to be clearly dependent on the substrate and in each case the observed trends were different. Ni-Mo/Ti is described above, and similarly, Ni-Mo/StSt shows an optimum in capacitance change, but in this case, it is followed by the Mo leaching found with ICP-AES. Ni-Mo/Ni and $\mathrm{Ni}-\mathrm{Mo} / \mathrm{Cu}$ both show that the capacitance change increases with overpotential. The ICP-AES signal for Mo 


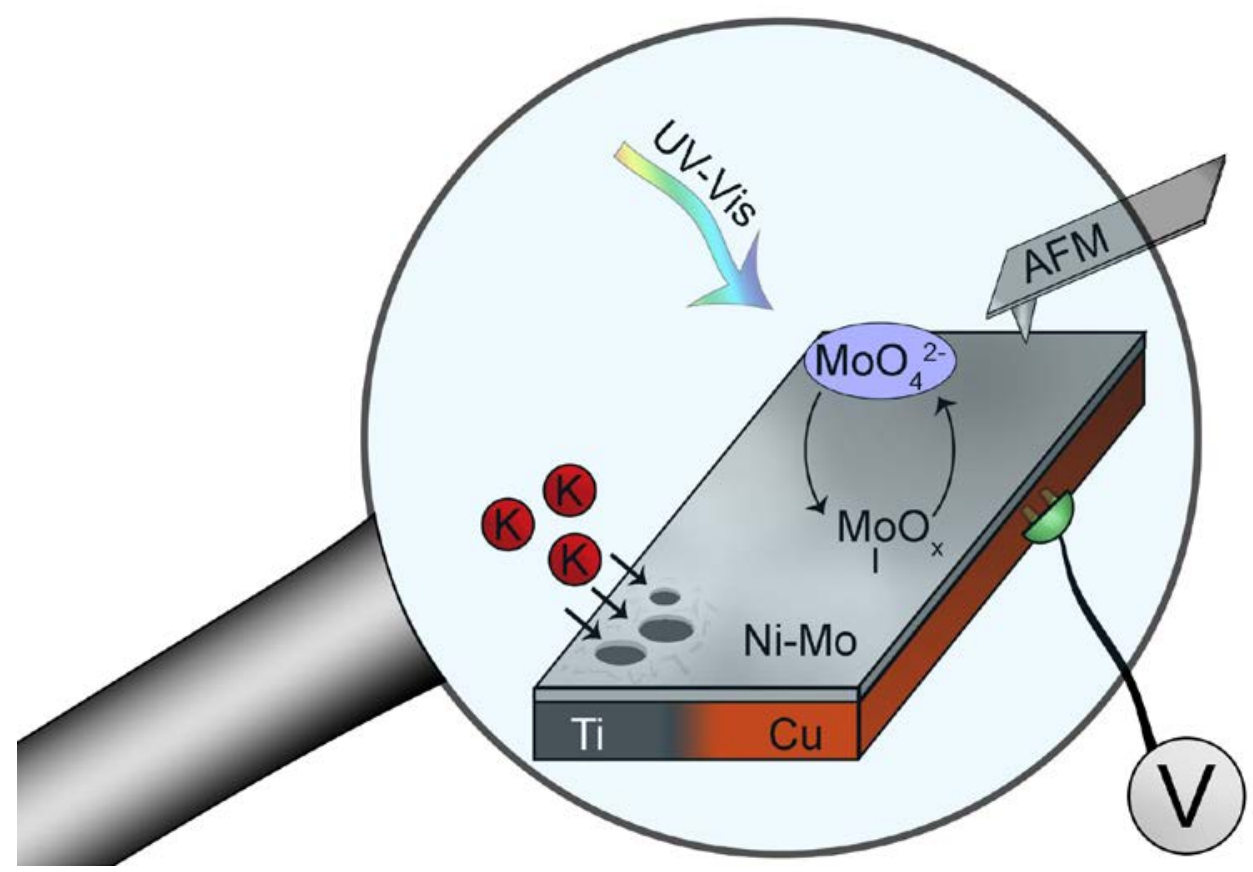

Figure 4.16: Schematic summary of the results obtained in this PhD chapter. $\mathrm{K}^{+}$ presence is linked to the morphology change and porosity formation and $\mathrm{MoO}_{4}{ }^{2-}$ leaching clearly is an equilibrium and re-deposition occurs. In situ UV-Vis spectroscopy and in situ AFM were used to follow these effects as a function of potential and substrate.

does not follow this result however and shows that leaching decreases with potential for $\mathrm{Ni}-\mathrm{Mo} / \mathrm{Cu}$ and hits an optimum for $\mathrm{Ni}-\mathrm{Mo} / \mathrm{Ni}$.

Exploring further the effects in situ UV-Vis spectroscopy was again employed and in that case it can be seen there is a slow build-up of the $\mathrm{MoO}_{4}{ }^{2-}$ near the electrode surface in each system. This is again in disagreement with the ICPAES data that followed and led us to suggest that $\mathrm{MoO}_{4}{ }^{2-}$ not only leaches but also re-adsorbs.

So finally it was thus found that $\mathrm{MoO}_{4}{ }^{2-}$ leaches and is affected by potential in at least two ways. These are suggested to be Mo stabilization by the reducing potential as well as an increase in local $\mathrm{pH}$ near the surface destabilizing it. $\mathrm{K}^{+}$ found in the pores is clearly linked to the observed morphology changes but it cannot be concluded whether it's the cause or a result of said change. Finally, the substrate also plays a vital role in Ni-Mo performance and stability and 
changes the response of Mo stability in multiple ways as the change in capacitance, Mo leaching, and surface composition without any clear trends.

The best stability for Ni-Mo was found at $-0.067 \mathrm{~V}$ vs RHE for Ni-Mo/StSt exhibiting the lowest Mo leaching after $24 \mathrm{~h}$ as well as a very low change in capacitance.

\subsection{Experimental}

\subsubsection{Chemicals and Materials}

All materials were used as received without further purification. $\mathrm{NiSO}_{4} \cdot 6 \mathrm{H}_{2} \mathrm{O}$ (ReagentPlus, $>99 \%$ pure), $\mathrm{NaMoO}_{4} \cdot 2 \mathrm{H}_{2} \mathrm{O}$ (ACS reagent, $>99 \%$ pure), $\mathrm{KOH}$ (ACS reagent, $>85 \%$ pure), and $\mathrm{Na}_{3} \mathrm{C}_{6} \mathrm{H}_{5} \mathrm{O}_{7} \cdot 2 \mathrm{H}_{2} \mathrm{O}$ (sodium citrate, ACS reagent, $>99 \%$ pure) were received from Sigma Aldrich. $\mathrm{NH}_{3} 28-30 \%$ (ACS reagent, ph. Eur. for analysis) was obtained from Emsure. In all experiments, deionized water was used.

\subsubsection{Electrodeposition}

Ti stubs (99.99+ \%, Goodfellow), Ni stubs (99.99+\%, Goodfellow), Cu stubs (99.99+ \%, Goodfellow) and StSt (AISI 316L, $69 \% \mathrm{Fe}, 18 \% \mathrm{Cr}, 10 \% \mathrm{Ni}, 3 \%$ Mo, Goodfellow) were machined into round substrates of similar shape to SEM stubs with a surface area of $1.257 \mathrm{~cm}^{2}$ (Figure 2.22a-b) in Chapter 2 for details). The stubs were fixed into three-electrode cells for electrodeposition (Figure 2.22c-e in Chapter 2 for details on the cell) after being polished with SiC paper with increasing grit $(500,1200,4000)$, and cleaned by sonication in three steps (15 min each in 1:1 Ethanol:Acetone, $2 \mathrm{M} \mathrm{HNO}_{3}$ and deionized water). Galvanostatic electrodeposition was performed with an Ivium Compactstat at a current of $-100 \mathrm{~mA}$ for $1200 \mathrm{~s}$ while stirring at $400 \mathrm{rpm}$. A Pt mesh electrode (Mateck, 99.9+\%) was used as a counter electrode and no Pt leaching was observed (Chapter 2). A $3 \mathrm{M} \mathrm{KCl} \mathrm{BASi} \mathrm{Ag} / \mathrm{AgCl}$ electrode was used as a reference electrode.

The used plating baths contained $0.3 \mathrm{M} \mathrm{NiSO}_{4}, 0.2 \mathrm{M} \mathrm{Na}_{2} \mathrm{MoO}_{4}$ and $0.3 \mathrm{M}$ $\mathrm{Na}_{3} \mathrm{C}_{6} \mathrm{H}_{5} \mathrm{O}_{7}$ in $100 \mathrm{~mL}$ deionized water. To this solutions $10 \mathrm{~mL} \mathrm{NH}$ is added to achieve a pH of 9.2. Separate plating baths were used for each substrate type to prevent cross contamination of the substrates. Prior to deposition the plating bath was purged with $\operatorname{Ar}(5.0)$ to deoxygenize at a flow of $20 \mathrm{~mL} / \mathrm{min}$ for at least $15 \mathrm{~min}$. The average Ni/Mo ratio (from SEM-EDX) of the materials after synthesis was $2.73 \pm 0.72(\mathrm{Ni}-\mathrm{Mo} / \mathrm{Ti}), 1.78 \pm 0.69$ (Ni-Mo/StSt), 13.47 \pm 9.7 (Ni$\mathrm{Mo} / \mathrm{Ni})$, and $2.35 \pm 0.28(\mathrm{Ni}-\mathrm{Mo} / \mathrm{Cu})$. The error in $\mathrm{Ni}-\mathrm{Mo} / \mathrm{Ni}$ is large due to the change in substrate contribution to the signal as a result of changing deposition thickness. 


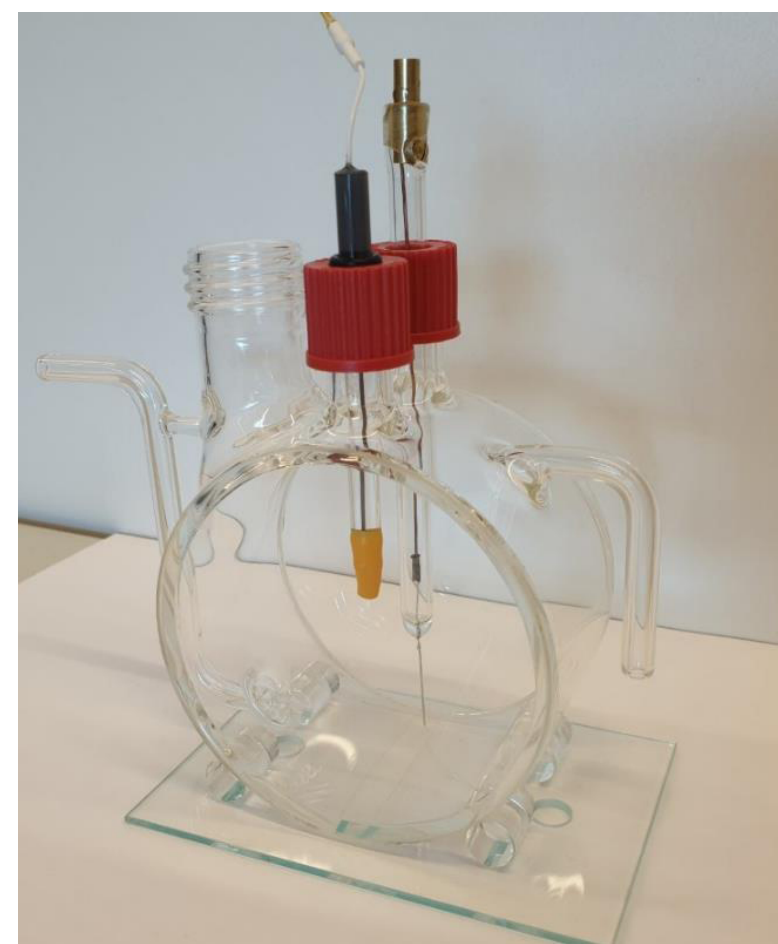

Figure 4.17: Photograph of the in situ UV-Vis spectroscopy cell with the Pt wire and BASi reference electrode.

\subsubsection{Electrochemical characterization}

Electrochemical testing on samples was done as follows. The samples were loaded in three-electrode cells with a $\mathrm{Pt}$ mesh counter electrode and a 3 M Ag/AgCl (Metrohm, shielded, $-0.207 \mathrm{~V}$ vs SHE, which is $-1.033 \mathrm{~V}$ vs RHE $(\mathrm{pH}$ 14)) reference electrode. $1 \mathrm{M} \mathrm{KOH}$ is used as an electrolyte at $\mathrm{pH}$ values of 14 . First, double layer capacitance measurements were performed between $-0.7 \mathrm{~V}$ and $-0.9 \mathrm{~V}$ vs $\mathrm{Ag} / \mathrm{AgCl}$ at $100,200,300,400$ and 500 $\mathrm{mV} / \mathrm{s}$ for 3 cycles each. Following this a linear sweep was performed at 50 $\mathrm{mV} / \mathrm{s}$ from $-1 \mathrm{~V}$ to $-1.3 \mathrm{~V}$ vs $\mathrm{Ag} / \mathrm{AgCl}$ to confirm no polluting electrochemical processes take place (data not shown). Finally, chrono-amperometry was performed for $24 \mathrm{~h}$ at $-1.1 \mathrm{~V}$, $1.2 \mathrm{~V}$ and $-1.3 \mathrm{~V}$ vs $\mathrm{Ag} / \mathrm{AgCl}(-0.067 \mathrm{~V},-0.167 \mathrm{~V}$ and $-0.267 \mathrm{~V}$ vs $\mathrm{RHE})$. The linear sweep and double layer capacitance measurements were performed again afterward. Double layer capacitance values were obtained by taking the difference between the forward and backward current of the third scan. Data was averaged between $0.795-0.805 \mathrm{~V}$ for each point. The resulting double layer thickness was then plotted versus the scan rate. The linear fit of these points yields the capacitance.

During the in situ UV-Vis spectroscopy experiments the samples were loaded in a three-electrode Suprasil Quartz cell (Figure 4.17). Chrono-potentiometry was performed for $4 \mathrm{~h}$ at $-5 \mathrm{~mA} / \mathrm{cm}^{2},-10 \mathrm{~mA} / \mathrm{cm}^{2}$ and $-20 \mathrm{~mA} / \mathrm{cm}^{2}$. The potentiostat was not used for the $0 \mathrm{~mA} / \mathrm{cm}^{2}$ measurements. No linear sweep, nor capacitance measurements were performed in these cases. A Pt wire (Mateck, 99.9+ \%) was used as a counter electrode and a $3 \mathrm{M} \mathrm{BASi} \mathrm{Ag} / \mathrm{AgCl}$ reference electrode was used. 


\subsubsection{In situ UV-Vis spectroscopy}

In situ UV-Vis spectroscopy was performed by using a PerkinElmer Lambda 950 s spectroscope. Measurements were done from $600 \mathrm{~nm}$ to $200 \mathrm{~nm}$ with 4 $\mathrm{nm}$ intervals which allows for 180 measurements during $4 \mathrm{~h} . \mathrm{A} \mathrm{D}_{2}$ lamp and tungsten lamp are used and the switch was set at $319.2 \mathrm{~nm}$. Measurements were done in transmission mode and a blank was taken prior to each measurement. Dense black cloth was effectively used to block incoming ambient light through the small opening left by the potentiostat cable, tested by measurements with and without the cloth and with and without the cable (data not shown). A long measurement range was used in each experiment as a control for possible $\mathrm{Ni}, \mathrm{Cu}, \mathrm{Cr}, \mathrm{Fe}$, or $\mathrm{Ti}$ leaching. The $\mathrm{MoO}_{4}{ }^{2-}$ peak was analyzed by plotting the intensity at the rising part of the band $(232 \mathrm{~nm})$ since $\mathrm{O}_{2}$ UV absorption (ozone formation) started at lower wavelengths and resulted in significant interference.

\subsubsection{In situ AFM}

In-situ liquid-phase Atomic Force Microscopy (AFM) measurements were performed on a Bruker Multimode using SNL-10A silicon nitride cantilevers ( $F$ $=0.175 \mathrm{~N} / \mathrm{m}$ ) in PeakForce tapping mode. The moment of sample immersion was set as $\mathrm{t}=0$, then the AFM was optimized to measure a $10 \times 10 \mu \mathrm{m}^{2}$ spot with a frequency of $0.8 \mathrm{~Hz}$, resulting in an image every $11 \mathrm{~min}$. The data was post-processed using Gwyddion. First, the images were flattened using a plane background subtraction and a trimmed median of differences row alignment. The resulting images were used in Figure (Figure 4.7). Subsequently, two
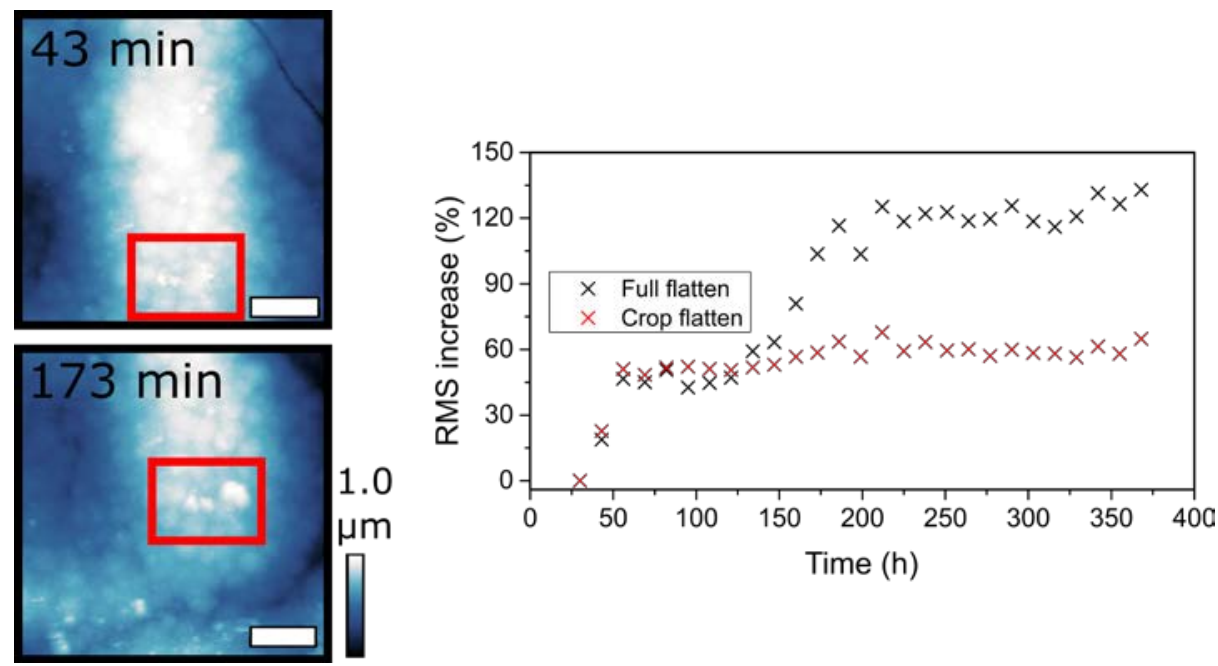

Figure 4.18: AFM micrographs of Ni-Mo-Ti in $6 \mathrm{M}$ solution at different times, showing the displacement due to drift. The black box represents the full image flattening area, while the red box represents the cropped selection area. Right: The RMS of the selected area (red) is plotted over time when flattening is performed over the red box only, or the full black box. 
region of interests which were found throughout the majority of timeframes were selected. These areas were cropped, flattened in a similar manner as described above, and then used to plot the roughness (RMS, from "Statistical Functions"). The crop/flattening was essential, as drift highly influences the general background plane in the full images (as can be seen from the two different displayed time snapshots), resulting in different RMS values over time when they are not selectively cropped, Figure 4.18 . The black crosses represent the RMS of the selected area when plotted after flattening was performed over the full images. The red crosses represent the RMS of the selected area when plotted after cropping the selection and repeating the flattening steps, fundamentally representing the roughness of the selected surface.

\subsubsection{Structural characterization}

ICP-AES was performed using an Optima 8300 instrument from Perkin Elmer. Electrolytes were decreased in $\mathrm{pH}$ to add $1 \mathrm{~mL} 65 \% \mathrm{HNO}_{3}$ per $10 \mathrm{~mL}$ electrolyte, resulting in ca. $2 \% \mathrm{HNO}_{3}$. Ni $(231.604 \mathrm{~nm}), \mathrm{K}(766.491 \mathrm{~nm}), \mathrm{Na}$ $(589.592 \mathrm{~nm}), \mathrm{Ti}(334.187 \mathrm{~nm}), \mathrm{Cr}(205.560 \mathrm{~nm}), \mathrm{Cu}(327.393 \mathrm{~nm}), \mathrm{Fe}$ $(259.939 \mathrm{~nm})$, Pt $(214.423 \mathrm{~nm})$, and Mo $(202.095 \mathrm{~nm})$ were then measured.

SEM-EDX was performed on a FEI Helios nanolab 600 DualBeam with an Oxford instruments Silicon Drift Detector X-Max energy dispersive spectroscope. EDX mapping was performed with an electron beam of $15 \mathrm{kV}$ and $0.8 \mathrm{nA}$. All SEM imaging was done using secondary electrons at $15 \mathrm{kV}$ and $0.8 \mathrm{nA}$. Wide images were first shot to ensure the larger magnifications were taken at representative areas of the material (data not shown for brevity).

\subsection{Author Contributions and Acknowledgements}

Jochem Wijten and Laurens Mandemaker conceived the research plans under the supervision of Bert Weckhuysen. Jochem Wijten and Jeroen Dubbeld designed and performed the in situ UV-Vis experiments under the supervision of Bert Weckhuysen. Jochem Wijten and Tess van Eeden performed the experiments on different substrates under the supervision of Bert Weckhuysen. Laurens Mandemaker performed the in situ AFM experiments in collaboration with Jochem Wijten. Jochem Wijten wrote the work with input from Laurens Mandemaker and with feedback and corrections by Bert Weckhuysen.

The following people are gratefully acknowledged: Oscar Kerkenaar (UU), and Ramon Oord (UU) are thanked for technical input with the in situ UV-Vis spectroscopy experiments. Peter de Graaf and Matthijs Krijnen are thanked for the help in designing the in situ UV-Vis electrochemical spectroscopic cell. Guusje Delen (UU) is thanked for her input while designing the in situ AFM electrochemical cell. Ivar Pel is thanked for making the photographs used in this PhD Chapter. 


\subsection{References}

[1] McCrory, C. C. L., Jung, S., Ferrer, I. M., Chatman, S. M., Peters, J. C. \& Jaramillo, T. F., J. Am. Chem. Soc. 2015, 137, 4347-4357

[2] Gao, M. Y., Yang, Y., Zhang, Q. B., Zeng, J. R., Li, X. T., Hua, Y. X., Xu, C. Y. \& Dong, P., J. Mater. Chem. A 2017, 5, 5797-5805

[3] Heide, D., von Bremen, L., Greiner, M., Hoffmann, C., Speckmann, M. \& Bofinger, S., Renew. Energy 2010, 35, 2483-2489

[4] Schlögl, R., Angew. Chem. Int. Ed. 2017, 56, 11019-11022

[5] Schlögl, R., Angew. Chem. Int. Ed. 2015, 54, 4436-4439

[6] Dong, B., Zhao, X., Han, G., Li, X., Shang, X. \& Liu, Y., J. Mater. Chem. A 2016, 4, 13499-13508

[7] Che, Q., Li, Q., Tan, Y., Chen, X., Xu, X. \& Chen, Y., Appl. Catal. B Environ. 2019, 246, 337-348

[8] Ganesan, P., Sivanantham, A. \& Shanmugam, S., J. Mater. Chem. A 2016, 4, 16394-16402

[9] Zhang, J., Hu, Y., Liu, D., Yu, Y. \& Zhang, B., Adv. Sci. 2017, 4, 1600343

[10] Liu, Y., Jiang, S., Li, S., Zhou, L., Li, Z., Li, J. \& Shao, M., Appl. Catal. B Environ. 2019, 247, 107-114

[11] Wijten, J. H. J., Riemersma, R. L., Gauthier, J., Mandemaker, L. D. B., Verhoeven, M. W. G. M. T., Hofmann, J. P., Chan, K. \& Weckhuysen, B. M., ChemSusChem 2019, 12, 3491-3500

[12] Zeng, Y. \& Zhou, S., Electrochem. Commun. 1999, 1, 217-222

[13] Petr, A., Dunsch, L. \& Neudeck, A., J. Elect. 1996, 412, 153-158

[14] Kaninski, M. P. M., Saponjic, D. P., Perovic, I. M., Maksic, A. D. \& Nikolic, V. M., Appl. Catal. A, Gen. 2011, 405, 29-35

[15] Lang, S., Shi, Y., Guo, Y., Wang, D., Wen, R. \& Wan, L., Angew. Chem. Int. Ed. 2016, 55, 15835-15839

[16] Lang, S., Shi, Y., Guo, Y., Wen, R. \& Wan, L., Angew. Chem. Int. Ed. 2017, 56, 14433-14437

[17] Deng, X., Galli, F. \& Koper, M. T. M., J. Am. Chem. Soc. 2018, 140, 13285-13291

[18] Schalenbach, M., Speck, F. D., Ledendecker, M., Kasian, O., Goehl, D., Mingers, A. M., Breitbach, B., Springer, H., Cherevko, S. \& Mayrhofer, K. J. J., Electrochim. Acta 2018, 259, 1154-1161

[19] Krstajic, N. V, Jovic, V. D., Gajic-Krstajic, L., Jovic, B. M., Antozzi, A. L. \& Martelli, G. N., Int. J. Hydrogen Energy 2008, 33, 3676-3687

[20] Lloyd, A. C., Noël, J. J., Mcintyre, S. \& Shoesmith, D. W., Electrochim. Acta 2004, 49, 3015-3027

[21] Reijen, J. E. Van Den, Versluis, W. C., Kanungo, S., Angelo, M. F., de Jong, K. P. \& de Jongh, P. E., Catal. Today 2019, 338, 31-39

[22] Zečević, J., Vanbutsele, G., de Jong, K. P. \& Martens, J. A., Nature 2015, 528, 245-248 
[23] Liu, K., Qin, R., Zhou, L., Liu, P., Zhang, Q., Jing, W., Ruan, P., Gu, L., Fu, G. \& Zheng, N., CCS Chem. 2019, 1, 207-214

[24] Dendisová, M., Zuzana, N., Martin, Č. \& Prokopec, V., Appl. Surf. Sci. 2019, 470, 716-723

[25] Yu, Y., Zhang, J., Xiao, W., Wang, J. \& Wang, L., Phys. Status Solidi B 2017, 254, 1600810

[26] Yu, Y., Hu, Q., Xiao, W., Wang, J. \& Wang, L., Intermetallics 2018, 94, 99-105

[27] Trasatti, S. \& Petrii, O. A., J. Electroanal. Chem. 1992, 327, 353-376

[28] Janssen, M., Griffioen, E., Biesheuvel, P. M., Roij, R. Van \& Erné, B., Phys. Rev. Lett. 2017, 119, 166002

[29] Csernica, P. M., Mckone, J. R., Mulzer, C. R., Dichtel, W. R., Abruna, H. D. \& DiSalvo, J., ACS Catal. 2017, 7, 3375-3383

[30] Marston, P. L., Langley, D. S. \& Kingsbury, D. L., Appl. Sci. Res. 1982, 38, 373-383

[31] Gileadi, E., Physical Electrochemistry, 2011, Wiley Vch Verlag Gmbh, Weinheim

[32] Scribner, L. L. \& Taylor, S. R., The Measurement and Correction of Electrolyte Resistance in Electrochemical Tests, 1990, American Society for Testing and Materials, Baltimore

[33] Pu, Z., Liu, Q., Tang, C., Asiri, M. \& Sun, X., Nanoscale 2014, 6, 1103111034

[34] Atkins, P., Overton, T., Rourke, J., Weller, M. \& Armstrong, F., Shriver \& Atkins' Inorganic Chemistry, 5th Ed., 2010, Oxford University Press, Oxford

[35] van Tendeloo, G., Mater. Sci. Eng. 1976, 26, 209-220

[36] Chassaing, E., Portail, N., Levy, A.-F. \& Wang, G., J. Appl. Electrochem. 2004, 34, 1085-1091

[37] Henderson, D., Li, X., Shoesmith, D. W., Noël, J. J. \& Ogle, K., Corros. Sci. 2019, 147, 32-40 
"Using rust as solar panels, dad? You have been telling weird things lately but that's just too much."

"I am not joking, son, it's possible. Give it a few years and you might just see nice and shiny orange panels here and there."

I roll my eyes and look out of the car window, the view now an endless expanse of brownish sand, which my dad claims could make solar panels. "Of course, they refine it, make incredibly thin sheet and that's what gets us electricity from the sun itself."

The mention only makes me glance up at the glaring light and makes me sweat more noticeably. If only it wasn't always so hot. 

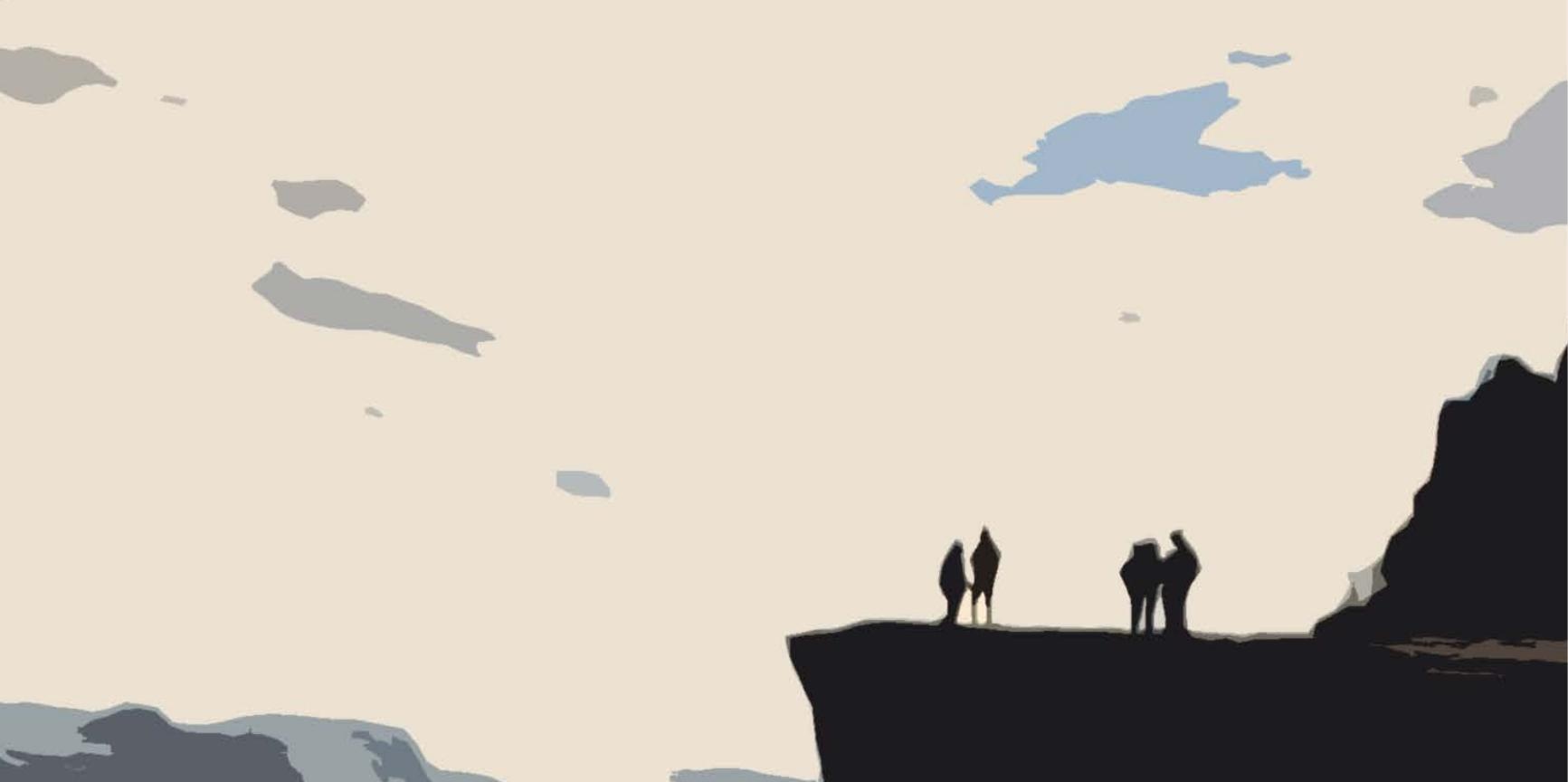

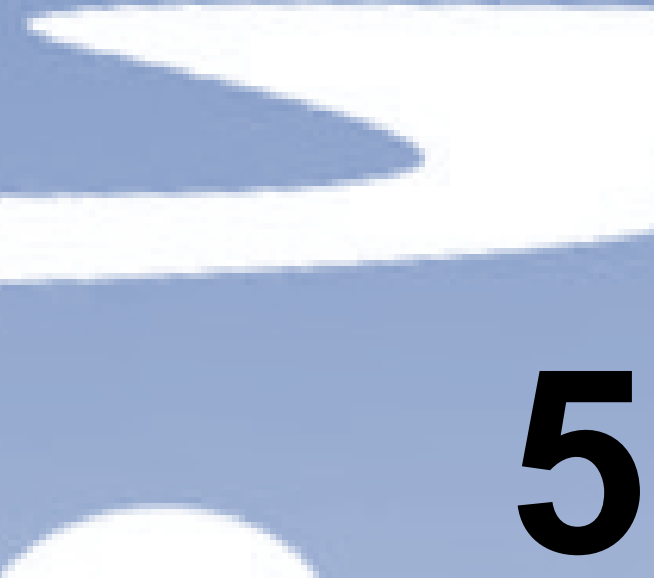

\section{Cathodic Electro-deposition of Ni-Mo on Semiconducting $\mathrm{NiFe}_{2} \mathrm{O}_{4}$ for Photo- electrochemical Hydrogen Evolution in Alkaline Media}

Photocathodes for hydrogen evolution from water were made by electro-deposition of $\mathrm{Ni}$-Mo layers on $\mathrm{NiFe}_{2} \mathrm{O}_{4}$ substrates, deposited by spin coating on $\mathrm{F}: \mathrm{SnO}_{2}$-glass. SEM-EDX and XRD analysis confirmed the formation of two separate layers, without significant reduction of $\mathrm{NiFe}_{2} \mathrm{O}_{4}$. While bare $\mathrm{NiFe}_{2} \mathrm{O}_{4}$ was found unstable under alkaline conditions during (photo)-electrochemistry. To improve the stability significantly, the deposition of a bifunctional Ni-Mo layer through a facile electrodeposition process was performed, and composite electrodes show stable operation for at least $1 \mathrm{~h}$. Moreover, photocurrents up to $-2.1 \mathrm{~mA} / \mathrm{cm}^{2}$ at $-0.3 \mathrm{~V}$ vs RHE were obtained for $\mathrm{Ni}-\mathrm{Mo} / \mathrm{NiFe}_{2} \mathrm{O}_{4}$ at ambient conditions, showing that the new combination functions as both a stabilizing and catalytic layer for photo-electrochemical hydrogen evolution. The photoelectrochemical response of these composite electrodes decreases with increasing $\mathrm{NiFe}_{2} \mathrm{O}_{4}$ layer thickness. Using transient absorption spectroscopy it is shown that the lifetime of excited states is short and in the ns timescale. An increase in lifetimes is observed for $\mathrm{NiFe}_{2} \mathrm{O}_{4}$ of large layer thickness, likely explained by decreasing defect density in the primary layer(s), as a result of repetitive annealing at elevated temperature. The photo-electrochemical and transient absorption spectroscopy results indicate that a short lifetime of charge carriers limits the performance of $\mathrm{Ni}-\mathrm{Mo} / \mathrm{NiFe}_{2} \mathrm{O}_{4}$ photocathodes. 


\subsection{Introduction}

The direct conversion of sunlight, $\mathrm{CO}_{2}$, and $\mathrm{H}_{2} \mathrm{O}$ into fuels and chemicals can be achieved in photoelectrochemical cells. ${ }^{[1-5]}$ The functionality of such cells, however, is depending on photo-electrodes containing semiconductors, which absorb light and generate electrons and holes with sufficient potential to drive the conversion of $\left(\mathrm{CO}_{2}\right.$ and $) \mathrm{H}_{2} \mathrm{O}$ into molecules, such as methane, methanol, and hydrogen ${ }^{[6]}$ Interestingly, the stability of photo-electrodes can be improved by the deposition of a metal layer, which protects the semiconductor against photo-corrosion. ${ }^{[7]}$ The performance of these materials is largely determined by the quality of the metal-semiconductor interfaces. Often methods, such as physical vapor deposition (PVD) or chemical vapor deposition (CVD), are utilized to achieve optimized interfaces ${ }^{[8,9]}$ However, these processes are quite expensive and require specialized equipment. An all-wet electrochemical process would be more desirable. ${ }^{[8]}$

An example of an electrochemical method for the formation of metals on semiconductors is galvanic displacement. ${ }^{[8,10,11]}$ This is a so-called electro-less deposition method, which does not require an external bias to drive electrochemical reactions. During galvanic displacement, the surface of the semiconductor in contact with the metal-cation solution is oxidized, while the metal layer is simultaneously formed by the reduction of the cations. The method is suitable for functionalization of e.g. Si or Ge surfaces ${ }^{[8]}$, after pretreatment with hydrogen fluoride-based solutions to remove native oxide. Unfortunately, galvanic displacement is typically unsuitable for the formation of metal-metal oxide interfaces. ${ }^{[8,10]}$

Electro-deposition, where a potential is applied to drive redox reactions on electrodes, is a suitable alternative for galvanic displacement. ${ }^{[8,12-16]}$ Anodic electro-deposition on semiconductors is already well-established, creating oxide layers on top of a semiconductor. ${ }^{[17,18]}$ For a metal layer to be formed, cathodic electro-deposition is required. One of the big issues with cathodic electro-deposition on many metal oxide semiconductors, is the reduction of the metal oxide layer. ${ }^{[8]}$

To circumvent this issue, ion-exchange and electro-less deposition are applied prior to electro-deposition. For example, $\mathrm{Sn}^{2+}$ ions have been adsorbed on a semiconductor-oxide surface. The material with adsorbed $\mathrm{Sn}^{2+}$ is immersed in a solution containing, for example, $\mathrm{Ag}^{+}$or $\mathrm{Pd}^{2+}$ cations, which react with the adsorbed $\mathrm{Sn}^{2+}$ to form $\mathrm{Sn}^{4+}$ and metallic $\mathrm{Ag}$ or $\mathrm{Pd}$. This metallic layer then protects the semiconductor metal oxide during sequential electrodeposition. Pre-metallization can also be done by using the aforementioned PVD or CVD techniques. ${ }^{[8]}$ 
In this $\mathrm{PhD}$ Chapter, we have investigated the possibility to directly deposit metal layers onto the metal oxide semiconductor $\mathrm{NiFe}_{2} \mathrm{O}_{4}$, which shows promising behavior when used as photo-cathode. ${ }^{[19-24]}$ We show that this material can be metallized with $\mathrm{Ni}-\mathrm{Mo}^{[13,16,25,26]}$ making use of simple aqueous cathodic electro-deposition baths containing the metal precursors, sodium citrate as a complexing agent, and sodium hydroxide or ammonia to adjust the $\mathrm{pH}^{[12,14,15,27]}$ UV-Vis spectroscopy, $\mathrm{X}$-ray diffraction $(\mathrm{XRD})$ and focused ion beam scanning electron microscopy with energy dispersive $X$-ray spectroscopy (FIB-SEM-EDX) were used to demonstrate the feasibility of this simple, onestep metallization procedure of $\mathrm{NiFe}_{2} \mathrm{O}_{4}$ through electro-deposition, resulting in novel $\mathrm{Ni}-\mathrm{Mo} / \mathrm{NiFe}_{2} \mathrm{O}_{4}$ photocathodes with a $\mathrm{NiFe}_{2} \mathrm{O}_{4}$ photo-absorbing layer and a stabilizing and catalytic Ni-Mo layer.

\subsection{Results and Discussion}

To ensure optimal oxidation of the layers, $\mathrm{NiFe}_{2} \mathrm{O}_{4}$ was formed by spin coating in a layer-by-layer fashion. During spin coating a thin layer of precursor nitrates is formed. The formation of the spinel phase by decomposition of the nitrates requires effective access to oxygen. Furthermore, nitrogen should be able to exit the precursor layers. In Figure 5.1 the growth of the $\mathrm{NiFe}_{2} \mathrm{O}_{4}$ layer on $\mathrm{F}: \mathrm{SnO}_{2} /$ glass substrates is illustrated. Separate samples were synthesized, and with increasing the number of deposition cycles, the samples become increasingly more orange, as seen in Figure 5.1a. SEM images of the cross sections made with FIB-cutting (Figure 5.1b) show that the thickness of the $\mathrm{NiFe}_{2} \mathrm{O}_{4}$ layer increases with the number of subsequent deposition cycles, and that the surface of the layers is rather smooth. The Pt layer was deposited on top of the semiconductor layer prior to FIB-cutting, to prevent damage to the underlying layers. Porosity between the $\mathrm{F}: \mathrm{SnO}_{2}$ and $\mathrm{NiFe}_{2} \mathrm{O}_{4}$, and between separate $\mathrm{NiFe}_{2} \mathrm{O}_{4}$ layers, can sometimes be observed due to initial roughness and suboptimal wetting of the previous layer, but is found sparingly when the $\mathrm{F}: \mathrm{SnO}_{2}$ layer is rougher. The chemical identity of each of these layers is confirmed, including the underlying conductive substrate layer. By crosssection EDX mapping, shown in Figure 5.2, the $\mathrm{NiFe}_{2} \mathrm{O}_{4}$ layer was found to contain 1.9:1 Fe:Ni.

XRD analysis (Figure 5.1c) confirms the growth of the trevorite, spinel, $\mathrm{NiFe}_{2} \mathrm{O}_{4}$ phase, since with increasing thickness the related diffraction lines become more pronounced. UV-Vis spectroscopy (Figure 5.1d) further confirms the formation of the desired spinel phase. The bandgap for $\mathrm{NiFe}_{2} \mathrm{O}_{4}$ is often reported at $1.56 \mathrm{eV}(795 \mathrm{~nm})$, however, as can be seen in the UV-Vis spectrum, 


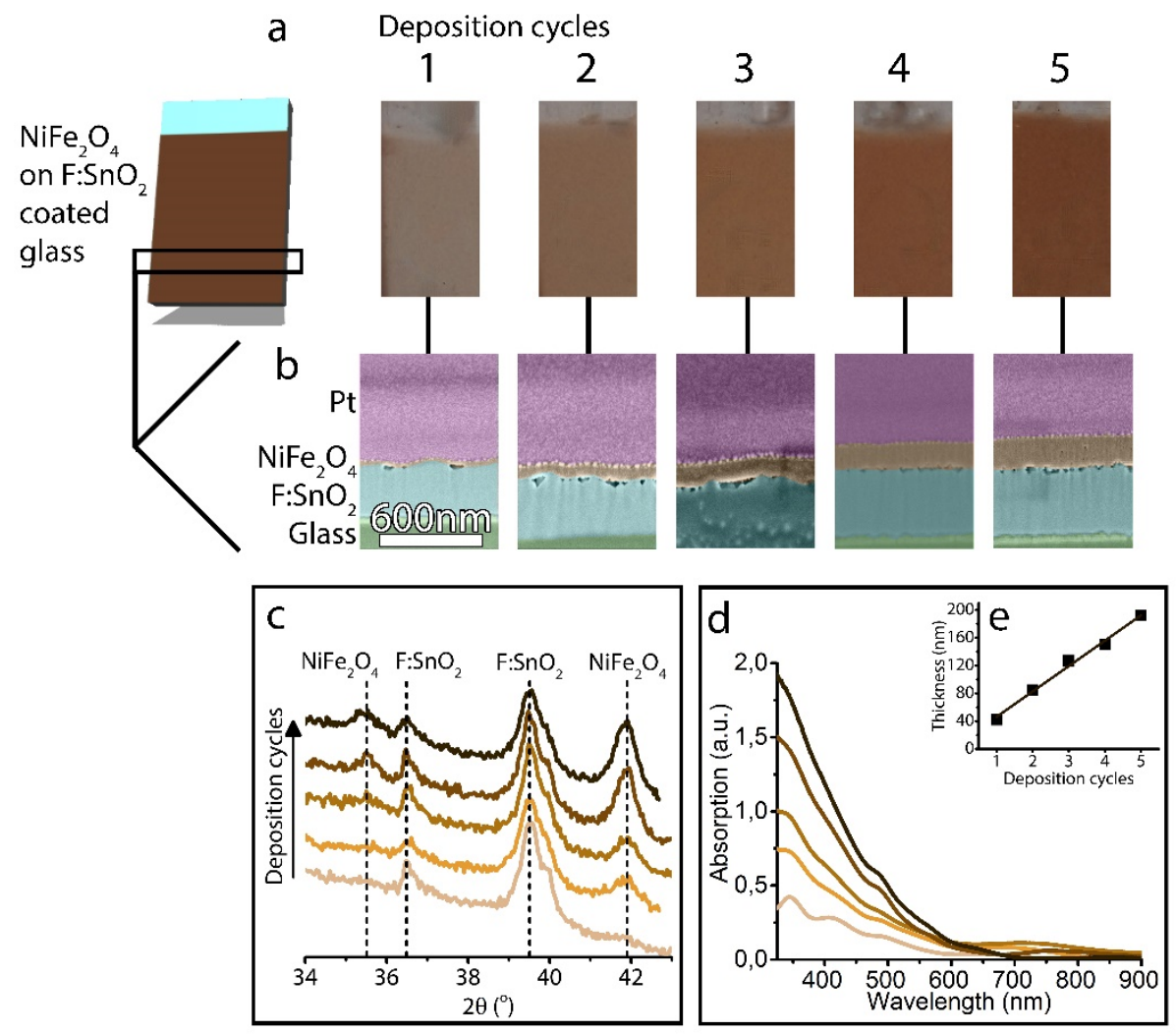

Figure 5.1: a) From left to right: a schematic representation of the $\mathrm{NiFe}_{2} \mathrm{O}_{4}$ film coated on $\mathrm{F}: \mathrm{SnO}_{2}$ /Glass substrates followed by photographs of samples with 1, 2, 3, 4 and 5 layers of spin coated $\mathrm{NiFe}_{2} \mathrm{O}_{4}$. b) SEM cross section images of (from left to right) 1,2 , 3, 4, 5 deposition cycles of $\mathrm{NiFe}_{2} \mathrm{O}_{4}$. The various layers have been colored: $\mathrm{Pt}$ (pink), $\mathrm{NiFe}_{2} \mathrm{O}_{4}$ (orange), $\mathrm{F}: \mathrm{SnO}_{2}$ (cyan) and glass (green). c) $X R \mathrm{R}$ of the spin coated $\mathrm{NiFe}_{2} \mathrm{O}_{4}$ layers with increasing thickness. d) UV-Vis spectra of the spin coated $\mathrm{NiFe}_{2} \mathrm{O}_{4}$ samples. e) The increase of thickness with increasing deposition cycles.

this is a low intensity band, related to an indirect bandgap between minority states. ${ }^{[28,29]}$ More significant for light absorption is the band starting at $2.1 \mathrm{eV}$ $(600 \mathrm{~nm})$, which is the transition between majority states, constituting a direct bandgap. The valence band maximum (VBM) is located mainly on Ni and $\mathrm{O}$. The conduction band minimum is mainly positioned on Fe and O. Due to $\mathrm{Fe}$ being in both octahedral and tetrahedral positions, there are two distinct gaps. ${ }^{[28,29]}$ Finally, the bandgap of the minority states is found to red-shift with increasing thickness and to decrease in intensity. The red-shift is explained by an increasing amount of $\mathrm{Ni}^{2+}$ ions occupying tetrahedral sites instead of the normal octahedral sites in the inverse spinel structures. This is possible due to partial inversion of the spinel structures, where in the normal spinel the bivalent ions are in the tetrahedral position. ${ }^{[30,31]}$ In the inset (Figure 5.1e) the increase 

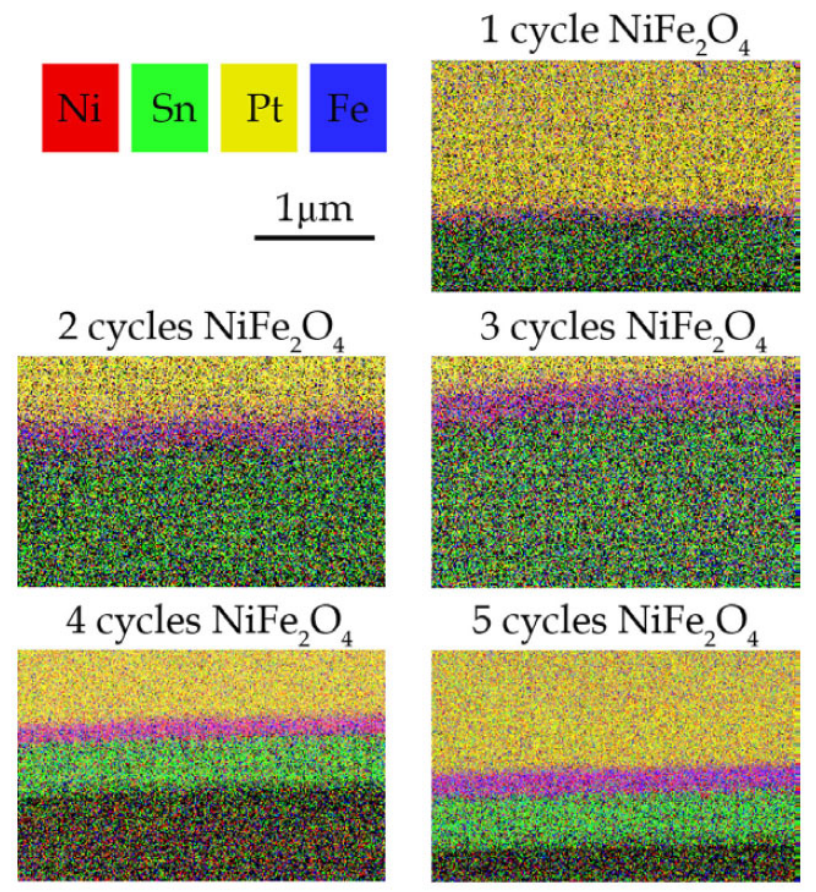

Figure 5.2: SEM-EDX cross-section images obtained for spin coated $\mathrm{NiFe}_{2} \mathrm{O}_{4}$ after 1 to 5 deposition cycles. Spatial resolution of these images is low due to different device constraints. First of all the samples would drift during mapping due to charging of the glass layer at the bottom of each image resulting in apparent stretching or contraction of the layers in the images. Furthermore, the EDX detector is at a tilt, meaning there can be cross contamination of signals from different layers at the interfaces. Nevertheless, it is clearly observable that from the top down a yellow platinum layer, a purplish Ni-Fe layer and a green Sn layer is present and a non-colored glass layer at the bottom. Furthermore, oxygen is observed in the Ni-Fe, Sn and glass layers.

in thickness is plotted against the number of deposition cycles, showing linear growth of thickness with a rate of $40 \mathrm{~nm} /$ cycle.

A Ni-Mo layer was electro-deposited on $\mathrm{NiFe}_{2} \mathrm{O}_{4}$ to act as both a protective, and catalyst layer for the hydrogen evolution reaction, as illustrated in Figure 5.3a. The composition of the Ni-Mo layer was found to be $\mathrm{Ni} 77.3 \%$ and Mo $22.7 \%$ by inductively coupled plasma atomic emission spectroscopy (ICPAES). 
The Faradaic efficiency of electrodeposition was found to be: $7.5 \%$ in $\mathrm{Ni}$ and $6.6 \%$ in Mo. This low current efficiency can be explained by the fact that the material formed is a hydrogen evolution catalyst, and that the deposition is carried out at potentials allowing hydrogen evolution. Thus, a significant portion of the current is invested in hydrogen evolution. Mild $\mathrm{pH}$ values and an intermediate deposition current were chosen to stabilize the $\mathrm{NiFe}_{2} \mathrm{O}_{4}$ layer. Too low currents result in too much exposure to the deposition bath (considering the required deposition time), damaging the oxide layer, whereas too high currents cause reduction of the oxides.

As shown in Figure 5.3, we found that $\mathrm{NiFe}_{2} \mathrm{O}_{4}$ can be metallized without deterioration of the oxide layer. This means that the stability of the spinel structure against reduction is sufficient during electro-deposition at the applied current. In Figure 5.3a, the electrodeposition curves are shown for bare $\mathrm{F}: \mathrm{SnO}_{2}$ and on $\mathrm{NiFe}_{2} \mathrm{O}_{4}$, indicating little variation in the curves. Slightly higher potentials are required for the deposition of Ni-Mo on $\mathrm{NiFe}_{2} \mathrm{O}_{4}$, which is ascribed to the additional resistance introduced by $\mathrm{NiFe}_{2} \mathrm{O}_{4}$ to the entire system, which is 21-30 Ohm for the $\mathrm{NiFe}_{2} \mathrm{O}_{4}$ layers on FTO compared to 12-15 Ohm for bare FTO glass. The cross section (Figure $5.3 b)$ shows a homogeneous layer of $\mathrm{Ni}$ Mo has indeed formed of about $200 \mathrm{~nm}$ thick. $\mathrm{NiFe}_{2} \mathrm{O}_{4}$ is also still $200 \mathrm{~nm}$ thick.

The apparent increase in porosity in the $\mathrm{NiFe}_{2} \mathrm{O}_{4}$ is not a result of the electrodeposition, but rather due to inhomogeneities in the film structure of a

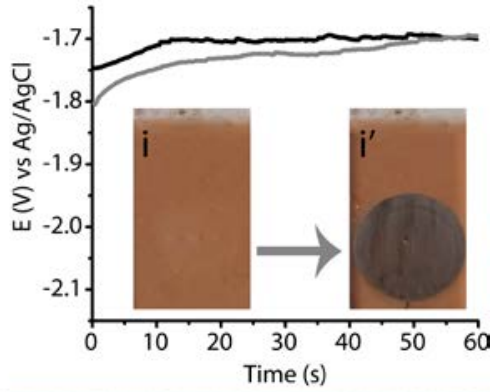

b

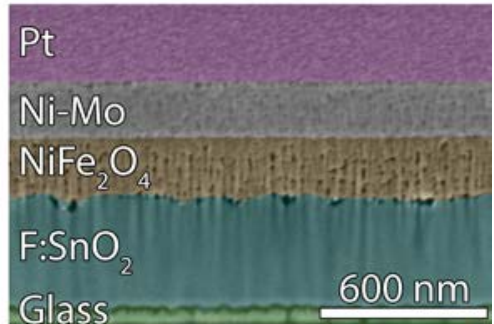

C

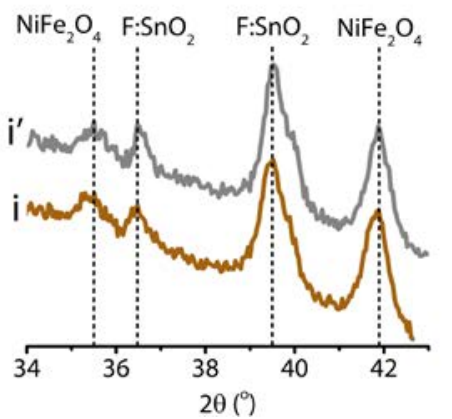

Figure 5.3: a) Ni-Mo electrodeposition (at -20 mA) curves on bare $\mathrm{F}: \mathrm{SnO}_{2} /$ glass (black) and on 5 spin coated cycles $\mathrm{NiFe}_{2} \mathrm{O}_{4} / \mathrm{F}: \mathrm{SnO}_{2} /$ glass (grey). Furthermore, photos are shown of the $\mathrm{NiFe}_{2} \mathrm{O}_{4}$ sample before (i) and after (i') Ni-Mo electrodeposition. b) SEM cross section images of the $\mathrm{Ni}$ $\mathrm{Mo} / \mathrm{NiFe}_{2} \mathrm{O}_{4} / \mathrm{F}: \mathrm{SnO}_{2} /$ glass sample. The various layers have been colored: Pt (pink), $\mathrm{NiFe}_{2} \mathrm{O}_{4}$ (orange), $\mathrm{F}: \mathrm{SnO}_{2}$ (cyan) and glass (green). c) $X R D$ of 5 spin coating cycles of $\mathrm{NiFe}_{2} \mathrm{O}_{4}$ before (i, orange) and after (i', grey) Ni-Mo electro-deposition. 


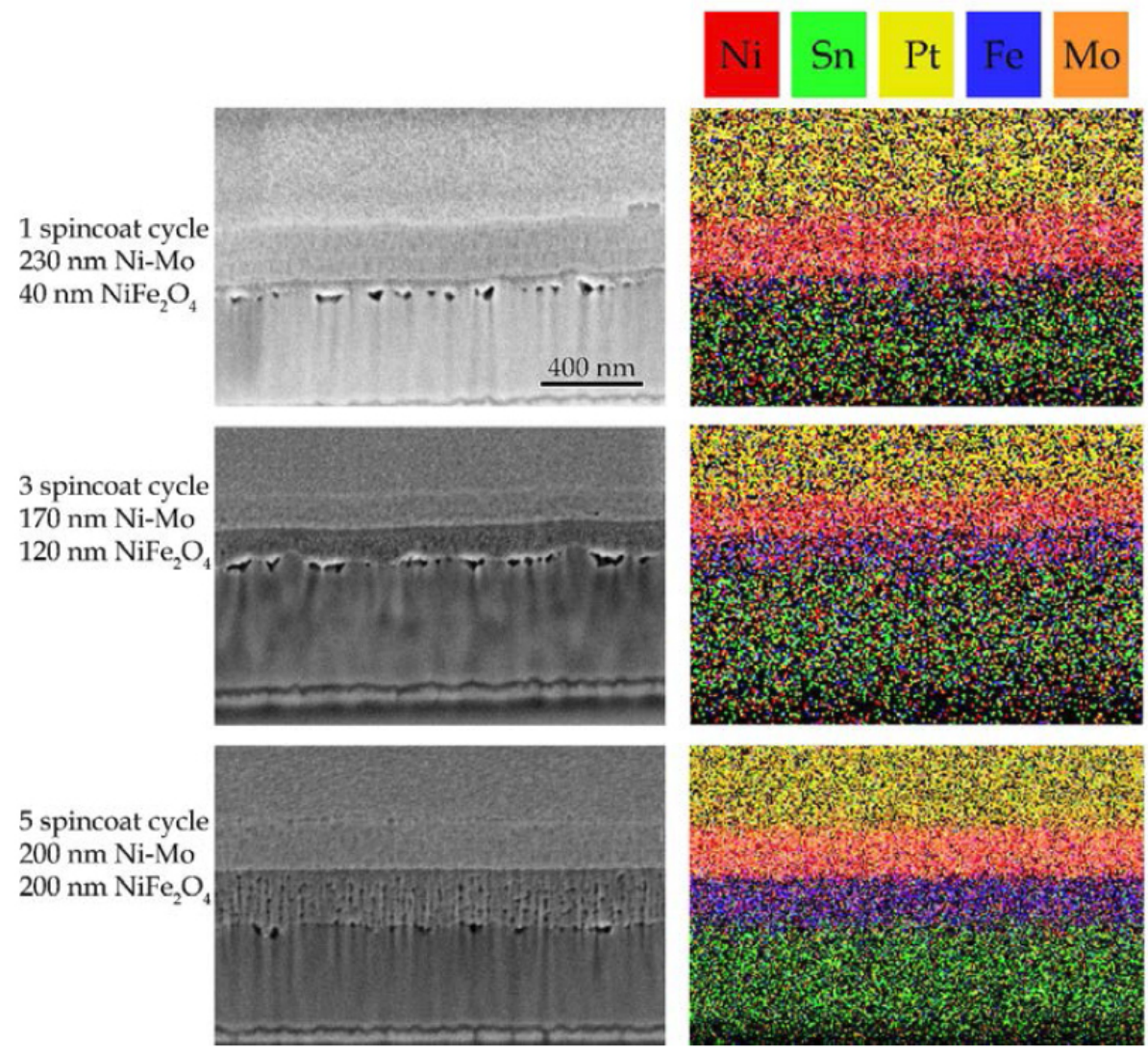

Figure 5.4: SEM and EDX cross-section images obtained for $\mathrm{Ni}-\mathrm{Mo} / \mathrm{NiFe}_{2} \mathrm{O}_{4}$ after 1, 3 and 5 spin coating deposition cycles. In the SEM images, it can be seen a 170-230 $\mathrm{nm} \mathrm{Ni}$-Mo layer is obtained on each thickness of $\mathrm{NiFe}_{2} \mathrm{O}_{4}$. In every case, the $\mathrm{NiFe}_{2} \mathrm{O}_{4}$ thickness is unaffected by the electrodeposition procedure. For the EDX maps same as with Figure 5.2 cross contamination of signal and some drifting occurred blurring the interfaces of the layers. Again, it is still clearly distinguishable to see a Pt layer, NiMo layer, Ni-Fe layer and Sn layer. Furthermore, oxygen was observed in Ni-Fe, Sn and glass.

$\mathrm{NiFe}_{2} \mathrm{O}_{4}$ after spin-coating, as illustrated in Figure 5.4. XRD analysis confirmed that the electro-deposition process did not affect the crystallinity of the spinel structure. Figure 5.4 shows electrodeposition was successful for all thicknesses of the $\mathrm{NiFe}_{2} \mathrm{O}_{4}$ films. UV-Vis spectroscopy data could not be reproduced due to the reflective metal layer. We also show that the synthesis technique can be extended to other metal coatings ( $\mathrm{Cu}, \mathrm{Co}-\mathrm{Mo})$ in Figure 5.5 , to prove that electro-deposition is a rather versatile method for functionalization of $\mathrm{NiFe}_{2} \mathrm{O}_{4}$. The copper layer that was obtained was inhomogeneous in height varying from $240 \mathrm{~nm}$ to $390 \mathrm{~nm}$, the $\mathrm{NiFe}_{2} \mathrm{O}_{4}$ layer was unaffected. With ICP-AES it was found a pure $\mathrm{Cu}$ layer formed and that the Faradaic efficiency of this deposition 


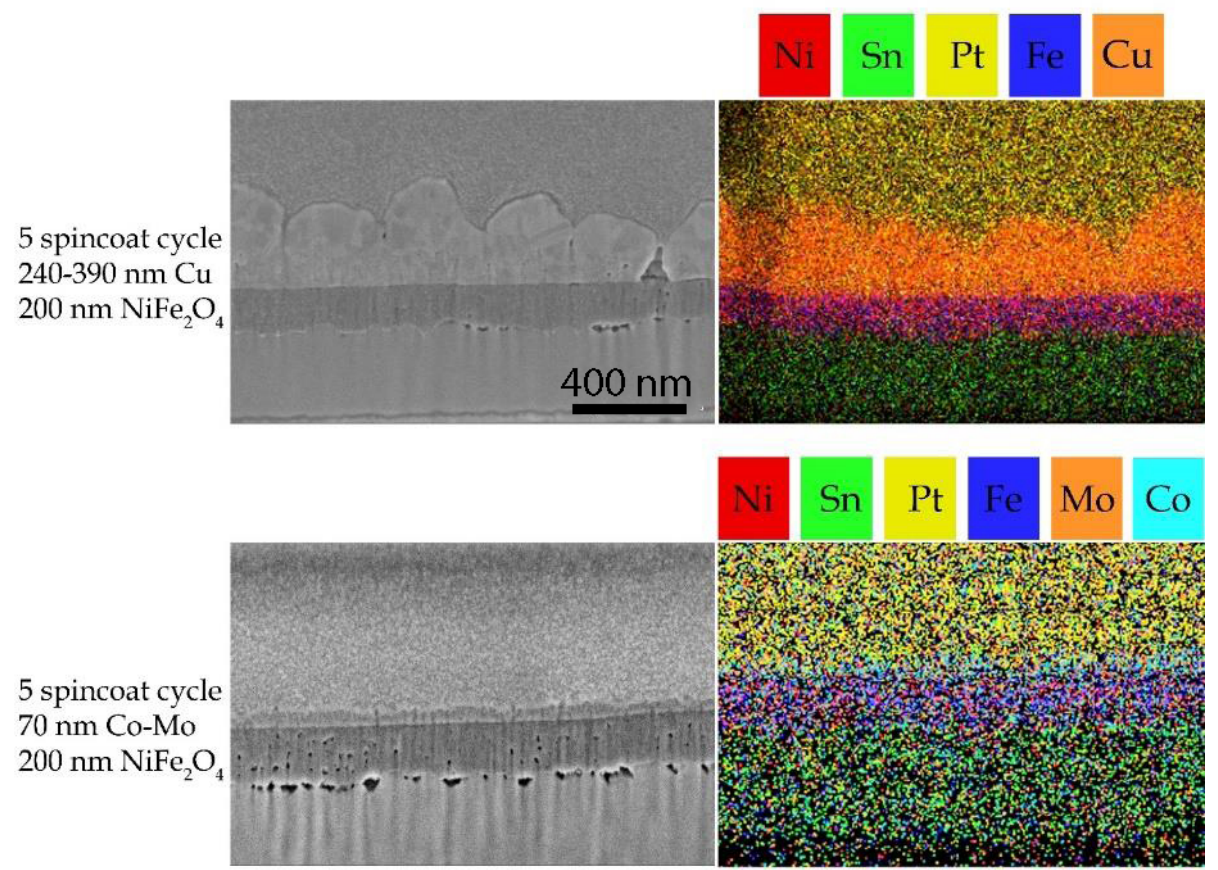

Figure 5.5: SEM and EDX cross-section images obtained for $\mathrm{Cu} / \mathrm{NiFe}_{2} \mathrm{O}_{4}$ (upper images) and $\mathrm{Co}-\mathrm{Mo}_{\mathrm{NiFe}} \mathrm{O}_{4}$ (lower images) after 5 spin coating deposition cycles of $\mathrm{NiFe}_{2} \mathrm{O}_{4}$.

was $79.7 \%$. The Co-Mo layer obtained was found to be quite homogeneous with a thickness of $70 \mathrm{~nm}$. Still, $\mathrm{NiFe}_{2} \mathrm{O}_{4}$ was found to be stable, suggesting this electrodeposition process can be performed at different $\mathrm{pH}$ values. With ICPAES it was found that the electrodeposition process had a Faradaic efficiency of $26.1 \%$ (17.3 \% in $\mathrm{Co}, 8.8 \%$ in $\mathrm{Mo}$ ) resulting in a $\mathrm{Co}_{2.0} \mathrm{Mo}$ alloy. Like with $\mathrm{Ni}-$ Mo the efficiency of this deposition is low because the parasitic hydrogen evolution reaction is quite well catalyzed by Co-Mo alloys. The Faradaic efficiency of Co-Mo is slightly higher than for Ni-Mo because Ni-Mo is the better catalyst.

To test the catalytic activity and stability towards the HER, the samples were suspended in $1 \mathrm{M} \mathrm{KOH}$ and cyclic voltammetry (CV) was measured in the absence and presence of illumination. In Figure 5.6 two reversible electrochemical peaks are observed for a single layer of $\mathrm{NiFe}_{2} \mathrm{O}_{4}$. First, at -0.02 $\mathrm{V}$ a reductive peak is observed, which is explained by the reduction of $\mathrm{Fe}^{3+}$ to $\mathrm{Fe}^{2+}$. When sweeping towards the oxidative side, first, oxidation of $\mathrm{Fe}^{2+}$ to $\mathrm{Fe}^{3+}$ is observed at approximately $0.15 \mathrm{~V}$. Then a sharper irreversible peak is observed at $0.34 \mathrm{~V}$ which is typical for hydroxide adsorption. ${ }^{[32]}$ 

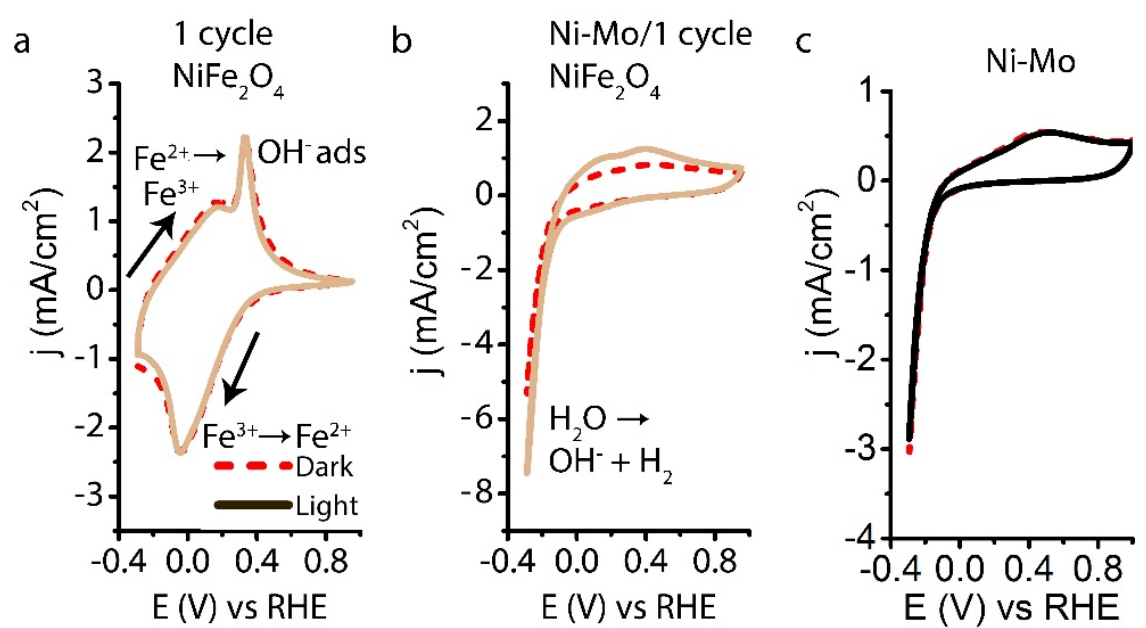

Figure 5.6: a) Cyclic voltammograms of 1 layer thick $\mathrm{NiFe}_{2} \mathrm{O}_{4}$. The dashed red lines show the dark current after 10 cycles in the dark. The solid lines show the light current after 10 cycles in the light. The cycles in the light have been performed after the cycles in the dark. b) Cyclic voltammograms of Ni-Mo electro-deposited on 1 layer of $\mathrm{NiFe}_{2} \mathrm{O}_{4}$

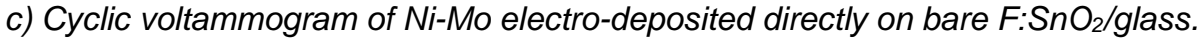

Since the CVs for bare $\mathrm{NiFe}_{2} \mathrm{O}_{4}$ are identical in the absence or presence of illumination, the reduction of $\mathrm{NiFe}_{2} \mathrm{O}_{4}$ is the main contribution to the observed current within this time scale.

The combined Ni-Mo/ $/ \mathrm{NiFe}_{2} \mathrm{O}_{4}$ system (Figure 5.6b) is quite different in its redox chemistry, and photo-response compared to bare $\mathrm{NiFe}_{2} \mathrm{O}_{4}$. In the dark cycle, the $\mathrm{Fe}$ reduction and $\mathrm{Fe}$ oxidation peaks are absent. Furthermore, the hydroxide adsorption peak is more broadened as compared to pure $\mathrm{NiFe}_{2} \mathrm{O}_{4}$. Also note the increase in hydrogen evolution current, indicating a reduction in over-potential for the formation of hydrogen. Finally, for the combined system a distinct photo-current is observed, reaching $-2.1 \mathrm{~mA} / \mathrm{cm}^{2}$ at $-0.3 \mathrm{~V}$. Clearly, the $\mathrm{Ni}$-Mo layer largely protects the $\mathrm{NiFe}_{2} \mathrm{O}_{4}$ layer against oxidation/reduction cycles and shows a strong positive effect with regard to the photo-response. The CV of Ni-Mo deposited directly on F: $\mathrm{SnO}_{2}$ (Figure 5.6c) shows a small, broad hydroxide adsorption peak, while, as expected, the material does not show the Fe-redox couple, nor a photo-response.

To explore the stability of the samples over time, chronoamperometry was performed first for $5 \mathrm{~min}$ in the dark (Figure 5.7), and then $1 \mathrm{~h}$ cycling of light on/off every 5 min (Figure 5.8). It can be seen that in the first $100 \mathrm{~s}$ the samples 


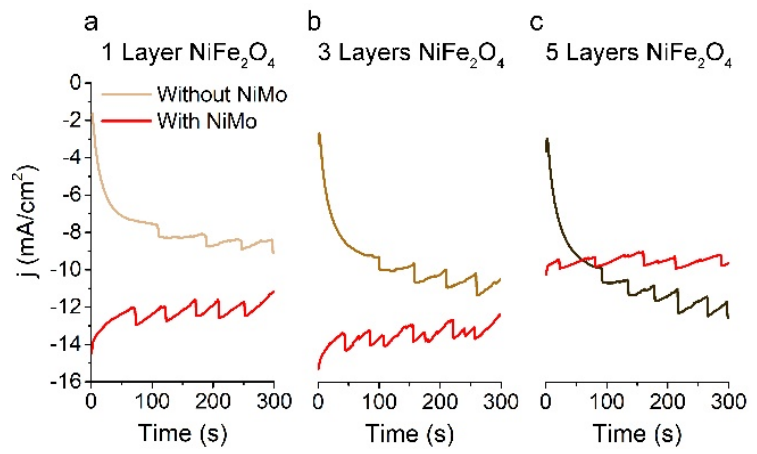

Figure 5.7: a) 5 min of chronoamperometry on 1 layer thick $\mathrm{NiFe}_{2} \mathrm{O}_{4}$ samples without (brown) and with (red) Ni-Mo at a constant potential of -0.3 V vs RHE in the dark, prior to the $1 \mathrm{~h}$ long measurements. b) Chronoamperometry on 3 layer thick $\mathrm{NiFe}_{2} \mathrm{O}_{4}$ samples. c) Chronoamperometry on 5 layer thick $\mathrm{NiFe}_{2} \mathrm{O}_{4}$ samples.
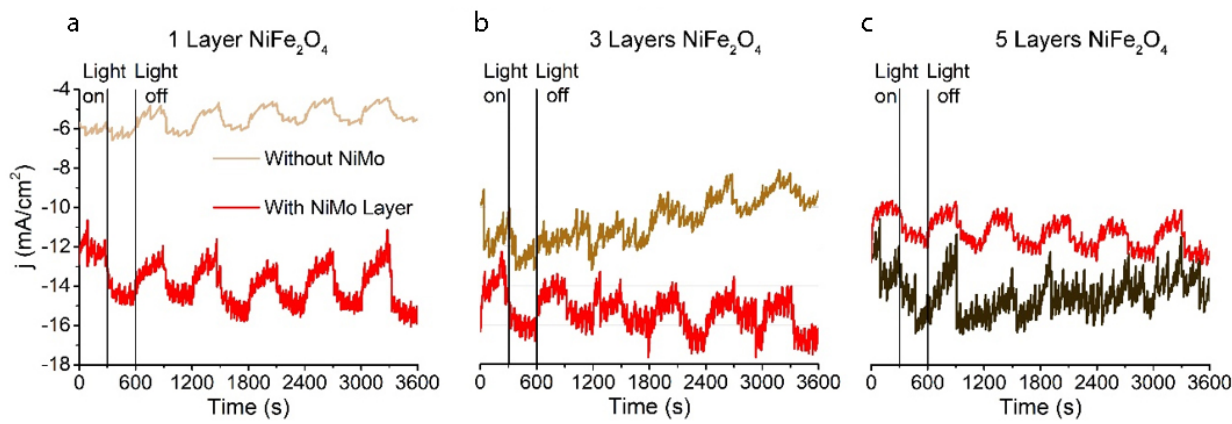

Figure 5.8: a) Chronoamperometric measurement on 1 layer thick $\mathrm{NiFe}_{2} \mathrm{O}_{4}$ samples without (brown) and with (red) Ni-Mo at a constant potential of -0.3 V vs RHE while cycling light on and off every $300 \mathrm{s.} \mathrm{b)} \mathrm{Chronoamperometric} \mathrm{measurement} \mathrm{on} 3$ layer thick $\mathrm{NiFe}_{2} \mathrm{O}_{4}$ samples. c) Chronoamperometric measurement on 5 layer thick $\mathrm{NiFe}_{2} \mathrm{O}_{4}$ samples.

without Ni-Mo behave similarly (Figure 5.7). A strong increase in reductive current, and a delay in active gas production (saw-tooth pattern) are observed during this period. This is due to the initial reduction of the exposed $\mathrm{NiFe}_{2} \mathrm{O}_{4}$ surface, after which hydrogen starts to evolve from the reduced electrode. Contrary, a slight decrease in current is observed for the Ni-Mo coated samples in the first $5 \mathrm{~min}$. This is attributed to the hydrogen evolution reaction, which introduces mass transport limitations on and near the electrode surface in the form of hydrogen gas bubbles.

Following this experiment, the $1 \mathrm{~h}$ chronoamperometry experiments are shown in Figure 5.8. Clear photocurrents are observed for several samples. The apparent increase in current seen for bare $\mathrm{NiFe}_{2} \mathrm{O}_{4}$, as a function of increasing layer thickness, is explained by an increased microporosity, as seen in SEM, and thus an increase of electrochemical surface area. Furthermore, the samples of larger thicknesses (5 layers) do not show any significant photocurrent (black curve). This suggests that the top layers of $\mathrm{NiFe}_{2} \mathrm{O}_{4}$ are 
reduced at the applied potential, limiting photo-activity. After the chronoamperometric measurements, ICP-AES was performed on the electrolyte, showing that $\mathrm{Ni}$ leaches into the electrolyte in the absence of a $\mathrm{Ni}$ Mo catalyst layer (Table 5.1).

Table 5.1: Amounts of $\mathrm{Ni}, \mathrm{Fe}$, and Mo leached after $1 \mathrm{~h}$ of chrono-amperometry. These values are corrected for the used dilution.

\begin{tabular}{l|l|l|l} 
& $\mathrm{Ni}(\mathrm{mg} / \mathrm{L})$ & $\mathrm{Fe}(\mathrm{mg} / \mathrm{L})$ & $\mathrm{Mo}(\mathrm{mg} / \mathrm{L})$ \\
\hline 1 Layer $\mathrm{NiFe}_{2} \mathrm{O}_{4}$ & 4.98 & 0.00 & 0.00 \\
\hline 3 Layers $\mathrm{NiFe}_{2} \mathrm{O}_{4}$ & 0.89 & 0.00 & 0.06 \\
\hline $5 \mathrm{Layers} \mathrm{NiFe} \mathrm{O}_{4}$ & 2.10 & 0.17 & -0.02 \\
\hline $\begin{array}{l}\mathrm{Ni}-\mathrm{Mo} / 1 \text { Layer } \\
\mathrm{NiFe} \mathrm{O}_{4}\end{array}$ & 0.90 & -0.03 & 0.93 \\
\hline $\begin{array}{l}\mathrm{Ni}-\mathrm{Mo}_{3} \text { Layers } \\
\mathrm{NiFe} \mathrm{O}_{4}\end{array}$ & 1.80 & -0.03 & 0.28 \\
\hline $\begin{array}{l}\mathrm{Ni}-\mathrm{Mo}_{5} \text { Layers } \\
\mathrm{NiFe} \mathrm{O}_{4}\end{array}$ & 0.80 & -0.03 & 0.39
\end{tabular}

All samples with the Ni-Mo catalyst layer show comparable currents (Figure 5.8). The small variation is ascribed to differences in the electrochemical surface area of the samples. The highest photocurrent is reached for the thinnest sample, which is $-2.1 \mathrm{~mA} / \mathrm{cm}^{2}$ at $-0.3 \mathrm{~V}$, similar to the observed photocurrent in Figure 5.7. It is clear that with increasing thickness of $\mathrm{NiFe}_{2} \mathrm{O}_{4}$ the photocurrent decreases. This suggests that charge carrier dynamics are a limiting factor.

Assuming that the diffusion length of charge carriers is comparable between samples, the recombination of the photogenerated charges becomes more prevalent as the distance to be traveled increases. Furthermore, since samples are illuminated from the back and the amount of photogenerated charges is directly related to the light intensity, it follows that the relative amount of charge carriers is lesser close to the electrochemical interface for a thicker $\mathrm{NiFe}_{2} \mathrm{O}_{4}$ layer.

Thus the addition of light absorber layers effectively lowers the photoresponse for these photo-

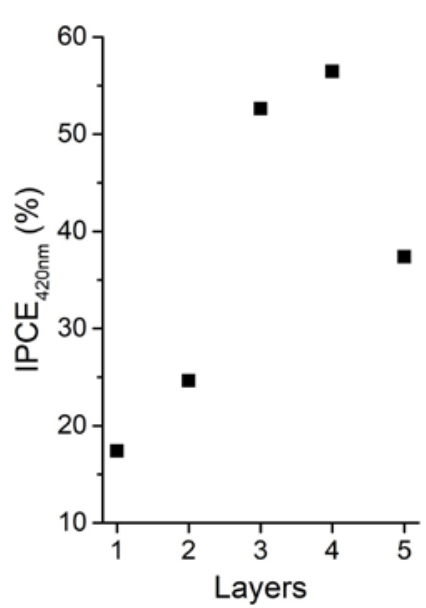

Figure 5.9: IPCE results of Ni$\mathrm{Mo} / \mathrm{NiFe}_{2} \mathrm{O}_{4} / \mathrm{FTO} / \mathrm{glass}$ samples using a $420 \mathrm{~nm}$ LED light source $\left(1.5 \mathrm{~mW} / \mathrm{cm}^{2}\right)$. The efficiency in \% is shown for samples of various thicknesses of $\mathrm{NiFe}_{2} \mathrm{O}_{4}$. 
photon to current efficiencies (IPCE) have been determined at $420 \mathrm{~nm}$, shown in Figure 5.9.

Degradation of bare $\mathrm{NiFe}_{2} \mathrm{O}_{4}$ during the photo-electrochemical tests can be observed by eye as is shown in Figure 5.10a. The $\mathrm{NiFe}_{2} \mathrm{O}_{4}$ samples show a lighter, greyish circle where the material was exposed to the electrolyte during photoelectrochemistry, which is not observed for Ni-Mo coated samples. This loss of absorber material is further supported by UV-Vis spectroscopy measurements (Figure 5.10b). When comparing the samples prior to, and after the catalytic tests, the absorption of each material is lower after the test. Finally, it can be observed with XRD (Figure 5.10c) that the $\mathrm{NiFe}_{2} \mathrm{O}_{4}$ diffraction lines of bare $\mathrm{NiFe}_{2} \mathrm{O}_{4}$ have slightly decreased after $\mathrm{PEC}$. On the other hand, the $\mathrm{Ni}-\mathrm{Mo} / \mathrm{NiFe}_{2} \mathrm{O}_{4}$ photocathode retained its crystallinity.

Thus, we find that bare $\mathrm{NiFe}_{2} \mathrm{O}_{4}$ is an unstable material for light-driven hydrogen evolution from water splitting in alkaline conditions. Coating with $\mathrm{Ni}$ Mo, however, stabilizes the system and furthermore improves the activity of the photo-electrode, if the $\mathrm{NiFe}_{2} \mathrm{O}_{4}$ is of limited thickness. A possible explanation for the instability under illumination is limited charge carrier mobility, making the material more a
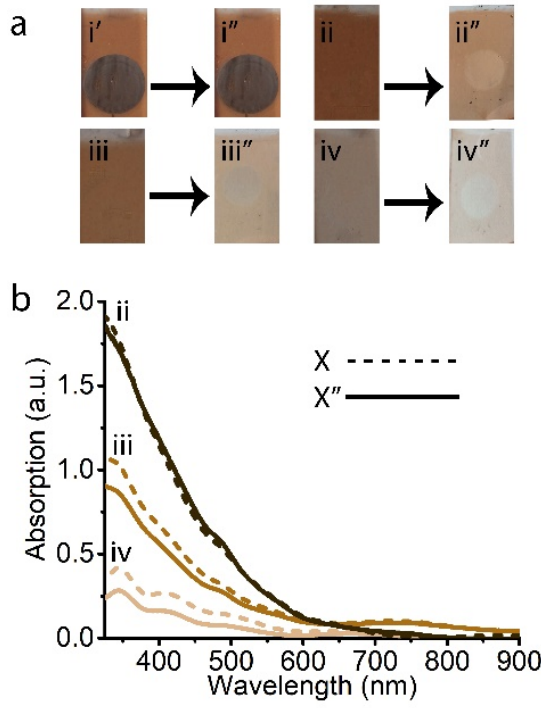

C

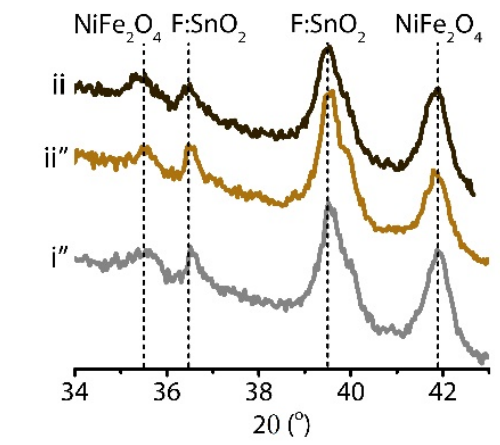

Figure 5.10: a) Photographs of fresh samples and spent samples (CV experiments), indicated by ". Ni$\mathrm{Mo} / \mathrm{NiFe}_{2} \mathrm{O}_{4}$ (i'), and 5 (ii), 3 (iii) and 1 (iv) spin coated cycles of $\mathrm{NiFe}_{2} \mathrm{O}_{4}$ are shown, the color difference between the bulk of each photograph is due to different incident light from the surroundings when the pictures were taken. b) UV-Vis spectra of the $\mathrm{NiFe}_{2} \mathrm{O}_{4}$ samples before (dashed) and after (solid) photoelectrochemical tests. c) XRD of fresh 5 cycles of $\mathrm{NiFe}_{2} \mathrm{O}_{4}$ (ii), spent 5 cycles of $\mathrm{NiFe}_{2} \mathrm{O}_{4}$ (ii") and spent $\mathrm{Ni}$ $\mathrm{Mo} / \mathrm{NiFe}_{2} \mathrm{O}_{4}$ (i"). 
prone to corrosion, as supported by the observation that $\mathrm{Ni}$ leaches into solution if the Ni-Mo layer is absent.

To explore the charge carrier dynamics of the $\mathrm{NiFe}_{2} \mathrm{O}_{4}$ samples in more detail, we used transient absorption spectroscopy (TAS). The results are given in
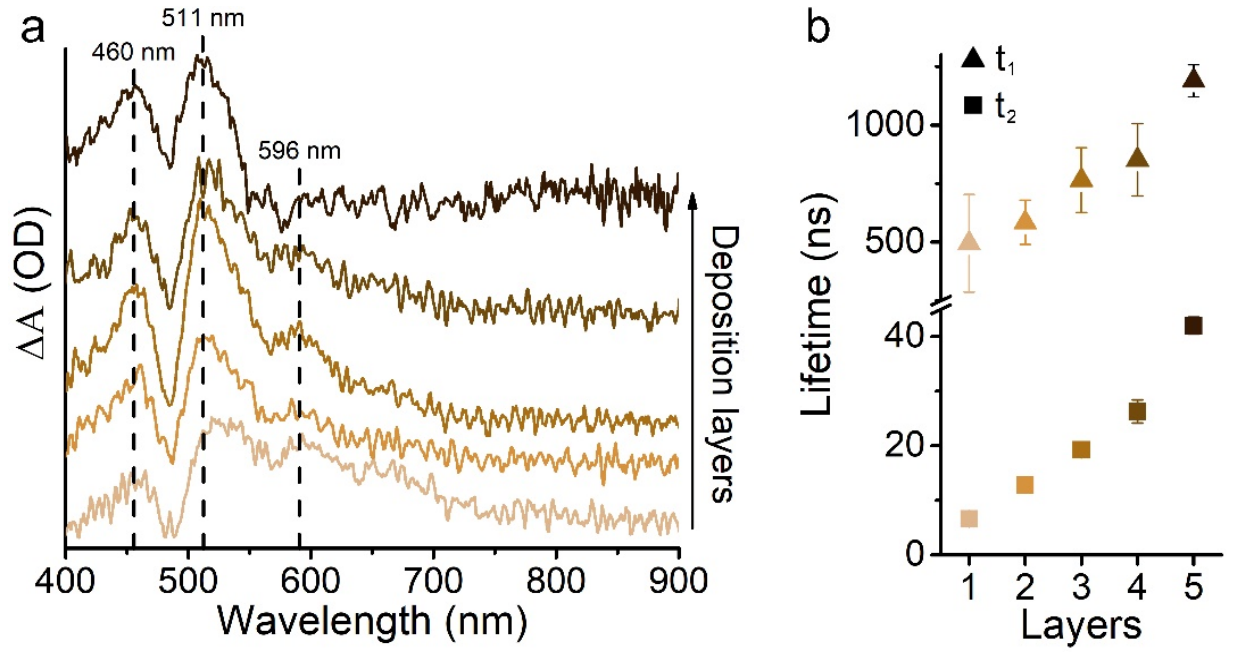

Figure 5.11: a) Transient absorption spectroscopy data of fresh, bare $\mathrm{NiFe}_{2} \mathrm{O}_{4}$ samples with increasing layer thickness, collected in transmission mode at a decay time of $1 \mathrm{~ns}$. b) Averaged lifetimes obtained for the kinetic traces.
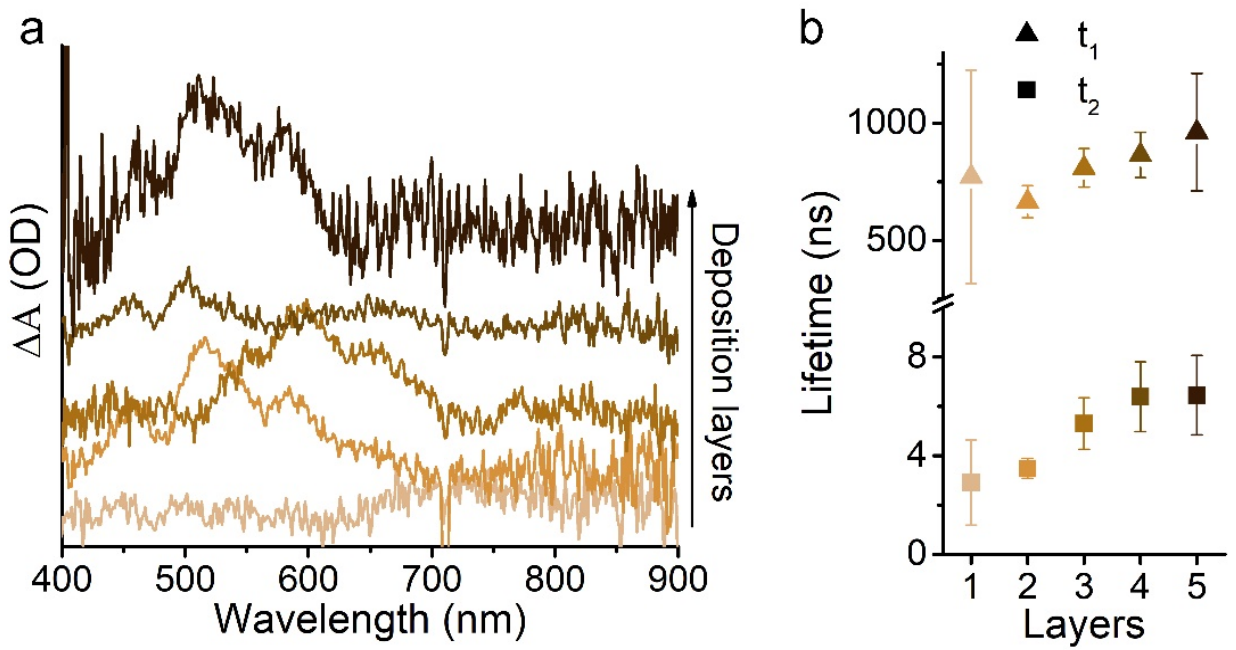

Figure 5.12: a) Transient absorption spectroscopy data of Ni-Mo coated $\mathrm{NiFe}_{2} \mathrm{O}_{4}$ samples consisting of 1,2, 3, 4 or 5 layers of $\mathrm{NiFe}_{2} \mathrm{O}_{4}$ at a time delay of $2 \mathrm{~ns}$. Spectra were obtained in reflection mode. b) Averaged lifetimes of the peaks observed in the spectra. 
Figure 5.11, where in panels $a$ and $b$ the data are given for samples without Ni-Mo coating, these were measured in transmission. Only lifetimes and relative peak intensities can be compared.

In Figure 5.12 the TAS data are shown for samples including the Ni-Mo layer. It can be observed that the transient absorption spectra change for some layers when $\mathrm{Ni}-\mathrm{Mo}$ is present. The shape of the spectra remains the same however and samples

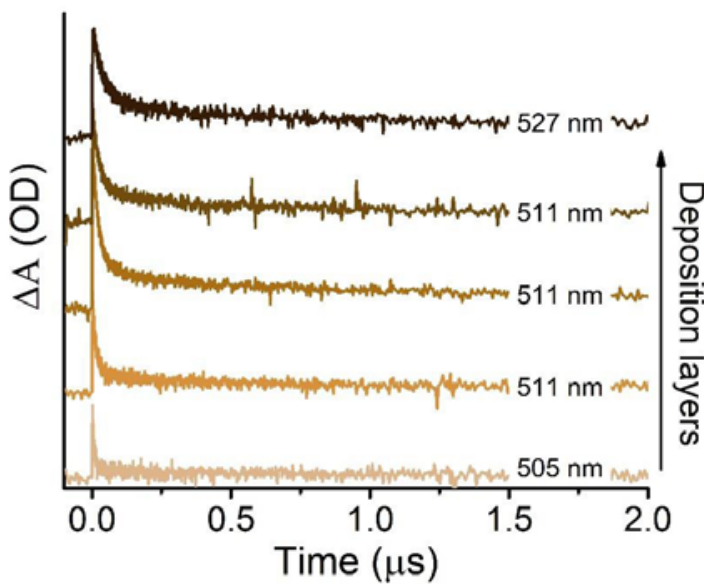

Figure 5.13: Representative kinetic traces, at the $511 \mathrm{~nm}$ peak, for bare $\mathrm{NiFe}_{2} \mathrm{O}_{4}$ samples with increasing layer thickness. are compared based on their peaks. It is not clear what the origin is of the shift occurring in some samples, but the authors cannot exclude instrumental errors due to the difficulty of aligning the TAS setup in reflection mode. The distance of the overlap in pump and probe light from the Ni-Mo layer might influence the behavior changes due to band bending, changing the energy of the $\mathrm{CB}$ to $\mathrm{CB}_{2}$ transitions. For these samples as well, an increase in the lifetime is observed with increasing layer thickness. Also notable is the fact that $t_{1}$ is significantly shortened by the presence of a Ni-Mo layer. This suggests that charges on the $\mathrm{Fe} T_{d}$ band deplete faster, which can be explained by electron extraction by the $\mathrm{Ni}-\mathrm{Mo}$ layer.

Several transient signals are observed for each sample, each having similar decay times per sample, after pumping with $355 \mathrm{~nm}$ light (thus the $\mathrm{O}^{2-} \rightarrow \mathrm{Fe}^{2+}$ transition). The exact fitting results are given in Figure 5.13. The kinetic traces are shown for the most intense signal around $511 \mathrm{~nm}$. Note that a slight shift in maximized wavelength was found, which indicates that the electronic structure is slightly different for each material. Data fitting is done with the following formula so that the residuals did not exceed $0.001 \mathrm{OD}$. The results of fitting are given in Table 5.2.

$$
S(t)=e^{-\left(\frac{t-t_{0}}{t_{p}}\right)^{2}} * \sum_{i} A_{i} e^{\frac{t-t_{0}}{t_{i}}}, t_{p}
$$

Were $t$ is the delay time, $t_{0}$ is the time of the pump pulse, $t_{p}$ is the half-time constant of the excitation, while the $t_{i}$ values are the half-time constants of the decays and the $A_{i}$ values are the amplitudes of the different components. 
Table 5.2: Fitting results of the various samples are given if several peaks are mentioned where these fits have been made the values have been averaged and included in the error, as shown in Figures 5.11 and 5.12.

\begin{tabular}{|c|c|c|c|c|c|c|c|}
\hline Sample & $A_{p}$ & $t_{p}(n s)$ & $A_{1}$ & $\mathrm{t}_{1}(\mathrm{~ns})$ & $A_{2}$ & $\begin{array}{l}\mathrm{t}_{2} \\
\text { (ns) }\end{array}$ & $\begin{array}{l}\text { Peaks } \\
(\mathrm{nm})\end{array}$ \\
\hline $\begin{array}{l}1 \text { Layer } \\
\mathrm{NiFe}_{2} \mathrm{O}_{4}\end{array}$ & $9.71 * 10^{-5}$ & 0.49 & $4.53^{\star} 10^{-4}$ & 544 & $4.55^{\star} 10^{-3}$ & 6.69 & $\begin{array}{l}460,527, \\
596\end{array}$ \\
\hline $\begin{array}{l}2 \text { Layers } \\
\mathrm{NiFe}_{2} \mathrm{O}_{4}\end{array}$ & $2.69 * 10^{-4}$ & 0.58 & $8.93^{\star} 10^{-4}$ & 572 & $5.09 * 10^{-3}$ & 12.6 & $\begin{array}{l}460,511, \\
596\end{array}$ \\
\hline $\begin{array}{l}3 \text { Layers } \\
\mathrm{NiFe}_{2} \mathrm{O}_{4}\end{array}$ & $5.10^{\star} 10^{-4}$ & 0.66 & $1.75^{\star} 10^{-3}$ & 754 & $8.46^{*} 10^{-3}$ & 19.5 & $\begin{array}{l}460,511, \\
596\end{array}$ \\
\hline $\begin{array}{l}4 \text { Layers } \\
\mathrm{NiFe}_{2} \mathrm{O}_{4}\end{array}$ & $4.10^{*} 10^{-4}$ & 0.62 & $1.24^{\star} 10^{-3}$ & 958 & $5.28 * 10^{-3}$ & 26.1 & $\begin{array}{l}460,511, \\
596\end{array}$ \\
\hline $\begin{array}{l}5 \text { Layers } \\
\mathrm{NiFe}_{2} \mathrm{O}_{4}\end{array}$ & $7.35 * 10^{-4}$ & 0.56 & $1.72 * 10^{-3}$ & 1141 & $5.56 * 10^{-3}$ & 42.9 & 460,505 \\
\hline $\begin{array}{l}\text { Ni-Mo/1 } \\
\text { Layer } \\
\mathrm{NiFe}_{2} \mathrm{O}_{4}\end{array}$ & $4.68 * 10^{-5}$ & 0.42 & $2.06 * 10^{-4}$ & 167 & $1.51 * 10^{-3}$ & 2.91 & 492 \\
\hline $\begin{array}{l}\mathrm{Ni}-\mathrm{Mo} / 2 \\
\text { Layers } \\
\mathrm{NiFe}_{2} \mathrm{O}_{4}\end{array}$ & $1.28 * 10^{-3}$ & 0.83 & $1.67 * 10^{-3}$ & 597 & $5.92 * 10^{-3}$ & 3.48 & 511 \\
\hline $\begin{array}{l}\mathrm{Ni}-\mathrm{Mo} / 3 \\
\text { Layers } \\
\mathrm{NiFe}_{2} \mathrm{O}_{4}\end{array}$ & $2.08 * 10^{-3}$ & 1.10 & $2.54 * 10^{-3}$ & 809 & $3.56 * 10^{-3}$ & 5.30 & 596 \\
\hline $\begin{array}{l}\mathrm{Ni}-\mathrm{Mo} / 4 \\
\text { Layers } \\
\mathrm{NiFe}_{2} \mathrm{O}_{4}\end{array}$ & $2.77 * 10^{-4}$ & 0.60 & $6.79 * 10^{-4}$ & 753 & $2.17^{*} 10^{-3}$ & 6.39 & 498 \\
\hline $\begin{array}{l}\mathrm{Ni}-\mathrm{Mo} / 5 \\
\text { Layers } \\
\mathrm{NiFe}_{2} \mathrm{O}_{4}\end{array}$ & $1.10 * 10^{-3}$ & 0.64 & $1.82 * 10^{-3}$ & 884 & $4.97 * 10^{-3}$ & 6.45 & 514 \\
\hline
\end{tabular}

Transient absorption is observed at $511 \mathrm{~nm}$, but also at 460 and $596 \mathrm{~nm}$ (see Figure 5.11). Two decay components are found: a short ( $\left.\mathrm{t}_{1}, 2-50 \mathrm{~ns}\right)$ and a longer lifetime ( $\left.\mathrm{t}_{2}, 500-1100 \mathrm{~ns}\right)$. Most notably is the fact that both, the short $\left(\mathrm{t}_{1}\right)$ and long $\left(\mathrm{t}_{2}\right)$, lifetime type transients increase as a function of $\mathrm{NiFe}_{2} \mathrm{O}_{4}$ layer thickness. Since these measurements are performed ex situ, in air, the dominant decay pathway in bare $\mathrm{NiFe}_{2} \mathrm{O}_{4}$ samples is via recombination of charges. The short lifetimes of charge carriers, indicate slow diffusion and a high likely hood of recombination. However, in the samples with a thicker $\mathrm{NiFe}_{2} \mathrm{O}_{4}$ layer the crystallinity is improved for the earlier deposited layers (due to exposure multiple heating steps). The increased crystallinity results in a material with fewer defect sites, thus extending the lifetime of the photogenerated charges. ${ }^{[33-34]}$ Although at first glance the increased lifetime of the probed states seems to contradict the PEC results presented in Figure 5.8, it is important to point out that the entire light absorber layer is probed. This entails that even though on average the lifetime of photo-generated states has 
increased, this increase is mainly due to the enhanced performance of the layers underneath the last spin coated $\mathrm{NiFe}_{2} \mathrm{O}_{4}$ layer.

As mentioned by Meinert and Reiss ${ }^{[28]}$, it is not straightforward to describe complex band structures such as that of $\mathrm{NiFe}_{2} \mathrm{O}_{4}$. Nevertheless, in Figure 5.14, based on our UV-Vis and TAS data as well as the results of Meinert ${ }^{[28]}$, we show a schematic representation of the electronic behavior of $\mathrm{NiFe}_{2} \mathrm{O}_{4}$. First of all, excitation by $355 \mathrm{~nm}$ laser pump light is done to excite electrons from the valence band, positioned on $\mathrm{Ni}_{\mathrm{h}}$ and $\mathrm{O}$, to the conduction bands positioned on both $\mathrm{O}_{h}$ (minority) and $\mathrm{T}_{\mathrm{d}}$ (majority) $\mathrm{Fe}$. From the $\mathrm{O}_{\mathrm{h}} \mathrm{Fe}$ species transitions of 511 $\mathrm{nm}(2.43 \mathrm{eV})$ and $460 \mathrm{~nm}(2.69 \mathrm{eV})$ are possible. The Oh Fe species relax back to the VB following a slow decay $\left(\mathrm{t}_{2}\right)$ in the order of $1 \mu \mathrm{s}$. This decay is slow because this is a transition between minority states, also observable from the fact that the $\Delta \mathrm{A}$ is 5 to 10 times smaller for this, $t_{2}$, component than it is for $t_{1}$. From the $T_{d} F e$ species transitions of $511 \mathrm{~nm}, 460 \mathrm{~nm}$ and also $596 \mathrm{~nm}(2.08 \mathrm{eV})$ are possible. The $T_{d}$ Fe species decay much faster, according to $t_{1}$ in the order of $10 \mathrm{~ns}$, because here majority states are considered. The energy scales of the observed optical transitions agree with the described density of states found by Meinert and Reiss. ${ }^{[28]}$

Although this strongly indicates the assignment of transitions is correct, it is not possible from this data to be conclusive about the exact origins of the decay components. For this more experiments such as transient X-ray absorption spectroscopy would be required to observe the electronic states, this is however outside the scope of this work and will be the subject of a separate work. To summarize, the data obtained proof that charge carrier dynamics are observable with ns timescales, which suggests fast recombination and a short diffusion length. This is in agreement with the photo-electrochemical measurements, and explains why a bias is necessary to observe any significant photo-current. 


\subsection{Conclusions}

$\mathrm{NiFe}_{2} \mathrm{O}_{4}$ can be formed homogeneously by spin coating on FTO-functionalized glass substrates. Thickness control down to $40 \mathrm{~nm}$ was achieved. Cathodic electro-deposition was successfully applied to deposit a film of Ni-Mo on top of $\mathrm{NiFe}_{2} \mathrm{O}_{4}$. The $\mathrm{NiFe}_{2} \mathrm{O}_{4}$ semiconducting layers were found to be stable during the synthesis process. Bare $\mathrm{NiFe}_{2} \mathrm{O}_{4}$, nor Ni-Mo showed photo-activity for hydrogen evolution. However, the studied $\mathrm{Ni}-\mathrm{Mo} / \mathrm{NiFe}_{2} \mathrm{O}_{4}$ photocathodes performed better, and photocurrents up to $-2.1 \mathrm{~mA} / \mathrm{cm}^{2}$ were observed at -0.3 $V$ vs RHE, showing strong synergistic effects. It was found that thinner light absorbing layers yielded the highest photocurrents. This is ascribed to the photo-induced charge carrier diffusion length being a limiting factor for $\mathrm{NiFe}_{2} \mathrm{O}_{4}$. This observation is complemented by the transient absorption spectroscopy (TAS) experiments, which indicate the photo-generated charge lifetimes to be on the order of ns. During continuous operation at $-0.3 \vee$ vs RHE under cycled light, it was found that without Ni-Mo layers the samples are unstable, whereas with Ni-Mo the material is stabilized over the course of at least $1 \mathrm{~h}$. The instability during photo-electrochemistry was found to be related to $\mathrm{Fe}$ and $\mathrm{Ni}$ reduction and oxidation. In summary, new semiconductor-metal constructs can be formed by a facile electro-deposition process without reduction of the semiconductor phase, enhancing the performance of $\mathrm{NiFe}_{2} \mathrm{O}_{4}$ in cathodic, photo-electrochemical hydrogen production, in terms of stability and activity.

\subsection{Experimental Section}

\subsubsection{Chemicals and Materials}

All materials were used as received without further purification. $\mathrm{NiSO}_{4} \cdot 6 \mathrm{H}_{2} \mathrm{O}$ (ReagentPlus, $>99 \%$ pure), $\mathrm{NaMoO}_{4} \cdot 2 \mathrm{H}_{2} \mathrm{O}$ (ACS reagent, $>99 \%$ pure), $\mathrm{NaOH}$ ( $99.99 \%$ trace metals, semiconductor grade), $\mathrm{KOH}$ (ACS reagent, $>85 \%$ pure), $\mathrm{Na}_{3} \mathrm{C}_{6} \mathrm{H}_{5} \mathrm{O}_{7} \cdot 2 \mathrm{H}_{2} \mathrm{O}$ (sodium citrate, ACS reagent, $>99 \%$ pure), and $\mathrm{Fe}\left(\mathrm{NO}_{3}\right)_{3} \cdot 9 \mathrm{H}_{2} \mathrm{O}$ (ACS reagent, $>98 \%$ pure) were received from Sigma Aldrich. $\mathrm{Ni}\left(\mathrm{NO}_{3}\right)_{2} \cdot 6 \mathrm{H}_{2} \mathrm{O}(99 \%)$, Citric acid (Rnase/protease free, anhydrous) and ethanol (anhydrous, extra dry, $99.5 \%$ ) were received from Acros. Ethylene glycol (P.a. reag., Ph. Eur. >99.5 \%) was received from Fluka. $\mathrm{NH}_{3} 28-30 \%$ (ACS reagent, ph. Eur. for analysis) was obtained from Emsure. Fluorine-doped tin oxide glass (FTO, grade TEC 15) was received from Pilkington.

\subsubsection{Spin coating of $\mathrm{NiFe}_{2} \mathrm{O}_{4}$}

$3 \times 3 \mathrm{~cm}^{2} \mathrm{~F}: \mathrm{SnO}_{2}$ coated glass slides were cleaned by first washing them with detergent (Eurobac hygienic soap 406307) followed by subsequently sonicating them for $15 \mathrm{~min}$ in a 1:1:1 mixture of acetone:ethanol:demineralized 
water, subsequently in a $1 \mathrm{M} \mathrm{HCl}$ solution and finally in demineralized water. As a last step the slides were treated in an UV ozone cleaner for 15 min. 2 $\mathrm{mmol} \mathrm{Fe}\left(\mathrm{NO}_{3}\right)_{3}, 1 \mathrm{mmol} \mathrm{Ni}\left(\mathrm{NO}_{3}\right)_{2}$ and $3 \mathrm{mmol}$ citric acid are dissolved in $10 \mathrm{~mL}$ anhydrous ethanol. This solution was stirred for at least $2 \mathrm{~h}$. Then $0.2 \mathrm{~mL}$ ethylene glycol was added and then the solution was stirred overnight. Prior to spin coating the solution was filtered and then $300 \mu \mathrm{L}$ was dropped on the FTO slides. This was then spun at $3000 \mathrm{rpm}$ for $60 \mathrm{~s}$ using an Electronic microsystems Itd model 4000 photo resist spinner. Part of the resulting thin layer of solution was removed using an ethanol-wetted cotton tip to keep a part of the FTO slide free for electrical connections. It was then dried in ambient conditions for about $10 \mathrm{~min}$, then heated on a hotplate at $100^{\circ} \mathrm{C}$ for $10 \mathrm{~min}$ and finally heated to $450{ }^{\circ} \mathrm{C}$ for $30 \mathrm{~min}$. This spin coating - oxidation procedure is referred to as 1 cycle.

\subsubsection{Metallization of the metal oxide layers}

The $\mathrm{NiFe}_{2} \mathrm{O}_{4}$ samples were fixed in a custom-made cell, as illustrated in Figure 5.15 for electro-deposition. Photos (Figure 5.15a, d, $f$ and $g$ ) and schematic representations (Figure 5.15b, c, e) of the custom-built electrodeposition cell are given. A photo of the glass electrochemical cell is seen in panel a and schematic representations are presented in panels $b$ and $c$. The cell is based on typical electrochemical cells. The main part of the cell consists of a square hole to insert the working electrode compartment and a GL inlet for the counter electrode. Furthermore, two gas inlets are included, gas inlet 1 for bubbling $\mathrm{N}_{2}$ or Ar for deoxygenating and gas inlet 2 for driving $\mathrm{N}_{2}$ or Ar over the solution during deposition. Finally, a second compartment is present connected with a Luggin capillary for the reference electrode. A photo of the working electrode compartment is shown in panel $d$ and a schematic cross-section is shown in panel e. Furthermore, photos of the disassembled compartment are given in photos $f$ and $g$. The compartment consists of a chemically inert Kel-F casing, protecting the rest of the assembly from the electrolyte. It has a slanted window, for optimal mass transfer, leading towards the (coated) $\mathrm{F}: \mathrm{SnO}_{2}$ substrate. The $\mathrm{F}: \mathrm{SnO}_{2}$ is kept in place with a $\mathrm{Kel}-\mathrm{F}$ window piece compressed between two Orings. The inner ring has an inner diameter of $1.2 \mathrm{~cm}$. The substrate is fixed in a PET bed with a Ti spring strip making electrical contact. This Ti strip is led through the PET for contact to the potentiostat. Finally, the PET bed is pressed against the window with a stainless steel sled containing tightening knobs and a spring for easy assembly and disassembly. As can be seen in photos $f$ and $g$ 
the stainless steel sled can move slightly upwards, lowering the compression on the O-rings and easing movement within the Kel-F casing.

a

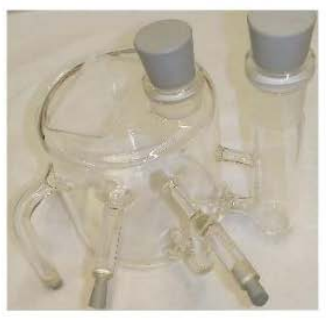

b

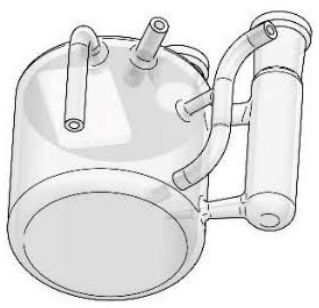

$\begin{array}{lll}\text { Working } & \text { Counter } \\ \text { Clectrode } & \text { Electrode }\end{array}$

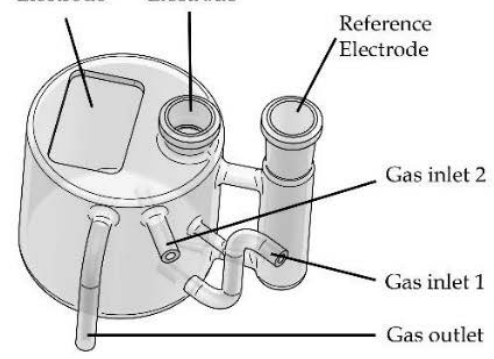

d

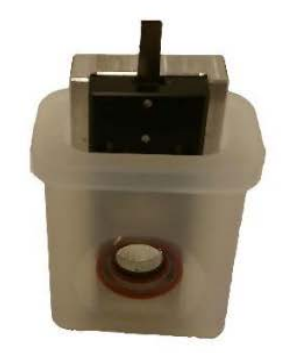

f

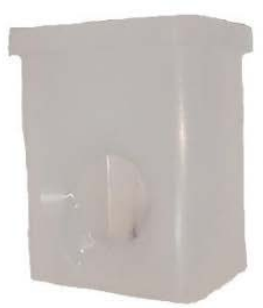

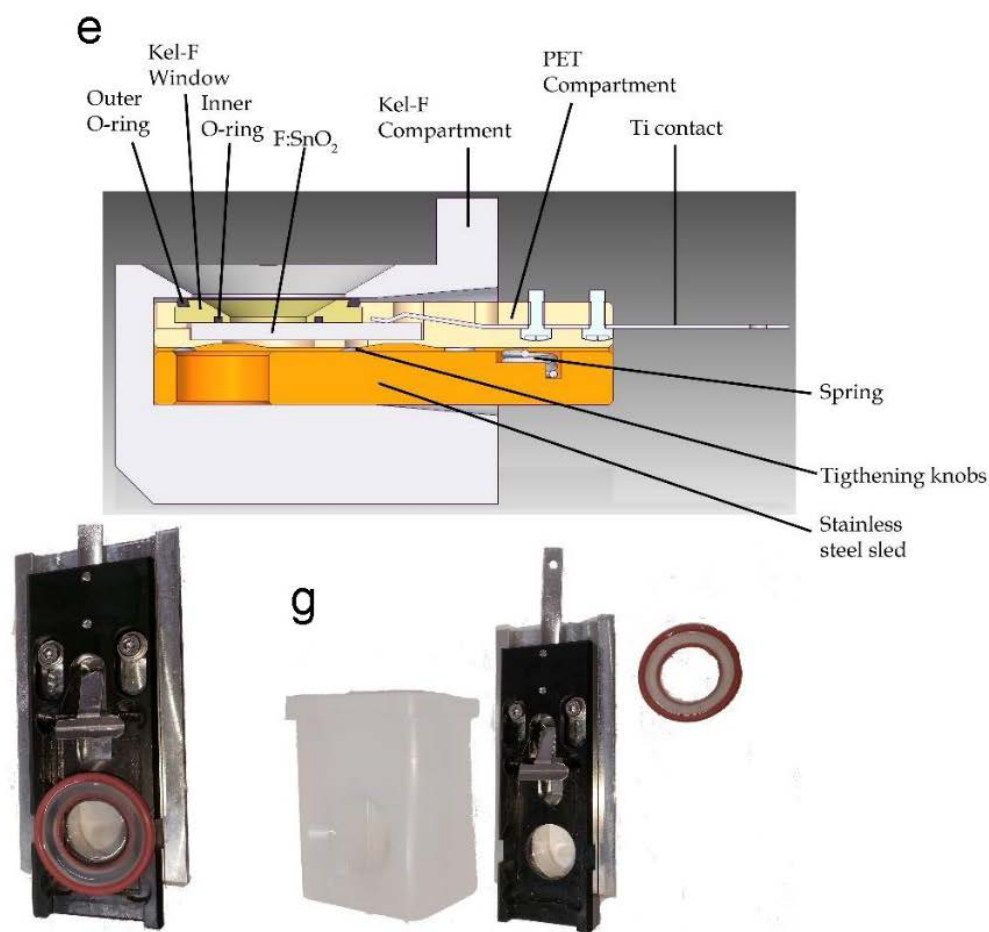

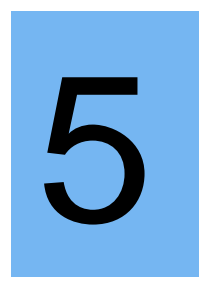

Figure 5.15: a) photograph of the custom-built electrochemical cell without electrodes. b) schematic view of the electrochemical cell from the bottom. c) schematic view of the electrochemical cell from the top with indicators for each part. d) photograph of the assembled working electrode compartment. e) schematic cross section of the working electrode compartment with each part indicated. f) photograph of the disassembled working electrode compartment with left the Kel-F casing and right the assembled sled with substrate. g) photograph of the disassembled working electrode compartment with left the Kel-F casing, in the middle the sled and on the right the Kel-F window with O-rings. 
Note that the FTO slides obtained through spin coating had to be cut into $3 \times 1.5$ $\mathrm{cm}^{2}$ pieces before performing electro-deposition. Electro-deposition was performed galvano-statically at a current of $-20 \mathrm{~mA}$ for $60 \mathrm{~s}$. As a counter electrode a Pt mesh (Mateck, 99.9+ \%) was used and as a reference electrode a $3 \mathrm{M} \mathrm{Ag} / \mathrm{AgCl}$ (BASi) was used. The plating bath used contained $0.3 \mathrm{M} \mathrm{NiSO}_{4}$, $0.2 \mathrm{M} \mathrm{Na}_{2} \mathrm{MoO}_{4} \& 0.3 \mathrm{M} \mathrm{Na}_{3} \mathrm{C}_{6} \mathrm{H}_{5} \mathrm{O}_{7}$ in $100 \mathrm{~mL}$ demineralized water. To this, $20 \mathrm{~mL} \mathrm{NH}_{3}$ was added to obtain a pH of 9.2. First, the metals were dissolved in water through stirring, then $\mathrm{NH}_{3}$ was added to adjust the $\mathrm{pH}$. Prior to the syntheses the baths were purged with Ar for 15 min, and a gentle Ar flow was kept over the solution during electro-deposition.

$\mathrm{Cu} / \mathrm{NiFe}_{2} \mathrm{O}_{4}$ was obtained after $\mathrm{Cu}$ electrodeposition at $-20 \mathrm{~mA}$ for $60 \mathrm{~s}$ from a bath containing $0.3 \mathrm{M} \mathrm{CuSO}_{4}$ pentahydrate (ReagentPlus, >98\% pure, Sigma Aldrich) and $0.3 \mathrm{M} \mathrm{Na}_{3} \mathrm{C}_{6} \mathrm{H}_{5} \mathrm{O}_{7}$ dihydrate (ACS reagent, >99\% pure, Sigma Aldrich) in $100 \mathrm{~mL}$ demineralized water. $20 \mathrm{~mL}$ 28-30\% $\mathrm{NH}_{3}$ (ACS reagent, ph. Eur. For analysis, Emsure) was added to this bath to obtain a pH of 9.2 to a total of $120 \mathrm{~mL}$.

Co-Mo/ $/ \mathrm{NiFe}_{2} \mathrm{O}_{4}$ was obtained after Co-Mo electrodeposition from 0.3 $\mathrm{M} \mathrm{CoSO}_{4}$ hexahydrate (ReagentPlus, $>99 \%$ pure, Sigma Aldrich), $0.2 \mathrm{M} \mathrm{Na}_{2} \mathrm{MoO}_{4}$ dihydrate (ACS reagent, $>99 \%$ pure, Sigma Aldrich) and $0.3 \mathrm{M} \mathrm{Na}_{3} \mathrm{C}_{6} \mathrm{H}_{5} \mathrm{O}_{7}$ dihydrate (ACS reagent, >99\% pure, Sigma Aldrich) in $100 \mathrm{~mL}$ demineralized water. This bath was kept at $\mathrm{pH} 6.2$ without any additions. Co would precipitate if the $\mathrm{pH}$ was raised to much.

\subsubsection{Measurements and characterization}

X-ray diffraction (XRD) was measured using a Bruker D2 Phaser instrument. Most scans were taken from $34-43^{\circ} 2 \theta$ with $0.02^{\circ} 2 \theta$ steps measuring 10 s/step while rotating at $15 \mathrm{~Hz}$. UV-Vis spectroscopy was performed using a Varian Cary 50 spectrometer. The spectra were obtained in transmission mode, in the range of 300-1000 nm using clean FTO as a reference. Inductively coupled plasma atomic emission spectroscopy (ICP-AES) was performed using an Optima 8300 instrument from Perkin Elmer and an average of three samples was used. Electrodeposited samples were dissolved in $10 \mathrm{~mL} 2 \% \mathrm{HNO}_{3}$ before oxidation. Then it was diluted further by adding $2 \mathrm{~mL}$ of sample to $8 \mathrm{~mL}$ of $2 \%$ $\mathrm{HNO}_{3}$. Ni (231.604 nm \& $\left.341.476 \mathrm{~nm}\right)$, Fe (238.204 nm, \& $\left.259.939 \mathrm{~nm}\right)$, Co (228.616 \& $236.380 \mathrm{~nm}), \mathrm{Cu}(327.393 \mathrm{~nm} \& 324.752 \mathrm{~nm})$ and Mo (202.031 \& $204.597 \mathrm{~nm}$ ) were then measured. Calibration curves of $0,0.2,0.4,0.6,0.8$, $1.0 \mathrm{mg} / \mathrm{L}$ were prepared of all the metals. Focused ion beam scanning electron microscopy with energy dispersive X-ray spectroscopy (FIB-SEM-EDX) was performed on a FEI Helios nanolab 600 DualBeam with an Oxford instruments Silicon Drift Detector X-Max energy dispersive spectroscope. EDX mapping was performed with an electron beam of $5 \mathrm{kV}$ and $0.2 \mathrm{nA}$. The beam used to obtain several images is described in the captions. All SEM imaging was done 
using secondary electrons at $2 \mathrm{kV}$ and $0.1 \mathrm{nA}$. FIB cuts for cross sectional images were made by covering an area of $5 \times 2 \mu \mathrm{m}^{2}$ of the substrate with 500 $\mathrm{nm}$ of Pt by sputtering at $30 \mathrm{kV}$ and $0.08 \mathrm{nA}$. Then a cut of $7 \times 5 \mu \mathrm{m}^{2}$ and $5 \mu \mathrm{m}$ deep is made with the ion beam at $30 \mathrm{kV}$ and $2.5 \mathrm{nA}$. Finally, the cross section is cleaned with an ion beam at $30 \mathrm{kV}, 0.23 \mathrm{nA}$ in an area of $6 \times 0.5 \mu \mathrm{m}^{2}$ and 5 $\mu \mathrm{m}$ deep near the edge. An image is then taken from the sample at a $52^{\circ}$ tilt.

Transient absorption spectroscopy (TAS) was performed on an EOS spectrophotometer. The pump laser is generated using a Nd:YAG crystal (1064 $\mathrm{nm}$ light), this is transformed into $355 \mathrm{~nm}$ using harmonic crystals. This laser was operated at a repetition rate of $1 \mathrm{kHz}$ and the intensity was kept at $1.5 \mathrm{~mW}$ using a neutral density filter. The probe pulse is generated using a LEUKOS super continuum light source generating a wide spectrum, which can be detected between $350 \mathrm{~nm}$ to $900 \mathrm{~nm}$ with a spectral resolution of $1.5 \mathrm{~nm}$. The repetition rate of the source is $2 \mathrm{kHz}$. The pulse duration of the lasers is below $1.2 \mathrm{~ns}$, allowing for a temporal resolution below $1 \mathrm{~ns}$. The probe light is split using a beam splitter into a dual beam mode so that unfiltered light can be used to correct for fluctuations in the light source. Samples were measured in transmission mode are probed for $1 \mathrm{~h}$ and in ambient air conditions. Samples coated with Ni-Mo were measured in reflectance mode and were probed for 2 $\mathrm{h}$ in ambient air conditions.

\subsubsection{Photo-electrochemical tests}

Photo-electrochemical tests are performed in $1 \mathrm{M} \mathrm{KOH}$ purged with $\mathrm{N}_{2}$ for at least $15 \mathrm{~min}$. The samples are mounted against a window with a diameter of 6 $\mathrm{mm}$, exposing $0.28 \mathrm{~cm}^{2}$. The reference electrode is a $\mathrm{Hg} / \mathrm{HgO}$ electrode $(0.956$ $\mathrm{V}$ vs RHE at $\mathrm{pH}$ 14) and the counter electrode is a Pt mesh. Chronoamperometry measurements are performed at a potential of $-0.3 \mathrm{~V}$ vs RHE for $1 \mathrm{~h}$ where light is cycled between dark and light every $300 \mathrm{~s}$, starting in the dark. Prior to these measurements each sample was subjected to $5 \mathrm{~min}$ of chronoamperometry in the dark at $-0.3 \mathrm{~V}$ vs RHE. During the cyclic voltammetry experiments the potential is cycled from $0.956 \mathrm{~V}$ to $-0.294 \mathrm{~V}$ vs RHE for 10 cycles at $100 \mathrm{mV} / \mathrm{s}$. All these photo-electrochemical tests were performed on a VERSASTAT 4 potentiostat from Princeton applied research. Directly afterwards 10 more cycles are performed while the sample is backilluminated with a Newport AM 1.5 solar simulator $\left(100 \mathrm{~mW} / \mathrm{cm}^{2}\right)$ consisting of a $300 \mathrm{~W}$ Xe lamp filtered with an air mass 1.5 global filter. Calibration was performed with a standard reference Si solar cell prior to the measurements. IPCE was done using a $420 \mathrm{~nm}$ LED light (380-460 nm spread, $\left.1.5 \mathrm{~mW} / \mathrm{cm}^{2}\right)$ at $20 \mathrm{~mm}$ distance on Ni-Mo coated samples using the VERSASTAT 4 potentiostat from Princeton applied research. Prior to the IPCE measurements first three measurements are done in the dark of 5 min each, then one measurement is done in the light for $5 \mathrm{~min}$. Bubble formation resulted in the data being averaged over these 5 min intervals. 


\subsection{Acknowledgments}

This Chapter is based on the following manuscript: Cathodic Electrodeposition of $\mathrm{Ni}-\mathrm{Mo}$ on Semiconducting $\mathrm{NiFe}_{2} \mathrm{O}_{4}$ for Photoelectrochemical Hydrogen Evolution in Alkaline Media, J.H.J. Wijten, R.P.H. Jong, G. Mul, B.M. Weckhuysen, ChemSusChem 2018, 11, 1374-1381.

Jochem Wijten and Bert Weckhuysen conceived the research plans. Jochem Wijten executed the experimental work under the supervision of Bert Weckhuysen. Jochem Wijten and Ronald Jong performed the photoelectrochemical experiments under the supervision of Guido Mul. Jochem Wijten wrote the work with the input of all co-authors and feedback and corrections by Bert Weckhuysen.

The following people are gratefully acknowledged: Christa van Oversteeg (UU) for performing the ICP-AES measurements and Marcel van Asselen (UU) for his contribution to the electrodeposition cell design.

\subsection{References}

[1] Fresno, F., Portela, R., Suárez, S. \& Coronado, J. M., J. Mater. Chem. A 2014, 2, 2863-2888

[2] Walter, M. G., Warren, E. L., McKone, J. R., Boettcher, S. W., Mi, Q., Santori, E. A. \& Lewis, N. S., Chem. Rev. 2010, 110, 6446-6473

[3] Horiuchi, Y., Toyao, T., Takeuchi, M., Matsuoka, M. \& Anpo, M., Phys. Chem. Chem. Phys. 2013, 15, 13243-13253

[4] Djurišić, A. B., Leung, Y. H. \& Ching Ng, A. M., Mater. Horizons 2014, 1, 400-410

[5] Lu, X., Xie, S., Yang, H., Tong, Y. \& Ji, H., Chem. Soc. Rev. 2014, 43, 7581-7593

[6] Ismail, A. A. \& Bahnemann, D. W., Sol. Energy Mater. Sol. Cells 2014, 128, 85-101

[7] Bae, D., Seger, B., Vesborg, P. C. K., Hansen, O. \& Chorkendorff, I., Chem. Soc. Rev. 2017, 46, 1933-1954

[8] Djokic, S., Electrodeposition and Surface Finishing, Springer, New York, 2014

[9] Zhao, J., Wang, X., Xu, Z. \& Loo, J. S. C., J. Mater. Chem. A 2014, 2, 15228-15233

[10] Carraro, C., Maboudian, R. \& Magagnin, L., Surf. Sci. Rep. 2007, 62, 499-525

[11] L. Magagnin, P. Cojocaru, F. S., in Electroless Synthesis of Metallic Nanostructures for Biomedical Technologies (Ed.: Djokic, S.) Springer, New York, 2012, 73-99

[12] Lačnjevac, U., Jović, B. M. \& Jović, V. D., Electrochim. Acta 2009, 55, 535-543 
[13] Manazoglu, M., Hapci, G. \& Gokhan, O., J. Mater. Eng. Perf. 2016, 25, 130-137

[14] Saba, A., Elsayed, E., Moharam, M. \& Rashad, M. M., ISRN Nanotechnol. 2012, 2012, 532168

[15] Sartale, S. D., Lokhande, C. D. \& Ganesan, V., Phys. Status Solidi 2005, 202, 85-94

[16] Xu, C., Zhou, J., Zeng, M., Fu, X., Liu, X. \& Li, J., Int. J. Hydrogen Energy 2016, 41, 13341-13349

[17] Zhong, D. K., Cornuz, M., Sivula, K., Grätzel, M. \& Gamelin, D. R., Energy Environ. Sci. 2011, 4, 1759-1764

[18] Seabold, J. A. \& Choi, K. S., Chem. Mater. 2011, 23, 1105-1112

[19] Bassi, P. S., Gurudayal, Wong, L. H. \& Barber, J., Phys. Chem. Chem. Phys. 2014, 16, 11834-11842

[20] Prévot, M. S., Guijarro, N. \& Sivula, K., ChemSusChem 2015, 8, 13591367

[21] Read, C. G., Park, Y. \& Choi, K.-S., J. Phys. Chem. Lett. 2012, 3, 1872 1876

[22] Rekhila, G., Bessekhouad, Y. \& Trari, M., Int. J. Hydrogen Energy 2013, 38, 6335-6343

[23] Sun, M., Chen, Y., Tian, G., Wu, A., Yan, H. \& Fu, H., Electrochim. Acta 2016, 190, 186-192

[24] Gunjakar, J. L., More, A. M., Gurav, K. V. \& Lokhande, C. D., Appl. Surf. Sci. 2008, 254, 5844-5848

[25] McCrory, C. C. L., Jung, S., Ferrer, I. M., Chatman, S. M., Peters, J. C. \& Jaramillo, T. F., J. Am. Chem. Soc. 2015, 137, 4347-4357

[26] Fan, C., J. Electrochem. Soc. 1994, 141, 382-387

[27] Lačnjevac, U., Jović, B. M., Maksimović, V. M. \& Jović, V. D., J. Appl. Electrochem. 2010, 40, 701-708

[28] Meinert, M. \& Reiss, G., J. Phys. Condens. Matter. 2014, 26, 115503

[29] Burns, R. G., Mineralogical Applications of Crystal Field Theory, Cambridge University Press, Cambridge, 1993

[30] Carta, D., Casula, M. F., Falqui, A., Loche, D., Mountjoy, G., Sangregorio, C. \& Corrias, A., J. Phys. Chem. C 2009, 113, 8606-8615

[31] Chinnasamy, C. N., Narayanasamy, A., Ponpandian, N., Chattopadhyay, K., Shinoda, K., Jeyadevan, B., Tohji, K., Nakatsuka, K., Furubayashi, T. \& Nakatani, I., Phys. Rev. B 2001, 63, 184108

[32] Hodes, G. \& Kamat, P. V., J. Phys. Chem. Lett. 2015, 6, 4090-4092

[33] Pendlebury, S. R., Barroso, M., Cowan, A. J., Sivula, K., Tang, J., Grätzel, M., Klug, D. \& Durrant, J. R., ChemComm, 2011, 47, 716-718

[34] Barroso, M., Pendlebury, S. R., Cowan, A. J. \& Durrant, J. R., Chem. Sci., 2013, 4, 2724-2734 
In Situ Study of Ni-Mo Stability: Effect of Substrate and Potential 
I look around in wonder inside the museum.

Together with my dad, I am walking over the surface of the moon, looking at replicas of space suits and the Apollo 11.

We walk into the next hall, a huge place where the ceiling is made into a night

sky.

A huge spacecraft is suspended by nearly invisible cables in the center, immediately drawing our attention.

Subtly, my dad guides me to a small corner, showing a machine with all kinds

of tubes and cables.

"Like I promised son, the machine that makes fuel out of sunlight and water."

"This little thing?" I ask as I am still distracted by the rocket over our heads. My dad chuckles at that, "Well, as a friend told me: 'the devil is in the details." "Yes, maybe one of the most vital components of that huge rocket. For it not only gives them fuel, but it also recycles their breath."

"How?" I question, while my attention is now actually drawn to it. "It takes the carbon dioxide of the astronauts' breath and it takes water. It then adds electricity... there." He points at one of the blocks that seems to contain some liquid.

"Together they make, via hydrogen, natural gas, and oxygen. So it makes fuel and allows the astronauts to breathe to boot!" He continues to explain it to me in detail. I only understand little of it, but I listen, impressed. "Amazing... How do you know so much about it?" My dad chuckles again, "Well, perhaps the fact that I built it helps" and he winks at me. 


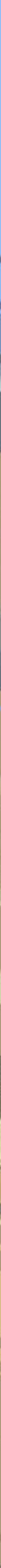




\section{Structure-Sensitive Alkali Promotion in the Formation of $\mathrm{CH}_{4}$ from $\mathrm{CO}_{2}$ and Renewably Produced $\mathrm{H}_{2}$ over Supported Ni Catalysts}

In Power-to-Methane (PtM) plants, the renewable electricity grid is stabilized by using green electrons to produce $\mathrm{H}_{2}$ via $\mathrm{H}_{2} \mathrm{O}$ electrolysis, which is subsequently used to hydrogenate $\mathrm{CO}_{2}$ into $\mathrm{CH}_{4}$. In this $\mathrm{PhD}$ Chapter, PtM is studied in a cascade fashion, assessing the effects of the purity of the $\mathrm{H}_{2}$ stream on the activity of industrial $\mathrm{Ni} / \mathrm{SiO}_{2}$ methanation catalysts. There is an effect of the upstream electrolysis step on the downstream methanation step, which is Ni nanoparticle size dependent. Small amounts of $\mathrm{K}^{+}$are shown to affect $\mathrm{CH}_{4}$ production, and are deposited via $\mathrm{KOH}$ aerosols that evolve from the electrochemistry, which is performed in $1 \mathrm{M} \mathrm{KOH}$ solutions. Furthermore, we establish a Sabatier relationship, as $\mathrm{K}^{+}$promotion is not observed for Ni nanoparticle sizes above a certain nanoparticle size where strong $\mathrm{CO}$ adsorption is already observed in the pristine $\mathrm{Ni} / \mathrm{SiO}_{2}$ catalyst. We thus explain discrepancies found for alkaline promotion in literature. Furthermore, we show relevance in the application of in-situ aerosol promotion for PtM, via a homogeneous $\mathrm{K}^{+}$distribution, which is difficult to achieve via standard catalyst synthesis methods. With calculations, we show the significance of both technological and catalytic components in terms of energy storage efficiency. 


\subsection{Introduction}

In what is called the Power-to-Gas (PtG) concept, the temporal mismatch in renewable energy demand and supply is overcome and stored chemically in for example methane. ${ }^{[1-5]} \mathrm{CH}_{4}$ production can be done via $\mathrm{CO}_{2}$ hydrogenation, which a reaction with the potential to be applied in this concept and thus chemically store renewable electricity. In this way, via a closed-cycle process, $\mathrm{CO}_{2}$ can be captured and utilized as a resource for chemical energy storage. [6] In the case that even negative carbon emissions will become imperative to facilitate the minimization of the environmental impact of greenhouse gases, appropriate $\mathrm{CO}_{2}$ storage methods are highly needed and should be further explored and developed. ${ }^{[1-9]}$

The cascade synthesis of $\mathrm{CH}_{4}$ from solar light, a PtG process which is often specified as Power-to-Methane (PtM), is an attractive concept that will allow us to decrease $\mathrm{CO}_{2}$ emissions, simultaneously tackling the mismatch in renewable electricity demand and supply, and stabilizing the electricity grid as a result. ${ }^{[1,2]}$ In specific geographic sweet spots with point sources of $\mathrm{CO}_{2}$, and an excess renewably produced electricity, this PtM process may become viable for the long-term, e.g. seasonal storage of electricity, for which an estimated $480 \mathrm{TWh}$ per year is needed in Europe alone. ${ }^{[10]}$

In the PtM concept, first renewably produced electrons are used to split water. While this renewable $\mathrm{H}_{2}$ can be used to store the energy as was done in the previous Chapters, storing $\mathrm{H}_{2}$ is approximately an order of magnitude more costly than storing $\mathrm{CH}_{4}$, due to material embrittlement by $\mathrm{H}_{2}$ and high costs for storing it under pressure compared to $\mathrm{CH}_{4}$. Thus, particularly for long-term (seasonal) storage of electricity, using the $\mathrm{H}_{2}$ on-site to form $\mathrm{CH}_{4}$ out of $\mathrm{CO}_{2}$ would be a more economical choice. ${ }^{[11]} \mathrm{CH}_{4}$ (also called e-gas) formed this way can be stored and transported safely in large quantities through the existing natural gas infrastructure. ${ }^{[4,11-13]}$ Furthermore, methanation is a crucial element of any engineering solution involving on-site $\mathrm{H}_{2}$ production through lowtemperature catalytic reforming of organic substrates (e.g. alcohols, formic acid). ${ }^{[14]}$

Several important steps occur for the application of this PtM process, as outlined in Figure 6.1. Solar light is first converted into electrons via photovoltaics (step 1). Then, these green electrons are converted into $\mathrm{H}_{2}$ via electrolysis of $\mathrm{H}_{2} \mathrm{O}$ (step 2) where $\mathrm{O}_{2}$ is formed as a by-product, relevant, for example, in spacefaring as it supplies astronauts with breathable air. ${ }^{[15,16]} \mathrm{CO}_{2}$ streams are captured and purified (step 3), and can then be converted into $\mathrm{CH}_{4}$ using the renewably made $\mathrm{H}_{2}$ (step 4). This $\mathrm{CH}_{4}$ is then stored and distributed to close the cycle (step 5).

$\mathrm{CO}_{2}$ reduction to methane may be regarded as an established process as Paul Sabatier discovered the reaction over 100 years ago ${ }^{[17,18]}$, yet there are new challenges to the application of this process as chemical industry is slowly but 


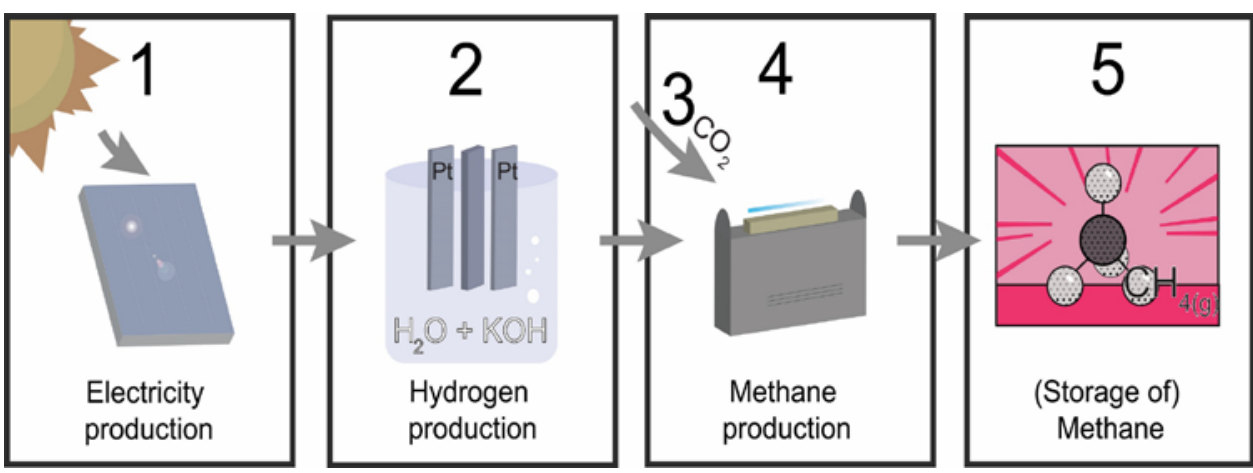

Figure 6.1: Schematic representation of the steps being taken in the cascaded PtM process. 1) Renewable electricity production. 2) Electrocatalytic water splitting for $\mathrm{H}_{2}$ production. 3) $\mathrm{CO}_{2}$ capture. 4) Thermal $\mathrm{CH}_{4}$ production via $\mathrm{CO}_{2}$ hydrogenation. 5) Storage/use of $\mathrm{CH}_{4}$.

surely being electrified. We thus bring, to the best of our knowledge for the first time, together all elements of this process in a single experimental setup at the laboratory scale, which is schematically represented in Figure 6.1 and will be thoroughly described in this Chapter. By physically bringing together electrochemistry and catalysis engineering we highlight the interplay of each of the separate components on each other, bringing forth new practical considerations and providing fundamental explanations for observed phenomena.

Most notably, we fundamentally explain the current discrepancy in literature whether alkali promotes methanation catalysis, or poisons it ${ }^{[19,20]}$. We show that aerosols formed from the alkaline $\mathrm{KOH}$ electrolyte have a structure-sensitive effect in the methanation reaction over $\mathrm{Ni} / \mathrm{SiO}_{2}$ methanation catalysts, resulting in the promotion or deactivation depending on the precise particle size of the supported $\mathrm{Ni}$ nanoparticles. On one hand, smaller particles $(\leq 4.4 \mathrm{~nm})$ are activated as the addition of $\mathrm{K}^{+}$weakens the $\mathrm{C}-\mathrm{O}$ bond of adsorbed $\mathrm{CO}$. On the other hand, in larger particles $(6 \mathrm{~nm})$ the $\mathrm{C}-\mathrm{O}$ bond is even further weakened due to the addition of $\mathrm{K}^{+}$but no further promotion is observed, suggesting the bond is weakened enough to no longer be rate limiting. The present work has both technical and fundamental implications in the rational design of Ni-based catalysts, and it shows in one set-up that not only the activity of the Sabatier reaction is structure-sensitive ${ }^{[3]}$, but also its promotion by alkali metal contaminants in impure $\mathrm{H}_{2}$ streams following from electrolysis.

In this Chapter, $1 \mathrm{M} \mathrm{KOH}$ and $\mathrm{NaOH}$ alkaline solutions are used for the production of renewable $\mathrm{H}_{2}$ via $\mathrm{H}_{2} \mathrm{O}$ electrolysis ${ }^{[21,22]}$, and we focus on their effect on the catalytic hydrogenation of $\mathrm{CO}_{2}$ into $\mathrm{CH}_{4}$. Our experiments began by determining the possible presence of aerosols in our $\mathrm{H}_{2}$ feed, which may evolve from the HER in alkaline medium. This was done, as NASA literature from 1974 already reports the possible presence of aerosols in the feed of electrolysis systems ${ }^{[23]}$, and industrially, often aerosol filters are applied. As the water splitting reaction is preferably performed in alkaline media, due to the 
kinetically difficult step (OER), these aerosols may contain alkaline material, for which literature shows both promoting ${ }^{[2,25]}$, and deactivating ${ }^{[19,20]}$ effects for the addition of alkaline dopants to $\mathrm{Ni} / \mathrm{SiO}_{2}$-based methanation. This Chapter supplies further knowledge on the reason behind this apparent disagreement in literature.

\subsection{Results and Discussion}

\subsubsection{Cascaded Setup}

The cascaded setup, as schematically described in Figure 6.1 necessarily needed several components. Step 1, the photovoltaics was simulated by a small solar module comprised of four commercial (B-class) Si solar cells (Figure 6.2a) similar to the one used in Chapter 3. Furthermore, the sun was simulated with a Solar Simulator (Newport, AAA-class Solar Simulator). The output measured with this setup was $2.44 \mathrm{~V}$ and $0.832 \mathrm{~A}(2.03 \mathrm{~W})$. The solar simulator has an output of $100 \mathrm{~mW} / \mathrm{cm}^{2}$ and an illumination spot of $104.04 \mathrm{~cm}^{2}$ and the solar module was sizable enough to capture the entire spot. Thus, the efficiency of this step was $19.5 \%$ efficiency, which is comparable to commercial solar panels.

Step 2 was performed using a traditional $\mathrm{H}$-cell two-electrode electrochemical cell (Figure 6.2b). A Nafion membrane, activated in $\mathrm{HNO}_{3}$ to supply $\mathrm{H}^{+}$into the sulfonic membrane to facilitate conductivity, was used to separate the two compartments. The membrane was found to be both conductive and stable for extended periods of time (>168 h), despite alkaline solutions being used; no gas or liquid transport could be observed. The configuration of the cell resulted in a loss of electrochemical efficiency, observable as a significantly higher overpotential (Figure 6.3) than those in the previous Chapters and $\mathrm{O}_{2} \mathrm{FE}$ checks show $99.6 \%$ efficiency, comparable to Chapter 3 . With an input of 0.832 $\mathrm{A}$, a $\mathrm{H}_{2}$ flow of $5.797 \mathrm{~mL} / \mathrm{min}$ (1.043 W worth of $\mathrm{H}_{2}$, assuming the ideal gas law and $120 \mathrm{MJ} / \mathrm{kg}$, lower heating value (LHV)) can be expected at $100 \%$ Faradaic
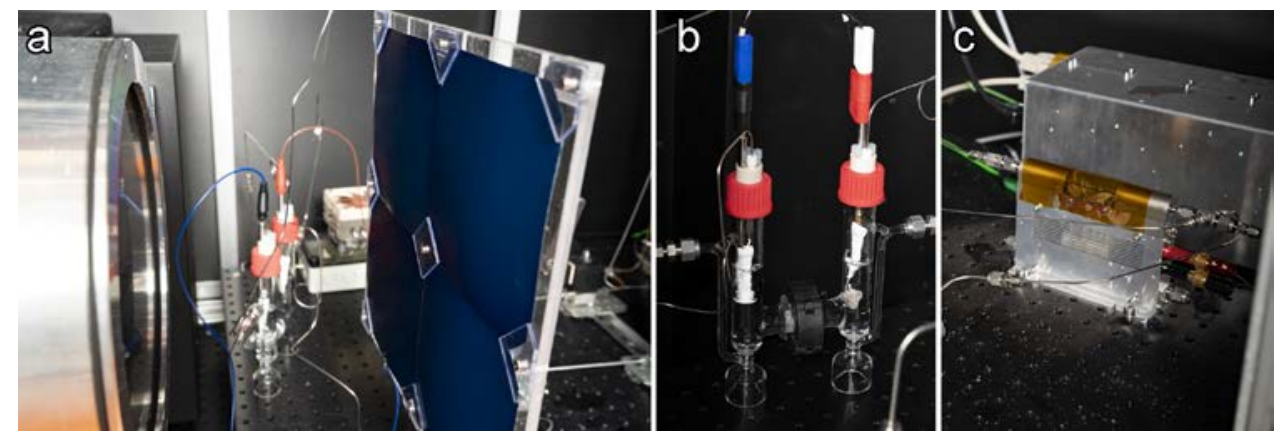

Figure 6.2: a) Photograph of the solar module used in this Chapter. b) Photograph of the electrochemical water splitting $\mathrm{H}$-cell. c) Photograph of the infrared heated plug flow reactor. 
efficiency (FE). This makes sense as the applied overpotential induces a loss
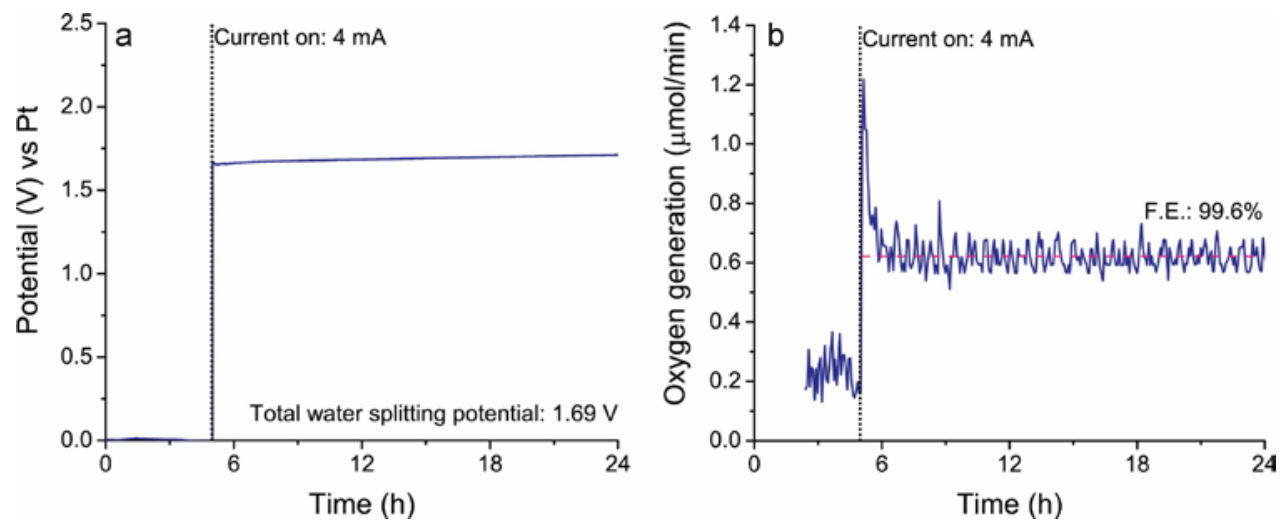

Figure 6.3: a) Chrono-potentiometric curve of Pt vs Pt to achieve a current of $4 \mathrm{~mA}$. b) $\mathrm{O}_{2}$ production during cascaded operation.

of $1.21 \mathrm{~V} * 0.832 \mathrm{~A}=1.007 \mathrm{~W}$. This indeed adds up to $2.05 \mathrm{~W}$, which is close to the measured $2.03 \mathrm{~W}$ output, and the mismatch is ascribed to the assumption of an ideal gas which logically results in a small error. This results in a maximum energy efficiency of $51.4 \%$ for the electrolysis step.

Step 3 is not done actively in the presented setup. Instead, an $820 \mathrm{ppm} \mathrm{CO}_{2}$ in $\mathrm{N}_{2}$ gas mixture could be used to simulate air. Together with dilution by the carrier gas used in electrolysis (Under operation a gas flow of $\mathrm{Ar} / \mathrm{Kr}(2 \mathrm{~mL} / \mathrm{min}$ and $0.1 \mathrm{~mL} / \mathrm{min}$ respectively) was utilized) a concentration of $\left(1 \mathrm{~mL} / \mathrm{min} \mathrm{CO}_{2}\right.$ mixture) $265 \mathrm{ppm} \mathrm{CO}_{2}$ is achieved, excluding $\mathrm{H}_{2}$, which can be considered representative of captured air after $\mathrm{O}_{2}$ separation. The option to use pure $\mathrm{CO}_{2}$ is also included to simulate $\mathrm{CO}_{2}$ point sources or purified $\mathrm{CO}_{2}$ feeds after capture.

Step 4 (Figure 6.2c) is performed in a lab-scale plug flow reactor (PFR). Unless noted otherwise $2 \mu \mathrm{m}$ particle filters were used to capture aerosols in the $\mathrm{H}_{2}$ stream before introducing it to the PFR. These filters were sufficient to reduce the aerosol count below countable concentrations as is discussed in detail in Section 6.2.2. Electrical heating is applied to the system using infrared heating and operates at $19 \mathrm{~V}$ and $3.5 \mathrm{~A}(66.5 \mathrm{~W})$ to achieve $400^{\circ} \mathrm{C}$. The heating is the most energy-intensive process in the setup of the steps that are being considered by an order of magnitude. The reactor, as seen in Figure $6.2 \mathrm{c}$ is far from ideal in terms of heat management as the isolation is limited (Kapton foil) and using infrared heating without direct contact to the catalyst bed. Thus the efficiency values taking into account the energy loss due to heating are not representative for the electrical heating done in industrial grade reactors. The purpose of this setup is, however, not to achieve high level efficiencies but to study the interplay between electrolysis and $\mathrm{H}_{2}$ utilization when cascading these reactions. The reaction $\mathrm{CO}_{2}+4 \mathrm{H}_{2} \rightarrow \mathrm{CH}_{4}+2 \mathrm{H}_{2} \mathrm{O}$ inherently has an energy efficiency of $92.2 \%\left(\mathrm{CH}_{4}\right.$ has an energy density of $\left.55.6 \mathrm{MJ} / \mathrm{kg}\right)$.

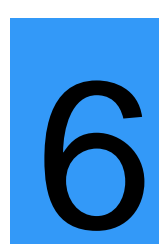


Assuming full conversion of all generated $\mathrm{H}_{2}$ would result in $0.962 \mathrm{~W}$ worth of $\mathrm{CH}_{4}$. Taking into account the heat a maximum efficiency of $1.42 \%$ is possible in this step.

The final step, the storage or transport of $\mathrm{CH}_{4}$, has not been considered in this setup. Putting together the efficiency of each of the considered steps a maximum achievable energy efficiency of $0.14 \%$ is achievable for PtM in this setup. When not taking into account the inefficient heating that's installed the energy efficiency would be $9.2 \%$ energy efficiency for PtM.

As mentioned before, this particular Solar-to-Methane setup has been designed for the purpose of research focused on steps 2 and 4 presented in Figure 6.1. We focused on allowing for multiple gasses through the system from several points of entry to study the effect of gas mixtures as well as the effect of carrier gasses (on e.g. aerosol formation). Remotely adjustable valves are present between the $\mathrm{H}$-cell and PFR to allow switching between measuring the $\mathrm{HER} \mathrm{H}_{2}$ stream and feeding the $\mathrm{H}_{2}$ to the PFR, introducing dead volume which is unnecessary for continuous operation. A non-ideal PFR was chosen for the potential to allow for in situ measurements on $\mathrm{Ni} / \mathrm{SiO}_{2}$. From an engineering point of view many improvements can be made, such as utilizing A-class solar panels (B-class solar cells are the highest grade commercially available and were thus used in this setup as the module is much smaller than a full solar panel). The $\mathrm{H}$-cell can be optimized to reduce the pressure drop introduced by the electrolyte and Nafion membrane, for example by using a wider bridge for better diffusion of solutes. The $2 \mu \mathrm{m}$ filters could be replaced by water filters, effectively recovering the electrolyte, as is done in the Audi e-gas plant in Werlte (of which an artistic rendition of a photograph is shown as the cover picture of this Chapter). Finally, the PFR could be vastly improved by more efficient heating, better isolation and using optimized catalyst beds.

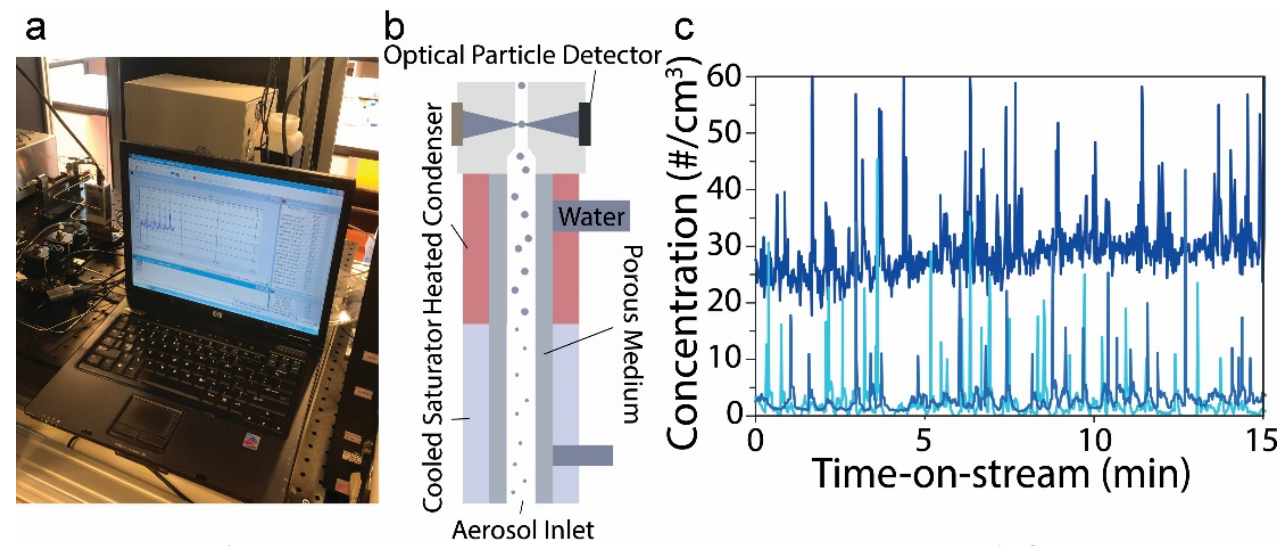

Figure 6.4: a) Photograph of the condensed particle counter. b) Schematic of the operation of a condensed particle counter. c) The results of the condensed particle counter without filter (dark blue), with filter (blue) and with filter and electrochemical water splitting (light blue). 
a

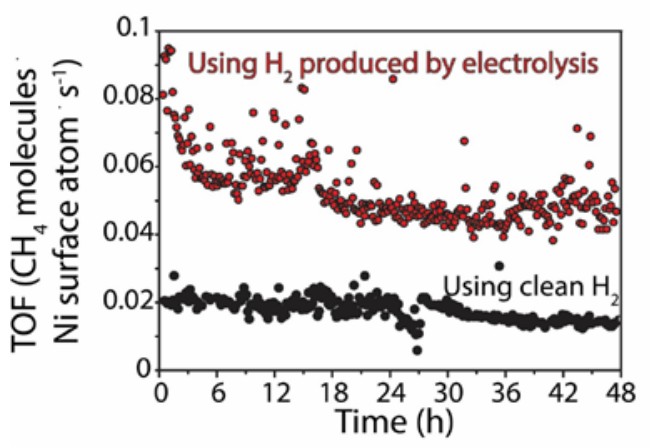

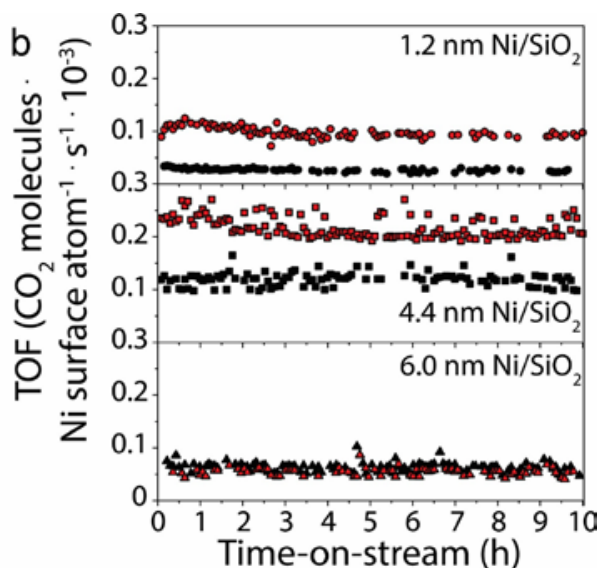

Time-on-stream (h)

Figure 6.5: a) Trends in the methanation reaction using clean $\mathrm{H}_{2}$ (black), and unfiltered $\mathrm{H}_{2}$ produced via the HER in alkaline medium (red) for 2 days run time, $\mathrm{CH}_{4}$ activity is indicated by TOF values are shown at $400{ }^{\circ} \mathrm{C}$, over a Ni/SiO2 catalyst with $4.4 \mathrm{~nm}$ mean particle size. b) $10 \mathrm{~h}$ trends in the methanation reaction $\mathrm{CO}_{2} \mathrm{TOF}$ at $400{ }^{\circ} \mathrm{C}$ over $\mathrm{Ni} / \mathrm{SiO}_{2}$ catalyst of $1.2 \mathrm{~nm}$ (top), $4.4 \mathrm{~nm}$ (middle) and $6.0 \mathrm{~nm}$ (bottom) mean $\mathrm{Ni}$ nanoparticle size, using $\mathrm{H}_{2}$ from a cylinder (black) or from the HER reaction (red). Conditions: $400 \mathrm{ppm} \mathrm{CO}_{2}, 9600 \mathrm{ppm} \mathrm{H}_{2}, \mathrm{~N}_{2}$ balance, and gas hour space velocity (GHSV): 30,000.

\subsubsection{Aerosol Promotion of $\mathrm{Ni} / \mathrm{SiO}_{2}$ Hydrogenation Catalysts}

In a first set of experiments we measured the concentration of aerosols coming from the electrochemical $\mathrm{H}$-cell using a $\mathrm{H}_{2} \mathrm{O}$-based condensation particle counter (Figure 6.4a-b). Figure 6.4c shows that when no filter is applied a measurable concentration of circa 30 particles $/ \mathrm{cm}^{3}$ is found (after 500 times dilution with dry $\mathrm{N}_{2}$ ), thus 15000 particles $/ \mathrm{cm}^{3}$ in undiluted streams. Applying the $2 \mu \mathrm{m}$ filter resulted is significantly lower aerosol counts, comparable to the signal found when an empty cell is used and thus no particles can be detected. $\mathrm{H}_{2} \mathrm{O}$ splitting in this section was done with two Pt electrodes and $\mathrm{H}_{2} \mathrm{O}$ could be split into $\mathrm{H}_{2}$ and $\mathrm{O}_{2}$ stably at $1.69 \mathrm{~V}$ at a current of $4 \mathrm{~mA}$ (as shown in Figure 6.3).

As shown in Figure 6.5 , the investigated $\mathrm{Ni} / \mathrm{SiO}_{2}$ catalysts show stable methanation activity at $400{ }^{\circ} \mathrm{C}$, over $48 \mathrm{~h}(6.0 \mathrm{~nm}$ Ni particles, Figure 6.5a) when pure (5.0) $\mathrm{H}_{2}$ from a cylinder is used as a feedstock, but is significantly changed when unfiltered $\mathrm{H}_{2}$ from the HER is used. For the pure $\mathrm{H}_{2}$ stream, when comparing the observed turnover frequency (TOF) values, they agree with previously reported results for $\mathrm{CO}_{2}$ methanation over $\mathrm{Ni} / \mathrm{SiO}_{2}$ catalysts. ${ }^{[3]}$ Yet, the values found for the reaction with $\mathrm{H}_{2}$ produced via the HER, which is performed in a $1 \mathrm{M} \mathrm{KOH}$ alkaline solution, show notable trends for the methanation catalysts. It is also clear, in Figure $6.5 \mathrm{~b}$, that this trend is sensitive to the $\mathrm{Ni}$ particle size of the catalyst. Over $4.4 \mathrm{~nm} \mathrm{Ni} / \mathrm{SiO}_{2}$, a strong transient increase in methanation activity is observed, followed by a decay in activity over time, which nonetheless remains considerably higher than the values observed 

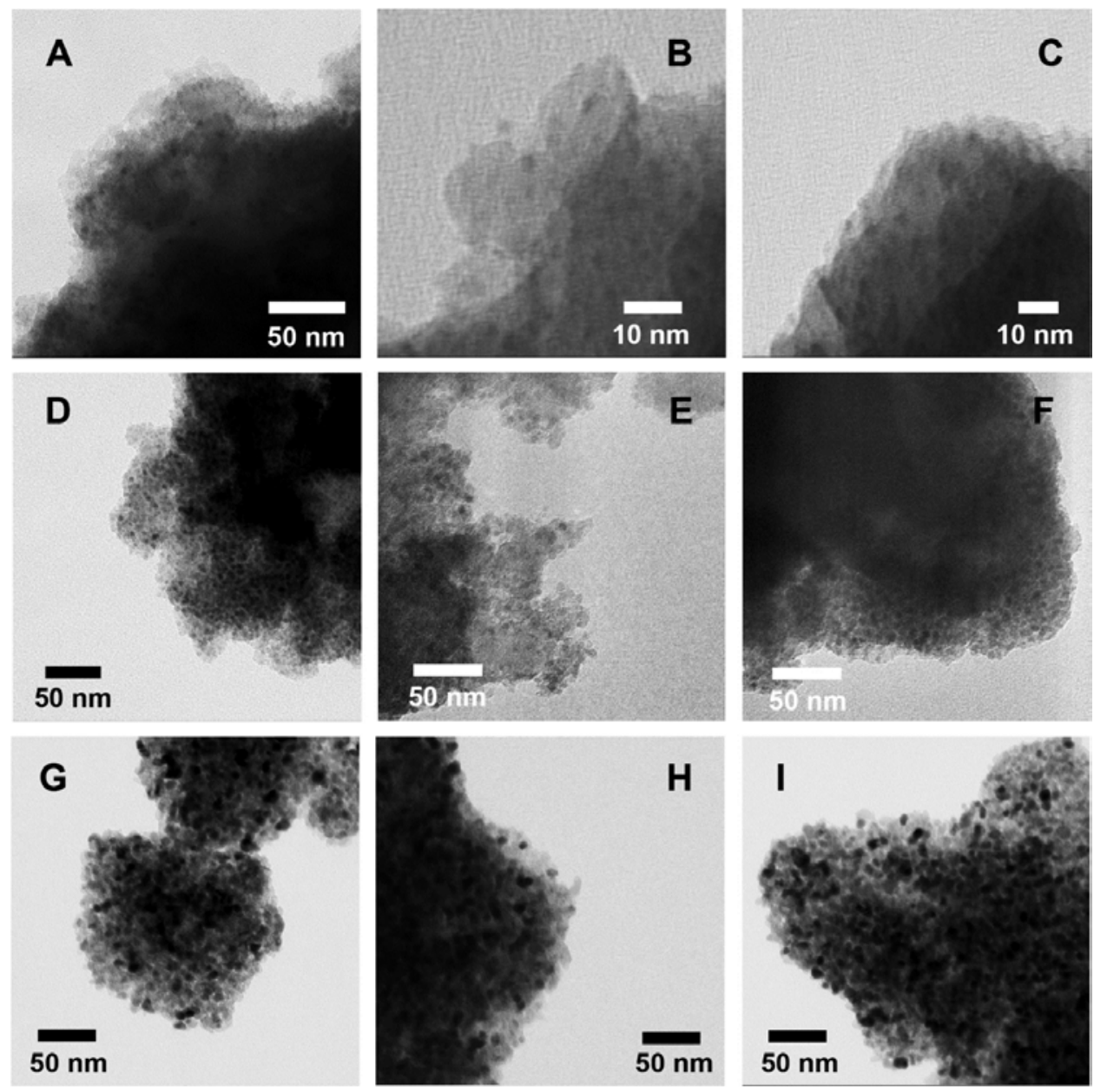

Figure 6.6: TEM images of the $(A-C)$ the $1.2 \mathrm{~nm}$ Ni/SiO2 catalyst, $(D-F)$ the $4.4 \mathrm{Ni} / \mathrm{SiO}_{2}$ catalyst, and (G-I) the $6.0 \mathrm{~nm}$ catalyst. Left row images are after 2 days of reaction at $400^{\circ} \mathrm{C}$ with the ex-situ doped catalyst, the middle row using filtered, and the right row using unfiltered $\mathrm{H}_{2}$ coming from the HER reaction.

using pure $\mathrm{H}_{2}$ (Figure 6.5b, middle). On the other hand, over larger $\mathrm{Ni}$ metal nanoparticles (i.e., $6.0 \mathrm{~nm}$ ), no promotion is observed and the catalyst steadily deactivates over time (Figure 6.5b, bottom). The smallest mean Ni metal nanoparticle size tested in this way, $1.2 \mathrm{~nm} \mathrm{Ni} / \mathrm{SiO}_{2}$, shows an increased activity as well but to a lesser extent than the $4.4 \mathrm{~nm}$ catalyst sample (Figure 6.5b, top).

In these experiments, TOF values are proportional to activity as the particle size distribution does not change significantly for the spent catalysts, as shown by TEM analysis (Figures 6.6 and 6.7), regardless of the $\mathrm{H}_{2}$ stream used. Quite obviously, the impurities in the $\mathrm{H}_{2}$ feed from HER have an effect on the downstream catalytic methanation reaction without inducing for example 


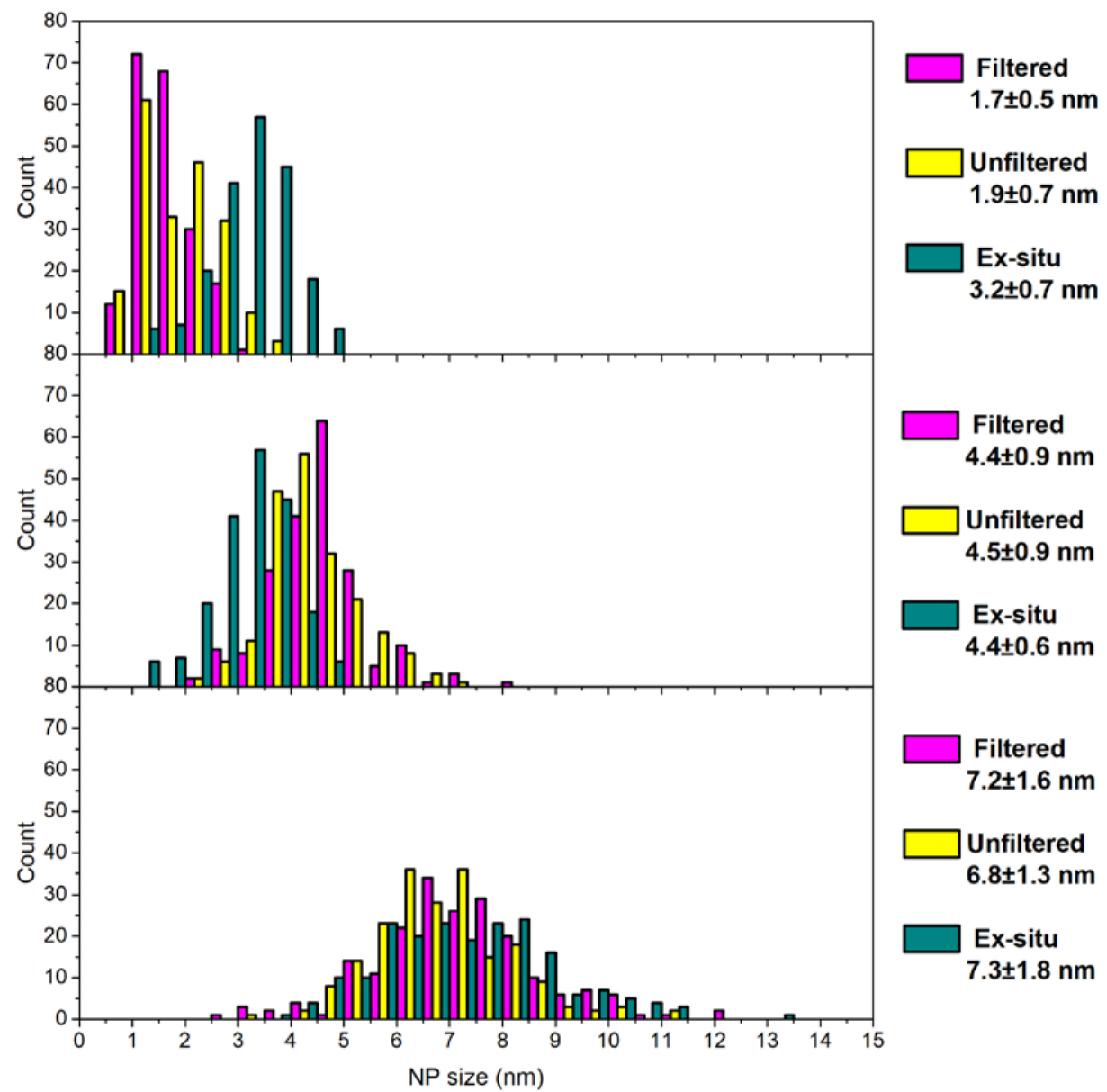

Figure 6.7: Histogram and statistics of the Ni metal nanoparticle size distribution for the samples in Figure 6.6.

sintering. Thus, as could be expected, $\mathrm{K}$ was present on the material after using impure, unfiltered $\mathrm{H}_{2}$ feeds, resulting from $\mathrm{KOH}$ in the aerosols. $0.6 \pm 0.2 \mathrm{wt} \% \mathrm{~K}$ was observed by ICP-AES analysis of the $\mathrm{Ni} / \mathrm{SiO}_{2}$ catalysts after 2 days of reaction when using HER-produced $\mathrm{H}_{2}$, while on the pristine sample and the catalyst tested with pure $\mathrm{H}_{2} \mathrm{~K}$ amount was expectedly below the detection limit.

Assuming all $\mathrm{K}$ present in the gas feed absorbs on the $\mathrm{Ni} / \mathrm{SiO}_{2}$ material this would result in a value of 4-11 $\mu \mathrm{g} / \mathrm{L} \mathrm{KOH}$ (the catalyst bed consisted of $4 \mathrm{mg}$ of $\mathrm{Ni} / \mathrm{SiO}_{2}$ and a flow of $2 \mathrm{~mL} / \mathrm{min}$ of gas was used in the calculations). NASA earlier reported 3-5 $\mu \mathrm{g} / \mathrm{L} \mathrm{KOH}$ in aerosols, which is comparable. ${ }^{[26]}$ The density of pure $\mathrm{KOH}$ is $2.12 \mathrm{~g} / \mathrm{mL}$ and thus the volume of $\mathrm{KOH}$ in $\mathrm{mL}$ per $\mathrm{mL}$ would be $2-5 \times 10^{-9}$. Dividing this by the earlier mentioned value of 15000 particles $/ \mathrm{mL}$, we gain a particle volume of circa $0.3-0.6 \times 10^{-12} \mathrm{~mL}$, which translates to $0.3-0.6$ 

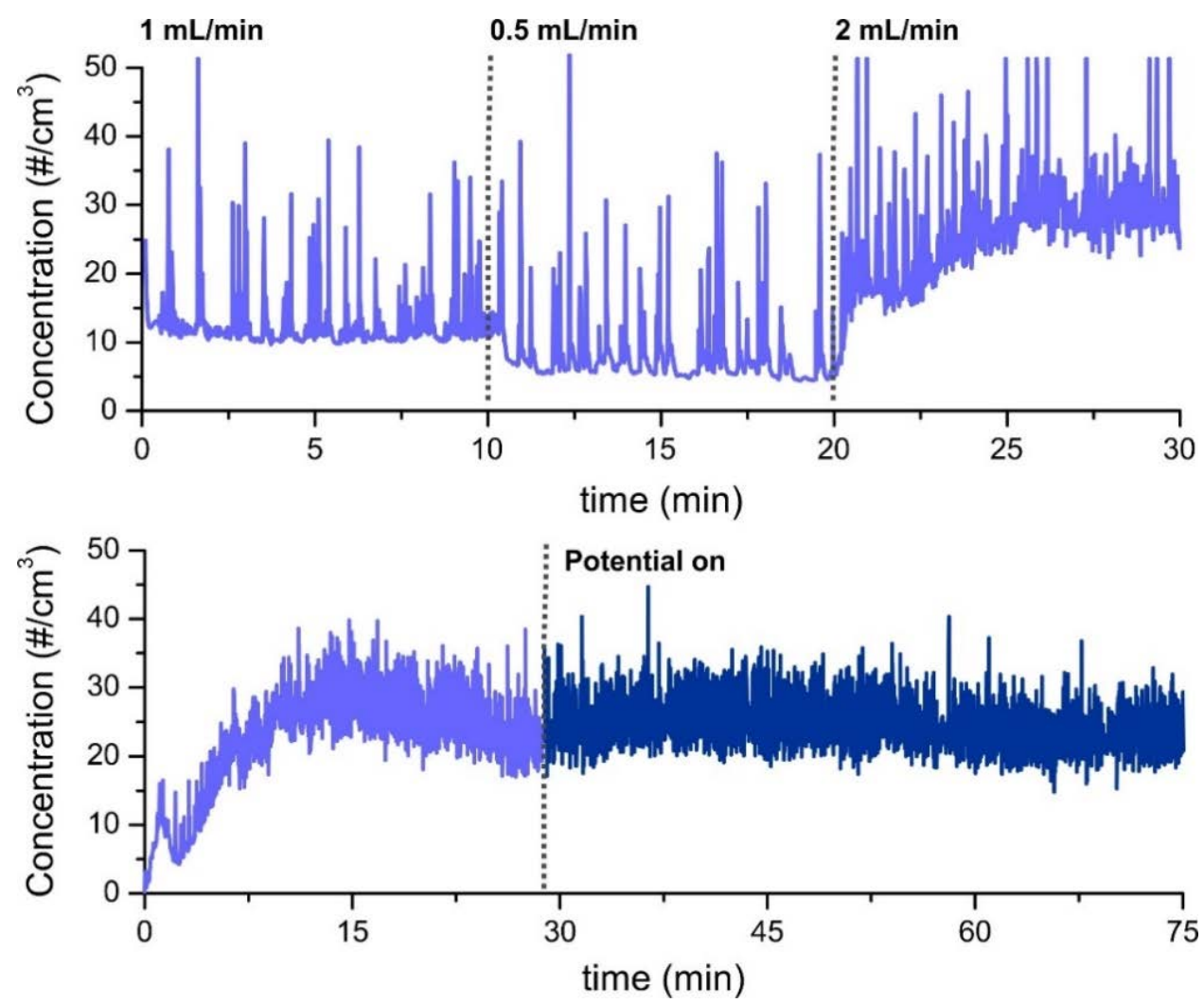

Figure 6.8: Particle count from a $1 \mathrm{M} \mathrm{KOH}$ solution with various $\mathrm{N}_{2}$ flows (top). Particle count with $2 \mathrm{~mL} / \mathrm{min}$ flow through the $1 \mathrm{M} \mathrm{KOH}$ solution in the electrocatalytic cell without applied current and applying the current used for $\mathrm{H}_{2}$ evolution (chronopotentiometry, $2.5 \mathrm{~mA}$ ).

$\mu \mathrm{m}^{3}$. Finally, assuming spherical shapes, we gain $0.4-0.5 \mu \mathrm{m}$ radii and thus, in accordance with literature, 4-11 $\mu \mathrm{g} / \mathrm{L} \mathrm{KOH}, 1 \mu \mathrm{m}$ diameter particles. ${ }^{[27,28]}$

Furthermore, it should be noted that the particle count is proportional to the gas flow through the electrocatalytic cell, while it did not detectably vary with the potential that is applied to carry out the HER (Figure 6.8). No effect of potential was expected as only $4 \mathrm{~mA}$ is applied $\left(0.028 \mathrm{~mL} / \mathrm{min}_{2}\right.$ at $\left.100 \% \mathrm{FE}\right)$. Based on ICP-AES and BET results, one can hereby calculate an average $\mathrm{K}^{+}$ concentration on the surface of the catalysts of $0.2 \mathrm{~K}^{+} / \mathrm{nm}^{2}$. Assuming hemispherical Ni metal nanoparticles, this would correspond to roughly $1 \mathrm{~K}^{+} / 50$ Ni surface atoms. We also assumed a homogeneous distribution as SEM-EDX (Figure 6.9 for the $6.0 \mathrm{~nm} \mathrm{Ni} / \mathrm{SiO}_{2}$ catalyst) suggests no clustering of $\mathrm{K}$ nor $\mathrm{Ni}$ occurs, resulting in either being below the detection limit for this technique. Had significant clustering occurred it would have shown in EDX mapping. The sensitivity of SEM-EDX is regrettably too low to sense the low concentrations of $\mathrm{Ni}$ and $\mathrm{K}$ when they are well dispersed, however, TEM imaging and ICP-AES 

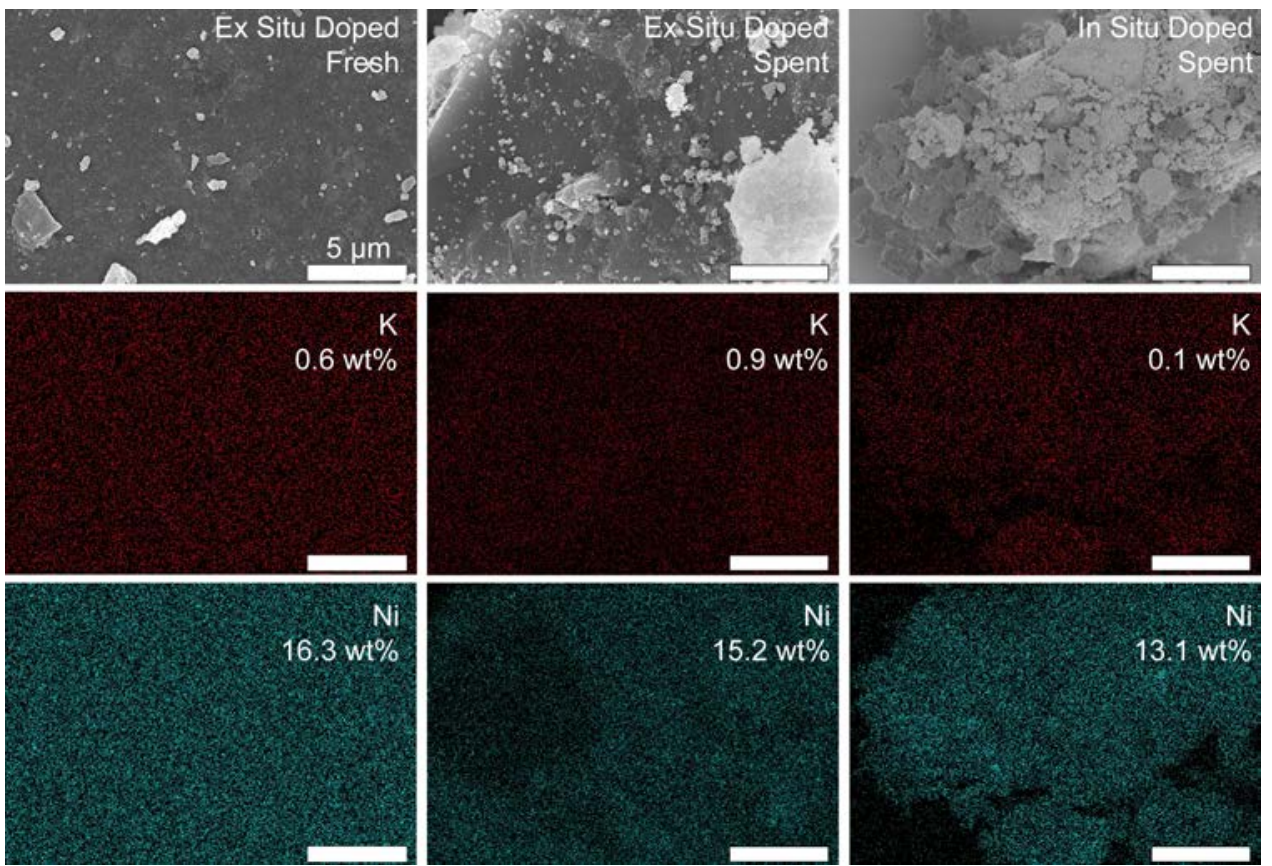

Figure 6.9: Left: $4.4 \mathrm{~nm} \mathrm{Ni/SiO} 2$ hydrogenation catalyst after ex situ doping with $\mathrm{K}^{+}$ before $\mathrm{CO}_{2}$ hydrogenation. Middle: The same catalyst, after $\mathrm{CO}_{2}$ hydrogenation. Right: $4.4 \mathrm{~nm} \mathrm{Ni} / \mathrm{SiO}_{2}$ hydrogenation catalyst after being doped in situ with $\mathrm{K}^{+}$during $\mathrm{CO}_{2}$ hydrogation.

already showed the presence of these elements, making the assumptions highly likely to be true.

In short the calculation of $0.6 \mathrm{wt} \% \mathrm{~K}^{+}$on $\mathrm{Ni} / \mathrm{SiO}_{2}$, which are $482.7 \mathrm{~m}^{2} / \mathrm{g}$ from BET analysis, an average distribution of $\mathrm{K}^{+}$on the catalyst surface can be calculated. About $6 \mathrm{mg}$ of $\mathrm{K}^{+}$is deposited per $\mathrm{g}$ of catalyst, which is translated to $12.4 \mu \mathrm{g} / \mathrm{m}^{2} \mathrm{~K}^{+}\left(0.2 \mathrm{~K}^{+}\right.$atoms $\left./ \mathrm{nm}^{2}\right)$. The Ni particles are about $2.5,30$ and 57 $\mathrm{nm}^{2}$ per particle for $1.2,4.4$ and $6.0 \mathrm{~nm}$ in diameter, assuming semi-spherical shapes (as seen in TEM). This results in 0.5, 6 and $12 \mathrm{~K}^{+}$atoms/Ni particle respectively. Assuming that there are $10 \mathrm{Ni}$ atoms $/ \mathrm{nm}^{2}$ we would get a $\mathrm{K}: \mathrm{Ni}$ surface atomic ratio of 1:50.

Accordingly, an effect on $\mathrm{Ni}$ activity at such low $\mathrm{K} / \mathrm{Ni}$ ratios is consistent with results on $\mathrm{Ni}(100)$ surface, for which $\mathrm{CO}$ and $\mathrm{CO}_{2}$ methanation were affected starting from well-below monolayer coverage $(0.05 \mathrm{ML}) \cdot{ }^{[29,30]}$ As can be seen in Figure $6.4 \mathrm{~b}$, when a filter is placed before the methanation reactor, the aerosol can be effectively removed from the $\mathrm{H}_{2}$ stream. In order to rule out a possible direct effect of the aerosol on the catalytic activity, e.g. by reaction with $\mathrm{CO}_{2}$ in the gas-phase leading to carbonate formation (which is known to occur in mere seconds in the case of $\mathrm{NaOH}^{[27]}$ ), an aerosol filter was installed on a by-pass between the electrochemical cell and the methanation unit, and the $\mathrm{H}_{2}$ feed was switched from unfiltered to filtered during the reaction. Notably, the activity 
promotion on the $4.4 \mathrm{~nm} \mathrm{Ni} / \mathrm{SiO}_{2}$ was maintained, which strongly suggests that the aerosol itself does not play an active role in the activity enhancement, which therefore will be solely due to $\mathrm{K}$ deposition on the catalyst. Strikingly, this also means that one can dose just the right amount of $\mathrm{KOH}$ to promote methanation activity and then remove the aerosol at will, to avoid further $\mathrm{K}$ accumulation, which will eventually be detrimental.

These experiments were driven by two Pt mesh electrodes. These were found to allow a current of $38.49 \mathrm{~mA}$ at $2.44 \mathrm{~V}$. The FE of HER in this case was found to be $94.4 \%$. This means $44.7 \mathrm{~mW}$ worth of $\mathrm{H}_{2}$ was produced and the efficiency is $0.43 \%$ (also taking into account the efficiency of $19.5 \%$ of the solar panels). Note that simply increasing the size (as will be shown in section 6.2.4) can easily ramp up the efficiency to, with this FE, $9.28 \%$. Measuring the $\mathrm{CO}_{2}$ conversion we find $3 \%$ of the $\mathrm{CO}_{2}$ feed is converted: $0.5 \%$ into $\mathrm{CH}_{4}(0.03$ $\mathrm{mL} / \mathrm{min}$ ) and $2.5 \%$ into $\mathrm{CO}$. Focusing on $\mathrm{CH}_{4}$ as the energy storage medium we find that $0.0199 \mathrm{~W}$ is stored in this material. Taking into account the inefficient heating we gain an energy efficiency of the entire setup of $1.2 \times 10^{-}$ $4 \%$. This is only $0.086 \%$ of what is theoretically achievable in this setup.

\subsubsection{Cascading Solar-Driven Electrocatalysts with $\mathrm{CO}_{2}$ Hydrogenation}

Using the Ni-Mo HER and Ni-Fe-S OER catalysts presented in Chapter 3 we find, when using electrodes of $15 \mathrm{~cm}^{2}$ foam of $1.6 \mathrm{~mm}$ thickness $\left(5400 \mathrm{~m}^{2} / \mathrm{m}^{3}\right.$, thus ca. $130 \mathrm{~cm}^{2}$ substrate surface area), that $2.746 \mathrm{~mL} / \mathrm{min} \pm 0.039 \mathrm{H}_{2}$ is created. This decreased slightly to $2.739 \mathrm{~mL} / \mathrm{min} \pm 0.139 \mathrm{H}_{2}$ after $72 \mathrm{~h}$ of operation. Hereby we aim to improve on the current utilization of the current, which was only $4.6 \%$ in Section 6.2 .2 , to $47.4 \%$. It should be noted that the GC is optimized for measuring low values of $\mathrm{H}_{2}$ and thus the precision for such higher values is low. The $\mathrm{Kr}$ internal standard could not be used as it resulted in noisy data because it was on the limit of the detection limit due to the high concentration of $\mathrm{H}_{2}$ in the flow. If $\mathrm{Kr}$ was used unlikely values of $33.1 \mathrm{~mL} / \mathrm{min} \pm$ $13.1 \mathrm{H}_{2}$ were found (and $18.96 \mathrm{~mL} / \mathrm{min} \pm 11.6 \mathrm{H}_{2}$ afterward). Hence, the absolute values of the peak area were used from the calibration and the data as it yielded realistic values and lower standard deviations.

Nevertheless, the improvement is clear and is an order of magnitude. The strategy is two-fold. First, the catalysts are improved as Ni-Mo/Ni-foam and NiFe-S/Ni-foam were found to outperform our Pt mesh electrodes and, more importantly, this removes the need for noble metals in the system. Secondly, an engineering improvement is made by increasing the electrode size to $15 \mathrm{~cm}^{2}$ which is close to the maximum achievable electrode size in our setup from a practical point of view. Though the uncertainty is great due to the difficulties with data analysis the indications are that the electrodes performed stably over the course of $72.5 \mathrm{~h} . \mathrm{O}_{2}$ was not measured in this experiment, the OER side was disconnected from the system to prevent $S$ from entering and contaminating it, either as potentially formed $\mathrm{S}$ gasses, or via $\mathrm{S}$ containing aerosols as S was found to leach in Chapter 3. 
Earlier we already found that the FE of the materials is close to $100 \%$ and no electrochemical destabilization has been observed on Ni-Mo at the applied potential of $2.44 \mathrm{~V}$. Hence the lower current that is found is likely a result of the resistance introduced by the Nafion membrane. Note that the size optimization was done based on the I/E relationship in a threeelectrode cell without any such membranes (Chapter 3) for a demonstration setup which does also not

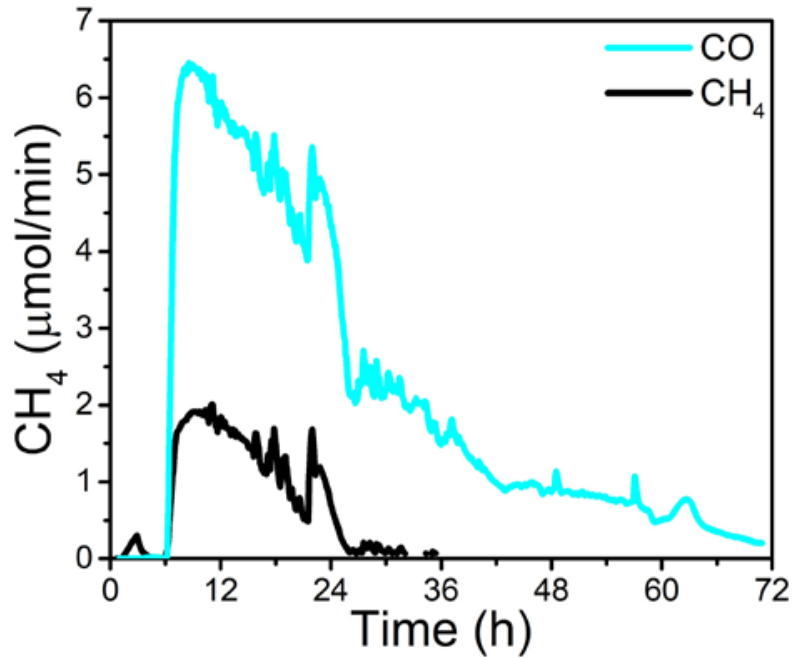

Figure 6.10: $\mathrm{CO}$ (blue) and $\mathrm{CH}_{4}$ (black) generated over a $6.0 \mathrm{~nm} \mathrm{Ni} / \mathrm{SiO}_{2}$ from $1 \mathrm{~mL} / \mathrm{min}$ pure $\mathrm{CO}_{2}$ mixed with $2.75 \mathrm{~mL} / \mathrm{min} \mathrm{H}_{2}$ from solar-driven water electrolysis. The GHSV was 36300. include this membrane.

Nevertheless, the estimated effective energy gain by preventing a gas separation step is still significant enough on the energy scheme to call the loss of nearly half the current through resistance acceptable. Furthermore, increasing cell size to allow for even larger electrodes is likely to circumvent the issue all-together.

This $\mathrm{H}_{2}$ flow was filtered and reacted together with $1 \mathrm{~mL} / \mathrm{min} \mathrm{CO}_{2}$ on a similar reactor bed as described in Section 6.2.2. This translates to $44.6 \mu \mathrm{mol} / \mathrm{min} \mathrm{CO}_{2}$ as a feed. Note that this resulted in a sub-optimal $\mathrm{H}_{2}: \mathrm{CO}_{2}$ ratio of 2.75:1. As can be seen in Figure 6.10 the production of $\mathrm{CO}$ and $\mathrm{CH}_{4}$ rapidly declines and the catalyst is practically deactivated after $72 \mathrm{~h}$ of continuous operation. At the peak $6.39 \mu \mathrm{mol} / \mathrm{min} \mathrm{CO}$ is generated and $1.91 \mu \mathrm{mol} / \mathrm{min} \mathrm{CH}_{4}$ is found in the mixture. This tells us there is still a lot to gain on this step of the setup, both in terms of activity, stability and likely reactor design (catalyst bed size). At the peak that means that there is a generation of $30.2 \mathrm{~mW}$ worth of $\mathrm{CO}(10 \mathrm{MJ} / \mathrm{kg})$ and $28.3 \mathrm{~mW}$ worth of $\mathrm{CH}_{4}(55.6 \mathrm{MJ} / \mathrm{kg})$. Assuming perfect reactions of $\mathrm{CO}_{2}$ to these compounds with $\mathrm{H}_{2}$ means the $\mathrm{H}_{2}$ consumption was $14.03 \mu \mathrm{mol} / \mathrm{min}$ at the peak (which is $11.4 \%$ of the total amount of $\mathrm{H}_{2}$ passing through). That means there is still $108.56 \mu \mathrm{mol} / \mathrm{min}$ of $\mathrm{H}_{2}$. This means there is still $434 \mathrm{~mW}$ of $\mathrm{H}_{2}$ remaining $(120 \mathrm{MJ} / \mathrm{kg})$.

This yields the following numbers, not taking into account the efficiency of solar cells: $2.03 \mathrm{~W}$ of electricity is stored in $0.434 \mathrm{~W} \mathrm{H}_{2}(21.7 \%), 0.028 \mathrm{~W} \mathrm{CH}_{4}(1.4 \%)$ and $0.030 \mathrm{~W}$ CO (1.5\%). An additional energy investment was made through heating at $66.5 \mathrm{~W}$. This means we achieved an energy storage of $0.72 \%$ in chemical bonds using only $\mathrm{H}_{2} \mathrm{O}$ and $\mathrm{CO}_{2}$ as chemical resources. In terms of 
methane, the desired compound, we achieved an electrical energy storage of $0.041 \%$ in $\mathrm{CH}_{4}$.

\subsection{Conclusions}

In summary, by combining a well-defined set of $\mathrm{Ni} / \mathrm{SiO}_{2}$ catalysts, we show alkali promotion by $\mathrm{KOH}$, which is dependent on the Ni nanoparticle size. This can be rationalized in terms of the electronic effect of $\mathrm{K}^{+}$in combination with the Sabatier principle. Practically, by applying a method of doping which is similar to dosing the right amount of $\mathrm{K}^{+}$from a $\mathrm{H}_{2}$ feed coming directly from $\mathrm{H}_{2} \mathrm{O}$ electrolysis in $\mathrm{KOH}$ electrolytes, the catalytic activity of small $\mathrm{Ni}$ metal nanoparticles supported on $\mathrm{SiO}_{2}$ in the Sabatier reaction can be efficiently enhanced. The present work shows how a small number of alkali promoters can dramatically change catalyst performance. Thus, care should be taken towards the presence of impurities on solid catalysts when cascading different reactions. Yet once the promoter effects and the reaction pathway are wellunderstood, they can be leveraged to tweak the catalytic performance in a tailored manner.

Technological analysis of the machine presented in this PhD Chapter shows us that a solar-to-methane efficiency could be achieved of $0.14 \%$. The final efficiency obtained by the machine was $0.041 \%$ in terms of solar-to-methane power storage. Fairly high selectivity towards $\mathrm{CO}$ was found and fast catalyst degradation of the $\mathrm{Ni} / \mathrm{SiO}_{2}$ catalyst was observed despite filtering away the aerosols. To put the numbers into perspective: back-of-the-envelope calculations show that the world energy consumption in $2015\left(1.812 * 10^{13} \mathrm{~W}\right)$ was only $0.20 \%$ of the estimated amount of sunlight hitting the Sahara $\left(9.2 * 10^{15} \mathrm{~W}\right)$. We furthermore identified the losses of energy in detail, with the heating of the $\mathrm{CO}_{2}$ hydrogenation PFR being most significant.

\subsection{Experimental}

\subsubsection{Materials}

The catalysts used in this study has already been described in terms of preparation method and detailed characterization in ref. [4]. In particular, relevant to this work are the $\mathrm{Ni}(19.5 \mathrm{wt} \%) / \mathrm{SiO}_{2}, \mathrm{Ni}(60 \mathrm{wt} \%) / \mathrm{SiO}_{2}$ and $\mathrm{Ni}(4.7$ $w \mathrm{t} \%) / \mathrm{SiO}_{2}$ catalysts, having a $4.4 \mathrm{~nm}, 1.2$ and 6.0 mean Ni particle size, which were used as is and doped with potassium. To do this, a $0.6 \mathrm{wt} \% \mathrm{~K}$ was achieved by suspending the nickel nanoparticles in $\mathrm{KOH}$ solution and evaporating under vacuum at around $60^{\circ} \mathrm{C}$ for $1 \mathrm{~h}$. Doped catalysts were stored at $120^{\circ} \mathrm{C}$ for over $72 \mathrm{~h}$.

\subsection{2. $\mathrm{H}_{2}$ Production via Electrolysis and Cascade Methanation Reaction} Pt mesh electrodes (MaTecK, $99.9 \%, 25 \times 50$ mm, 3600 mesh/cm², 0.04 mm wire diameter) interwoven with a Pt wire (MaTecK, 99.9 \%, 1 mm diameter, 100 $\mathrm{mm}$ length) were suspended in a $1 \mathrm{M} \mathrm{KOH}$ electrolyte (ACS reagent, >85\% pure, $\sim 15 \%$ water) loaded into a homemade $\mathrm{H}$-cell. This cell consists of GL14 
glass tubes with an internal volume of $20 \mathrm{~mL}$ for the electrolyte on each side, resulting in $40 \mathrm{~mL}$ electrolyte in total (as shown in Figure 6.2b). The HER and OER reactions are spatially separated by a Nafion 117 perfluorinated membrane (Aldrich, 0.007 in. thick). Prior to use the membrane is activated by immersion in nitric acid for several hours, while the Pt electrodes were cleaned by using a butane flame. The electrolyte was purged with $2 \mathrm{~mL} / \mathrm{min}$ Ar, 0.1 $\mathrm{mL} / \mathrm{min} \mathrm{Kr}$ on the HER side and $2 \mathrm{~mL} / \mathrm{min} \mathrm{N}_{2}, 0.1 \mathrm{~mL} / \mathrm{min} \mathrm{Kr}$ on the OER side for at least $2 \mathrm{~h}$ prior to the experiments.

The $\mathrm{Ni} / \mathrm{SiO}_{2}$ catalyst was reduced at $550{ }^{\circ} \mathrm{C}$ for $60 \mathrm{~min}$, with a heating rate of 5 ${ }^{\circ} \mathrm{C} / \mathrm{min}$ under a flow of $1 \mathrm{~mL} / \mathrm{min}$ of pure $\mathrm{H}_{2}$. Afterwards, the catalyst it was cooled down to $400{ }^{\circ} \mathrm{C}\left(5{ }^{\circ} \mathrm{C} / \mathrm{min}\right)$ under a flow of pure $\mathrm{N}_{2}$. This flow was maintained for $3 \mathrm{~h}$ to remove residual $\mathrm{H}_{2}$ from the system.

Electrochemistry (Ivium CompactStat) was then started potentiometrically at a current of $4 \mathrm{~mA}$, requiring ca. $1.69 \mathrm{~V}$ potential (the Nafion membrane yields a high resistance in the system), $1.69 \mathrm{~V}$ also being close the output of a small solar cell module of three cells in series. The flow or Ar/Kr and $\mathrm{N}_{2} / \mathrm{Kr}$ was constantly maintained as a carrier gas for the produced $\mathrm{H}_{2}$ and $\mathrm{O}_{2}$. The feed from the HER was led over the plug flow reactor containing the $\mathrm{Ni} / \mathrm{SiO}_{2}$ catalyst, optionally filtered by an aerosol filter.

After 15 min of flow from the $\mathrm{H}$-cell an $820 \mathrm{ppm} \mathrm{CO} 2$ feed was opened over the PFR at a rate of $1 \mathrm{~mL} / \mathrm{min}$ and was mixed with the HER feed prior to injection on the PFR. The reactor output gas was again filtered by an aerosol filter before being injected on an InterScience CompactGC every 4 min and analyzed by FID detectors. The flow was split over two column systems optimized for measure hydrocarbons on one end and $\mathrm{CO} / \mathrm{CO}_{2} / \mathrm{CH}_{4}$ on the other. The latter was equipped with a methanizer to visualize each component. On a separate channel the flow from the oxygen halve of the system was injected and measured by a TCD detector every 4 min. This state was maintained for 2 or 3 days depending on the experiment.

\subsubsection{Aerosol Measurement and Formation}

To measure the aerosol formation from the electrochemical cell, a water-based condensation particle counter (WCPC, TSI model 3785) was attached to the output of the cell, in place of the methanation reactor. In a typical experiment, a $2 \mathrm{~mL} / \mathrm{min}$ flow of $\mathrm{N}_{2}$ was bubbled through the electrochemical cell filled with $1 \mathrm{M} \mathrm{KOH}$, and the outlet stream was diluted with $1 \mathrm{~L} / \mathrm{min}$ filtered air before being fed to the particle counter. The effect of flow, applied potential and $\mathrm{KOH}$ concentration was also studied. Control experiments carried out bypassing the cell or using water instead of $1 \mathrm{M} \mathrm{KOH}$ didn't show any aerosol formation. 


\subsubsection{Solar-driven Hydrogen and Cascade Methanation Reaction}

$15 \mathrm{~cm}^{2} \mathrm{Ni}-\mathrm{Mo}$ (HER) and Ni-Fe-S (OER) electrodes were prepared as described previously on $\mathrm{Ni}$ foam (Chapter 3 ). These were attached to a solar module consisting of 4 B-class solar cells (MONO solar cells, monocrystalline $\mathrm{Si}$ ). Light is introduced with a Newport, AAA-class Solar Simulator (model 94043A, IEC/JIS/ASTM, $450 \mathrm{~W}$ Xenon, $4 \times 4$ in.) yielding $100 \mathrm{~mW} / \mathrm{cm}^{2}$. A pure $\mathrm{CO}_{2}$ feed (4.5, Lindegas) was used in these experiments at a flow of $1 \mathrm{~mL} / \mathrm{min}$. The remainder of the experiment was operated as described in Section 6.4.2.

\subsection{Author Contributions and Acknowledgements}

This Chapter is based on the following manuscript: Structure-Sensitive Alkali Promotion in the Formation of $\mathrm{CH}_{4}$ from $\mathrm{CO}_{2}$ and Renewably Produced $\mathrm{H}_{2}$ over Supported Ni Catalysts, C. Vogt*, J.H.J. Wijten*, C.L. Madeira, O. Kerkenaar, K. Xu, R. Holzinger, M. Monai, B.M. Weckhuysen, ChemCatChem 2020. *These authors contributed equally to this work. Charlotte Vogt wrote the manuscript in collaboration with Jochem Wijten and Matteo Monai. Matteo Monai, Charlotte Vogt, Jochem Wijten and Bert Weckhuysen conceived the research plans. Jochem Wijten and Oscar Kerkenaar designed and built the setup. Jochem Wijten and Matteo Monai performed the experiments on the hydrogenation setup and analyzed the data thereof under the supervision of Bert Weckhuysen. Matteo Monai, Chantal Madeira and Charlotte Vogt performed the Operando IR experiments and analyzed the data thereof. Jochem Wijten, Matteo Monai, and Kangming Xu performed the aerosol measurements and analyzed the data thereof under the supervision of Rupert Holzinger and Bert Weckhuysen. Jochem Wijten wrote this Chapter based on the manuscript with feedback and corrections by Bert Weckhuysen.

The following people are gratefully acknowledged: Pascal Wijten (UU) and Herrick Schaink (UU) are thanked for their assistance with the GC and software respectively, and Coen Mulder (UU) is thanked for the ICP-AES measurements.

\subsection{References}

[1] R. Schlögl, Angew. Chem. Int. Ed. 2015, 54, 4436-4439

[2] R. Schlögl, Angew. Chem. Int. Ed. 2017, 56, 11019-11022

[3] C. Vogt, E. Groeneveld, G. Kamsma, M. Nachtegaal, L. Lu, C. J. Kiely, P. H. Berben, F. Meirer, B. M. Weckhuysen, Nat. Catal. 2018, 1, 127-134

[4] C. Vogt, M. Monai, G. J. Kramer, B. M. Weckhuysen, Nat. Catal. 2019, 2 , 188-197

[5] E. B. Creel, B. D. McCloskey, Nat. Catal. 2018, 1, 6-7.

[6] United Nations, Paris Agreement, 2015 
[7] R. C. Armstrong, C. Wolfram, K. P. de Jong, R. Gross, N. S. Lewis, B. Boardman, A. J. Ragauskas, K. Ehrhardt- Martinez, G. Crabtree, M. V. Ramana, Nat. Energy 2016, 1, 1-8

[8] Q. Schiermeier, J. Tollefson, T. Scully, A. Witze, O. Morton, Nature 2008, 5, 816-823

[9] K. F. Kalz, R. Kraehnert, M. Dvoyashkin, R. Dittmeyer, R. Gläser, U. Krewer, K. Reuter, J. Grunwaldt, ChemCatChem 2017, 9, 17-29

[10] D. Heide, L. von Bremen, M. Greiner, C. Hoffmann, M. Speckmann, S. Bofinger, Renew. Energy 2010, 35, 2483-2489

[11] M. Götz, J. Lefebvre, F. Mörs, A. McDaniel Koch, F. Graf, S. Bajohr, R. Reimert, T. Kolb, Renew. Energy 2016, 85, 1371-1390

[12] J. Kopyscinski, T. J. Schildhauer, S. M. A. Biollaz, Fuel 2010, 89, 17631783

[13] H. Yang, C. Zhang, P. Gao, H. Wang, X. Li, L. Zhong, W. Wei, Y. Sun, Catal. Sci. Technol. 2017, 7, 4580-4598

[14] S. Freni, N. Mondello, S. Cavallaro, G. Cacciola, V. N. Parmon, V. A. Sobyanin, React. Kinet. Catal. Lett. 2000, 71, 143-152

[15] T. Haas, R. Krause, R. Weber, M. Demler, G. Schmid, Nat. Catal. 2018, 1, 32-39

[16] G. Ertl, H. Knözinger, F. Schüth, J. Weitkamp, Handbook of Heterogeneous Catalysis, Wiley-VCH, Weinheim, 1997

[17] J.-B. Senderens, P. Sabatier, Compt. Rend. 1902, 82, 514-516

[18] P. Sabatier, J.-B. Senderens, Compt. Rend. 1903, 134, 689-691

[19] G.-Y. Chai, J. L. Falconer, J. Catal. 1985, 93, 152-160

[20] T. K. Campbell, J. L. Falconer, Appl. Catal. 1989, 2, 189-197

[21] Q. Yin, C. L. Hill, Nat. Chem. 2017, 10, 6-7

[22] Z. W. Seh, J. Kibsgaard, C. F. Dickens, I. Chorkendorff, J. K. Nørskov, T. F. Jaramillo, Science 2017, 355, eaad4998

[23] AMES Reasearch Center, NASA, Static Feed Water Electrolysis Module, 1974

[24] V. J. Cybulskis, J. Wang, J. H. Pazmiño, F. H. Ribeiro, W. N. Delgass, J. Catal. 2016, 339, 163-172

[25] B. Liang, H. Duan, X. Su, X. Chen, Y. Huang, X. Chen, J. J. Delgado, T. Zhang, Catal. Today 2017, 281, 319-326

[26] N. Anastasijevic, J. Holst, A. Orth, M. Schuster, B. Schurtakow, M. Stroeder, Process and Apparatus for Producing Hydrogen, 2015, US9090984B2

[27] D. W. Cooper, D. W. Underhill, M. J. Ellenbecker, Am. Ind. Hyg. Assoc. J. 1979, 40, 365-371

[28] Y. Kim, H. Sievering, J. Boatman, D. Wellman, A. Pszenny, J. Geophys. Res. 1995, 100, 23027

[29] C. T. Campbell, D. W. Goodman, Surf. Sci. 1982, 123, 413-426

[30] D. E. Peebles, D. W. Goodman, J. M. White, J. Phys. Chem. 1983, 87, 4378-4387 
Alkali Promotion of Ni Catalysts in $\mathrm{CO}_{2}$ Hydrogenation using Renewable $\mathrm{H}_{2}$ 
"One day, son, we will explore the planets and sky. Whether or not that will happen in your time, I cannot say." I listen to my dad with new-found respect, as we sit on the couch, relaxing. "I sure hope so dad! Is there anything I can do to make it happen?" "The only thing you, well, anyone, can do is his or her best. Strife to leave the world better than you found it and I am certain you have helped humankind to realize our next step in our unquenchable thirst for exploration." Together with him I look wistfully at the space explorers we are watching in an old movie he likes.

"You sure left the world in a better state, dad" He looks surprised, "I hope I did, thank you, for saying that" Together we continue with the movie, and I am curious what next adventure dad will take me along on. 
A 2
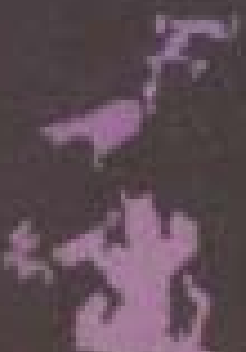

4

$t$

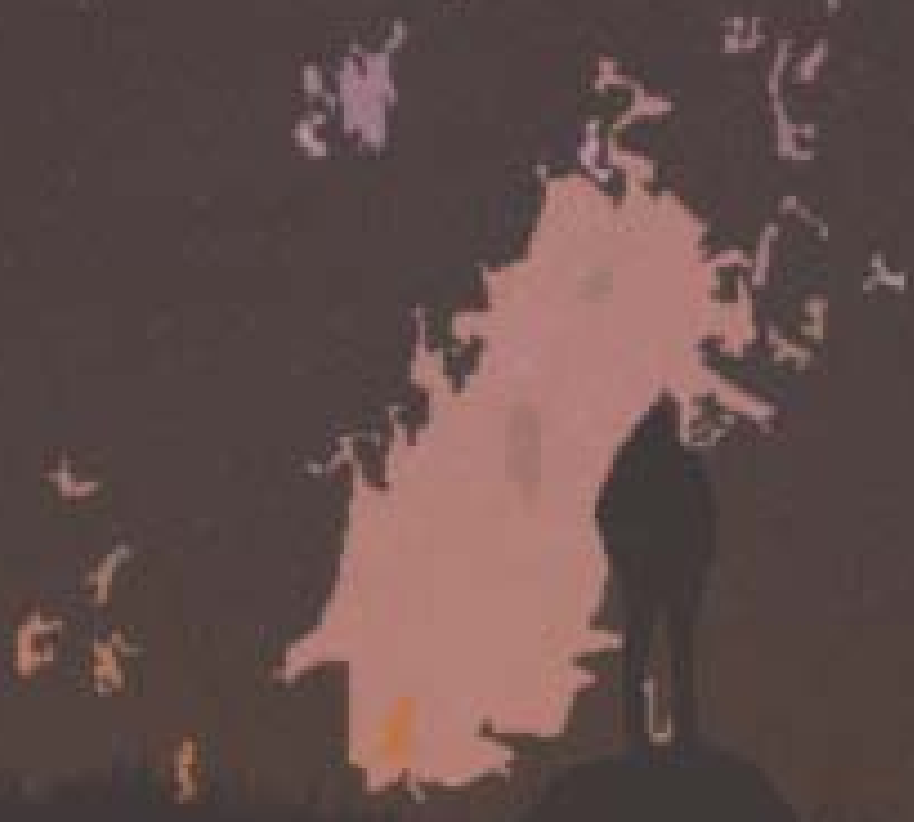

y
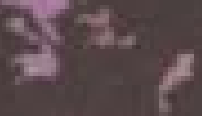


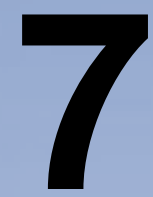

\section{Summary, Outlook and Conclusions}

This $\mathrm{PhD}$ Thesis is focused on the Ni-Mo hydrogen evolution catalyst and its stability and application in electrochemical water splitting driven by renewable energy sources. In this Chapter, the findings are summarized as well as reflected upon with an outlook on future research possibilities and opportunities. The Chapter will wrap up with conclusions. 


\subsection{Summary}

This thesis started with a general introduction in Chapter 1 on the world energy scheme, discussing how renewable energy sources are necessary but still facing numerous scientific and technological challenges. One of the main issues to be addressed was discussed to be energy storage to overcome the intermittency of many renewable sources such as sunlight and wind. This was followed by a discussion on hydrogen as an energy storage medium or intermediary for storage in, for example, methane. The focus was then shifted to water splitting as the reaction through which energy can effectively be stored in hydrogen. Several technological approaches are discussed, which make use of photo-catalysis, photo-electrochemistry or electrochemistry. The mechanism and thermodynamics of water splitting are shown and, importantly, also kinetics are described. These kinetics result in the need of electro-catalysts, materials which ideally do not get consumed by the reaction but speed up the process by lowering energy barriers of the various steps present in such a reaction. The introduction wrapped up by introducing the well-studied electro-catalyst $\mathrm{Ni}-\mathrm{Mo}$ for the hydrogen evolution reaction. This $\mathrm{PhD}$ thesis was then focused on studying the stability of this material in depth and revisiting technological approaches and challenges of implementing this material in solar-driven water splitting. In the following paragraphs the main findings of each chapter are summarized as visually displayed in Chapter 1, Figure 1.12.

$\mathrm{Ni}$-Mo is a well-studied material, yet discussion was still ongoing on the stability and reason of activity of this material. In Chapter 2 we study this material in detail and give answer to this discussion. Combining both theoretical and experimental studies we find these materials are indeed highly active towards the hydrogen evolution reaction. Density function theory shows us that at a moderate surface coverage a $\Delta G_{H}$ approaching 0 is expected for all terrace sites. This was indicative of the high activity also found by experiments. Experiments showed us activation of the materials on an hour timescale to a low overpotential of $0.13 \mathrm{~V}$ after which it approached stable operation for at least $100 \mathrm{~h}$. To study this activation in detail we employed several complementary techniques and combine it with theory. From this we found that the material roughens over time under operation, the double layer capacitance increases gradually and could be linked to the increase in activity. Furthermore, Mo leached and it was found to be highly dependent on the electrolyte, not only the $\mathrm{pH}$ but also the nature of the cation employed during operation. The mode of leaching was established to be $\mathrm{Mo}+2 \mathrm{OH}^{-}+2 \mathrm{H}_{2} \mathrm{O} \rightarrow \mathrm{MoO}_{4}{ }^{2-}+3 \mathrm{H}_{2}$, which could explain that Mo leached less at lower $\mathrm{pH}$, and why a faradaic efficiency higher than $100 \%$ was found. The behavior was more complex however and $\mathrm{Li}^{+}, \mathrm{Na}^{+}$or $\mathrm{K}^{+}$were found to significantly influence leaching as well. With XPS depth profiles these cations were found to penetrate deep $(>600 \mathrm{~nm})$ into the material. The influence of the cations was hard to predict and the solubility constant of the respective salts was presented as a possible explanation for the 
observations. The observations led us to determine the activity of Ni-Mo stems from both a synergy between $\mathrm{Ni}$ and $\mathrm{Mo}$ as well as an increased surface area due to in situ leaching of Mo. This chapter wrapped up by presenting $0.1 \mathrm{M}$ $\mathrm{LiOH}$ electrolytes as the least destabilizing of the tested electrolytes.

Water splitting occurs at two electrodes, however, and in Chapter 3 we present an oxygen evolution reaction catalyst, Ni-Fe-S. Using a simple one-step hydrothermal synthesis method this material was easily synthesized on $\mathrm{Ni}$ foams. This material showed, as was reported before, high activity and high apparent stability. We used this anode material to combine it with the Ni-Mo cathodes to establish a system that operated at $1.55 \mathrm{~V}$ for water splitting at 10 $\mathrm{mA} / \mathrm{cm}^{2}$, achieving goals set by literature to have it operate at a potential lower than $1.68 \mathrm{~V}$. The system performed stably for at least 1 week. Nevertheless, as we had already found with Ni-Mo that the stability was apparent we also studied the Ni-Fe-S material in detail. We established that Fe mostly functioned to increase the surface area of the electrodes where-as $S$ clearly seemed a synergistic addition. We find that $\mathrm{S}$ leaches strongly however during operation, but also that it segregates towards the surface. Furthermore, Fe was only present in low amounts and in a particulate shape which was (mostly) leached after operation. The Ni-Fe-S and Ni-Mo materials were finally combined into a demonstrative, solar-cell driven setup. Simply increasing the electrode sizes to $15 \mathrm{~cm}^{2}$ allowed them to operate at $2.1 \mathrm{~V}$ and $1 \mathrm{~A}$ as delivered by the utilized cells.

The potential and current might have had an influence on Mo leaching from $\mathrm{Ni}$ Mo as well, and as such we studied it in more detail in Chapter 4. Furthermore, the choice to use Ni foam instead of Ti stubs led us to the question of whether the substrate is important when considering the stability and activity of Ni-Mo as is known for many other heterogeneous processes. Indeed, when we studied potential and substrate effects we saw that both have a strong impact on the performance of Ni-Mo cathodes. Firstly, it was found that the change in capacitance is most extreme at intermediary potentials. This tells us that there are at least two processes involved when changing potential. The change in surface morphology, on the other hand, could be linked to the presence of $\mathrm{K}^{+}$. Importantly we found that Mo leaching was not directly linked to the change in double layer capacitance, as leaching increased with applied potential, likely due to an increase of local $\mathrm{pH}$ as a result of the hydrogen evolution reaction. EDX showed the Ni-Mo ratio changed with the same trend as the capacitance, this is a strong indicator that, at least in the case of these Ni-Mo cathodes, the capacitance is not indicative of surface area but actually surface composition. Though both play a significant role in this value linking the capacitance to surface area should be treated carefully indeed, especially if the material changes in the electrode as does Ni-Mo. Finally, it was shown in this chapter that the substrate also influences the performance of Ni-Mo. Using materials which are FCC structures $(\mathrm{Cu}, \mathrm{Ni})$ like Ni-Mo itself seems to increase the activity 
of the material. Capacitance changes, and even trends, as well as trends in leaching are highly dependent on the used substrate, though no clear trend has been observed yet to allow prediction of how the material would behave. The chapter wraps up with showing that Ni-Mo performs best on stainless steel at low overpotential in terms of stability while exhibiting high activity.

Chapter 5 takes another turn on using Ni-Mo electrocatalysts. In this chapter we explore its potential as a co-catalysts for photo-electrochemical systems. Using $\mathrm{NiFe}_{2} \mathrm{O}_{4}$ as a hydrogen evolution photoelectrode we studied the electrodeposition of Ni-Mo on this oxide. While oxides are usually unstable under the strong reductive potentials applied during electrodeposition, such as $\mathrm{Fe}_{2} \mathrm{O}_{3}$ (hematite), yet we found that $\mathrm{NiFe}_{2} \mathrm{O}_{4}$ was stable during the process. This opened interesting potential synthesis methods for photoabsorber/electro-catalyst systems, depending on their resistance to reduction. We showed that applying Ni-Mo to $\mathrm{NiFe}_{2} \mathrm{O}_{4}$ had a double function. Firstly it acted as the catalyst as was intended, nearly doubling the hydrogen evolution photocurrent. Secondly, and just as important, it acted as a protecting layer for the oxide $\mathrm{NiFe}_{2} \mathrm{O}_{4}$ layer and prevented reduction under testing conditions. In this chapter the $\mathrm{NiFe}_{2} \mathrm{O}_{4}$ itself is studied in detail as well, and it was found that thinner layers yielded higher photocurrents, which shows that charge carrier diffusion length is a limiting factor. This observation was underlined by the fact that the average lifetime of the charge carriers was in the order of ns as found by transient absorption spectroscopy.

Finally, in Chapter 6 we explored a different application of Ni-Mo. We used it as an electrocatalyst as is for water splitting. In this approach we cascaded this reaction with thermal $\mathrm{CO}_{2}$ methanation using $\mathrm{Ni} / \mathrm{SiO}_{2}$ catalysts to effectively store the energy in $\mathrm{CH}_{4}$ which is safer to handle and easier to store. It was found that aerosols evolving from the electrolyte affect the downstream $\mathrm{Ni} / \mathrm{SiO}_{2}$ catalysts. $\mathrm{KOH}$ in the aerosols deposited on the methanation catalysts and showed a size dependent promotion effect. From a technological point of view we find that the electrochemistry operates well, and simple adjustments to electrode size allow for optimal usage of the energy delivered by solar cells. We show that aerosol filtering, as already applied in industry, is indeed critical to maintain stable methanation catalysts, though interesting promotion effects could be induced. From the discussion also follows that the catalysts are only a small part of the full energy conversion efficiency for storing renewable electrical energy in $\mathrm{CH}_{4}$ when using two steps. For example heating of the methanation catalyst, in our lab scale setup, was a significant reducer of efficiency, decreasing the theoretical maximum efficiency from $9.2 \%$ to $0.14 \%$ and thus the entire picture should be considered. 


\subsection{Outlook}

This thesis explored various aspects of renewable energy storage. Electrolyzers, as well as pilot plants of methanation plants with on-site generated renewable hydrogen, are being built, and the technology is thus clearly, slowly but surely, maturing. Industry, however, is mostly still biding their time, due to a lack of public and political acceptance and funding, as well as the high capital costs of carbon capture and storage (CCS). $\mathrm{CO}_{2}$ taxing is unlikely to work due to the effect known in industry as 'Carbon Leakage' which is the occurrence of companies shifting their production facilities to countries with laxer emission constraints, and thus will only mostly serve to cripple the country apply higher $\mathrm{CO}_{2}$ taxes. Hence making water splitting as well as $\mathrm{CO}_{2}$ utilization more economically viable is one of the challenges. One of the possibilities for the future would be to integrate the $\mathrm{CO}_{2}$ hydrogenation with other chemical processes in industry to produce carbon-based products with renewable feedstocks.

\subsubsection{Ni-Mo Cathodes}

$\mathrm{Ni}$-Mo is an excellent material for water splitting when utilized as a cathode. Nevertheless, more work is likely necessary before it can be employed. Exceptional stability is desired for electrodes, preferably $>1000 \mathrm{~h}$. Hence they need to be explored at longer timescales. Furthermore, industrial electrolyzers usually operate at $6 \mathrm{M} \mathrm{KOH}$ and elevated temperatures $\left(85^{\circ} \mathrm{C}\right)$. It would be interesting to study the stability of $\mathrm{Ni}$-Mo as a function of temperature in detail. It is also important to study the effect $\mathrm{MoO}_{4}{ }^{2-}$ contamination would have on water splitting systems and if it is detrimental for large scale operation.

Some costs could be saved on this material when using cheap substrates, such as copper. However, as was discussed in Chapter 4 the substrate influences the performance of Ni-Mo, so further studies to properly understand this would likely benefit the development of large-scale electrodes. Also, despite being significantly cheaper than e.g. $\mathrm{Pt}, \mathrm{Ni}$ and $\mathrm{Mo}$ are still relatively expensive elements. Using a filler-like material, such as Fe, in ternary alloys (Ni-Fe-Mo) might be a viable option to decrease the production cost of renewable hydrogen. Ni-Fe-Mo was explored at a basic level in this thesis but not studied in depth, these first results indicated it is indeed a viable option, though at the cost of an increased overpotential.

\subsubsection{Ni-Fe-S Anodes}

$\mathrm{Ni}-\mathrm{Fe}-\mathrm{S}$ is an interesting material to be used as an anode. It does, however, require a lot of work to be made viable. The leaching of $S$ from this material does not come without risks such as potential formation of toxic $\mathrm{H}_{2} \mathrm{~S}$ gasses, which is significant at larger scale. Furthermore, being quite a novel material in 
the use as OER anode, it would likely benefit from further research into its synthesis, composition, and morphology. The roles of Fe and $\mathrm{S}$ for example were found to be different in Chapter 3 but we have not explored whether this knowledge can be exploited to further improve upon the material.

\subsubsection{Cascading Water Splitting and $\mathrm{CO}_{2}$ Methanation}

A lot of progress can be made in these systems. Pilot plant scale installations already exist and are proven to work. The example that will be described is based on the e-gas plant in Wertle from Audi. They utilize amine scrubbers to gain $\mathrm{CO}_{2}$ from waste gas streams, and react it with Raney nickel based catalysts for methanation. Water splitting is done with steel-based electrodes in heated $6 \mathrm{M} \mathrm{KOH}$ solutions in three megawatt electrolyzers. Water filters are used to clean the hydrogen gas stream of $\mathrm{KOH}$ containing aerosols and subsequently the gas tubing is cooled to remove the remaining water aerosols. Before introducing the hydrogen gas into the methanizer it is compressed to be able to run the $\mathrm{CO}_{2}$ methanation under pressure. This means there are many steps which require energy input before finally the $\mathrm{CO}_{2}$ is utilized and transformed into $\mathrm{CH}_{4}$.

One of the most energy consuming components are the pumps to build up $\mathrm{H}_{2}$ pressure, something that was not explored in our lab scale setup. Possible gains could be made either by exploring low-pressure methanation or by improving on such pumps. Other processes through which energy could be gained is by improving $\mathrm{CO}_{2}$ capture, since the amine scrubber requires significant heating before the $\mathrm{CO}_{2}$ is released again in a relative pure flow. The heating of $\mathrm{CO}_{2}$ methanation was mentioned before and was the main energy consumer in our lab scale system, industrial heating is already well established and significantly more efficient, nevertheless finding catalyst systems that allow for similar methanation rates at lower temperatures would be very beneficial from an efficient energy storage point of view. Finally, at the electrolyzers, potentially efficiency can be gained by switching to systems which require less or no heating, or can operate at lower alkalinity, making the electrolytes more environmentally friendly as well as making it easier to keep them clean from detrimental aerosols.

\subsection{Conclusions}

This thesis showed the viability of Ni-Mo as a cathode for water splitting, as well as discussing Ni-Fe-S as an option to be used as an anode. Thorough characterization methods for the electrodes were established to show that despite their apparent stability there are still leaching processes ongoing. Through these experiments we came to question things often assumed in literature, such as electrolyte cations being spectator species and the use of double layer capacitance as a measure of surface area. With this, the thesis 
aims to show that electrochemistry is complex and all components should be considered with care when measuring and when trying to determine catalyst stability.

We continued with using these electrocatalyst materials in demonstration labscale setups to show that the materials are able to operate under real, solarcell driven conditions and furthermore could be combined with $\mathrm{CO}_{2}$ methanation to store energy from renewable sources in chemical via carbon utilization. The methane, for example, can be injected in the existing grid and used in chemical industry as well as a fuel. 



\section{Back Matter}




\section{Nederlandse Samenvatting}

De thesis vangt aan met een generieke introductie in Hoofdstuk 1 met de focus op energiegebruik op wereldschaal. Hernieuwbare energiebronnen zijn noodzakelijk, maar ondergaan nog altijd onderhevig aan een aantal wetenschappelijke en technische uitdagingen. Een van de grote uitdagingen die wordt besproken is het opslaan van de (elektrische) energie die volgt hernieuwbare bronnen zoals zonne- en windenergie. Opslag is namelijk nodig omdat onregelmatigheden in gebruik en productie bestaan, we benutten namelijk veel energie in de nacht en het wordt geproduceerd gedurende de dag. Hierin is bijvoorbeeld de zomer-winter cyclus nog een schaal van uitdaging groter. In dit hoofdstuk bespreken we de mogelijkheid deze energie op te slaan in chemische verbindingen, zoals waterstof of methaan (de laatste kent men vaak als aardgas). Deze chemicaliën worden dan niet vervuilend gewonnen, maar juist gemaakt uit bijvoorbeeld uitgestoten koolstofdioxide. Waterstof, is in dit opzicht simpeler en wordt gemaakt uit water; het hoofdstuk focust op hoe water splijting te werk gaat. Verschillende technologische aanpakken worden besproken hoe energie in waterstof opgeslagen kan worden: foto-katalyse, foto-elektrochemie, en elektrochemie. De chemische details zoals het mechanisme en de natuurkundige overwegingen (thermodynamica) die bij deze reactie horen komen hierbij ook aan de orde. Meer van belang is de kinetiek, wat inhoud hoe snel de reactie verloopt. Dit is waar elektro-katalyse in het spel komt. Zoals je een ei kan bakken op een stoep in een warme zomer gaat het toch sneller, en ook schoner, wanneer je het in een pan doet. Dit komt omdat hitte efficiënter bij het ei komt en de pan is een medium om deze hitte aan te brengen. Een elektro-katalysator werkt hetzelfde: het is een medium die elektronen aanbiedt om water te splijten. Tegelijkertijd kan je de stroom opvoeren om snellere productie van waterstof te krijgen. Om de stroom te laten lopen moeten de elektronen wel aangespoord worden te bewegen, deze druk noemen we potentiaal. De extra potentiaal die we aanvoeren om een wenselijke snelheid te krijgen is eigenlijk een energieverlies die we betalen om tijd te besparen. Deze extra potentiaal noemen we overpotentiaal. Deze thesis focust vervolgens op nikkel-molybdeen (Ni-Mo) als katalysator. Deze materiaal zijn relatief goedkoop in vergelijking met andere materialen die gebruikt worden en daarnaast is deze ook erg effectief voor het evolueren van waterstof. Om een werkelijk duurzaam systeem te maken is het echter nodig dat de materialen in het systeem zelf ook duurzaam zijn. Dat betekend dat ze stabiel moeten zijn. Deze thesis beschrijft en onderzoekt de houdbaarheid van Ni-Mo als materiaal in detail, zodat deze kennis beschikbaar is voor technische en economische overwegingen het te gebruiken in zon-gedreven systemen om energie op te slaan. In de komende paragrafen worden de hoofdzakken genoemd zoals deze ook zijn samengevat in Hoofdstuk 1, Figuur 1.12.

$\mathrm{Ni}$-Mo is al in heel veel onderzoeken uitgepluisd, echter bestond dus nog de discussie waarom dit materiaal zo effectief is in de reactie en hoe houdbaar het is. In Hoofdstuk 2 duiken we in op deze vragen en geven antwoorden binnen deze discussie. Door gebruik te maken van een combinatie van theoretische berekeningen en experimenten op het lab kunnen we bevestigen dat deze 
materialen inderdaad actief zijn in de reactie. De berekeningen laten ons zien dat er bijna geen energieverschil is voor het aanhechten of loslaten van waterstof. Als je waterstof als het ei ziet: te sterke aanhechting betekend dat het ei (extreem) aanbakt en je pan dus niet meer goed te gebruiken is, te zwakke aanhechting gebeurt in het echt gelukkig nooit maar dat zou betekenen dat je ei de pan uit zweeft voordat het gebakken is. In dit geval bakt het eitje (de waterstof) dus totdat hij klaar is, en laat dan ook zonder aanbakken los. De $\mathrm{Ni}$-Mo katalysatoren, zagen we, begonnen beter te werken na een paar uur. Nu is dit op zich geen slecht nieuws, maar het betekend dat er iets veranderd. $\mathrm{Na}$ deze verandering waren ze stabiel voor ten minste 100 uur, maar dat is geen garantie dat het later, na mogelijk weken of maanden, toch slechter gaat worden. Met onder andere elektronenmicroscopie, om zo op nanometerschaal (een nanometer is een miljardste meter, 0.000000001 meter) te kunnen kijken en zien we dat ons materiaal ruiger wordt. We hebben dus meer oppervlakte waar katalyse gebeurd, wat kan verklaren waarom het materiaal het beter gaat doen. Het ruiger worden betekend echter wel dat er waarschijnlijk iets uit het materiaal weglekt, wat dus betekend dat het eigenlijk langzaam kapot gaat. Inderdaad we vonden dat het molybdeen (Mo) langzaam weglekte in het water. We zagen ook dat het zout wat in het water opgelost was een rol speelde in hoeverre en hoe snel het lekken plaatsvond. De zuurtegraad speelde een grote rol maar ook het kation (het positief geladen deeltje) beïnvloedde het lekken. De chemische reactievergelijking die we hebben gevonden als de boosdoener is als volgt: $\mathrm{Mo}+2 \mathrm{OH}^{-}+2 \mathrm{H}_{2} \mathrm{O} \rightarrow \mathrm{MoO}_{4}{ }^{2-}+3 \mathrm{H}_{2}$. Hier is $\mathrm{OH}^{-}$hydroxide, het actieve deel van bijvoorbeeld gootsteenontstopper. Dit zit in de oplossing zodat water geleid, dit doet het eigenlijk van nature namelijk niet, maar in ons drinkwater zitten genoeg (ongevaarlijke) zouten dat dit toch stroom geleid. $\mathrm{H}_{2} \mathrm{O}$ is de chemische manier van water beschrijven. $\mathrm{H}_{2}$ is waterstof en $\mathrm{MoO}_{4}{ }^{2-}$ heet molybdaat. Dat laatste zit dus in oplossing en is hoe we langzaam het Mo uit onze katalysator verliezen. Interessant is dat het lekken van die molybdeen ook waterstof vormt, we zagen dus ook een efficiëntie voor waterstofproductie van boven de 100\%! Met geavanceerde technieken zoals Röntgen foto-elektron spectroscopie konden we zien dat deeltjes (lithium, natrium of kalium ionen) ons materiaal inkropen. Met behulp van de theoretische berekeningen konden we concluderen dat ze zeer kleine kanaaltjes inkropen die zich in het materiaal vormden. We konden hierna dus zeggen dat het Ni-Mo heel goed werkt, niet alleen omdat Ni en Mo samenwerken maar ook omdat Mo weglekt en dus extra oppervlak vormt. We konden ook zeggen dat de oplossing die je gebruikt een grote rol speelt en dat $\mathrm{LiOH}$ de minste Mo lekken veroorzaakt wanneer gebruikt op 0.1 M (M staat voor molair, een maat van concentratie, het betekend mol per liter, waar mol een manier is waarop wij zeggen '602.214.076.000.000.000.000.000 deeltjes', je snapt dus wel waarom we dat afkorten).

Wanneer je water splijten leest zou je de vraag kunnen stellen: je splijt het, dus wat is de andere helft waarin je het splijt? De andere helft die vormt is zuurstof. Het splijten van water wordt dus ook vaak besproken met twee half-reacties, waterstof vorming en zuurstof vorming. In Hoofdstuk 3 bespreken we een elektrode die als elektro-katalysator dient voor het vormen van zuurstof. Dit materiaal is nikkel-ijzersulfide (Ni-Fe-S). Met éen simpele stap kunnen we dit 
materiaal vormen door nikkel te koken in een oplossing van ijzer en zwavel. We doen dit op nikkel in de vorm van metaalschuim, metaal dat gevormd is zoals een spons zodat het veel oppervlakte heeft terwijl het een stuk minder ruimte inneemt. Ni-Fe-S stond al bekend als een materiaal dat erg actief is en ogenschijnlijk ook stabiel. Echter is dit materiaal een stuk minder goed onderzocht dan Ni-Mo omdat het pas recenter tot het licht is gekomen als kandidaat voor de zuurstof evolutie reactie. Inderdaad, wanneer we dit materiaal combineren met Ni-Mo zien we goede stabiliteit voor ten minste éen hele week (wat lang is voor lab-schaal experimenten). Daarnaast hebben we een potentiaal gehaald van 1.55 volt voor een stroom van 10 milliampère per centimeter. Voor economische haalbaarheid is beschreven dat een systeem maximaal 1.68 volt mag gebruiken voor die stroom, dus daar zitten we ruim onder wat goed is. Desalniettemin onderzochten we in hoeverre de ogenschijnlijke stabiliteit daadwerkelijke stabiliteit was. Met deze zoektocht vonden dat ijzer de rol speelt om de elektrodes zelfs nog meer oppervlakte te geven terwijl het eigenlijk bijna niet in het materiaal zit na de vorming. Zwavel daarentegen zit juist wel in het materiaal en functioneert voornamelijk om samen met nikkel de zuurstof te vormen uit water. We vinden echter dat zwavel daadwerkelijk uit het materiaal lekt. Interessant genoeg is toch het zwavelgehalte na 24 uur katalyse op de oppervlakte hoger dan het was voordat de katalyse begon. Dit betekent dat in deze vaste stof de materialen toch niet zo rigide zijn als vaak lijkt, en de zwavel 'loopt' door de vaste stof naar de oppervlakte. Dit is waarschijnlijk ook de reden dat het materiaal ogenschijnlijk stabiel is, maar toch lekt: de zwavel wordt constant aangevuld. We hebben dit niet getest, maar de kans is dat dus na langere katalyse de voorraad zwavel op gaat zijn. Desalniettemin was dit systeem te opereren met lage energieverliezen, en ter demonstratie hebben we een systeem gebouwd dit met echte zonnecellen inderdaad water splijting kon doen. Dit systeem opereerde op 2.1 volt en leverde 1 ampère.

Doordat ons demonstratiesysteem op een hogere voltage en merkbaar hoger ampèrage werkte besloten we het Mo lek gedrag uit Ni-Mo nog eens opnieuw te bekijken. In Hoofdstuk 4 kijken we in detail naar het gedrag als een functie van voltage en ampèrage. Daarnaast werd ook nikkel schuim genoemd. In andere velden van katalyse is al langere tijd bekend dat de ondergrond die je gebruikt om een katalysator op te bouwen significante invloed kan hebben op je katalysator zelf. Dit hebben we meteen meegenomen in de onderzochte stappen in dit hoofdstuk. Zoals we al vermoedde zagen we inderdaad significante effecten op het gedrag van Ni-Mo wanneer deze delen veranderen. We zagen dat de verandering van de Ni-Mo oppervlakte het meest significant is wanneer we een middelmatige stroom toepassen. Het was minder met minder stroom, maar ook minder met meer stroom. Dit betekent dat er, ten minste, twee dingen gebeuren die een rol spelen en de verandering beïnvloeden. We konden onder meer ook zeggen dat de aanwezigheid van kalium direct in verband staat met de veranderingen in structuur van de oppervlakte, maar we hebben nog niet kunnen halen welke, het kalium of het veranderde oppervlak, de oorzaak en welke het gevolg is. Verder hebben we gevonden dat het lekken van Mo niet een direct verband heeft met de capaciteit. In elektrochemie wordt capaciteit gezien als maat van de 
beschikbare oppervlakte. Met oppervlakte-gevoelige technieken vonden we dat deze capaciteit direct gelinkt kan worden aan de ratio in $\mathrm{Ni}$ en Mo aan de oppervlakte. Dit geeft echter sterke indicaties dat de aanname om capaciteit en oppervlakte aan elkaar te verbinden, die vaak gedaan wordt, in het geval van Ni-Mo niet klopt. Als processen die Mo lekken beïnvloeden hebben we voorgesteld dat het deels komt doordat meer hydroxide wordt gecreëerd als bijproduct van de waterstof evolutie. Deze hydroxide wordt meteen weer verbruikt voor zuurstof evolutie, dus is niet vervuilend, maar de elektrodes staan uit elkaar en het kost dus tijd voor die hydroxide bij de andere elektrode is. Lokaal veranderd de chemische samenstelling dus. Zoals in hoofdstuk 2 beschreven is, versterkt hydroxide het lekken van molybdeen. Als we echter naar nog sterkere potentiaal gaan zien we dat het lekken afneemt. Het lekken van molybdeen is wat heet een oxidatie reactie. Dit betekent dat het elektronen afstaat om positief geladen molybdeen te vormen. Omdat we bij een hogere potentiaal juist meer elektronen naar het molybdeen toedrukken voorkomt dat dat molybdeen de ruimte heeft zijn elektronen af te staan. Ten slotte hebben we nog naar het substraat, de ondergrond, gekeken. We hebben verschillende materialen, titaan, nikkel, koper en roestvrijstaal bekeken. We vonden dat materialen die qua kristal lijken op Ni-Mo, namelijk nikkel en koper, ervoor zorgen dat Ni-Mo meer actief is dan op de andere twee substraten. We zagen ook dat de gebruikte ondergrond op een complexe manier de trends in stabiliteit beïnvloeden. Aangezien dit nog onbegane grond was voor het systeem zijn we nog niet op het punt beland waarbij we kunnen voorspellen hoe het materiaal zich gedraagt op een bepaalde ondergrond. Wel hebben we kunnen bepalen dat het Ni-Mo materiaal het beste gedrag vertoond wanneer het wordt gemaakt op roestvrijstaal en een lage potentiaal wordt aangehouden. Hierbij is het het stabielst terwijl het nog steeds hoge activiteit vertoond.

Hoofdstuk 5 geeft een andere draai aan het Ni-Mo elektrokatalysator systeem. In principe is iedere extra stap in een systeem een stap waar energie verloren gaat. Oftewel, omdat we zonnecellen combineren met de elektrokatalyse hebben we een energieverlies omdat de elektriciteit van de zonnecellen naar de elektrochemische cel moet. Een manier om hier omheen te werken is door de zonnecel letterlijk in de elektrochemische cel te maken. In dit geval krijgt het de eerdergenoemde naam: foto-elektrochemie (de benaming foto slaat terug op de rol van licht). We gebruiken nikkel-ijzeroxide $\left(\mathrm{NiFe}_{2} \mathrm{O}_{4}\right)$ als materiaal om licht te absorberen. De energie van de licht absorptie, zoals zonnecellen ook werken, wordt dan aangeboden aan de Ni-Mo en deze doet vervolgens katalyse. In dit hoofdstuk beschrijven we een nieuwe synthese mogelijkheid om de dubbele laag van $\mathrm{Ni}-\mathrm{Mo}$ op $\mathrm{NiFe}_{2} \mathrm{O}_{4}$ te maken door middel van stroom. Verder vonden we dat de Ni-Mo een dubbele functie heeft. Allereerst was het, zoals bedoeld, een katalysator. Het bood dus de oppervlakte om waterstof evolutie gunstiger te laten verlopen. Het beschermde daarnaast ook de $\mathrm{NiFe}_{2} \mathrm{O}_{4}$ laag. Zonnecel materialen, bekend als semiconductoren, zijn over het algemeen erg gevoelig voor lucht en water, en gaan snel stuk zo gauw ze eraan worden blootgesteld. De Ni-Mo voorkwam dat het water bij de $\mathrm{NiFe}_{2} \mathrm{O}_{4}$ laag kon komen en zorgde zo voor een langere stabiliteit. We hebben ten slotte het $\mathrm{NiFe}_{2} \mathrm{O}_{4}$ in nog meer detail onderzocht. Bij zonnecellen, en dus ook dit materiaal, worden elektronen aangeslagen door licht. Dat betekent dat een 
elektron tijdelijk meer energie bevat omdat hij een licht foton bij zich draagt. Dit is niet een heel erg stabiele toestand, en al snel laat hij deze energie weer gaan, soms als licht, soms als warmte. We kunnen met tijdsgevoelige absorptie spectroscopie deze elektronen specifiek meten en volgen op zeer korte tijdsspanne, namelijk nanoseconden (herinner je: nano betekend miljardste). Hiermee konden we vinden dat inderdaad het verliezen van energie van de elektronen voordat ze waterstof evolutie konden doen de grootste factor was wat de efficiëntie van dit systeem nog beperkte. Dit hoofdstuk geeft dus een nieuwe synthesemethode en inzicht, maar het is duidelijk maar een stap in vele stappen die nog gedaan moeten worden.

Ten slotte, in Hoofdstuk 6, combineren we alle kennis uit de vorige hoofdstukken met een andere chemische reactie. Deze reactie heet de Sabatier reactie, ofwel koolstofdioxide hydrogenatie. Wat dit inhoudt is dat we waterstof in koolstofdioxide persen. Hiermee maken we methaan (aardgas) en water. Dit maakt dus een $\mathrm{CO}_{2}$ neutrale cirkel: alle $\mathrm{CO}_{2}$ die we krijgen door het methaan te verbranden is origineel gebruikt om die methaan te maken. We stoten dus niets extra's uit hiermee! Maar, waarom methaan als we al waterstof hebben? Er zijn verschillende redenen, allereerst is waterstof het kleinste molecuul, en een van de kleinste gassen, dat maakt dat het door solide metaal heen kan lekken, het past tussen de atomen. Opslag, en dus vervoer, van waterstof is lastig, en kost veel energie. En juist energie is de reden dat we met waterstof werken, dus een verlies daarin is belangrijk. Methaan is veel handelbaarder, en hebben we al een infrastructuur voor doordat we dit gebruiken uit fossiele brandstoffen. Er hoeft dus weinig te veranderen, behalve de manier waarop we het winnen. Dit voorkomt graafwerken, dit scheelt een hele boel geld, en is bovenop alles veiliger om mee te werken. Nu hebben we de elektrochemie, eerder beschreven, werkend. De Sabatier reactie is een flink onderzochte reactie en er is veel kennis in. Het lijkt dus zo simpel als die twee aan elkaar plakken en we kunnen gaan. In dit hoofdstuk doen we dat ook, we hebben een testopstelling ontwikkeld waarin we deze reacties direct gekoppeld kunnen doen, terwijl we ook aan alle kanten kunnen meten wat er gebeurd om zo te zien waar we verbeteringen kunnen maken. En inderdaad, we vonden dat minuscule waterdruppels uit de elektrokatalyse invloed hadden op de katalysatoren voor de $\mathrm{CO}_{2}$ hydrogenatie (nikkel op silica). Deze waterdruppels bevatte nog de zouten, het kalium hydroxide. Het kalium hieruit kwam op het nikkel terecht en zorgde ervoor dat hun gedrag in $\mathrm{CO}_{2}$ hydrogenatie veranderde. Hoewel de vondst erg interessant is, en met wat sleutelen aan bijvoorbeeld het formaat van de nanometer nikkel deeltjes zelfs als voordelig beschouwd kon worden, is het voor een constante operatie handig om veranderingen te voorkomen. Hierdoor wisten we dus, vanuit een technologisch oogpunt dat we filters moesten toepassen. Vanuit hetzelfde oogpunt hebben we zonnecellen gekoppeld aan de elektrokatalyse, en de waterstof daaruit gebruikt voor de katalyse. We konden berekenen dat de uiteindelijke energieopslag van zonlicht in methaan maar $0.14 \%$ was. Zeer klein dus. De efficiëntie die we hebben gehaald met het uiteindelijke experiment was kleiner, namelijk $0.041 \%$. Hoewel wij hiermee nog niet op de nummers zijn waarmee je een fabriek gaat bouwen (welke tevens al wel bestaat, zoals de E-gas plant van Audi in Werlte) konden we wel achterhalen welke stappen 
de grootste energievraag hadden. Allereerst hebben we de zonnecellen, welke een efficiëntie hebben van $19.5 \%$. Er is nog altijd veel onderzoek in het verbeteren van zonnecellen maar dit is het resultaat na jaren aan onderzoek daaraan. Dit is onder geen geval een slechte efficiëntie, planten, welke al miljoenen jaren aan evolutie hebben ondergaan, hebben een efficiëntie van ongeveer $5 \%$. Vervolgens is er een inherent verlies van nog eens $50 \%$ in de elektrokatalyse stap omdat de zonnecellen 2.1 volt leveren. Dit zou mogelijk gereduceerd kunnen worden door het toepassen van een transformator om het voltage te verlagen en in het ideale geval het ampèrage te verhogen (ampère is te vertalen naar elektronen per seconde, wat weer te vertalen is naar waterstof per seconde, in ideale gevallen). Desalniettemin blijft de noodzaak voor de eerdergenoemde overpotentiaal dus een verlies blifft in deze stap. Zoals ook eerdergenoemd: iedere stap neemt nu eenmaal energieverlies met zich mee. Ten slotte de grootste boosdoener in ons systeem was verhitting. De $\mathrm{CO}_{2}$ hydrogenatie heeft verhitting nodig tot wel 400 graden Celsius. Deze verhitting had ruim dertig keer zoveel energie nodig als de water splijting cel en deze warmte-energie is niet eens opgeslagen in het methaan (methaan bevat namelijk minder energie dan waterstof, maar door transport en opslag is het wel energie efficiënter in gebruik). Deze stap alleen bracht de haalbare efficiëntie op dit punt omlaag van $9.2 \%$ naar $0.14 \%$. Gelukkig is de manier van verwarmen in de industrie al een stuk efficiënter dan wat wij hebben gebruikt. Het doel, uiteindelijk, van onze opstelling is het testen van de katalysatoren en daarvoor betalen wij een prijs in energie.

Om dit alles nog in perspectief te plaatsen: in de Sahara valt ongeveer 9.200.000.000.000.000 W aan zonne-energie. In 2015 consumeerde de wereld ongeveer 18.120.000.000.000 W aan energie. Dat betekent dat onze consumptie $0.20 \%$ was van wat alleen al als zonne-energie op de Sahara valt. Onze, niet geoptimaliseerde, lab opstelling is dus al bijna genoeg. Het is dus een kwestie van tijd, en geld, voordat de industrie (hernieuwbaar) elektrisch is (zonnecellen op je dak vinden veel mensen al duur, stel je voor dat je zonnecellen moet aanleggen voor een hele fabriek die ook nog eens niet mag uitvallen). We laten in deze thesis dus zien dat het zeker haalbaar is zonneenergie in twee stappen in methaan op te slaan waarbij alleen water en $\mathrm{CO}_{2}$ worden gebruik. Het is geen aanslag op ons drinkwater, want al het water komt gewoon weer terug als regen, daarnaast kunnen we gewoon zeewater gebruiken wat toch niet als drinkwater wordt beschouwd. Onderzoek blijft echter nodig, want de transitie voor de industrie is traag en erg duur en $\mathrm{CO}_{2}$ taxatie werkt alleen als de hele wereld hieraan deelneemt (wat weer een politieke uitdaging is), omdat anders 'Carbon Leakage', koolstoflekken plaatsvindt. Dit is het scenario waarin industrie massaal hun productiefaciliteiten naar landen zonder taxatie verplaatst. Vandaar dat een van de beste oplossingen dus bestaat uit het verbeteren van de mogelijkheden en het aantrekkelijk maken door te laten zien dat het werkt.

Ter conclusie laten we zien dat Ni-Mo geschikt is voor het splijten van water. Het kan werken met relatief lage energieverliezen wanneer gecombineerd met $\mathrm{Ni}-\mathrm{Fe}$-S. In deze thesis stellen we de stabiliteit van deze materialen op de proef en laten zien dat hoewel stabiliele operatie mogelijk is dat er toch nog stukken 
van de katalysator lekken. We hebben aannames die vaak gedaan worden in elektrochemische literatuur aan de kaak gevoeld en duidelijk gemaakt dat er voorzichtiger omgesprongen moet worden met dergelijke conclusies. Uiteindelijk laten we zien dat het daadwerkelijk mogelijk is methaan uit koolstofdioxide te maken met via twee stappen, maar dat er nog veel te winnen is qua energie efficiëntie op vele vlakken van het systeem. 


\section{List of Abbreviations}

AFM - Atomic force microscopy

BE - Background emission

BET - Brunauer-Emmett-Teller (theory)

BFDH - Bravais-Friedel-Donnay-Harker

CE - Counter electrode

CV - Cyclic voltammetry

CVD - Chemical vapor deposition

DFT - Density functional theory

DL - Double layer

DTU - Danmarks Tekniske Universitet (Denmark Technical University)

ECSA - Electrochemically active surface area

EDX - Energy dispersive X-ray spectroscopy

FE - Faradaic efficiency

FIB - Focused ion beam

FIB-SEM-EDX - Focused ion beam scanning electron microscopy with energy dispersive X-ray spectroscopy

FID - Flame ionization detector

FTO - Fluor-doped tin oxide $\left(\mathrm{F}: \mathrm{SnO}_{2}\right)$

FTS - Fischer-Tropsch synthesis

FWHM - Full width at half maximum

GC - Gas chromatography

GHSV - Gas Hour Space Velocity 
HDM - Hydrodemetalation

HDN - Hydrodenitration

HDS - Hydrodesulfurization

HER - Hydrogen evolution reaction

ICP-AES - Inductively coupled plasma atomic emission spectroscopy

IPCE - Incident photon to current efficiency

LED - Light emitting diode

LHV - Lower heating value

NHE - Normal hydrogen electrode

OER - Oxygen evolution reactions

PAW - Projector augmented wave

PEC - Photo-electrochemical

PEM - Proton exchange membranes

PET - Polyethylene terephthalate

PFR - Plug Flow Reactor

PtG - Power to Gas

PtM - Power to Methane

PV - Photovoltaic

PVD - Physical vapor deposition

RE - Reference electrode

RHE - Reversible hydrogen electrode

RMS - Root mean square

RPM - Rotations per minute 
SEM - Scanning electron microscopy

SEM-EDX - Scanning electron microscopy with energy dispersive X-ray spectroscopy

SLAC - Stanford Linear Accelerator Center

STH - Solar-to-hydrogen

TAS - Transient absorption spectroscopy

TCD - Thermal conduction detector

TEM - Transmission electron microscopy

TOF - Turn-over frequencies

TON - Turn-over numbers

TU/e - Technical University Eindhoven

UU - Utrecht University

UV - Ultraviolet

UV-Vis - Ultraviolet and visible light

VASP - Vienna ab-initio simulation package

VBM - Valence band maximum

WE - Working electrode

XPS - X-ray photoelectron spectroscopy

XRD - X-ray diffraction 


\section{List of Publications \& Presentations}

\section{The following publications are derived from this PhD Thesis}

Chapter 2: Electrolyte Effects on the Stability of Nickel-Molybdenum Cathodes for the Hydrogen Evolution Reaction, J.H.J. Wijten, R.L. Riemersma, J. Gauthier, L.D.B. Mandemaker, M.W.G.M. Verhoeven, J.P. Hofmann, K. Chan, B.M. Weckhuysen, ChemSusChem 2019, 12, 3491-3500

Chapter 3: Basicity and Electrolyte Composition Dependent Stability of Ni-Fe$\mathrm{S}$ and Ni-Mo Electrodes during Water Splitting, J.H.J. Wijten, I. GarciaTorregrosa, E.A. Dijkman, B.M. Weckhuysen, ChemPhysChem 2020, doi: 10.1002/cphc.201901219

Chapter 4: In Situ Study of Ni-Mo Stability in a Solar Driven Water Splitting Device: Effect of Catalyst Substrate and Applied Potential, J.H.J. Wijten, L.D.B. Mandemaker, J.E. Dubbeld, T. van Eeden, B.M. Weckhuysen, in preparation

Chapter 5: Cathodic Electrodeposition of Ni-Mo on Semiconducting $\mathrm{NiFe}_{2} \mathrm{O}_{4}$ for Photoelectrochemical Hydrogen Evolution in Alkaline Media, J.H.J. Wijten, R.P.H. Jong, G. Mul, B.M. Weckhuysen, ChemSusChem 2018, 11, 1374-1381

Chapter 6: Structure-Sensitive Alkali Promotion in the Formation of $\mathrm{CH}_{4}$ from $\mathrm{CO}_{2}$ and Renewably Produced $\mathrm{H}_{2}$ over Supported Ni Catalysts, C. Vogt*, J.H.J. Wijten*, C.L. Madeira, O. Kerkenaar, K. Xu, R. Holzinger, M. Monai, B.M. Weckhuysen, ChemCatChem 2020, doi: 10.1002/cctc.202000327

*These authors contributed equally to this work

\section{Other publications by the author}

Probing the dynamics of photogenerated holes in doped hematite photoanodes for solar water splitting using transient absorption spectroscopy, G.X. Pei, J.H.J. Wijten, B.M. Weckhuysen, Phys. Chem. Chem. Phys., 2018, 20, 98069811

Template-Free Nanostructured Fluorine-Doped Tin Oxide Scaffolds for Photoelectrochemical Water Splitting, I. Garcia-Torregrosa, J.H.J. Wijten, S. Zanoni, F.E. Oropeza, J.P. Hofmann, E.M.J. Hensen, B.M. Weckhuysen, ACS Appl. Mater. Interfaces, 2019, 11, 36485-36496 


\section{Oral Presentations}

Development of Metal-Organic Frameworks for Photocatalytic Applications, J.H.J. Wijten, R.P.H. de Jong, M. Barroso, J.P. Hofmann, B.M. Weckhuysen, CHAINS, 2016, The Netherlands

Cascading Solar Driven Water Splitting with Catalytic CO2 Hydrogenation, J.H.J. Wijten, B.M. Weckhuysen, Alliance UU/UMCU/TU/e Day, 2018, The Netherlands

An Electrochemical Water Splitting Cell Driven by Renewable Energy Operating at Low Overpotentials, J.H.J. Wijten, R.L. Riemersma, C. Vogt, I. Garcia-Torregrossa, B.M. Weckhuysen, NCCC, 2018, The Netherlands

$\mathrm{Ni}-\mathrm{Fe}-\mathrm{S}$ as Oxygen Evolution Catalyst in a Solar-Driven Water Splitting Cell Operating at Low Overpotential, J.H.J. Wijten, I. Garcia-Torregrosa, E.A. Dijkman, B.M. Weckhuysen, Europacat, 2019, Germany

Electrolyte Effects on the Stability of Ni-Mo Cathodes for the Hydrogen Evolution Reaction, J.H.J. Wijten, R.L. Riemersma, J. Gauthier, L.D.B. Mandemaker, M.W.G.M. Verhoeven, J.P. Hofmann, K. Chan, B.M. Weckhuysen, Europacat, 2019, Germany, Presented by R.L. Riemersma

\section{Poster Presentations}

Development of Ferrite Spinel Structures for Photoreduction Reactions, J.H.J. Wijten, M. Barroso, B.M. Weckhuysen, ISPC, 2016, Italy

Transient Absorption Spectroscopy of Metal-Organic Frameworks Developed for Solar Water Splitting, J.H.J. Wijten, M. Barroso, B.M. Weckhuysen, NCCC, 2016, The Netherlands

Stability of Ni-Mo Electrocatalysts for the Hydrogen Evolution Reaction, J.H.J. Wijten, B.M. Weckhuysen, NCCC, 2017, The Netherlands

Cascading Solar Driven Water Splitting with Catalytic Carbon Dioxide Hydrogenation, J.H.J. Wijten, C. Vogt, M. Monai, B.M. Weckhuysen, NCCC, 2019, The Netherlands 


\section{Acknowledgements}

Tijd is vreemd. Hoewel duidelijk beschreven door natuurkundige is onze perceptie ervan vaak verbogen. De afgelopen vier jaar lijken zowel voorbijgevlogen als een eeuwigheid te hebben geduurd. Hoewel klassieke natuurkunde geen relatie beschrijft tussen tijd en massa, kon de observeerder toch een correlatie vinden tussen mijn perceptie van tijd en mijn massa. Gelukkig waren er veel van deze observeerders die de correlatie inderdaad zagen en mij door dik en dun hebben bijgestaan.

Vooraan in deze lijst staat Bert. Bert, bedankt voor alle hulp, en vooral ook geduld, in de afgelopen vier jaar. Nog nooit heb ik in mijn leven iemand ontmoet met de passie en het doorzettingsvermogen om zo diep in een vak te zitten als $u$. De kansen, en vrijheid, in het bewandelen van onderzoekspaden voelden haast eindeloos, maar toch was $\mathrm{u}$ er om mij weer met mijn voeten op de grond te zetten als ik weg leek te zweven, of juist tot lopen te manen als mijn voeten iets te stevig op de grond geplant waren. Het enthousiasme waarmee nieuwe ideeën soms als een waterval op mij op kwamen leken me soms te verdrinken, maar ik denk dat, met $u$ als zwemhulp, we toch een mooi meer hebben gemaakt uit de oceaan van ideeën. En hoewel we elkaar soms letterlijk nachtmerries hebben bezorgd hebben toch zeker wel meer dromen van elkaar verwezenlijkt.

Although, sadly, we haven't worked together a lot in the end, I would also like to thank Monica. Monica, I would like to thank you and Bert for giving me the opportunity to start in this group as a PhD student. Furthermore, thank you for playing a large role in my education, not only in the field of (photo)electrochemistry but also as a scientist and person. Ivan, Ahmed, Guangxian, thank you too for being my brothers- and sister-in-arms in the field of water splitting, photo-electrochemistry. Together we managed to fight our way through the trenches of building up (photo)electrochemical lab equipment and expertise in the Inorganic Chemistry and Catalysis group. I am confident that we left something beautiful for the next generations to work with.

Inorganic Chemistry and Catalysis is een immense groep, en zoiets kan niet bestaan zonder een sterk fundament. Sandra, Belen, Monique, Iris, Dymph, llonka, $\mathrm{Ad}^{2}$, Dennie, Marjan, Jan Willen, Ramon, Hannie, Hans, Chris, Fouad, bedankt dat jullie er voor ons PhD's zijn. Het eindeloze geduld en jullie interesse in niet alleen onderzoek maar ook ons als persoon is een zegen. Jullie staan altijd klaar voor ons en dat wordt erg op prijs gesteld. Herrick, naast dit alles wil ik jou ook nog erg bedanken voor de hulp met het in elkaar zetten van simpel te begrijpen software voor mijn opstelling en de gezelligheid met 'één' biertje. Pascal, bedankt voor je vertrouwen en geduld met mijn neiging de GC op te lossen in base. Daarnaast hebben we talloze gezellige gesprekken gehad die erg hebben geholpen een deel van mijn sanity te bewaren. Oscar, bedankt. We hebben nagenoeg gedurende mijn hele $\mathrm{PhD}$ nauw 
samengewerkt. Dankzij jou heb ik ongelovelijk veel geleerd op het gebied van techniek, plannen, slechte grappen (die je de helft van de tijd zelf niet door had) en sushi (samen met Tara, Renée en Iris, jullie ook bedankt!). Je bent niet alleen een geweldige en behulpzame collega die ik altijd van de stoel kon trekken als ik weer eens hulp nodig heb maar zeker ook een onvervangbare vriend, nogmaals, bedankt.

Then there is the little office corner, Mark, Jogchum, Nikos, Marisol, thank you for the conversations, as well as being understanding when work needs doing. Nynke, although I have had to miss you in the last month, thank you for the endless supply of candy (let me refer back to the first paragraph of the Acknowledgements here), showing me a desk can always be more filled than mine was, but above all else our silly dance sessions.

Science is a collaboration and not only limited to one group. Both from the inside, Laurens, Ivan, Matteo, Charlotte, and also from all over, Jan Philipp, Tiny, Joe, Karen, Ronald, Guido, thank you all for your collaboration in making the (upcoming) publications used in this thesis a reality. I would not have gotten anywhere without you. Also elementary to this were my exemplary students. Romy, Jeroen, Tess, Eva, Nathalie, Annemieke, you all did a tremendous job and were vital to this research blossoming. You showed me when I stubbornly made assumptions that sometimes simple experiments I would never think of show us how certain parameters which usually are considered irrelevant are, in fact, very relevant. You also were wonderful people to interact with and talk with about whatever. Well done, and thanks a bunch!

To all colleagues from Inorganic Chemistry and Catalysis, thank you for the fun times during the drinks, conferences, labuitjes, and numerous other activities. Mark, thanks for being my buddy as the borrel committee, making sure there were always consumables whenever necessary. Also thanks for sharing the pain and loss of our beloved beer. Jogchum, also thanks for sharing the task of maintaining the website as well as our fruitful collaboration in upgrading it to its current state. Also, Jochem, Jochem and Jogchum, thanks for being Jo(g)ch(e/u)ms!

Buiten de universiteit draait nog een hele wereld, vol met mensen. Ik heb het uitzonderlijke geluk een mooi aantal daarvan tot vrienden te mogen rekenen. Nederlanders zijn goed in zeuren, en met regelmaat ben ik een topsporter daarin. Toch hebben jullie me nooit laten vallen en heb ik talloze fijne herinneringen aan jullie. Sven, je bent toch wel een belangrijk onderdeel van Svochem, ik hoef niet veel hierin op te schrijven want je kan mijn gedachten lezen, maar voor het nut van de lezer die dat niet kan: dankjewel. Merel, je mag nu dan wel een Belg zijn, maar voor mij ben je nog steeds een mede-Brabo en begrijpt al te goed was een PhD inhoudt. Bedankt voor al je support in alle jaren dat we elkaar kennen zowel over de PhD als op andere vlakken, en ik weet dat 
Thomas (rust in vrede), beide onze theses met plezier zou lezen en zonder meer volledig aan de kaak voelen. Aan jullie beide heb ik nog maar één woord te zeggen: Basashi.

Jasper en Ludo, ook jullie zijn gigantische (pun intended) pilaren aan mentale support geweest voor me. Het poolen, spelletjes spelen, verschrikkelijke humor delen en ga zo maar door zijn geweldig geweest en gaan in de toekomst zonder meer onvergetelijk blijven. Rob, Kitty, jullie ook bedankt voor je vriendschap en ik vraag me onderhand toch wel af of we niet, samen met ook Sven en Ludo, ons tot culinair onderwezen kunnen tellen. Kevin, Melanie, ook jullie bedankt voor de gezelligheid iedere keer weer dat we spelletjes spelen, en aangezien ik jullie altijd 'laat winnen', graag gedaan. Thijs, Dennis, Martijn, Addy, Mark, dank jullie wel voor alle plezier op de vakanties, en tijdens het rollenspellen spelen! Laurens, Stan, Tim, (en Sven wederom) ook erg bedankt voor alle ongein tijdens onze rollenspellen! Steven, Hugo, we zien elkaar helaas niet vaak meer, maar iedere keer bewijst weer: uit het oog maar niet uit het hart!

'Maar wie gaat er dan toch ook in Utrecht wonen?' Nou, ik. Desalniettemin, Alex (miw!), Simon, Maud, Rachel, Jurre, Moniek, Suze, Ifa, Joost, Marjolein, Maxime, Sam, Tom, Luc, Joep, Carry, Bas, Michelle, bedankt he! Hoewel ik niet vaak meer fysiek in Brabant ben, ben ik mentaal nog altijd een Brabo in hart en lever. ledere keer dat ik er dan ben, of we elkaar waar dan ook zien is het als vanouds. Dank jullie wel dat ik in Brabant altijd thuis kom alsof ik nooit ben weggeweest! Misschien kan ik nu eindelijk wat vaker komen en onderhand eens een keer mee naar het trappistenklooster! Simon, zoals net geschreven, iedere keer als ik er weer ben dan is het als vanouds, hoewel we wel, ietsje, volwassener zijn geworden dan met een ijskoud glas water en een tand in de winter op de fiets zitten. Bedankt voor je onvoorwaardelijke vriendschap!

Friendship knows no boundaries, Harald, Carrie, Eduardo, Erland, thank you for being great friends, for listening whenever I needed to vent and also for being hilarious gaming buddies. You taught me a lot on difference in culture and ways of looking at the world. Fahad, you're certainly a writing buddy and a great writer, thanks for all the chats and support in my writing! Chris, special thanks to you for supporting me during all my lows as well as highs, as well as being endlessly enthusiastic about my written stories.

En nu toch wel de belangrijkste! Mam, Pap, Brodda, Schoonsuzzie, dank jullie wel! Ik zeg het niet vaak, maar ik hou van jullie. Jullie steun, bijstaan, geduld met de lange stiltes, en begrip voor alle irritaties zijn een eeuwige steun. Als er iets is wat niet had kunnen missen om tot dit boekje te komen is het de kennis dat jullie er altijd voor mij zijn. Zie het maar zo, zonder jullie opvoeding was ik niet wie ik was, want ten slotte zoals ik op het begin al schreef: de toekomst leert van $z$ 'n verleden. 


\section{About the Author}

Jochem Wijten was born on the $10^{\text {th }}$ of October 1991 in Hilvarenbeek, the Netherlands. He enrolled in the study Chemistry at Utrecht University in 2010 from which he graduated in 2013 with a thesis on the preparation of SURMOFs and a Raman and AFM based characterization study. He immediately enrolled in the Solar Fuels Honors program which was part of the Nanomaterials: Chemistry and Physics master at Utrecht University. Supervised by Dr. Monica Barroso and Prof. dr. ir. Bert Weckhuysen he finished his master thesis on the

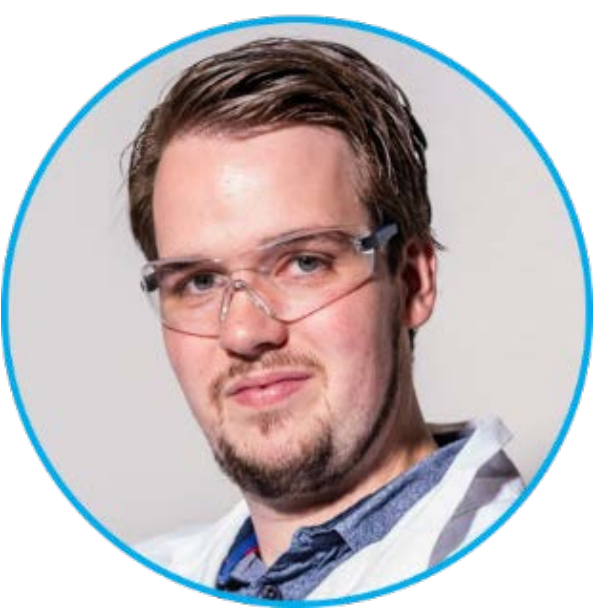
development of metal-organic frameworks for photocatalytic applications. He graduated from this masters with cum laude October 2015. Jochem continued his work on renewable energy storage within the same group of Inorganic Chemistry and Catalysis the main results whereof are described in this PhD thesis and published as articles in peer-reviewed scientific journals. He is interested in research to enabling the implementation of renewable energy on large scales in hopes of aiding the environment. During his $\mathrm{PhD}$ he furthermore gained interest in building and designing lab equipment for proper experimentation. When not working on science Jochem enjoys spending time with friends or making use of his creativity in creative writing and in tabletop model building. 